UNIVERSIDADE DE SÃO PAULO

FACULDADE DE FILOSOFIA, CIÊNCIAS E LETRAS DE RIBEIRÃO PRETO DEPARTAMENTO DE PSICOLOGIA PROGRAMA DE PÓS-GRADUAÇÃO EM PSICOLOGIA

Estratégias de aprendizagem em ações educacionais a distância: Relação com características da clientela e reações ao curso 


\title{
Estratégias de aprendizagem em ações educacionais a distância: Relação com características da clientela e reações ao curso
}

\author{
CLÁUDIO GASPAR DE MELLO
}

Dissertação apresentada ao Programa de Pós-Graduação de Psicologia do Departamento de Psicologia da Faculdade de Filosofia, Ciências e Letras de Ribeirão Preto da Universidade de São Paulo, como parte das exigências para a obtenção do título de Mestre em Ciências, Área de concentração: Psicologia.

Orientadora: Prof. ${ }^{a}$ Dr. ${ }^{a}$ Thaís Zerbini

RIBEIRÃO PRETO

2017 
Autorizo a reprodução e divulgação total ou parcial deste trabalho, por qualquer meio convencional ou eletrônico, para fins de estudo e pesquisa, desde que citada a fonte.

Mello, Cláudio Gaspar de

Estratégias de aprendizagem em ações educacionais a distância: Relação com características da clientela e reações ao curso. Ribeirão Preto, 2017.

Dissertação de Mestrado, apresentada à Faculdade de Filosofia, Ciências e Letras de Ribeirão Preto/USP. Área de concentração: Psicologia.

Orientador: Thais Zerbini

1. Educação a Distância; 2. Estratégias de Aprendizagem; 3. Características da Clientela; 4. Reações. 
Nome: Mello, C. G.

Título: Estratégias de aprendizagem em ações educacionais a distância: Relação com características da clientela e reações ao curso.

Dissertação apresentada à Faculdade de Filosofia, Ciências e Letras de Ribeirão Preto da Universidade de São Paulo para obtenção do título de Mestre em Psicologia

Aprovada em:

Banca Examinadora:

Prof.(a) Dr.(a) Thais Zerbini

Instituição: FFCLRP / Universidade de São Paulo

Assinatura:

Prof.(a) Dr.(a) Marina Greghi Sticca

Instituição: FFCLRP / Universidade de São Paulo

Assinatura:

Prof.(a) Dr.(a) Célia Regina Vieira de Souza Leite

Instituição: Centro Universitário Moura Lacerda

Assinatura: 
"Refletir sobre processo de conhecimento, $e$, por conseguinte, de aprendizagem é, antes de tudo, pensar a construção de significados. [...] o professor não pode ter em mente apenas a estratégia de ensino; ele precisa conhecer as estratégias de aprendizagem que os seus alunos utilizam."

Elisa Pereira Gonsalves 


\section{AGRADECIMENTOS}

Primeiramente a Deus e aos meus amigos espirituais, por me dar força, me guiar e iluminar durante toda trajetória desse mestrado.

À minha orientadora, Thais Zerbini, por quem tenho profunda admiração. Obrigado por acreditar em mim, por seu apoio, sua confiança, orientação e conhecimentos passados ao longo desses anos e, especialmente pela sua amizade.

As professoras Marina Greghi Sticca e Célia Regina Vieira de Souza Leite que aceitaram fazer parte da banca examinadora, dispondo de seus conhecimentos para analisar este trabalho e por dividir comigo este momento especial e tão esperado.

Ao Prof. Fernando Seixas dos Reis, coordenador do polo de Serrana da UAB, por aceitar e incentivar a parceria de pesquisa, e pela colaboração durante a coleta de dados desta pesquisa.

Ao Tadeu, pelo apoio e incentivo fundamental em todos os momentos, por ser meu companheiro e estar ao meu lado em todas as horas, ser meu suporte e exemplo de pessoa e profissional da educação, e por ter mudado minha vida quando me apresentou a docência, sem sua influência e apoio esse trabalho não aconteceria.

À minha mãe Inides e minha filha Beatriz, por me apoiarem e entenderem minha ausência em diversos momentos, sem vocês eu nada conseguiria. À minha irmã, que mesmo de longe acompanhou meu mestrado.

Ao amigo Carlos, por ter me colocado em contato com a instituição parceira, e por dividir comigo meus momentos de angustia e felicidade, sempre me incentivando e me apoiando.

À Raissa, pelo auxilio em vários momentos desse trabalho, pela troca de conhecimentos, e pela sua presença, apoio e amizade.

À universidade participante, alunos e funcionários, pela colaboração que proporcionou a produção de novos conhecimentos.

Aos colegas do Laboratório de Psicologia Organizacional e do Trabalho (LabPOT), pela disponibilidade para ajudar e pelas discussões compartilhadas.

Aos amigos, pelo incentivo, torcida e presença. 


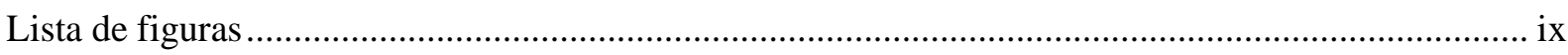

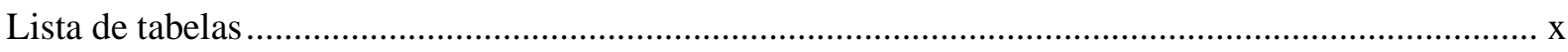

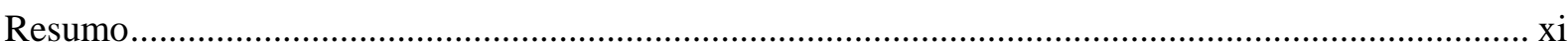

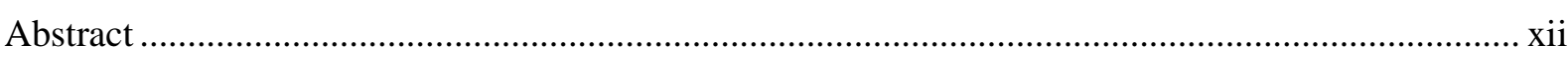

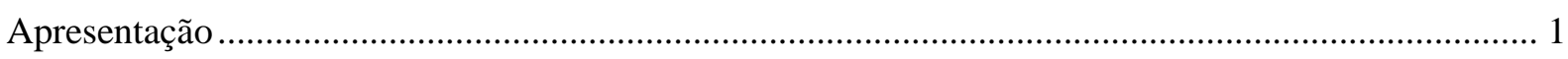

CAPÍTULO 1. TREINAMENTO, DESENVOLVIMENTO E EDUCAÇÃO ...................................... 5

1.1. Treinamento, Desenvolvimento e Educação: definições e características .................................. 5

1.2. Modelos de Avaliação de treinamento presencial e a distância ................................................. 10

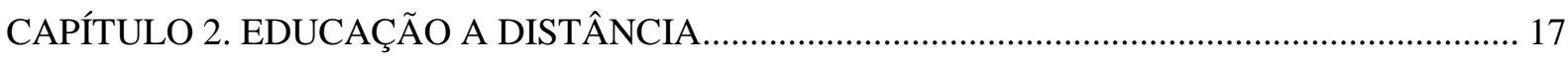

2.1. Educação a Distância: definições, características e políticas públicas .......................................... 17

2.2. Educação a Distância em Instituições de Ensino Superior............................................................. 22

CAPÍTULO 3. ANÁLISE DA LITERATURA: DESCRIÇÃO E ACHADOS DE PESQUISA ......... 26

3.1. Descrição do percurso metodológico para busca bibliográfica ...................................................... 26

3.2. Estratégias de Aprendizagem (variável critério): definições e características ............................... 32

3.2.1. Estratégias de aprendizagem na modalidade de EAD .................................................................. 35

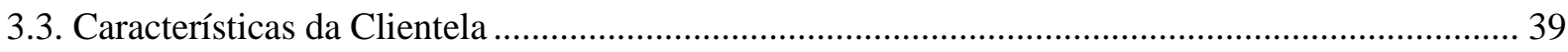

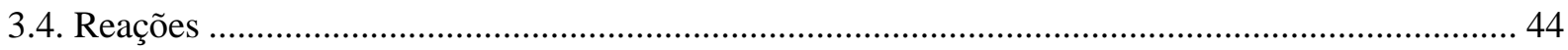

CAPÍTULO 4. CARACTERÍSTICAS METODOLÓGICAS DA PESQUISA...................................... 57

4.1. Delimitação do problema, objetivos de pesquisa e modelo de investigação .................................... 57

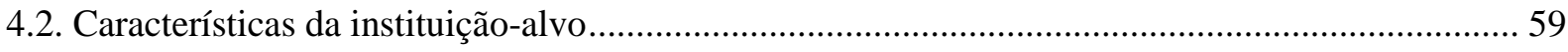

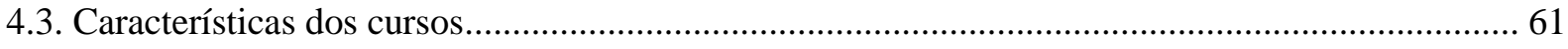

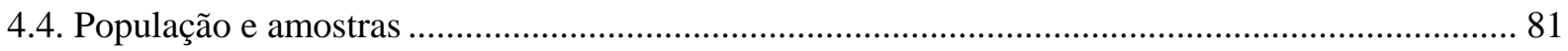

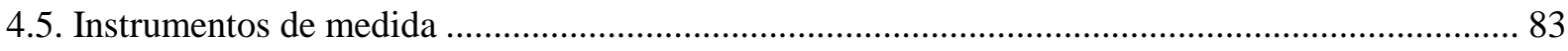

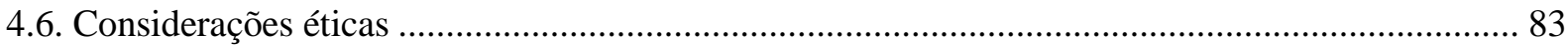

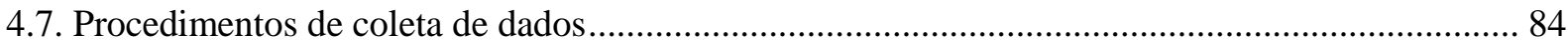

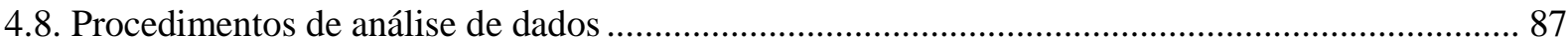

4.8.1. Procedimentos de análises exploratórias das estruturas empíricas dos questionários .................. 88

4.8.2. Procedimentos de análise dos testes de Regressão Múltipla, ANOVA e Testes t...................... 91

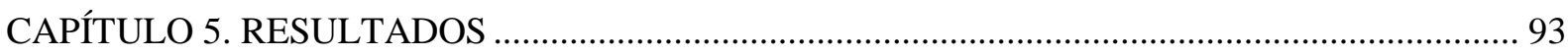

5.1. Adaptação e validação dos instrumentos de medida ........................................................................ 93

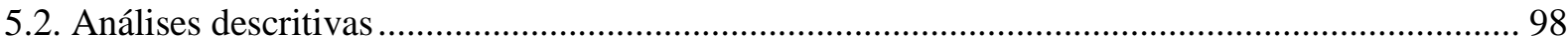

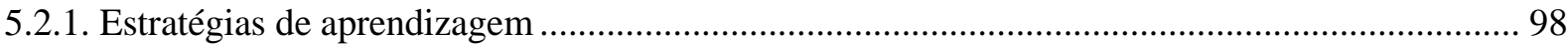

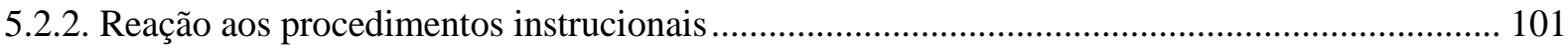


5.2.3. Reação ao desempenho do tutor.

5.3. Análises das evidências de validade dos questionários ................................................................. 106

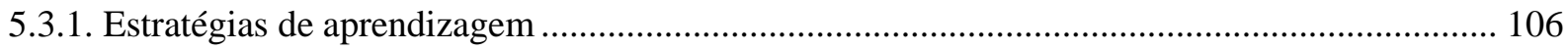

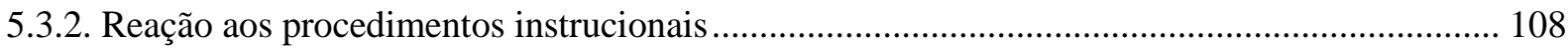

5.3.4. Síntese dos resultados: verificação de evidências de validade dos instrumentos ....................... 114

5.4. Análises complementares sobre as escalas: ANOVA e Testes $t$................................................ 114

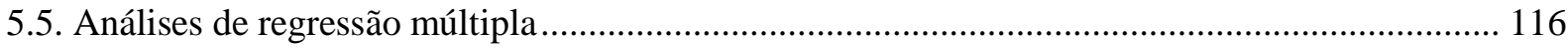

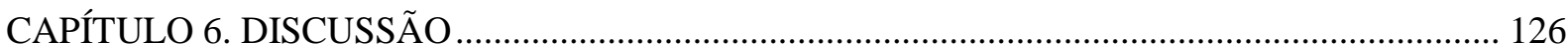

6.1. Discussões dos resultados de análises fatoriais exploratórias dos instrumentos .......................... 126

6.2. Discussões dos resultados das análises de regressão: teste do modelo multivariado .................... 132

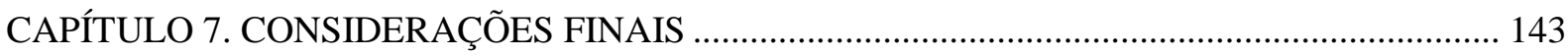

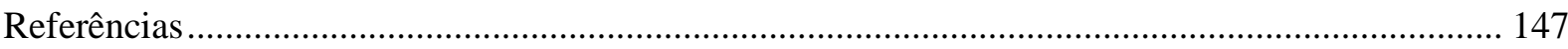

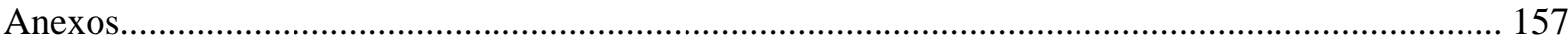




\section{Lista de figuras}

Figura 1. Estrutura geral do desenvolvimento do texto.................................................................... 3

Figura 2. TD\&E: Sistema integrado (Borges-Andrade, 2006; Borges-Andrade, Zerbini, Abbad \& Mourão, 2013).

Figura 3. Modelo de Avaliação Integrado e Somativo - MAIS (Borges-Andrade, 1982 e 2006)

Figura 4. Modelo de Avaliação do Impacto do Treinamento no Trabalho - IMPACT (Abbad, 1999). 12

Figura 5. Modelo geral de avaliação da Transferência de Treinamento via web no Trabalho (Zerbini,

2007)

Figura 6. Modelo de investigação proposto por Martins (2012) ……............................................. 14

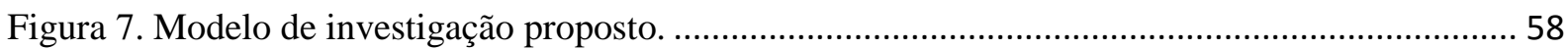

Figura 8. Porcentagem de questionários respondidos por curso na coleta de dados............................. 86

Figura 9. Distribuição dos valores próprios (scree plot) da escala de Reação aos Procedimentos Instrucionais.

Figura 10. Modelo de Análise de predição de EA1 - Estratégias Cognitivas. .................................... 117

Figura 11. Representação do modelo de regressão múltipla para EA1 como variável critério............ 118

Figura 12. Modelo de Análise de predição de EA2 - Controle da Emoção........................................ 119

Figura 13. Representação do modelo de regressão múltipla para EA2 como variável critério............ 120

Figura 14. Modelo de Análise de predição de EA3 - Estratégias Autorregulatórias.......................... 121

Figura 15. Representação do modelo de regressão múltipla para EA3 como variável critério............ 122

Figura 16. Modelo de Análise de predição de EA4 - Busca Ajuda Interpessoal. ............................... 123

Figura 17, Representação do modelo de regressão múltipla para EA4 como variável critério............ 124

Figura 18. Resumo dos resultados dos modelos de regressão.......................................................... 124 


\section{Lista de tabelas}

Tabela 1. Pontos em comum entre as definições para EAD. 18

Tabela 2. Etapas da revisão da literatura sobre as variáveis de interesse do presente estudo. 26

Tabela 3. Distribuição dos artigos de acordo com bases de dados consideradas. 27

Tabela 4. Resultados de buscas na biblioteca eletrônica SciELO, Web of Science, Banco de

Dissertações e Teses da USP e Banco de Dissertações e Teses da UnB. 30

Tabela 5. Controle de busca da revisão bibliográfica de Reações. 31

Tabela 6. Classificação e definições das Estratégias de Aprendizagem.

Tabela 7. Resumo resultados revisão bibliográfica Estratégias de Aprendizagem (Martins, 2015). 38

Tabela 8. Resumo resultados revisão bibliográfica Reações (Martins, 2015). 50

Tabela 9. Revisão de literatura para Reação.

Tabela 10. Resumo achados revisão da literatura sobre Reações dos últimos 5 anos (2011 a 2015). 56

Tabela 11. Características dos cursos de graduação ofertados pelas IES parceiras e avaliados na

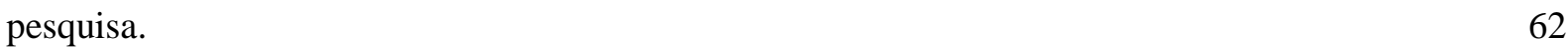

Tabela 12. Estrutura e Organização do curso "Licenciatura em Educação Física". 63

Tabela 13. Estrutura e Organização do curso "Bacharelado em Administração Pública". 66

Tabela 14. Estrutura e Organização do curso "Licenciatura em Matemática". 69

Tabela 15. Estrutura e Organização do curso "Pedagogia". 71

Tabela 16. Características dos cursos de especialização ofertados pelas IES parceiras e avaliados na $\begin{array}{ll}\text { pesquisa. } & 74\end{array}$

Tabela 17. Estrutura e Organização do curso "Gestão em Enfermagem".

Tabela 18. Estrutura e Organização do curso "Educação Empreendedora".

Tabela 19. Estrutura e Organização do curso "Mídias na Educação".

Tabela 20. Estrutura e Organização do curso "Práticas de Letramento e Alfabetização".

Tabela 21. Composição da População e Amostra por curso. 81

Tabela 22. Perfil da amostra de alunos dos Cursos de Graduação e Pós-Graduação. 82

Tabela 23. Resumo das informações sobre os instrumentos a serem utilizados na pesquisa. $\quad 83$

Tabela 24. Índice de retorno dos questionários na coleta de dados. 86

Tabela 25. Resumo análise dos cursos ofertados pelas IES parceiras. $\quad 98$

Tabela 26. Resultados descritivos de Estratégias de Aprendizagem. 99

Tabela 27. Resultados descritivos de Reação aos Procedimentos Instrucionais. 101

Tabela 28. Resultados descritivos de Reação ao Desempenho do Tutor. 104

Tabela 29. Definição dos Fatores de Estratégias de Aprendizagem. 107

Tabela 30. Consistência Interna (Alfa de Cronbach) da escala de Estratégias de Aprendizagem. 107

Tabela 31. Valores próprios empíricos e aleatórios dos primeiros dez componentes de Procedimentos

Instrucionais. $\quad 111$

Tabela 32. Estrutura empírica da Escala de Reação aos Procedimentos Instrucionais. 112

Tabela 33. Consistência Interna (Alfa de Cronbach) da escala de Reação ao Desempenho do Tutor. 113

Tabela 34. Resumo das informações sobre os instrumentos utilizados nesta pesquisa. $\quad 114$

Tabela 35. Teste de diferença entre médias (Teste $t$ ), segundo idade dos participantes. 115

Tabela 36. Teste de diferença entre médias (ANOVA), segundo o curso dos participantes. $\quad 116$

Tabela 37. Resumo dos resultados das análises de diferenças de médias (Teste $t$ e ANOVA). $\quad 116$

Tabela 38. Regressão Múltipla padrão para o modelo de investigação A. $\quad 118$

Tabela 39. Regressão Múltipla padrão para o modelo de investigação B. $\quad 120$

Tabela 40. Regressão Múltipla padrão para o modelo de investigação C. 121

Tabela 41. Regressão Múltipla padrão para o modelo de investigação D. 123

Tabela 42. Estratégias mais utilizadas pela amostra. 138 


\section{Resumo}

Mello, C. G. (2017). Estratégias de aprendizagem em ações educacionais a distância: Relação com características da clientela e reações ao curso. Dissertação de Mestrado, Departamento de Psicologia, Universidade de São Paulo, Ribeirão Preto.

$\mathrm{Na}$ atualidade, as ações educacionais ofertadas por instituições de ensino superior (IES), bem como organizações de trabalho, buscam atender novas exigências de desenvolvimento de competências individuais e organizacionais. Nesse contexto, destacam-se os programas de educação a distância oferecidos via internet e por videoconferência. A análise dos resultados produzidos, bem como da eficácia desses eventos instrucionais é de fundamental importância para verificar se os indivíduos alcançaram aprendizagem satisfatória. Apesar disso, a área de avaliação de ações educacionais, ofertadas a distância ainda é incipiente em estudos de modelos multivariados e sistemáticos. A identificação e a avaliação dos preditores envolvidos na aprendizagem e transferência de aprendizagem por meio de relatos empíricos trariam contribuições significativas para suprir lacunas de pesquisa. Dessa forma, a presente pesquisa objetivou propor e testar um modelo de avaliação de ações educacionais ofertadas a distância, visando identificar variáveis preditoras de estratégias de aprendizagem relacionadas às características da clientela (perfil sociodemográfico e uso de ferramentas eletrônicas) e às reações ao curso (Procedimentos Instrucionais e Desempenho do Tutor). As universidades parceiras fazem parte do sistema Universidade Aberta do Brasil (UAB) no polo da cidade de Serrana. No polo são ofertados cursos de graduação e especialização, entre eles, os participantes da pesquisa: Administração Pública, Licenciaturas em Matemática e Educação Física, Pedagogia; Educação Empreendedora; Mídias na Educação; Práticas de Letramento e Alfabetização e Gestão em Enfermagem. Para verificar evidências de validade do instrumento de Reação aos Procedimentos Instrucionais, foi realizada a Análise Fatorial Exploratória (AFE). Visando constatar a consistência interna dos instrumentos foram calculados e analisados os valores do Alfa de Cronbach. A análise de regressão múltipla foi realizada para cumprir o objetivo de testagem do modelo, verificando a influência das características da clientela, da satisfação dos alunos com os procedimentos instrucionais e tutor nas estratégias de aprendizagem utilizadas pelos alunos no decorrer da ação educacional. Os resultados demonstraram que as Reações favoráveis aos Procedimentos Instrucionais e a Idade dos participantes explicaram o uso de determinadas Estratégias de Aprendizagem. Foi demonstrado também que os alunos que fizeram mais uso das Estratégias de Aprendizagem Cognitivas e das Estratégias Autorregulatórias. Tais achados apontam a importância do desenvolvimento de estratégias de ensino no processo de planejamento da ação educacional, que promovam o autogerenciamento da aprendizagem. São necessários mais estudos sobre as Estratégias de Aprendizagens utilizadas por estudantes universitários, utilizando métodos estatísticos mais robustos, visando a sistematização de conhecimentos acerca das ações educacionais ofertadas na modalidade a distância.

Palavras-chave: Educação a Distância; Estratégias de Aprendizagem; Características da Clientela; Reações. 


\begin{abstract}
Mello, C. G. (2017). Strategies of learning in educational actions at a distance: Relationship with characteristics of the clientele and reactions to the course. Dissertação de Mestrado, Departamento de Psicologia, Universidade de São Paulo, Ribeirão Preto.
\end{abstract}

Nowadays, the educational actions provided from institutions of higher education (IES), as well as work organizations, aim to meet new requirement for development of individual and organizational competence. In this context, distance learning curses are standing out through internet and videoconference. An analyze of results, as well as the performance of these instructional events, are of fundamental importance to verify if the individuals achieved successful learning. Despite this, the rating of educational actions, offered from distance, still is incipient multivariate and systematic models of study. The identification and valuation of the involved predictors on the learning exchange of learning by means of empirical reports would bring significant contributions to supply research gaps. Therefore, the current research had as intent to propose and test a model of valuation of educational actions offered from distance, aimed to identify predictors variants of strategy of learning related to costumers characteristics (sociodemographic profiles and use of electronic instruments) and to reactions to the course (Instructional Procedures and Reactions to Tutor's Performance). The partner universities are part Opened University from Brazil (UAB) system in Serrana city. There, are offered undergraduate and specialization courses, including the survey participants: Public Administration, Mathematics and Physical Education Degrees, Pedagogy, Entrepreneurial Education, Media in Education, Literacy and Nursing Management Practices. To verify instruments' validity evidences to Instructional Procedures and Reactions, an Exploratory Factor Analyzes (AFE) were performed. Aiming to determinate the internal consistency of the instruments that were calculated and analyzed the values of Cronbach's Alpha, in exception of Procedures and Reactions Instructional, that in addition to consistency analyze that also passed through procedures of Exploratory Factor Analyzes (AFE). Multiple regression analysis was performed in order to fulfil the purpose of testing the model to verify the influence of costumer's profiles, the contentment of students with the instructional procedures and tutoring on learning strategies applied by students in the course of educational action. The results show that Favorable Reactions to the Instructional Procedures and the age of the participants explained the use of certain Strategies of Learning. It was also indicated the students used even more the Strategies of Cognitive Learning and Self-regulatory Learning. Such findings highlight the importance of development of strategies of education in the process of planning the educational action which promote self-management of learning. It is necessary more studies about the Strategies of Learning exercised by university students, using a stronger statistical method, aiming the systematization of knowledge about the educational actions offered by distance learning.

Palavras-chave: E-learning; Learning Strategies; Characteristics of the Clientele; Reactions. 


\section{Apresentação}

As mudanças no âmbito social e tecnológico nas organizações contemporâneas ocorrem em função de diversos fatores, tais como: avanço e desenvolvimento tecnológico, mercados cada vez mais internacionalizados, alto grau de exigência por parte dos consumidores e competição acirrada (Pantoja \& Borges-Andrade, 2009). Tais mudanças afetam o mundo do trabalho fazendo com que os processos contínuos de aprendizagem se tornem fundamentais para o desenvolvimento e qualificação dos indivíduos e o crescimento das organizações (Abbad, Zerbini \& Souza, 2010). Assim, a aprendizagem no trabalho se torna o foco central no desenvolvimento e sobrevivência dos indivíduos no mercado de trabalho.

Na última década no Brasil, as crescentes exigências do mercado de trabalho voltadas para a formação e qualificação profissional fizeram com que a demanda por ações educacionais com a utilização de novas tecnologias de comunicação e informação (NTICs) aumentasse consideravelmente (Coll, Mauri \& Onrubia, 2010; Zerbini \& Abbad, 2010). Diante desse cenário, para atender a crescente demanda de mão de obra qualificada, e com base no artigo 80, lei 9.394/96 da LDB - Lei de Diretrizes e Bases na Educação Nacional, de 23 de dezembro de 1996, as instituições de ensino superior (IES) oferecem formação e qualificação profissional na modalidade de ensino não presencial ou semipresencial e à distância. As IES integram as NTICs na educação, objetivando o alcance de um número maior de pessoas em diversas regiões do país.

A crescente oferta de cursos de graduação e programas de educação coorporativa na modalidade de educação a distância (EAD) requer atenção, pois ocupam posição estratégica tanto nas organizações como nas IES (Martins \& Zerbini, 2014). A qualidade dessas ações deve ser avaliada visando mensurar os resultados obtidos e verificar se estão de acordo com os objetivos pré-definidos. Tornam-se necessárias investigações mais robustas que testem a eficácia e a aplicabilidade dessas ações educacionais, bem como a necessidade de entender como as estratégias de aprendizagem são utilizadas por estudantes e trabalhadores, objetivando compreender quais são os processos de aprendizagem subjacentes envolvidos e os fatores influentes (Martins, 2012).

Por meio da revisão da literatura acerca do tema de interesse dessa pesquisa foi possível verificar resultados satisfatórios nas ações educacionais, tal como aprendizagem bem-sucedida, quando usadas estratégias de aprendizagem adequadas (Giangreco, Carugati, Sebastiano \& Della Bella, 2010; Gunawardena, Linder-VanBerschot, LaPointe \& Rao, 2010; Morgan \& Casper, 2000; Vaugham \& MacVicar, 2004; Womble, 2008. Contudo, foram encontrados 
poucos estudos dessa natureza no contexto universitário, ofertados a distância, o que justifica a necessidade de pesquisas mais robustas em torno do tema. Mesmo com a crescente oferta da EAD, a área de avaliação de cursos no nível superior de ensino, especificadamente, cursos de graduação ofertados a distância é bastante incipiente no Brasil (Martins \& Zerbini, 2015).

O presente estudo, portanto, tem como objetivo propor e testar um modelo de avaliação de ações educacionais ofertadas a distância, via internet, no qual pretende-se identificar e mensurar as variáveis antecedentes de características da clientela (perfil sociodemográfico e uso de ferramentas eletrônicas), e de reações dos participantes (ao desempenho do tutor e aos procedimentos instrucionais), relacionadas à variável critério Estratégias de Aprendizagem. Para facilitar o acompanhamento do texto, a Figura 1 mostra o modo como os capítulos e as seções estão estruturadas e sua sequência de apresentação no presente estudo. 


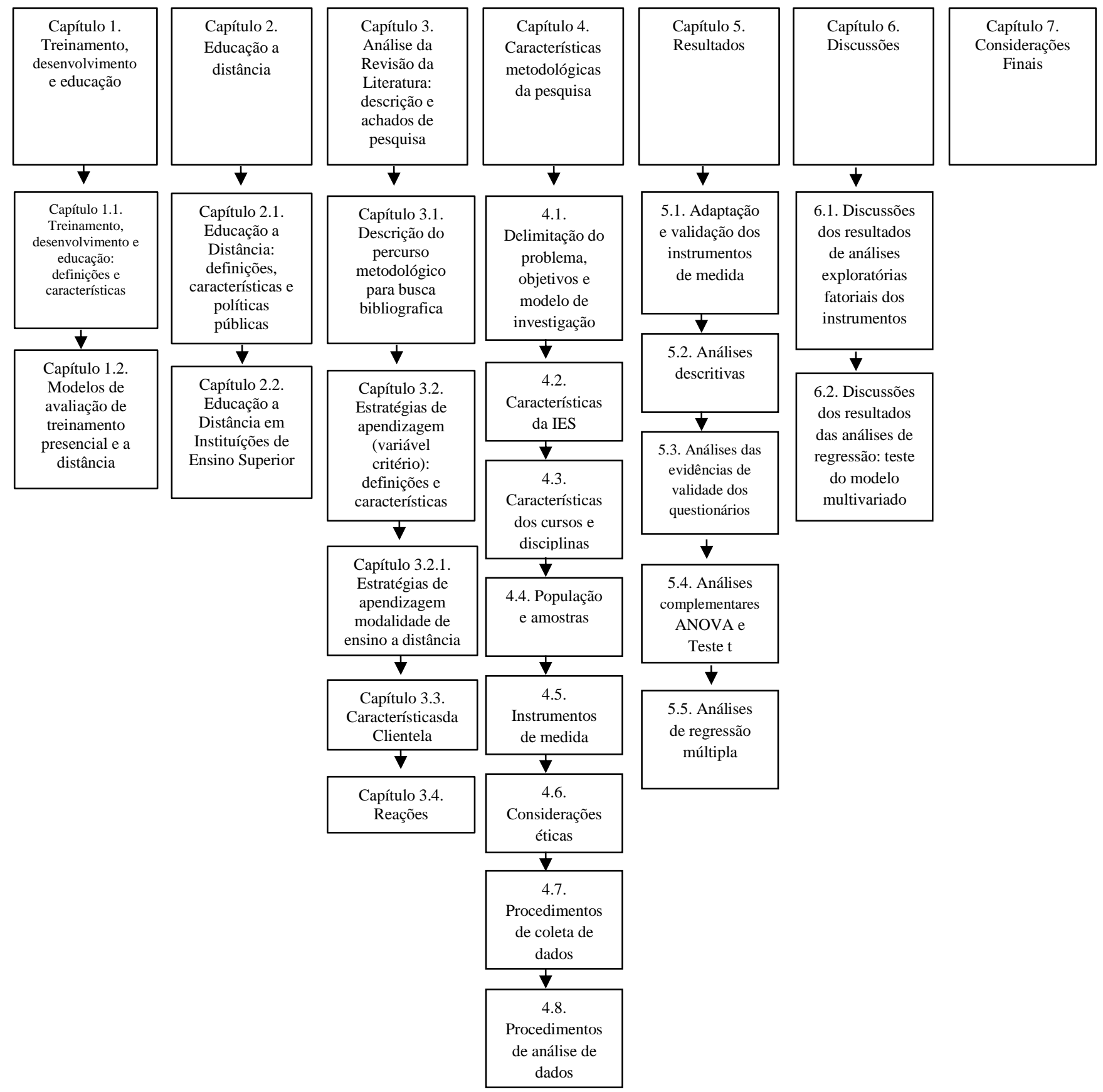

Figura 1. Estrutura geral do desenvolvimento do texto.

O Capítulo 1 apresenta os componentes e as características específicas do sistema de Treinamento, Desenvolvimento e Educação (TD\&E), assim como realiza um retrospecto situando os progressos, tendências e limitações sobre a área. Também apresenta alguns modelos de avaliação destinados a treinamentos presenciais e a distância, disponíveis na literatura internacional e brasileira.

O Capítulo 2 contextualiza a modalidade EAD enquanto recurso utilizado, nacional e internacionalmente, para a promoção do ensino em contextos de Organização e Trabalho (O\&T) 
e por Instituições de Ensino Superior (IES). Discute a EAD na área educacional, apontando as alterações nas políticas públicas e legislação nacional.

No Capítulo 3 é apresentado de forma detalhada o trajeto da revisão de literatura sobre as variáveis de interesse do estudo: as Estratégias de Aprendizagem, Característica da Clientela e Reação. Também são apresentados e discutidos terminologias, conceitos, características e resultados de pesquisas relacionadas a essas variáveis.

O Capítulo 4 apresenta a delimitação do problema, a justificativa e os objetivos da pesquisa. É delineado o modelo de investigação proposto, apresentadas as características da instituição de ensino superior parceira e analisados os cursos de graduação de tal instituição. Define-se população e amostras, os instrumentos de medida e os procedimentos de coleta e análise dos dados.

No Capítulo 5 são apresentados detalhamente todos os resultados dessa pesquisa: os resultados descritivos dos instrumentos de Estratégias de Aprendizagem, Procedimentos Instrucionais e Desempenho do Tutor, a validação semântica e por juízes do Roteiro de Análise de Cursos de Graduação - EAD e os resultados das análises de evidência de validade dos intrusmentos, que foram complementados com os Testes $t$ e ANOVA. Por fim, é apresentada a análise dos modelos de regressão.

O Capítulo 6 expõem as discussões acerca dos resultados da presente pesquisa. Por fim, no capítulo 7 são feitas considerações finais sobre o presente estudo, indicando suas principais contribuições e limitações, além de propor uma agenda de pesquisa. 


\section{CAPÍTULO 1. TREINAMENTO, DESENVOLVIMENTO E EDUCAÇÃO}

\section{Objetivo do capítulo 1}

Este capítulo visa descrever os componentes e as características de ações de TD\&E, bem como apresentar os progressos e limitações identificados no subsistema de avaliação de eventos formais de treinamento, especialmente aqueles voltados a ações educacionais em contexto de IES. Apresenta-se ainda, alguns modelos de avaliação de eventos instrucionais presenciais e a distância disponíveis na literatura científica.

\subsection{Treinamento, Desenvolvimento e Educação: definições e características}

O investimento realizado por organizações e indivíduos em programas de Treinamento, Desenvolvimento e Educação (TD\&E) é considerável e merece atenção sobre quais estratégias de aprendizagem estão sendo utilizadas pelos aprendizes durante o processo de aprendizagem visando seu aprimoramento e desenvolvimento profissional. Assim, há cada vez mais interesse científico pelo modo de como os programas de TD\&E vem sendo oferecidos. Existem diversos fatores que contribuem para a crescente atenção por este tema, como já discutido anteriormente (Aguinis \& Kraiger, 2009), entre eles, a crescente competitividade entre as empresas, pessoas não qualificadas para o trabalho, a necessidades das organizações em consolidar a aprendizagem como uma estratégia organizacional etc.

A importância e a necessidade de ações desenvolvidas na área de TD\&E têm aumentado e se destacam com maior intensidade devido aos novos contextos de ensino e trabalho que necessitam de iniciativas aptas para sanar lacunas de competências e que proporcionem atualização constante visando o bom desempenho acadêmico e profissional. Cada vez mais indivíduos e organizações recorrem aos benefícios decorrentes dos esforços instrucionais que se refletem, entre outras coisas, em incrementos financeiros, ocupacionais e de mercado, aquisição de conhecimentos, aprendizagem efetiva, otimização de desempenhos e produtividade (Iglesias \& Salgado, 2012; Meneses, Zerbini \& Abbad, 2010; Salas \& CannonBowers, 2001).

De acordo com Vargas e Abbad (2006) existe uma diversidade de conceitos e definições na literatura acerca da área de TD\&E que merecem um exame detalhado em consequência do crescimento e desenvolvimento da área de treinamento e da inclusão de novos termos ao longo do tempo. A área se demonstra carente de definições claras, que facilitaria a compreensão e aplicação de programas. 
Para Borges-Andrade (2006), a área de TD\&E está voltada para o estudo de ações que visam proporcionar oportunidades de aprendizagem aos integrantes de uma organização, para o alcance de melhorias em seus desempenhos. Empresas utilizam tais ações como estratégias para se manter competitivas no mercado por meio de investimentos na qualificação de pessoal e no desenvolvimento de conhecimentos, habilidades e atitudes (CHAs) compatíveis com os objetivos organizacionais (Abbad, Zerbini \& Souza, 2010). Dessa forma, as ações de TD\&E se compõem como ferramenta importante para as organizações, de maneira que, quando bem planejadas e executadas, possibilitam o estabelecimento de novas competências (Meneses, Zerbini \& Abbad, 2010). A promoção constante de eventos de TD\&E em conformidade com as inovações, mudanças e exigências impostas pelo cenário globalizado, contribui para o desenvolvimento e atualização das organizações (Coelho Jr. \& Borges-Andrade, 2008).

Segundo Zerbini, Abbad e Mourão (2012), os processos de TD\&E podem ser definidos como ações organizacionais que utilizam uma tecnologia instrucional com o objetivo da aquisição de CHAs para suprir lacunas de desempenho no trabalho e preparar indivíduos para novas funções em empresas. As autoras delimitam os conceitos de TD\&E em: treinamento, que são ações que preparam o indivíduo a melhorar seu desempenho no cargo atual; programas de desenvolvimento que são direcionados a estimular o livre crescimento pessoal dos membros da organização e não possuem vínculos estreito com as atividades demandadas por esta; e educação, que se refere às oportunidades dadas pela organização ao indivíduo para capacitá-lo a ocupar cargos diferentes em outro momento dentro da mesma organização. Os conceitos de Informação e Instrução também podem ser considerados formas de indução de aprendizagem (Meneses, Zerbini \& Abbad, 2010). De acordo com Borges-Andrade (2006) e Borges-Andrade, Zerbini, Abbad e Mourão (2013), as ações de TD\&E são estruturadas em um sistema integrado por três subsistemas: Avaliação de Necessidades de Treinamento (ANT); Planejamento e Execução; e Avaliação de Treinamento, como mostra a Figura 2. 
TD\&E:

Sistema integrado

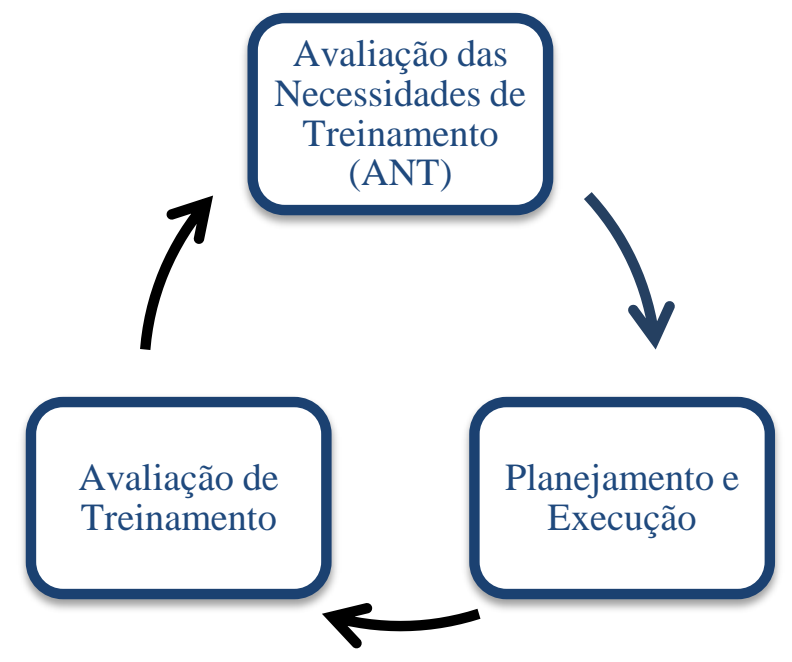

Figura 2. TD\&E: Sistema integrado (Borges-Andrade, 2006; Borges-Andrade, Zerbini, Abbad \& Mourão, 2013).

Visando a maior competitividade e capacidade de sobrevivência em um cenário globalizado em constantes mudanças, organizações e indivíduos investem cada vez mais em ações de TD\&E. Contudo, observa-se pequeno retorno dos investimentos realizados em tais ações, e entre as principais explicações para este resultado está a ineficiência dos processos de avaliação de necessidades educacionais (Menezes, Zerbini \& Abbad, 2010).

Abbad e Mourão (2012) definem a ANT como um conjunto de ações voltadas para a coleta, a avaliação e análise de dados com o objetivo de identificar as necessidades de treinamento em organizações. Assim, o primeiro dos subsistemas de TD\&E pode ser entendido como o levantamento sistemático dos conhecimentos, habilidades e atitudes (CHAs). Ainda segundo as autoras, a ANT tem como objetivo o diagnóstico ou prognóstico das necessidades de TD\&E, para que quando transformadas em objetivos educacionais possam facilitar o desempenho de situações de aprendizagem.

A ANT se caracteriza pelo levantamento do diagnóstico de necessidades em três níveis: organizacional, de tarefas e individual. Assim, análises devem ser realizadas em tais níveis visando a garantia da qualidade para as etapas seguintes (planejamento e avaliação educacional), e para que isso ocorra, os programas de TD\&E devem estar alinhados a estratégias organizacionais (Abbad \& Mourão, 2012; Menezes, Zerbini \& Abbad, 2010).

A análise de necessidades realizada no nível organizacional deve alinhar as ações de TD\&E com a estratégia organizacional. A partir da análise do cenário da ação educacional, consideram-se as informações societal, organizacional, de grupos e equipes de trabalho, para a identificação das lacunas de CHAs e determinar a necessidade do treinamento, bem como identifica as variáveis contextuais que possam restringir ou potencializar a emergência dos resultados organizacionais ligados a ação de TD\&E e visa garantir o sucesso do programa de 
treinamento que depende do clima organizacional em que está inserido (Abbad \& Mourão, 2012; Menezes, Zerbini \& Abbad, 2010).

A ANT realizada no nível das tarefas parte da identificação e definição dos CHAs que são requeridos para o bom desempenho do profissional no trabalho para o alcance dos objetivos e metas dos grupos e equipes de trabalho e organizacionais. A análise das tarefas tem como foco a descrição das atividades, competências e operações de determinada atividade laboral para sua correta execução. Normalmente é realizada pela análise de tarefas ou cargos que geram informações sobre as atividades de um determinado trabalho, bem como sobre a sua execução. As tarefas são avaliadas de acordo com o grau de importância, frequência, dificuldade e domínio. Dessa forma, a partir da análise de tarefas é definido o conteúdo que deve ser aplicado no treinamento, ou seja, o que deve ser treinado (Abbad \& Mourão, 2012; Menezes, Zerbini \& Abbad, 2010).

O último nível que compõe o processo de avaliação de necessidades de treinamento é o nível individual, que por meio de análise é possível identificar os indivíduos que precisam participar da ação educacional em termos quantitativos (números) e qualitativos (informações sociodemográficos, funcional, motivacional etc.), bem como identificar se tais indivíduos possuem pré-requisitos necessários para o efetivo aproveitamento dos conteúdos do treinamento (Abbad \& Mourão, 2012; Meneses, Zerbini \& Abbad, 2010; Pilati, 2006). A análise individual é realizada para o apontamento dos profissionais que precisam passar por determinado treinamento.

Assim, este subsistema é responsável por identificar as necessidades de ações instrucionais, mapear os CHAs necessários para um indivíduo desempenhar sua função e o conteúdo a ser treinado, bem como, identificar os indivíduos e equipes potenciais a participarem do treinamento. De acordo com Gondim e Silva (2004) é necessária uma profunda análise da situação problema identificada, devido às frequentes reclamações decorrentes da desmotivação para exercício profissional ou de condições inadequadas de trabalho, por não se tratarem do foco das ações educacionais de TD\&E. Para que a ação de TD\&E atinja seus objetivos é necessária a realização de uma ANT sistemática, alinhada tanto aos interesses da organização como dos indivíduos, conhecer e avaliar as condições pré-treinamento bem como as características individuais dos treinandos (Aguinis \& Kraiger, 2009; Bowman \& Wilson, 2008).

O subsistema Planejamento e Execução do treinamento ocorre após a identificação das necessidades de competências a serem treinadas. Sua característica básica consiste na aplicação de técnicas e estratégias para proporcionar a aquisição sistêmica dos CHAs (Pilati, 2006). O 
planejamento das ações de TD\&E inicia-se com a definição dos objetivos e conteúdos instrucionais, ou seja, com os desempenhos que os participantes de tais ações deverão desenvolver e alcançar. Essa etapa envolve: i) a transformação das necessidades de treinamento em objetivos instrucionais, onde tais objetivos devem ser escritos de forma objetiva e precisa dos CHAs que se deseja avaliar no comportamento de treinando durante e após a ação de treinamento; ii) especificação dos componentes dos objetivos (resultados de aprendizagem); iii) avaliação da qualidade dos objetivos instrucionais; e iv) especificação dos níveis de análise dos objetivos específicos, intermediários e gerais. Na sequência, é realizada a escolha de estratégias e métodos de ensino, que representa a escolha da modalidade de entrega da ação de TD\&E. Tal ação envolve a decisão sobre ações presenciais, a distância ou semipresenciais, e esta decisão deve considerar, além das lacunas de CHAs que levaram à ação educacional, o perfil demográfico, funcional e profissional a fim de garantir a adequada modalidade de entrega. Ao final, devem-se estabelecer os critérios de avaliação apropriados para o alcance dos objetivos elencados. Assim, os critérios de avaliação de aprendizagem devem partir dos objetivos instrucionais, para que possam ser definidas ferramentas de avaliação compatíveis com as características dos treinandos. Pode-se dizer que o subsistema planejamento instrucional possui grande influência no bom funcionamento do sistema de TD\&E (Abbad, Zerbini, Carvalho \& Meneses, 2006; Meneses, Zerbini \& Abbad, 2010).

E, por fim, para que haja a garantia da efetividade das ações instrucionais fazem-se necessárias iniciativas de avaliação de sistemas instrucionais, principalmente nos casos em que os subsistemas anteriores foram mal projetados ou implantados de modo deficitário (Meneses, Zerbini \& Abbad, 2010). A Avaliação de Treinamento é definida como um processo sistemático de coleta de informações que visa a revisão e o aprimoramento das ações instrucionais para o processo de decisões em torno da seleção, adoção valorização e modificações dos eventos instrucionais já existentes (Goldstein, 1991). O objetivo deste subsistema é adquirir controle sobre o processo, fornecer feedback aos demais componentes do sistema, tomar decisões sobre o treinamento e torná-lo capaz de promover modificações no ambiente (Meneses, Zerbini \& Abbad, 2010). Ainda, a avaliação de treinamento fornece informações sobre as lacunas de aprendizagem dos indivíduos e desempenho de tutores, identifica falhas no planejamento de procedimentos instrucionais, sua aplicabilidade e utilidade, bem como o desempenho dos participantes e instrutores, funcionando como retroalimentações para o aperfeiçoamento do sistema de TD\&E (Aguinis \& Kraiger, 2009; Goldstein, 1991; Meneses, Zerbini \& Abbad, 2010; Salas \& Cannon-Bowers, 2001). No que diz respeito à avaliação das ações educacionais, 
foco da presente pesquisa, é fundamental identificar variáveis preditoras e fatores que influenciam na efetividade de treinamentos ofertados a distância, visto que muitas organizações têm utilizado de recursos multimídias para mediar seus processos de TD\&E na modalidade de EAD (Alvarez, Salas \& Garofano, 2004).

Com o avanço e a influência da tecnologia nos programas de TD\&E na atualidade fazse necessário o desenvolvimento de pesquisas que possam responder questões como: quais as estratégias de aprendizagem são mais adequadas para ações educacionais baseadas na web? Quais são os papéis exercidos por instrutores e treinandos nessas ações? Como as NTICs podem melhorar a aprendizagem e o desempenho humano no trabalho ou no próprio contexto escolar? (Abbad, Pilati \& Pantoja, 2003; Salas \& Cannon-Bowers, 2001; Zerbini, 2007). A seguir, serão apresentados alguns modelos de Avaliação de treinamento presencial e a distância.

\subsection{Modelos de Avaliação de treinamento presencial e a distância}

Como discutido, as transformações no mundo do trabalho fizeram com que o investimento em ações de TD\&E aumentasse consideravelmente. Porém, o retorno dos investimentos em tais ações é pequeno em decorrência da falta de eficácia e de critérios metodológicos encontrados nos processos de TD\&E (Meneses, Zerbini \& Abbad, 2010). Assim, a crescente demanda por ações educacionais exige estudos na área de avaliação de sistemas instrucionais ao favorecer a verificação da eficácia de tais ações (Martins, 2012). Diante desse contexto, as modalidades de treinamento presencial e a distância contam com metodologias e instrumentos capazes de auxiliar no processo de avaliação de treinamento.

O modelo clássico proposto por Kirkpartrick (1976) se tornou um marco pioneiro na literatura, o qual é estruturado em quatro níveis de avaliação: reação, aprendizagem, comportamento e resultados. Estes níveis, de acordo com o autor, seriam sequenciais, lineares e fortemente correlacionados entre si. A relação hierárquica e positiva entre os níveis apontada por Kirkpartrick (1976) foi questionada por pesquisas posteriores, e constata-se que certos resultados, alcançados ou não, são insuficientes frente ao escopo do processo avaliativo do modelo. Dessa forma, houve o enfraquecimento dos chamados modelos clássicos de avaliação por considerar apenas os resultados produzidos pelas ações educativas, e modelos contemporâneos vêm ganhando destaque por também focalizar componentes capazes de explicar a ocorrência dos resultados dos eventos instrucionais (Zerbini, Abbad \& Mourão, 2012). Dentre tais modelos, destaca-se o modelo proposto por Borges-Andrade (1982 e 2006) e atualizado em suas implicações teóricas e práticas por Borges-Andrade, Zerbini, Abbad e 
Mourão (2013), intitulado Modelo de Avaliação Integrado e Somativo (MAIS), que recomenda que outros componentes e características devem ser considerados quando da ocasião de avaliação dos efeitos produzidos por ações de TD\&E.

O modelo MAIS considera que as variáveis do indivíduo, do curso e do ambiente podem afetar os resultados de uma ação educacional e é composto por cinco componentes: (1) insumo, (2) procedimentos, (3) processo, (4) resultados e (5) ambiente, sendo que este último é desdobrado em avaliação de necessidades, suporte, disseminação e efeitos em longo prazo. $\mathrm{O}$ esquema gráfico do modelo é apresentado na Figura 3.

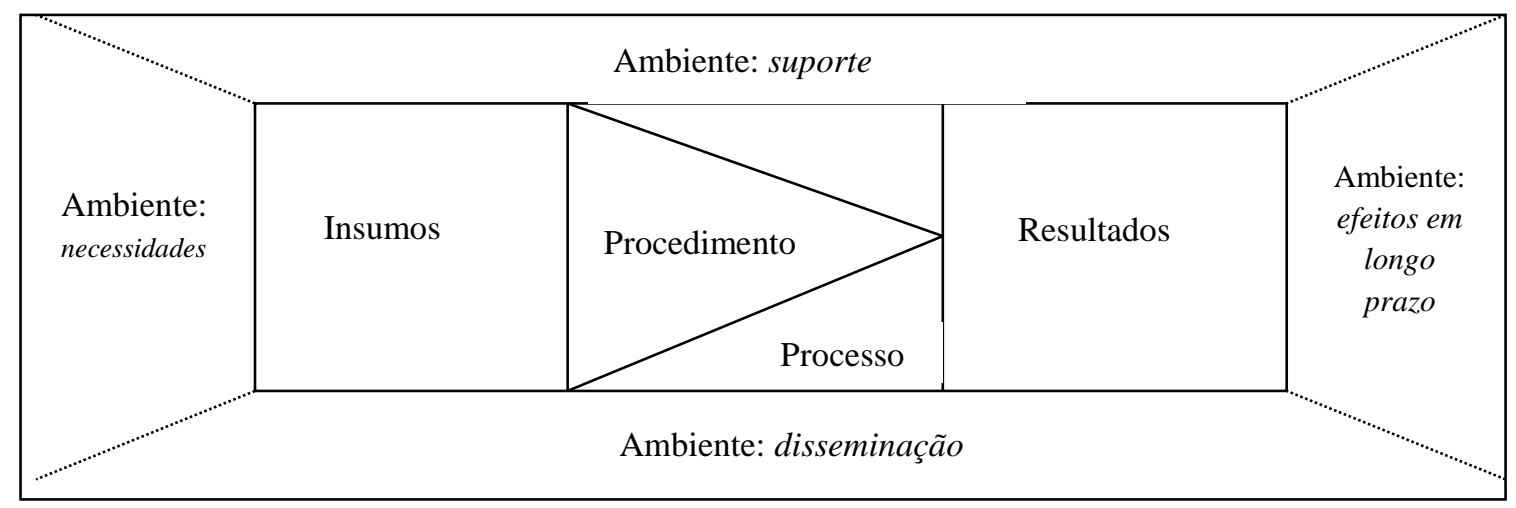

Figura 3. Modelo de Avaliação Integrado e Somativo - MAIS (Borges-Andrade, 1982 e 2006).

O componente Insumo refere-se aos fatores físicos e sociais e aos estados comportamentais e cognitivos, prévios à instrução, que podem influenciar seus resultados (ex.: variáveis motivacionais, sociodemográficas, psicossociais, cognitivo-comportamentais). Procedimentos são as operações necessárias para facilitar ou produzir os resultados instrucionais como, por exemplo, sequência de objetivos, meios e estratégias instrucionais, exercícios propostos. Processo são resultados intermediários ou efeitos parciais da ação instrucional verificados no comportamento dos estudantes à medida que os procedimentos são apresentados durante o treinamento (ex.: resultados em exercícios práticos, relações interpessoais estabelecidas entre pares e tutores). Resultados são os efeitos imediatos produzidos pelo treinamento, ou seja, são os desempenhos dos treinandos adquiridos logo após o evento educacional.

O Ambiente representa o contexto em que se insere a ação de TD\&E, e é dividido em quatro subcomponentes, sendo eles: a avaliação de necessidades, que identifica as lacunas entre o desempenho ideal e atual, buscando estabelecer os CHAs que devem ser adquiridos e quais indivíduos necessitam de treinamento por não possuírem esses CHAs; o suporte, que se refere aos fatores ambientais que podem facilitar ou dificultar ações de treinamento, como: recursos materiais, financeiros, tecnológicos, humanos, psicossociais presentes nos diversos âmbitos que 
circundam o aprendiz, e que podem favorecer ou não o alcance dos objetivos instrucionais, organizacionais e pessoais esperados; a disseminação, que consiste nas informações que a organização disponibiliza a respeito do evento educacional a ser desenvolvido e os efeitos em longo prazo que se referem às consequências ambientais provenientes do treinamento nos comportamentos e resultados organizacionais, grupais e individuais (Meneses, Zerbini \& Abbad, 2010).

Modelos empíricos específicos de avaliação de TD\&E foram elaborados a partir do MAIS. Abbad (1999) propõe o modelo integrado de avaliação de treinamento denominado Modelo de Avaliação do Impacto do Treinamento no Trabalho - IMPACT. Este modelo é composto por sete itens: (1) percepção de suporte organizacional, (2) características de treinamento, (3) características da clientela, (4) reação, (5) aprendizagem, (6) suporte à transferência e (7) impacto do treinamento no trabalho. O modelo é representado pela Figura 4.

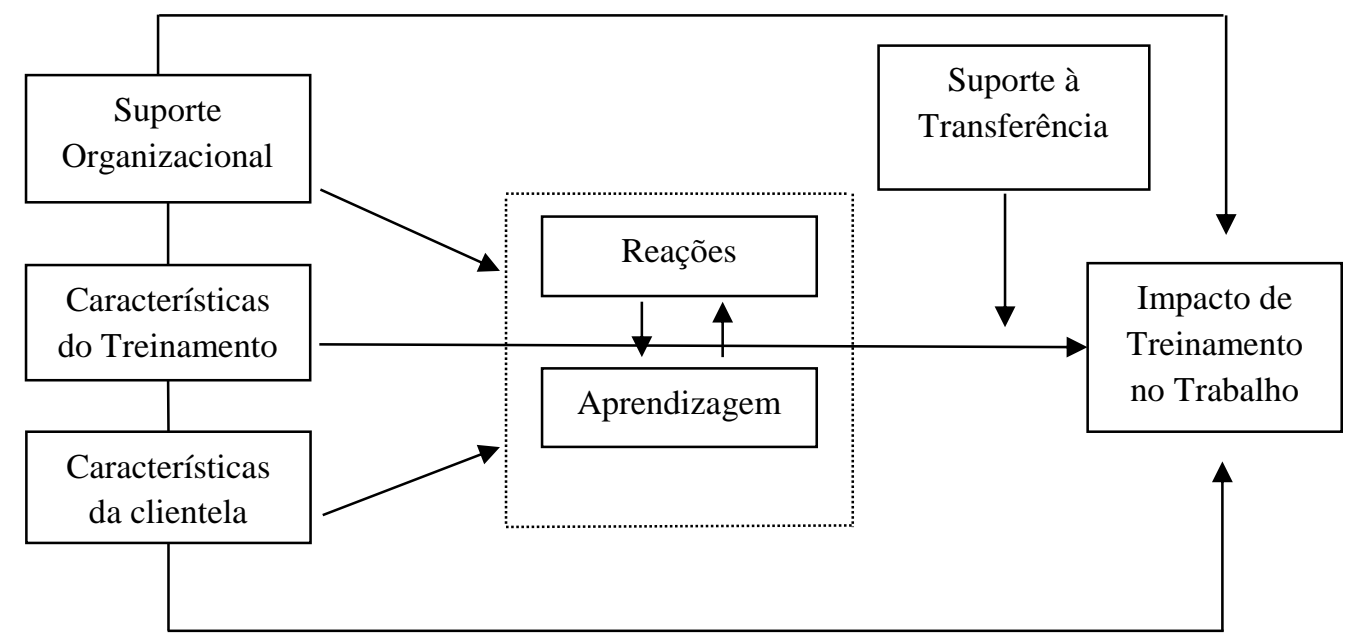

Figura 4. Modelo de Avaliação do Impacto do Treinamento no Trabalho - IMPACT (Abbad, 1999).

O elemento Suporte Organizacional compreende a opinião dos participantes acerca das práticas organizacionais de gestão de desempenho, de valorização do servidor e de apoio gerencial ao treinamento, relacionadas às condições do ambiente e nível de apoio fornecido ao treinando para participar do treinamento. As Características de Treinamento dizem respeito a variáveis próprias ao curso (área de conhecimento do curso, duração, natureza do objetivo principal do evento, origem institucional, escolaridade e desempenho do instrutor e qualidade do material didático). Características da Clientela é o conjunto de informações demográficas, funcionais, motivacionais e atitudinais dos treinandos.

Reação é uma medida relacionada à satisfação dos participantes com diversos aspectos da ação educacional (programação de atividades, apoio ao desenvolvimento do curso, aplicabilidade e utilidade das ações educacionais, resultados, expectativas de suporte organizacional e desempenho do instrutor). Aprendizagem refere-se ao grau de assimilação e 
retenção dos conteúdos ministrados no curso, medido em termos dos escores obtidos pelo participante em testes ou provas de conhecimentos parciais e finais. Suporte à Transferência compreende no suporte psicossocial - fatores situacionais de apoio e consequências associadas ao uso das novas habilidades no trabalho - e o suporte material à transferência, que são elementos de apoio ambiental oferecidos pela organização para que o treinando tenha a possibilidade de aplicar no trabalho. O Impacto do Treinamento no Trabalho envolve a auto e a heteroavaliação feita pelo próprio aprendiz acerca dos efeitos produzidos pelo treinamento em seus níveis de desempenho, motivação, autoconfiança e abertura a mudanças nos processos de trabalho (impacto em amplitude) ou pode ser definido como a aplicação (ou transferência) dos CHAs aprendidos na ação educacional para o trabalho (impacto em profundidade).

A partir dos modelos MAIS e IMPACT, Zerbini (2007) desenvolveu um modelo específico para a avaliação de treinamentos a distância, ofertados pela internet, que tem como foco a identificação das variáveis preditivas da transferência de treinamento em cursos de qualificação profissional. A autora analisou o curso gratuito IPGN - "Iniciando um Pequeno Grande Negócio" do SEBRAE (Serviço Brasileiro de Apoio às Micro e Pequenas Empresas), oferecido integralmente pela internet. O modelo avalia o poder preditivo de variáveis individuais (estratégias de aprendizagem), de contexto de estudo (ambiente e procedimentos) e de reações (reação aos procedimentos e ao tutor) quanto à transferência de treinamento para o ambiente de trabalho. A Figura 5 apresenta o Modelo.

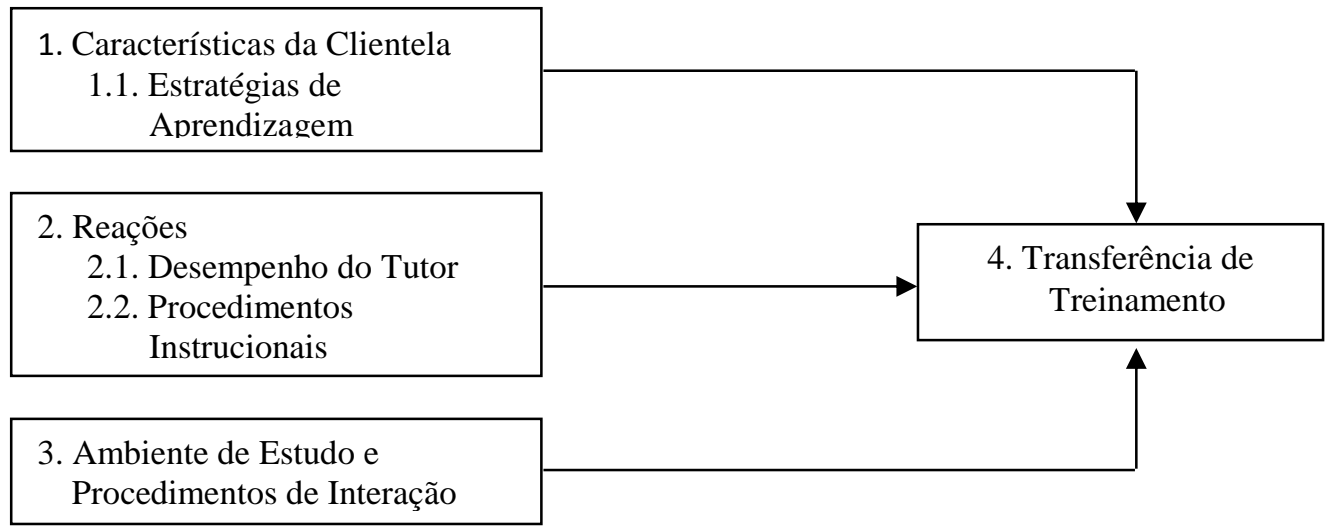

Figura 5. Modelo geral de avaliação da Transferência de Treinamento via web no Trabalho (Zerbini, 2007).

As variáveis envolvidas no modelo são definidas como:

1. Estratégias de Aprendizagem: capacidades cognitivas complexas aprendidas pelo indivíduo ao longo da vida. Envolvem capacidades cognitivas, habilidades comportamentais e de autocontrole emocional, empregadas pelo aprendiz para controlar os próprios processos psicológicos de aprendizagem, como atenção, aquisição, memorização e transferência. 
2. Reações ao Curso: satisfação dos participantes com características instrucionais do curso e com o desempenho do tutor.

3. Ambiente de estudo e Procedimentos: aspectos do contexto pessoal de estudo do aluno e do próprio curso que podem dificultar a permanência do aluno no curso.

4. Transferência de Treinamento: refere-se à aplicação dos CHAs aprendidos no curso no contexto de trabalho do participante. É medido em termos das respostas dos participantes à escala de frequência de aplicação do aprendido no curso no ambiente de trabalho, e das respostas dos participantes à pergunta "Você elaborou o plano de negócios ao final do curso?".

Outro modelo de avaliação foi desenvolvido por Martins (2012) que propõe identificar preditores de aprendizagem vinculados às características da clientela (estratégias de aprendizagem e frequência nos recursos da $w e b$ ) e às reações aos procedimentos instrucionais e ao tutor. Para tanto, foram administradas presencial e virtualmente escalas de medida referentes a Estratégias de aprendizagem, Reação aos procedimentos instrucionais e Reação ao desempenho do tutor junto a graduandos matriculados em disciplinas semipresenciais ofertadas a todos os estudantes de uma instituição de ensino superior da rede privada. A Figura 6 ilustra o modelo em questão.

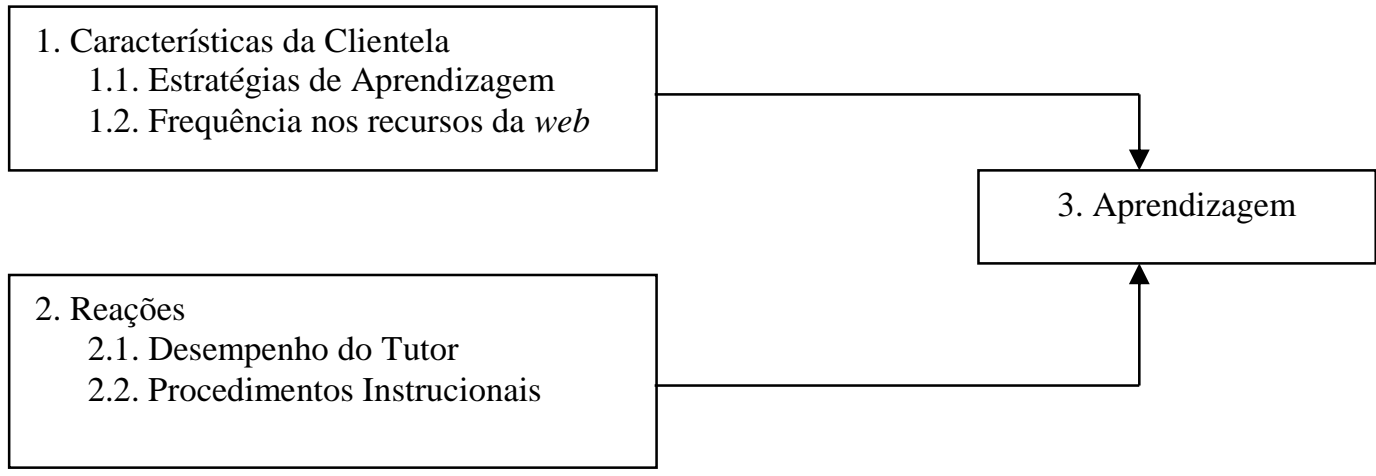

Figura 6. Modelo de investigação proposto por Martins (2012).

A partir da aplicação do modelo proposto por Martins (2012), a autora verificou que as Estratégias de Aprendizagem Autorregulatórias, a frequência no uso de recursos da web e as Reações favoráveis aos Procedimentos Instrucionais estão relacionadas com a aprendizagem na amostra considerada em seus estudos. Assim, Martins (2012) apresenta a importância do ambiente virtual de aprendizagem no processo de comunicação entre os envolvidos na ação educacional (tutores e alunos), bem como a utilização de estratégias que permitam o autogerenciamento da aprendizagem, a autorregulação da motivação, ansiedade e atenção com objetivo do alcance dos resultados almejados por tais ações. 
Mesmo diante dos estudos dedicados a testagem de modelos de avaliação, tais como aqueles aqui apresentados, a literatura indica diversas lacunas no campo da avaliação de ações educacionais. Considerando que no Brasil os estudos realizados no campo da EAD ainda são escassos e não conclusivos (Abbad et al., 2006; Martins \& Zerbini, 2014; 2015; Sales, 2009), torna-se de grande importância a condução de pesquisas que envolvam os cursos ofertados a distância.

Dessa forma, os modelos aqui apresentados orientam a escolha das variáveis estudadas na presente pesquisa e a partir deles será proposto um modelo de investigação que visa incluir a variável "Estratégias de Aprendizagem" como variável critério. Nos modelos de investigação de Zerbini (2007) e Martins (2012) a variável Estratégia de Aprendizagem é apresentada como variável antecedente para a transferência de treinamento (Zerbini, 2007) e aprendizagem (Martins, 2012). Contudo, fazem-se necessários estudos que respondam se determinadas características da clientela (dados sociodemográficos, uso de ferramentas eletrônicas) e/ou reações (procedimentos instrucionais, desempenho do tutor) influenciam o uso de estratégias de aprendizagem mais ou menos adequadas no contexto de EAD. Estudos indicam uma relação entre o sucesso no processo de aprendizagem com percepções favoráveis e satisfação positiva com a ação educacional (Giangreco, Carugati, Sebastiano \& Della Bella, 2010; Gunawardena, Linder-VanBerschot, LaPointe \& Rao, 2010; Morgan \& Casper, 2000; Vaugham \& MacVicar, 2004; Womble, 2008). Assim, as Estratégias de aprendizagem, quando bem planejadas e adequadas ao contexto (modalidade de ensino e característica do público-alvo) podem influenciar na reação satisfatória do aluno em relação ao curso. Outros achados mostram a relação entre satisfação (reação) com: o curso; o desempenho acadêmico e dos tutores; com a interface gráfica; com o uso de estratégias cognitivas de aprendizagem (Abbad, Côrrea \& Meneses, 2010; Testa \& Luciano, 2010), bem como a relação entre a interação do aluno com seus pares (tutor/colegas) e a autoconfiança para aprender (Testa \& Luciano, 2010). Ainda, estudos confirmam a influência de variáveis pessoais (idade, gênero, escolaridade, categoria profissional, etc.) no uso de determinadas estratégias de aprendizagem (Holman, Epitropaki \& Farnie, 2001; Pantoja, 2004). Dessa forma, percebe-se que as estratégias de aprendizagem, quando bem planejadas e adequadas para determinada ação educacional, podem influenciar positivamente a entrega e o resultado de tais ações por meio dos procedimentos adotados pelo tutor e do planejamento em função da característica da clientela.

De acordo com autores da educação, uma ação educacional deve considerar não somente as estratégias de ensino, para que o sucesso de tal ação seja alcançado no seu planejamento, 
deve-se levar em consideração as estratégias de aprendizagem utilizadas pelos possíveis indivíduos participantes da ação, bem como suas características (Assmann, 1998; Gonsalves, 2014). É confirmada, dessa forma, a possibilidade e importância do uso da variável Estratégia da Aprendizagem como critério para outras variáveis, dentre elas as de interesse da presente pesquisa, ou seja, Características da Clientela e Reações ao Curso, visando a qualidade e sucesso da ação educacional.

O presente estudo tem como objetivo investigar a variável Estratégia de Aprendizagem no contexto da EAD. Para uma maior compreensão dessa modalidade de ensino, o capítulo dois tem como intuito fazer uma caracterização da EAD, no contexto das políticas públicas e das IES. 


\section{CAPÍTULO 2. EDUCAÇÃO A DISTÂNCIA}

\section{Objetivo do capítulo 2}

O objetivo do capítulo discorre sobre as definições e características da modalidade EAD e a contextualiza, na esfera das políticas públicas nacionais, além de considerar as potencialidades e os desafios estabelecidos frente às inovações no campo educacional. Discute ainda a EAD no contexto das Instituições de Ensino Superior (IES) no Brasil e no mundo.

\subsection{Educação a Distância: definições, características e políticas públicas}

Diante do mercado competitivo, o perfil do trabalhador passa a ser de um profissional com múltiplas competências e com capacidade de adaptação a novas situações. Desta maneira, as organizações buscam por diversas estratégias educacionais que proporcionem o desenvolvimento de seus colaboradores, bem como os profissionais, ainda que de forma individual, buscam o aprimoramento de seus CHAs (Walter, 2006). Nesse contexto, a modalidade de ensino a distância se insere e é considerado elemento adequado para essa nova realidade por estar disponível para atender à crescente demanda por qualificação e profissionalização impostas pelo mercado de trabalho, (Abbad, Zerbini \& Souza, 2010; Meneses, Martins \& Zerbini, 2012; Umekawa \& Zerbini, 2015).

Com o avanço das NTICs, barreiras temporais são eliminadas e quando combinadas com a importância da aprendizagem ao longo da vida, novos cenários educacionais são impulsionados, ou mesmo, as transformações dos atuais cenários se tornam necessários (Meneses, Martins \& Zerbini, 2012). Dessa forma, as ações educacionais se ajustam às novas características apresentadas pela atual demanda, formada por indivíduos constantemente conectados e com acesso a celulares, internet e múltiplas mídias, envolvidos por tecnologias interativas (Garrison \& Vaughan, 2008; Martins \& Zerbini, 2014). Assim, a EAD vem sendo utilizada como estratégia instrucional por recorrer às avançadas mídias digitais e ferramentas de interação para possibilitar que o maior número de indivíduos tenha acesso a informações e conteúdos, estabelecer contato, mesmo estando fisicamente separados (Umekawa \& Zerbini, 2015). Contudo, as NTICs são empregadas como recurso para a redução de custos financeiros, barateando os programas de treinamento, devido a possibilidade do alcance de um maior número de potencias usuários das ações de TD\&E (Iglesias \& Salgado, 2012) e por essa razão merecem atenção. 
De acordo com Vargas e Abbad (2006) a literatura apresenta diversas conceitualizações para definição de EAD, e pode ser entendida como uma abordagem de ensino e aprendizagem, mediada ou não por mídias tecnológicas que torna possível a ocorrência de diferentes formas de interação entre professor-aluno e aluno-aluno (Associação Brasileira de Educação a Distância [ABED], 2012; Badia \& Monereo, 2010; Reis, 2009; Vargas, 2004). O artigo 80 da LDB, do Decreto $n^{\circ} 2.494$ de 10/02/98, apresenta a EAD como uma forma de ensino que possibilita a autoaprendizagem mediada por recursos didáticos organizados sistematicamente, apresentados em diferentes suportes de informação, podendo ser utilizados de forma isolada ou combinados, bem como veiculado pelos diversos meios de comunicação (NTICs). A definição também é encontrada no Decreto $\mathrm{n}^{\mathrm{o}}$ 5.622, de 19/12/2005, onde a EAD é “modalidade educacional na qual a medição didático-pedagógica nos processos de ensino e aprendizagem ocorre com a utilização de meios e tecnologias de informação e comunicação, com estudantes e professores desenvolvendo atividades educativas em lugares ou tempos diversos" (Brasil, 2005). A figura 1 mostra pontos em comum com as definições apresentadas até o momento.

Tabela 1. Pontos em comum entre as definições para EAD.

\begin{tabular}{|l|l|}
\hline Artigo 80 LDB & \multirow{2}{*}{ Modalidade de ensino que possibilita a autoaprendizagem; } \\
\cline { 1 - 1 } Decreto 2.494/98 & $\begin{array}{l}\text { - Utilização de TICs; } \\
\text { - Alunos e professores ultrapassando barreiras do tempo e } \\
\text { espaço; }\end{array}$ \\
\cline { 1 - 1 } $\begin{array}{l}\text { Associação Brasileira de } \\
\text { Educação a Distância (ABED) }\end{array}$ & $\begin{array}{l}\text { - Recursos didáticos organizados sistematicamente; } \\
\text { Diferentes formas de interação entre professor e aluno. }\end{array}$ \\
\hline
\end{tabular}

Vargas (2003) define a EAD como uma modalidade de ensino e aprendizagem que promove diferentes formas de interação entre alunos e professores, ultrapassando as barreiras do tempo e do espaço. Para Abbad, Zerbini e Souza (2010) a EAD é uma modalidade de ensino com condições adequadas para adultos e possibilita a construção de mecanismos que favorecem a aprendizagem e a qualificação continuada no decorrer da vida, bem como está sendo utilizada também no ambiente coorporativo ao possibilitar o desenho de eventos educacionais focados em situações específicas, ampliando e democratizando o acesso às oportunidades de treinamento.

Entre as principais características da EAD pode-se citar: a) uso extensivo de tecnologia; b) não existência de barreiras geográficas (professor e aluno separados fisicamente); c) fácil reprodução em larga escala com um grande número de alunos no mesmo evento; c) aluno como gestor do processo de aprendizagem, sendo ele responsável pelo seu aprendizado e o 
professor/tutor apresenta um papel mediador nesse processo; d) a relação professor-aluno acontece por algum recurso tecnológico entre eles: televisão, rádio, material impresso, $C D$ $R O M$, internet, intranet; e e) versatilidade de conteúdos, onde a construção do conhecimento se dá pelo aluno de acordo com as suas necessidades (Mourão, Abbad \& Zerbini, 2014; Walter, 2006). A partir de características próprias como: metodologia flexível e adaptada para indivíduos adultos, a EAD permite o ajuste e conciliação do estudo com outras atividades pelos discentes, porém, com um maior controle dos elementos tempo, espaço e ritmo de estudo (Sales, 2009; Yukselturk \& Inan, 2006).

O aumento no consumo por bens com tecnologia agregada possibilitou a EAD utilizar a internet como meio de ensino, bem como inserir o aluno em novas propostas de estudo (contatos restritos aos ambientes virtuais, estudo fora do ambiente escolar) e formas diferenciadas de se relacionar com professores e colegas (interação virtual) o que podem influenciar o resultado do evento instrucional (Carvalho \& Abbad, 2006; Dean \& Webster, 2000; Martins \& Zerbini, 2014). Na EAD o processo de ensino e aprendizagem requer uma grande variedade de procedimentos, recursos e meios instrucionais proporcionados pelas NTICs, favorece a interação entre os envolvidos, promove a interatividade tecnológica e pedagógica, bem como complementa a entrega dos conteúdos, flexibiliza e diversifica as atividades de aprendizagem e estimula a aprendizagem colaborativa (Badia \& Monereo, 2010; Carvalho \& Abbad, 2006; Coll, 2004; Martins, 2012; Martins \& Zerbini, 2014; Mauri, Onrubia, Coll \& Columbia, 2005).

De acordo com Martins e Zerbini (2014), ao adotar a internet como meio de ensino, a EAD oferece novas condições de estudo para o aluno, entre elas: o ambiente de estudo deslocado; contato com seus pares (tutor e colegas) restritos aos ambientes virtuais; uso de bibliotecas, bem como novos meios de interação entre aluno e professor. Ainda segundo as autoras, a EAD oferece uma aprendizagem individualizada, independente e flexível ao considerar o tempo e o espaço do educando, isso acontece por meio dos recursos didáticos que são adaptados às NTICs.

Com a aplicação das NTICs em ações de EAD, o acesso dos participantes aos materiais e recursos de ensino e aprendizagem é ampliado, por meio de ferramentas tais como: chats, aulas virtuais, vídeo aulas etc. O estudo síncrono é possível a qualquer momento e lugar, bem como o assíncrono com o uso de wikis, fóruns de discussão em ambientes virtuais de aprendizagem (AVA), bem como possibilita o trabalho em equipe e a formação de comunidades e redes de aprendizagem (Abbad, Mourão, Zerbini \& Correia, 2015). 
A oferta de cursos a distância apresenta vantagens e benefícios e são vastamente difundidos se referindo ao estudo individualizado com determinação do ritmo do treinando, à permanência do trabalhador na organização, à possibilidade de formação de vários treinandos ao mesmo tento em locais distantes, e ao acesso de um ambiente para simulação dos mesmos simultaneamente (Abbad, Mourão, Zerbini \& Correia, 2015; Martins \& Zerbini, 2014). Contudo, existem poucas sistematizações de resultados de aprendizagem alcançados por ações de EAD, principalmente pela internet (Carvalho \& Abbad, 2006; Castro \& Ferreira, 2006; Martins \& Zerbini, 2014 e 2015; Umekawa \& Zerbini, 2015).

No Brasil, o aumento da oferta e demanda por cursos oferecidos por meio da educação a distância estão voltados para programas de qualificação e formação profissional, bem como em ações educacionais oferecidas por organizações do sistema produtivo. A utilização da modalidade vem aumentando consideravelmente nos últimos anos e vem sendo empregada desde a Educação Básica até o Ensino Superior, assim como em programas de ensino não tradicionais como cursos de caráter aberto (Alves, 2011; Martins \& Zerbini, 2014 e 2015; Mourão, Abbad \& Zerbini, 2013). Embora haja um crescente interesse por cursos ofertados na modalidade de ensino a distância e o reconhecimento dos benefícios e vantagens dos mesmos, ainda se fazem necessárias análises e discussões mais robustas sobre ações educacionais a distância e a sistematização de conhecimentos sobre o tema (Abbad, Carvalho \& Zerbini, 2006; Umekawa \& Zerbini, 2015; Zerbini, 2007).

No contexto das políticas públicas educacionais nacionais, a EAD consta nas principais legislações, bem como promove modificações consideráveis de ordem jurídico-institucional (Martins \& Zerbini, 2014). Teve seu marco na aprovação da Constituição Federal de 1988 e importantes alterações na legislação da área educacional merece atenção. A Lei de Diretrizes e Bases da Educação Nacional - LDB (Lei n 9.394/1996) que reestrutura e define as diretrizes e bases da educação escolar no Brasil, aborda a EAD e estabelece que o "Poder Público incentivará o desenvolvimento e a veiculação de programas de ensino a distância, em todos os níveis e modalidades de ensino, e de educação continuada" (caput do artigo 80 da LDB), cabendo à União credenciar e avaliar as instituições que oferecem cursos dessa modalidade, sendo esta organizada com abertura e regime especiais.

Simultaneamente a LDB, outras legislações de grande importância para a educação merecem ser citadas e algumas específicas a modalidade EAD:

- O Plano Nacional de Educação - PNE (Lei no 10.172/2001) apresenta novas políticas e ações governamentais na educação; 
- A Resolução CNE/CES $n^{\circ} 1 / 2001$ determina as normas que regulamentam o funcionamento da pós-graduação;

- A Portaria Ministerial no 4.361/2004 prevê o credenciamento e recredenciamento de IES, para oferta de cursos superiores a distância;

- O Decreto $\mathrm{n}^{\circ}$ 5.622/2005 regulamenta o artigo 80 da LDB;

- A Lei n ${ }^{\circ}$ 12.056/2009 acrescenta parágrafos ao artigo 62 da LDB, aborda a formação inicial, a continuada e a capacitação dos profissionais de magistério - onde: a primeira deve dar prioridade ao ensino presencial, subsidiariamente fazendo uso de recursos e tecnologias de educação a distância; e as demais, podem utilizar tais recursos e tecnologias.

Ações e programas governamentais relativos a EAD são propostos pelo Ministério da Educação (MEC) entre eles estão: Escola Técnica Aberta do Brasil, Programa Nacional de Acesso ao Ensino Técnico e Emprego (Pronatec), Universidade Aberta do Brasil (UAB), Rede Nacional de Formação Continuada de Professores, Mídias na Educação, ProInfo, ProInfo Integrado e e-ProInfo. A Escola Técnica Aberta do Brasil e o Pronatec têm como objetivo expandir e democratizar a oferta de cursos de educação profissional técnica e tecnológica a distância. A UAB busca ampliar a oferta de cursos voltados para a educação superior por meio da EAD, tendo como foco a formação inicial e continuada a professores e profissionais de educação básica da rede pública, bem como a redução da desigualdade na oferta de ensino superior e o desenvolvimento do sistema nacional de educação superior a distância (Martins \& Zerbini, 2014). Contudo, constata-se que o sistema de educação formal atual é insuficiente para atender as novas demandas sociais, bem como de qualificação e profissionalização, assim, exige-se que medidas educacionais se ampliem (Martins, 2012), sendo a modalidade EAD uma solução para tal cenário, para tanto, faz-se necessário formulação de políticas que possibilitem uma maior democratização do ensino.

A estruturação efetiva da modalidade EAD como política, amparada pela internet e pelas NTICs, pode contribuir para democratização dos sistemas de ensino, ao possibilitar o atendimento de alunos em todo o território nacional e residentes em locais onde não há instituições de ensino convencionais (Santos, 2006). Nesse sentido, a EAD pode contribuir com a ampliação da educação em um país com grandes dimensões geográficas e territoriais como o Brasil. Contudo, tal processo deve envolver cuidados fundamentais na sua elaboração, infraestrutura adequada, acompanhamento e avaliação das ações e programas, bem como a 
formação de professores para tal realidade, com o objetivo de garantir a qualidade dos sistemas de ensino.

De acordo com Martins (2012) a normatização de parâmetros para a avaliação de tais programas ainda apresenta déficits, entretanto, o Ministério da Educação (MEC) apresenta esforços para a definição de princípios, diretrizes e critérios para acompanhar os cursos oferecidos na modalidade a distância. Ainda segundo a autora, regras e orientações são estabelecidas para a avaliação de programas de EAD no país, bem como procedimentos avaliativos já são utilizados, entre eles pode-se citar a indicação de que as avaliações de aprendizagem devem acontecer em momentos presenciais, assim como recomendações sobre o papel da tutoria também são indicados.

É indiscutível que a EAD tem se firmado, no Brasil e no mundo, como modalidade de ensino, e as possibilidades de ampliação das estratégias de ensino em larga escala torna essa modalidade educacional um enorme atrativo para as organizações (Abbad, Mourão, Zerbini \& Correia, 2015). A próxima seção apresenta os avanços da EAD no contexto das Instituições de Ensino Superior.

\subsection{Educação a Distância em Instituições de Ensino Superior}

A EAD aparece como uma alternativa de ensino e é analisada como uma possibilidade viável ao criar mecanismos que favorecem o processo de aprendizagem e a qualificação continuada, seja no nível superior de ensino como nos ambientes coorporativos (Abbad, Zerbini, \& Souza, 2010). O contexto mundial indica a presença de inúmeras universidades que oferecem cursos de graduação na modalidade EAD, o que mostra o grande impacto da introdução da EAD por intermédio da internet (Abbad, Zerbini, \& Souza, 2010; Martins \& Zerbini, 2014). Segundo Martins e Zerbini (2014), a Universidade Aberta do Reino Unido (Open University), fundada há mais de 30 anos, foi uma das precursoras da educação a distância e atualmente conta com cerca de 200 mil alunos matriculados em cursos nessa modalidade. De acordo com Bohadana e Valle (2009), encontra-se na Índia a maior universidade aberta do mundo com 1,5 milhões de alunos, a Universidade a Distância Índia Gandhi. As autoras ainda citam outras universidades a distância com um número superior de alunos de outras universidades que oferecem cursos totalmente presenciais, entre elas: Universidade Nacional de Educação a Distância (Espanha); Universidade Aberta (Portugal); Universidade do Ar (Japão); Fern Universität (Alemanha); Télé-Université (Canadá); Universidade Nacional Aberta (Venezuela); Universidade PayameNoor (Irã); Universidade da África do Sul. 
Na última década, no Brasil, a oferta e a demanda por cursos de graduação oferecidos na modalidade EAD se multiplicaram. Dados do Ministério da Educação (MEC) e do Instituto Nacional de Estudos e Pesquisas Educacionais Anísio Teixeira (INEP), divulgados no Censo da Educação Superior de 2010 mostram que as matrículas na graduação do ensino a distância aumentaram 170 vezes do ano de 2001 para 2010, os estudantes matriculados em tal modalidade de ensino saltaram de 5.359 para 930.179 no período citado. De acordo com os dados do MEC e do INEP, divulgados no Censo da Educação Superior de 2012, a presença maciça do setor privado na educação superior é evidenciada: em 2009, das 2.314 IES existentes, 89\% (2.069) eram privadas; em 2012, a categoria privada era responsável pela oferta de 87,4\% (2.112) do total de 2.416 dos cursos de graduação. Mesmo com o aumento percentual das instituições da rede pública, ainda predominam as instituições privadas. O Censo mostra que a oferta de cursos na modalidade EAD vem crescendo no país, em 2012, houve um aumento de $36 \%$ em relação ao ano de 2009, saltando de 844 cursos oferecidos para 1.148 em 2012. Apesar do aumento percentual do número de cursos de graduação ter ocorrido em tal modalidade, os cursos presenciais são a grande maioria no sistema de educação superior no Brasil. Dos 31.866 cursos de graduação declarados ao Censo em 2012, 30.718 (96,4\%) eram presenciais e 1.148 (3,6\%) eram a distância. $\mathrm{O}$ total de alunos matriculados em cursos de graduação na modalidade não presencial chegou a 1.113.850. No período entre os anos de 2009 a 2012 foi registrado um crescimento de $32,9 \%$ na quantidade de matriculas nos cursos de graduação a distância.

As IES iniciaram a oferta de conteúdos para as universidades virtuais ao disponibilizar aos alunos parte substancial da carga horária das disciplinas na modalidade a distância (Martins, 2012). Assim, as IES passaram a utilizar processos educacionais mediados pela internet e NTICs em larga escala. De acordo com Martins e Zerbini (2014) as ações educacionais oferecidas a distância estão voltadas para as características da população que mais usa de tais serviços, que é formada por jovens cada vez mais conectados, com acesso a internet, celulares e múltiplas mídias. Estes jovens cresceram cercados por tecnologias interativas e podem não se adaptar às abordagens tradicionais de ensino, por meio da transmissão do conhecimento em longas aulas, muitas vezes expositivas (Garrison \& Vaughan, 2008). Não se pode negar que o mundo atual, envolto por tecnologia digital, apresenta-se como tendência contemporânea sem retorno; assim como as interações sociais e o trabalho, a educação sofre as influências e modificações geradas por tais tendências (Martins \& Zerbini, 2014). Segundo as autoras, a complexidade dos cenários e das modalidades de formação exige a ampliação de medidas educacionais alternativas, pois o atual sistema formal de educação torna-se insuficiente para 
atender às novas demandas sociais de qualificação e profissionalização, em razão das características da nova clientela, ou seja, a população jovem contemporânea das NTICs.

Com o aumento da demanda por cursos de graduação na modalidade EAD, bem como o aumento de oferta de cursos em tal modalidade, ocorrem questões que merecem ser discutidas nos processos educacionais em tal modalidade de ensino (Martins \& Zerbini, 2014). A efetividade das ações educacionais na EAD deve ser avaliada por investigações com o objetivo de mensurar os resultados alcançados, bem como verificar se tais resultados estão de acordo com os objetivos previamente estabelecidos pela própria ação educacional, explicar como acontece o processo de aquisição de aprendizagem em tal modalidade de ensino, as possíveis variáveis que levem aos bons resultados, com o objetivo de minimizar falhas no processo e aumentar os bons resultados (Martins \& Zerbini, 2014). De acordo com Martins e Zerbini (2014) há a necessidade e a relevância de estudos com o objetivo de verificar as medidas e as variáveis investigadas em tal modalidade, entre elas: características da clientela, variáveis motivacionais e de autoeficácia, medidas de reação etc., usando-as concomitantemente aos estudos da área de avaliação de cursos no nível superior de ensino, especificamente em cursos de graduação ofertados a distância. Ainda segundo as autoras, a área necessita de estudos sistemáticos que proponham modelos multivariados de avaliação e façam uso de instrumentos de medida para cursos na modalidade EAD.

Quando se refere à avaliação de ações educacionais ofertadas a distância há indicações que pesquisas, nas áreas de educação corporativa, qualificação profissional e ensino superior, principalmente pela internet e com medida de aprendizagem em suas análises, ainda são incipientes no Brasil (Abbad, Zerbini e Souza, 2010; Martins e Zerbini, 2014 e 2015; Meneses, Zerbini \& Martins, 2012; Mourão, Abbad \& Zerbini, 2013). Como foi discutido, com o aumento do EAD como modalidade de ensino, questões são apresentadas e merecem ser discutidas e a efetividade das ações em tal modalidade deve ser avaliada por estudos com o objetivo de mensurar os resultados obtidos, explicar como a aquisição da aprendizagem acontece em tal modalidade e as possíveis variáveis que possam levar aos bons resultados, visando otimizar os ganhos para um número maior de participantes e diminuir as falhas no processo, como forma de garantir a boa qualidade do ensino ofertado e a formação profissional dos alunos egressos dessa modalidade de formação acadêmica (Martins \& Zerbini, 2014). Diante do exposto, percebe-se a necessidade de investigações relacionadas à EAD, bem como estudos referentes às estratégias de aprendizagem utilizadas por estudantes de graduação em tal modalidade. Nessa pesquisa, especificamente, é estudado as Estratégias de Aprendizagem e suas variáveis 
preditoras. O próximo capítulo apresenta a trajetória metodológica utilizada para a revisão bibliográfica dos resultados de pesquisa que envolve as variáveis de interesse do presente estudo. 


\section{CAPÍTULO 3. ANÁLISE DA LITERATURA: DESCRIÇÃO E ACHADOS DE PESQUISA}

\section{Objetivos do capítulo 3}

O presente capítulo tem como objetivo caracterizar as variáveis estudadas neste estudo: a variável critério Estratégias de Aprendizagem, e as variáveis preditoras Características da Clientela (perfil sociodemográfico e uso de ferramentas eletrônicas) e Reações (ao desempenho do tutor e procedimentos instrucionais). São analisados conceitos, características e resultados de pesquisas atuais.

\subsection{Descrição do percurso metodológico para busca bibliográfica}

A busca para a compreensão das variáveis de interesse do presente estudo partiu da revisão de resultados de pesquisa entre o período de 2009 a 2015 bem como da análise das revisões de literatura realizadas recentemente. A Tabela 2 apresenta, resumidamente, as etapas para o posicionamento das variáveis Estratégias de Aprendizagem, Características da Clientela e Reações na literatura.

Tabela 2. Etapas da revisão da literatura sobre as variáveis de interesse do presente estudo.

\begin{tabular}{c|l}
\hline $\begin{array}{c}\text { Estratégias de } \\
\text { aprendizagem }\end{array}$ & $\begin{array}{l}\text { - Revisão dos resultados de pesquisa dos últimos cinco anos; } \\
\text { Análise da revisão de literatura realizada por Martins (2015). }\end{array}$ \\
\hline $\begin{array}{c}\text { Característica da } \\
\text { Clientela }\end{array}$ & $\begin{array}{l}\text { - Levantamento bibliográfico de pesquisas sobre a temática de interesse (dados } \\
\text { sociodemograficos e uso de ferramentas eletrônicas). }\end{array}$ \\
\hline Reações & $\begin{array}{l}\text { Análise da revisão de literatura realizada por Martins (2015); } \\
\text { Atualização e sistematização dos resultados de pesquisas sobre o nível de } \\
\text { reações no período de 2011 a } 2015 .\end{array}$ \\
\hline
\end{tabular}

No caso da variável critério do presente estudo, Estratégias de Aprendizagem, foi realizada uma revisão dos resultados de pesquisa dos últimos cinco anos. Também foi analisada a revisão da literatura realizada por Martins (2015), na qual a autora apresenta um levantamento bibliográfico sobre instrumentos de medidas nacionais e internacionais de Estratégias de Aprendizagem em contextos educacionais e os resultados de pesquisas que objetivaram analisar o relacionamento entre variáveis de interesse na área de TD\&E.

Para a sistematização dos resultados de pesquisa sobre a variável critério de interesse foram realizadas revisões bibliográficas em bases de dados eletrônicos, abrangendo o período de 2009 a 2015, a partir da estrutura de percurso de revisão desenvolvida por Martins (2012). Foram analisadas produções científicas de caráter nacional e estrangeiro disponíveis na biblioteca eletrônica SciELO, nas bases de dados Web of Sciences, além dos bancos de 
dissertações e teses da Universidade de Brasília (UnB) e da Universidade de São Paulo (USP). Os resultados em aspectos quantitativos do levantamento realizado nas bases de dados mencionadas são apresentados na Tabela 3.

Tabela 3. Distribuição dos artigos de acordo com bases de dados consideradas.

\begin{tabular}{lcc}
\hline \multicolumn{1}{c}{ Bases de dados } & \multicolumn{2}{c}{ Resumos } \\
\cline { 2 - 3 } & Levantados & Selecionados \\
\hline SciELO & 2.569 & 138 \\
Web of Science & 996 & 99 \\
Banco de dissertações e teses da & 1211 & 9 \\
USP* & 43 & 4 \\
Banco de dissertações e teses da & 4819 & 250 \\
UnB** & & \\
\hline Total & & \\
*USP: Ciências Humanas - Educação, Filologia e Língua Portuguesa, Administração, Interfaces Sociais da Comunicação e \\
Psicologia.
\end{tabular}

O objetivo principal deste processo foi obter informações sobre a situação atual da temática escolhida, a partir da investigação das produções científicas com o mesmo enfoque de estudo em campos de conhecimento diversos. Dessa forma, o acervo levantado dos estudos publicados possibilitou situar a variável Estratégias de Aprendizagem no campo, com contribuições de outras áreas e suas diferentes perspectivas e objetivos, o que auxiliou no posicionamento do pesquisador a partir do referencial teórico. A seguir será apresentado o percurso do levantamento de pesquisas científicas realizadas na revisão bibliográfica, expondo um quadro geral sobre os principais estudos encontrados e seus respectivos resultados.

Com o objetivo de dar continuidade ao processo de levantamento bibliográfico, em um primeiro momento foi definido o tema de principal relevância do próprio trabalho e determinadas as palavras-chave, considerando medidas e termos a serem empregados na pesquisa. Inicialmente, trabalhou-se com as palavras-chave: instituições de ensino superior, educação a distância, estratégias de aprendizagem, distance learning, e-learning, learning $e$ evaluation. Na sequência foi realizado o cruzamento entre tais termos e outros, tais como: college \& universities, online instruction, training, internet, education, higher education. Para tanto, foram então realizadas buscas em pesquisadas em dois idiomas: português e inglês.

A SciELO - Scientific Electronic Library Online refere-se a uma biblioteca eletrônica de periódicos brasileiros, bem como pesquisas publicadas em diversos países tais como: Brasil, Venezuela, Espanha, Cuba, Chile, Portugal. Para o levantamento bibliográfico, a partir do tema central da pesquisa, foram elegidas as palavras-chave que contemplam os conceitos e medidas a serem utilizados no estudo. Muitas palavras buscadas conduziram aos mesmos estudos, sendo 
selecionados 138 resumos. As buscas foram realizadas no mês de novembro de 2014 e atualizadas em julho de 2015 .

Os bancos de dissertações e testes das universidades de São Paulo (USP) e Brasília (UnB) foram escolhidos para a pesquisa devido sua representatividade entre as universidades da América Latina dentre os bancos de maior volume de publicações, mundialmente reconhecidas e grau de importância, bem como por se tratar de referência nacional em estudos na área da Psicologia Organizacional do Trabalho, principalmente trabalhos envolvendo o campo de TD\&E. Na USP, foi realizada uma abrangente pesquisa na área de Ciências Humanas, no qual apontou a EAD ligada a estudos situados nas áreas da Psicologia, Educação, Administração, Filologia, Interfaces Sociais e Língua Portuguesa. Foram encontrados 1.211 estudos no período entre os anos 2009 a 2014 sendo selecionados 43 resumos. No banco de dados da UnB, foi pesquisado o banco de dissertações e teses do Departamento de Psicologia Social do Trabalho e das Organizações, resultando em 43 resultados de defesas realizas no mesmo período.

A Web of Science é uma base de dados que concentra trabalhos das áreas de Ciências, Humanidades, Ciências Sociais e Artes. O produto da base de dados da Web of Science são resumos presentes nas revistas ou jornais na sua maioria, das áreas da Saúde, Educação, Educação e Tecnologia e Sociais. A busca realizada nesta base bibliográfica corrobora os achados anteriormente identificados, apontando que os estudos sobre EAD são realizados em diversos países, tais como: África do Sul, Austrália, Áustria, China, Espanha, EUA, Estônia, Indonésia, Itália, Japão, Praga, Reino Unido e Ucrânia. A busca apontou para 996 estudos. Como aconteceu com as outras bases de dados, várias palavras pesquisadas levaram aos mesmos estudos, o que resultou na seleção de 99 resumos. As buscas foram realizadas no mês de novembro de 2014 e atualizadas em julho de 2015.

O levantamento das produções científicas de caráter nacional e estrangeiro disponíveis na biblioteca eletrônica SciELO, nas bases de dados Web of Science, e nos bancos de dissertações e teses da Universidade de Brasília (UnB) e da Universidade de São Paulo (USP) apontaram um total de 4.819 estudos científicos sendo selecionados 250 resumos sobre o tema estudado tendo como base os tipos de publicação (empírica, revisão, teórica, histórica, relato de experiência), as metodologias, tendências e lacunas.

As pesquisas selecionadas para análise na biblioteca eletrônica SciELO, e nos bancos de dissertações e teses da Universidade de Brasília (UnB) e da Universidade de São Paulo (USP) apontaram um grande número de pesquisas sobre EAD na área da saúde (Medicina, 
Enfermagem). Também foi possível verificar pesquisas nas áreas das ciências humanas (Educação, Administração, Psicologia do Trabalho) durante o período de 2009 a 2015.

Vários estudos foram encontrados sobre o uso das NTICs no processo de ensino de disciplinas, na comunicação, na inclusão e na mediação tecnológica na educação. Poucos estudos foram encontrados enfatizando as políticas públicas de educação a distância, sete artigos apenas. Estudos voltados para a EAD e Instituições de Ensino Superior foram encontrados, apresentando as características das iniciativas de EAD: estruturas dos cursos, público-alvo, tecnologias utilizadas, métodos de avaliação; avaliação das estratégias de aprendizagem em EAD, aprendizagem em ambientes virtuais de ensino, prática pedagógica do tutor em EAD.

Estudos sobre aprendizagem focam as dificuldades encontradas por alunos no processo de construção do conhecimento, poucos estudos sobre estratégias de aprendizagem voltados para o ensino superior na modalidade de ensino a distância foram encontrados no período pesquisado. Indicando que estudos ainda são necessários nesta área no Brasil.

Os estudos levantados na base de dados da Web of Science, que é uma base de dados que concentra trabalhos das áreas de Ciências, Humanidades, Ciências Sociais e Artes, são resumos presentes nas revistas ou jornais na sua maioria, das áreas da Saúde, Educação, Educação e Tecnologia e Sociais, apontam que os estudos sobre EAD são realizados em diversos países, tais como: África do Sul, Austrália, Áustria, China, Espanha, EUA, Estônia, Indonésia, Itália, Japão, Praga, Reino Unido e Ucrânia. A EAD vem sendo utilizada em várias áreas do conhecimento entre eles: educação (línguas, geografia, biologia, matemática, estatística), administração, saúde (medicina, enfermagem).

Por meio do levantamento dos resumos foi possível apontar a necessidade de estudos sobre as variáveis que influenciam a qualidade e os resultados das ações educacionais no ensino a distância. A partir da análise dos resumos das pesquisas científicas selecionadas nas bases de dados consideradas, foi possível situar a categoria de estudo empreendido a respeito da variável critério de pesquisa considerada. Alguns dos pontos levantados encontram-se dispostos na Tabela 4 , a seguir. 
Tabela 4. Resultados de buscas na biblioteca eletrônica SciELO, Web of Science, Banco de Dissertações e Teses da USP e Banco de Dissertações e Teses da UnB.

\begin{tabular}{|c|c|c|}
\hline Variável & Palavras-Chave & Resultados da Busca \\
\hline $\begin{array}{l}\text { Estratégias de } \\
\text { Aprendizagem }\end{array}$ & $\begin{array}{l}\text { Aprendizagem, Autoeficácia, } \\
\text { Estratégias de Aprendizagem, } \\
\text { Educação a Distância; Ensino } \\
\text { Superior; Instituições de Ensino } \\
\text { Superior; Políticas Públicas de } \\
\text { Educação a Distância; } \\
\text { Treinamento, Desenvolvimento } \\
\text { e Educação; Avaliação de } \\
\text { Cursos a Distância de IES; } \\
\text { Distance Learning; E-learning; } \\
\text { Online Instruction; Computer } \\
\text { Assisted Instruction; Learning; } \\
\text { Higher Education; Education; } \\
\text { Training; Knowledge, Skills \& } \\
\text { Abilities; Efectiveness } \\
\text { Teaching; Evaluation; College } \\
\text { \& Universities. }\end{array}$ & $\begin{array}{l}\text { - Aprendizagem foca as dificuldades } \\
\text { encontradas por alunos no processo de ensino; } \\
\text { - Poucos estudos sobre estratégias utilizadas } \\
\text { por estudantes universitários no EAD no } \\
\text { Brasil. } \\
\text { - Uso das TICs no processo de ensino de } \\
\text { disciplinas, na comunicação, na inclusão e na } \\
\text { mediação tecnológica na educação; } \\
\text { - Poucos estudos enfatizando as políticas } \\
\text { públicas de educação a distância; } \\
\text { - Necessário o aprofundamento do estudo a } \\
\text { respeito das variáveis influentes sobre a } \\
\text { qualidade e os resultados das ações de ensino } \\
\text { a distância; }\end{array}$ \\
\hline
\end{tabular}

Em relação à variável preditora Características da Clientela (perfil sociodemográfico e uso de ferramentas eletrônicas) são apresentados e discutidos seus conceitos e características, bem como, alguns dos resultados de pesquisa mais relevantes levantados através da leitura de publicações com enfoque nas temáticas de interesse do presente estudos (dados sociodemográficos e uso de ferramentas eletrônicas). Visando caracterizar a variável Reação (ao desempenho do tutor e aos procedimentos instrucionais) foi analisada a revisão de literatura produzida por Martins (2015). A autora realizou um levantamento bibliográfico, que dentre outros objetivos, pretendeu apresentar instrumentos nacionais e internacionais construídos com o objetivo de mensurar a satisfação (reação) dos aprendizes em ações educacionais ofertadas a distância, bem como resultados de pesquisa que objetivaram analisar o relacionamento entre variáveis, bem como foi realizado levantamento dos estudos dos últimos anos com o objetivo de atualizar os achados sobre a temática em questão.

Com o objetivo de atualização e sistematização de resultados de trabalhos científicos sobre o nível de reações, como citado anteriormente, foram realizadas buscas bibliográficas nas bases de dados eletrônicas: a biblioteca eletrônica SciELO, as bases de dados ProQuest, bem como os bancos de dados da Universidade de São Paulo (USP), considerando os estudos produzidos no período de 2011 a 2015, a partir da estrutura de percurso de revisão desenvolvida por Martins (2012). Para uma maior adequação à pesquisa, foram selecionados artigos das áreas da Psicologia, da Educação e da Administração. A partir dos resultados (número de resumos 
levantados), pertinência dos mesmos e/ou repetições, foram definidos os cruzamentos das palavras-chave para serem usados na revisão, a saber: reação e satisfação com ensino a distância, ensino superior, treinamento e curso. Na base de dados ProQuest também foram realizados os cruzamentos das palavras-chaves, reaction e satisfaction com distance learning e higher educacion.

A revisão da literatura encontrou, conforme a Tabela 5, o total de 829 artigos. Dentre eles foram selecionados os artigos das áreas de Psicologia e Educação, resultando em 70 artigos, dos quais 8 (oito) estavam disponíveis para download. Contudo, dos oito artigos lidos, 3 (três) discutiam ações educacionais ofertadas pela internet, porém, o foco não era a reação dos participantes em relação a tais ações, portanto, foram descartados. Sendo assim, o número de produções analisadas no presente estudo foram 5 (cinco). A Tabela 5 apresenta os resultados do controle busca realizado em torno do nível Reações.

Tabela 5. Controle de busca da revisão bibliográfica de Reações.

\begin{tabular}{|c|c|c|c|}
\hline \multirow{2}{*}{ Palavras-chave } & \multicolumn{3}{|c|}{ Número de artigos } \\
\hline & Encontrados & Selecionados & Lidos \\
\hline \multicolumn{4}{|l|}{ SciELO } \\
\hline Reação and educação a distância & 0 & 0 & 0 \\
\hline Reação and ensino superior & 3 & 0 & 0 \\
\hline Reação and treinamento & 6 & 0 & 0 \\
\hline Reação and Curso & 1 & 0 & 0 \\
\hline Satisfação and educação a distância & 0 & 0 & 0 \\
\hline Satisfação and ensino superior & 18 & 3 & 0 \\
\hline Satisfação and treinamento & 4 & 1 & 0 \\
\hline Satisfação and Curso & 21 & 1 & 0 \\
\hline \multicolumn{4}{|l|}{ ProQuest } \\
\hline Reação and educação a distância & 3 & 1 & 0 \\
\hline Reação and ensino superior & 36 & 1 & 0 \\
\hline Reação and treinamento & 69 & 1 & 0 \\
\hline Reação and Curso & 63 & 10 & 1 \\
\hline Satisfação and educação a distância & 16 & 3 & 0 \\
\hline Satisfação and ensino superior & 123 & 2 & 0 \\
\hline Satisfação and treinamento & 150 & 6 & 3 \\
\hline Satisfação and Curso & 192 & 15 & 1 \\
\hline Reactions and distance learning & 0 & 0 & 0 \\
\hline Reactions and higher educacion & 12 & 0 & 0 \\
\hline Satisfaction and distance learning & 68 & 25 & 3 \\
\hline Satisfaction and higher educacion & 1 & 1 & 0 \\
\hline \multicolumn{4}{|l|}{ USP } \\
\hline Reação and educação a distância & 2 & 1 & 0 \\
\hline Reação and ensino superior & 0 & 0 & 0 \\
\hline Reação and treinamento & 1 & 1 & 0 \\
\hline Reação and Curso & 9 & 0 & 0 \\
\hline Satisfação and educação a distância & 1 & 0 & 0 \\
\hline Satisfação and ensino superior & 6 & 0 & 0 \\
\hline Satisfação and treinamento & 3 & 0 & 0 \\
\hline Satisfação and Curso & 21 & 0 & 0 \\
\hline Total & 829 & 72 & 5 \\
\hline
\end{tabular}


A seguir, serão apresentadas as variáveis do presente estudo: Estratégias de Aprendizagem, Características da Clientela e Reação. Serão discutidos a revisão de literatura e os conceitos relacionados a cada uma delas.

\subsection{Estratégias de Aprendizagem (variável critério): definições e características}

Apesar de Estratégias de Aprendizagem ser considerada como uma variável pertencente ao componente Características da Clientela, a revisão de resultados de pesquisas se inicia pela mesma em função de ser a variável critério adotada nesse estudo. O interesse pelo estudo sobre Estratégias de Aprendizagem se justifica em função da existência de poucas pesquisas que avaliam sistematicamente a influência exercida por variáveis relativas à ação educacional e à clientela sobre a conduta do aprendiz ao longo do curso (Martins \& Zerbini, 2014; BorgesAndrade, Zerbini, Abbad \& Mourão, 2013; Abbad, Borges-Ferreira \& Nogueira, 2006). Além disso, os indivíduos cada vez mais são cobrados por competências que envolvem a autoadministração das ações que levam à aquisição do conhecimento - não somente no período de escolarização formal, mas por todo o ciclo de vida, assim, a compreensão sobre os processos que envolvem a aprendizagem tornou-se elemento chave para a sobrevivência de todos os agentes das sociedades atuais (Bjork, Dunlosky \& Kornell, 2013).

O conceito de Estratégia é encontrado em diversos contextos na literatura, principalmente no contexto empresarial. Dessa forma, não existe uma única definição para o conceito. Mintzberg e Quinn (2001) definem Estratégia como plano que integra as principais metas, políticas e sequências para determinadas ações, também podem ser, em um primeiro momento, afirmações voltadas para orientar determinadas providências visando resultados. Para Henderson (1998) Estratégia pode ser entendida como busca determinada de um plano de ação para desenvolver ou ajustar vantagens sobre algo.

De acordo com autores da administração, a Estratégia é a principal ligação entre fins, objetivos e políticas funcionais dos diversos setores das organizações trata-se dos planos que conduzem o nível operacional para as suas atividades diárias. Significa a escolha dos meios para se atingir os objetivos estratégicos de tais organizações (Henderson,1998). Por meio da Estratégia é possível o alcance dos objetivos de longo prazo, determinar as políticas e ações mais adequadas para atingir tais objetivos. No contexto educacional, entende-se com Estratégia o caminho ou meio utilizado para o alcance do conhecimento, pelos indivíduos envolvidos no processo de ensino e aprendizagem.

As definições encontradas na área da educação identificam Estratégias de Aprendizagem como competências ou processos que facilitam a aquisição, o armazenamento e 
a recuperação da informação (Cunha \& Boruchovitch, 2012). São ações mentais, bem como comportamentos com os quais os educandos se envolvem durante o processo de aprendizagem e que facilitam a recuperação de conhecimentos adquiridos anteriormente, o que leva a melhores resultados de qualidade no processo educacional (Perassinoto, Boruchovitch \& Bzneck, 2013). Assim, segundo estudiosos da área de TD\&E as definições encontradas na literatura para Estratégias de Aprendizagem vem da área da educação, sendo encontrados poucos estudos sobre o tema voltado para o contexto organizacional e do trabalho (Pantoja, 2004; Zerbini \& Abbad, 2008 e 2010).

De acordo com Zerbini e Abbad (2010) as definições de Estratégia de Aprendizagem encontradas na literatura no contexto educacional estão voltadas para os procedimentos que são utilizados por indivíduos na conquista da aprendizagem bem-sucedida. Segundo as autoras, Estratégias de Aprendizagem consistem em um conjunto de capacidades cognitivas complexas aprendidas pelo indivíduo ao longo da vida, o qual envolve capacidades cognitivas, habilidades comportamentais e de autocontrole emocional, utilizadas pelo mesmo para controlar os próprios processos psicológicos de aprendizagem, como atenção, aquisição, memorização e transferência.

Para Zerbini (2007), Estratégias de Aprendizagem envolvem os procedimentos (habilidades cognitivas e comportamentais) utilizados pelos indivíduos durante as atividades de aprendizagem que possibilitam a garantia do sucesso de todas as etapas de aprendizagem. Entende-se, portanto, como procedimentos, o caminho que os estudantes encontram para aumentar o êxito no processo de construção do conhecimento por meio da aprendizagem. Ainda segundo a autora, não existem Estratégias únicas que possam garantir o sucesso da aprendizagem, mas sim, Estratégias adequadas para determinadas atividades a serem desenvolvidas, ou seja, de acordo com o nível de dificuldade das atividades é exigido dos estudantes diferentes Estratégias para o alcance da aprendizagem e, consequentemente, a aquisição do conhecimento.

Zerbini e Abbad (2008) apresentam a definição de Denseraeu (1985) para Estratégias de Aprendizagem como um conjunto de processos ou etapas que facilitem a aquisição, a retenção, e a utilização da informação. Badia e Monereo (2010) definem Estratégias de Aprendizagem como a tomada de decisões, de forma consciente e intencional, adaptadas às condições do contexto em que a ação educacional será realizada e representa a ativação de conhecimentos de natureza diversa, para alcançar um objetivo de aprendizagem. Assim, cada aluno utiliza de diferentes procedimentos para conhecer, controlar e regular sua aprendizagem, 
e dessa forma não há uma melhor Estratégia, mas alternativas mais eficazes, que irão variar de acordo com diferentes contextos de aprendizagem (Martins \& Zerbini, 2014). Pantoja (2004) define Estratégias de Aprendizagem como um conjunto de atividades, com metas específicas, que levam à aquisição, retenção, recuperação e transferência de novos conhecimentos, habilidades e atitudes (CHAs) no contexto do trabalho. Verifica-se um avanço na definição de Estratégias de Aprendizagem apresentada pelas autoras. Além da aquisição, retenção, recuperação e transferência de novos conhecimentos, habilidades e atitudes, Zerbini e Abbad (2010) envolvem aspectos comportamentais e de autocontrole emocional, utilizados pelos indivíduos no processo de aprendizagem, que garantem o alcance do sucesso da aprendizagem.

Por meio das medidas de Estratégias de Aprendizagem é possível medir a eficácia e qualidade das atividades desenvolvidas pelos aprendizes que promovem processos cognitivos, identificando eventuais problemas durante a aprendizagem ou em condições oferecidas ao aprendiz à transferência dos CHAs desenvolvidos. Dessa forma, o elemento autorregulador desponta como imprescindível para o aprendiz, uma vez que fornece a este os estratagemas necessários para atingir os resultados almejados (McCormick, 2003).

Em classificação proposta por Warr e Allan (1998) duas categorias de Estratégias de Aprendizagem são destacadas em contextos organizacionais e de trabalho: primárias (cognitivas e comportamentais) e autorregulatórias. As primeiras interferem sobre os processos de escolha, processamento, retenção e recuperação de informações, sendo usadas, portanto, na ocasião em que se dá o contato do aprendiz com os conteúdos a serem transmitidos. Por outro lado, as autorregulatórias dizem respeito à motivação da pessoa para aprender, a autogestão de esforços, o automonitoramento do progresso durante a aprendizagem, e o controle da ansiedade frente a determinadas situações que estariam dissipando a atenção do aprendiz. Essa segunda categoria afeta de maneira indireta o momento de interação do aprendiz com o objeto de conhecimento, determinando a forma como o mesmo mantém a motivação, gerenciamento, monitoramento do seu progresso e da ansiedade (Zerbini \& Abbad, 2008).

Por considerarem que tarefas de natureza e graus de complexidade distintos requerem diferentes Estratégias de Aprendizagem para ocorrerem - nesse caso, as estratégias utilizadas pelo indivíduo em ambientes acadêmicos para alcançar a aprendizagem bem sucedida possivelmente se diferenciam daquelas empregadas em contextos laborais - Warr e Allan (1998) formularam um sistema taxionômico constituído por três grandes componentes, aos quais compreendem variados níveis de análise, como pode ser observado na Tabela 6. 
Tabela 6. Classificação e definições das Estratégias de Aprendizagem.

\begin{tabular}{|c|c|}
\hline \multirow{3}{*}{$\begin{array}{l}\text { Estratégias } \\
\text { cognitivas }\end{array}$} & $\begin{array}{l}\text { - Repetição: abrange procedimentos de repetição mental da informação na forma em que } \\
\text { foi apresentada }\end{array}$ \\
\hline & $\begin{array}{l}\text { - Organização: consiste na identificação de ideias centrais do material e criação de } \\
\text { esquemas mentais que agrupam e relacionam elementos a serem aprendidos }\end{array}$ \\
\hline & $\begin{array}{l}\text { - Elaboração: avalia ou reflete sobre implicações e conexões possíveis entre o material } \\
\text { aprendido e o conhecimento já existente }\end{array}$ \\
\hline \multirow{3}{*}{$\begin{array}{c}\text { Estratégias } \\
\text { comportamentais }\end{array}$} & $\begin{array}{l}\text { - Busca de ajuda interpessoal: obtenção de auxílio de outras pessoas, como pares e } \\
\text { professores, para tirar dúvidas sobre o material (representa um comportamento proativo } \\
\text { do indivíduo de solicitar ajuda ao invés de utilizar apenas as informações do próprio } \\
\text { procedimento instrucional) }\end{array}$ \\
\hline & $\begin{array}{l}\text { - Busca de ajuda no material didático: obtenção de informações em documentos escritos, } \\
\text { manuais de instruções, programas de computador e outras fontes que não envolvam } \\
\text { contato social }\end{array}$ \\
\hline & $\begin{array}{l}\text { - Aplicação prática: aprimoramento do conhecimento por meio de aplicação prática do } \\
\text { que foi aprendido }\end{array}$ \\
\hline \multirow{3}{*}{$\begin{array}{c}\text { Estratégias } \\
\text { autorregulatórias }\end{array}$} & $\begin{array}{l}\text { - Controle da emoção: controle da ansiedade e prevenção de dispersões de concentração, } \\
\text { causadas por sentimentos de ansiedade. }\end{array}$ \\
\hline & $\begin{array}{l}\text { - Controle da motivação: controlar a motivação e a atenção, apesar de existência de um } \\
\text { interesse limitado na tarefa a ser aprendida. }\end{array}$ \\
\hline & $\begin{array}{l}\text { - Monitoramento da compreensão: a avaliação do processo de aquisição de } \\
\text { aprendizagem e modificação do comportamento do indivíduo quando necessário }\end{array}$ \\
\hline
\end{tabular}
Fonte: Warr \& Allan (1998) e Zerbini (2007).

Vale considerar que a proposta de Warr e Allan (1998), de acordo com Meneses et al. (2010), não deve ser compreendida como uma taxionomia, mas como um sistema classificatório de tipos de estratégias diferenciadas, já que os níveis deveriam apresentar necessariamente uma noção de sequência e cumulatividade, ou seja, recairiam em uma classificação e hierarquização. No presente estudo, leva-se em consideração a área de TD\&E, área em que a presente pesquisa está inserida, e será utilizada a seguinte definição para Estratégias de Aprendizagem: "Procedimentos (habilidades cognitivas e comportamentais) utilizados pelos indivíduos durante as atividades de aprendizagem de modo a garantir o sucesso de todas as etapas do processo. São procedimentos focados apenas em atividades de aprendizagem" (Zerbini \& Abbad, 2008, p. 180). A próxima seção apresenta e discute as Estratégias de Aprendizagem no contexto da educação à distância.

\subsubsection{Estratégias de aprendizagem na modalidade de EAD}

$\mathrm{Na}$ EAD o processo de ensino e aprendizagem requer uma grande variedade de procedimentos, recursos e meios instrucionais proporcionados pelas NTICs. De acordo com Abbad, Zerbini e Souza (2010) não há dados conclusivos na literatura sobre o grau de aprendizagem na modalidade de ensino a distância, mas os dados existentes indicam que a aprendizagem em tal modalidade é igual ou superior à alcançada nas modalidades tradicionais por seus estudantes. 
Segundo Zerbini e Abbad (2010), na modalidade de ensino a distância, as características dos estudantes podem influenciar nos resultados dos seus estudos por se tratar de uma aprendizagem muito mais individual do que instrucional. Desta forma, o indivíduo pode utilizar diferentes Estratégias de Aprendizagem para o alcance dos seus objetivos educacionais, devido à especificidade dos procedimentos instrucionais da EAD. Para Zerbini e Abbad (2010) e Badia e Monereo (2010), as atividades de diferentes naturezas e complexidades exigem diferentes Estratégias de Aprendizagem. Ao comparar o ambiente de trabalho e ambientes acadêmicos, é possível identificar diferentes Estratégias de Aprendizagem utilizadas pelos aprendizes para o alcance da aprendizagem bem-sucedida. $\mathrm{O}$ mesmo acontece na educação presencial e a distância. A utilização constante e sistemática de Estratégias de Aprendizagem, principalmente as autorregulatórias, além de contribuir para uma apropriação significativa do conhecimento e para o próprio sucesso acadêmico, estaria ligada à predição da aprendizagem e à inteligência, relevando elementos analíticos do cenário no qual se efetiva o aprender (Boruchovitchet al., 2006; Martins \& Zerbini, 2014; Umekawa \& Zerbini, 2015; Veenman, Wilhelm \& Beishuizen, 2004).

Vê-se que as medidas de Estratégias de Aprendizagem possibilitam a mensuração da eficácia e qualidade das atividades que promovem processos cognitivos, identificando eventuais problemas durante a aprendizagem ou em condições oferecidas ao aprendiz à transferência dos CHAs desenvolvidos. Sendo os estudos sobre Estratégias de Aprendizagem muito escassos (Martins \& Zerbini, 2014; Zerbini \& Pilati, 2012), justificam-se trabalhos que proponham identificar as variáveis preditoras relacionadas, que possibilitem medi-la e melhor explicá-la. Nesse contexto, tornam-se necessários estudos referentes às Estratégias de Aprendizagem utilizadas por estudantes de graduação em EAD, visando a garantia da qualidade de ensino em tal modalidade.

De acordo com Beluce e Oliveira (2012), as pesquisas realizadas sobre Estratégias de Aprendizagem em contextos de ensino online vêm testemunhando avanços satisfatórios. Contudo é necessário reconhecer que tais progressos não se fazem suficientes tendo em vista a seriedade do tema à educação, presencial e a distância. Diante deste contexto, faz-se necessário o desenvolvimento de pesquisas científicas que avancem com novas contribuições ao estudo desta temática.

Martins (2015) realizou um levantamento bibliográfica acerca da variável Estratégias de Aprendizagem, que dentre outros objetivos, pretendeu apresentar instrumentos nacionais e internacionais construídos com o objetivo de mensurar Estratégias de Aprendizagem em 
contextos educacionais, bem como resultados de pesquisa que objetivaram analisar o relacionamento entre variáveis. Os estudos levantados na revisão de literatura mostram um esforço da área de pesquisa na elaboração de instrumentos válidos e padronizados destinados a medir Estratégias de Aprendizagem em diferentes níveis educacionais. A seguir é apresentado uma análise dos achados da pesquisa realizada por Martins (2015) e no Anexo A se encontra um resumo dos resultados de pesquisa da autora.

O estudo de Warr e Downing (2000) visava validar uma escala de Estratégia de Aprendizagem e investigar a relação entre Estratégias de Aprendizagem, ansiedade para aprender e aquisição de conhecimento. Os achados de seu estudo apontaram uma relação entre a Estratégia de Aprendizagem e o controle emocional, a motivação para o estudo, e a variáveis pessoais (idade, estudantes com mais idade usavam Estratégias de Aprendizagem).

Os achados dos estudos de Holman, Epitropaki e Farnie (2001) e Pantoja (2004) confirmam a influência das variáveis pessoais (idade, gênero, anos de estudo e categoria profissional) no uso de Estratégias de Aprendizagem. Ainda os estudos de Holman, Epitropaki e Fernie (2001) apontam que as Estratégias de Aprendizagem utilizadas no trabalho são as mesmas utilizadas nos ambientes educacionais. De acordo com Pantoja (2004) existem diferenças significativas entre as Estratégias Aprendizagens utilizadas por profissionais em seu local de trabalho conforme sua categoria profissional.

Pantoja e Borges-Andrade (2009) apontam que as variáveis aquisição, retenção e transferência de novas competências no trabalho são influenciadas pelas estratégias de aplicação prática e busca de ajuda interpessoal. Assim como Pantoja (2004), os autores indicam que de acordo com as categorias profissionais estudadas são usadas diferentes configurações de Estratégias de Aprendizagens.

Em Zerbini e Abbad (2008a, 2010a), os estudos tinham como objetivo identificar variáveis que explicassem a aplicação de habilidades ensinadas aos participantes de um curso de qualificação profissional a distância via internet. Os achados apontam que os participantes que utilizaram com mais frequência as Estratégias de Aprendizagem de elaboração e compreensão foram os que relataram maior impacto do treinamento no trabalho; e os que elaboraram o plano de negócios usaram mais frequentemente a estratégia de busca de ajuda interpessoal. Percebe-se a relação entre o uso de Estratégias de Aprendizagem e o bom resultado da ação educacional ofertada a distância.

A relação entre a satisfação com o curso, o desempenho acadêmico, da tutoria, os resultados de aprendizagem e a interface gráfica, estratégias para gestão do tempo, o uso de 
estratégias cognitivas de aprendizagem, foram apontadas no estudo de Abbad, Côrrea e Meneses (2010) e Testa e Luciano (2010). Os estudos de Testa e Luciano (2010) ainda apontam uma relação entre a interação do aluno com a tutoria e colegas com a autoconfiança para aprender, ou seja, quanto maior a interação do aprendiz com professores/tutores ou com outros alunos, maior será a sua autoconfiança para aprender.

Dessa forma, as pesquisas demonstram em seus achados que, de um modo geral, a aplicação das Estratégias de Aprendizagem levam ao êxito no processo de aprendizagem, bem como a existência de uma relação entre Estratégias de Aprendizagem com outras varáveis, entre elas: controle emocional e motivação para o estudo (Warr \& Downing, 2000), aquisição, retenção e transferências de novas competências (Pantoja \& Borges-Andrade, 2009); ajuda interpessoal (Brandão \& Borges-Andrade, 2011; Zerbini \& Abbad, 2008a e 2010a), satisfação com o curso (Abbad, Correa \& Menezes, 2010; Tasta e Luciano, 2010), e variáveis pessoais como: idade, gênero, anos de estudo e categoria profissional (Pantoja, 2004; Warr \& Downing, 2000). Percebe-se uma influência das Estratégias de Aprendizagem no processo de ensino e aprendizagem, consequentemente, nos resultados da ação educacional. A tabela 7 ilustra a relação entre Estratégias de Aprendizagem com outras variáreis encontradas por Martins (2015).

Tabela 7. Resumo resultados revisão bibliográfica Estratégias de Aprendizagem (Martins, 2015).

\begin{tabular}{|c|c|c|}
\hline Variável & Autores & Resultados \\
\hline \multirow{5}{*}{$\begin{array}{l}\text { Estratégias de } \\
\text { Aprendizagem }\end{array}$} & Warr e Downing (2000). & Controle emocional e motivação para o estudo. \\
\hline & Pantoja e Borges-Andrade (2009). & $\begin{array}{l}\text { Aquisição, retenção e transferências de novas } \\
\text { competências. }\end{array}$ \\
\hline & $\begin{array}{l}\text { Brandão e Borges-Andrade (2011); } \\
\text { Zerbini e Abbad (2008a e 2010a). }\end{array}$ & Ajuda interpessoal. \\
\hline & $\begin{array}{l}\text { Abbad, Correa e Menezes (2010); } \\
\text { Tasta e Luciano (2010). }\end{array}$ & Satisfação com o curso e tutoria. \\
\hline & $\begin{array}{l}\text { Pantoja (2004); } \\
\text { Warr e Downing (2000). }\end{array}$ & $\begin{array}{l}\text { Variáveis pessoais como: idade, gênero, anos de } \\
\text { estudo e categoria profissional. }\end{array}$ \\
\hline
\end{tabular}

A partir da revisão de Martins (2015), percebe-se a ausência de estudos relacionados a Estratégias de Aprendizagem utilizadas por estudantes universitários na modalidade de EAD, fato que foi indicado na revisão entre Estratégias de Aprendizagem e EAD. As pesquisas desenvolvidas com o objetivo de analisar a utilização das Estratégias de Aprendizagem estão concentradas na Educação e em ambientes profissionais, porém não no campo da educação universitária. Como apontado nos estudos, o uso de Estratégias de Aprendizagem favorece o processo de ensino e aprendizagem, pois de acordo com Gonsalves (2014) a ação educacional 
deve levar em consideração não apenas as estratégias de ensino, mas é necessário também conhecer as Estratégias de Aprendizagem utilizadas pelos aprendizes, para que o sucesso de tal ação seja alcançado. Assim, estudos encontrados na literatura especializada, identificam e medem Estratégias de Aprendizagem por meio de instrumentos de medidas validados e fidedignos, o que permite identificar quais estratégias são utilizadas no contexto a distância e como isso interfere no aproveitamento do aprendiz. Contudo, faz-se necessário estudos realizados em profundidade sobre Estratégias de Aprendizagem no contexto universitário e ofertado a distância, investigando se outras variáveis influenciam nas estratégias utilizadas por alunos acadêmicos, tais como a Característica da Clientela e Reações aos procedimentos instrucionais e desempenho do tutor, já que foram apontadas em vários estudos suas influências nas Estratégias de Aprendizagem utilizadas por alunos em ações educacionais. A seguir, serão apresentadas as variáveis Características da Clientela e na sequência, Reações aos procedimentos instrucionais e desempenho do tutor.

\subsection{Características da Clientela}

As manifestações de diferenças individuais em eventos instrucionais preocupam pesquisadores e profissionais desde os primeiros estudos da área de TD\&E, e mesmo sendo antigas, várias questões em torno do tema ainda não foram respondidas (Meneses, Abbad, Zerbini \& Lacerda, 2006). Estudos apontam a necessidade de se incluir medidas de Características da Clientela ao avaliar necessidades de ações educacionais em contextos profissionais e, que pesquisas compreendam as variáveis demográficas como preditoras de eficácia de treinamentos (Meneses, Zerbini \& Martins, 2012). De acordo com Meneses, Abbad, Zerbini e Lacerda (2006), as características dos aprendizes, hábitos de vida, expectativas, motivações, interesses e metas podem influenciar na aquisição de competências durante o evento instrucional e na posterior aplicação dessas competências em situações de trabalho. Os autores afirmam que todo indivíduo é capaz de aprender e de transferir novas habilidades, contanto que o desenho instrucional e as condições de apoio à aprendizagem e à transferência favoreçam esse processo de mudança comportamental.

Diante desse contexto é necessário conhecer o perfil da clientela, mesmo antes de se iniciar o planejamento da ação educacional, para que certas questões sejam respondidas, entre elas: i) até que ponto os indivíduos podem modificar seus repertórios de conhecimentos, habilidades e atitudes?; ii) as ações de TD\&E são capazes de desenvolver competências profissionais, algumas vezes, não-coerentes com os traços de personalidade e características do 
indivíduo?; iii) por que indivíduos, sob as mesmas condições de aprendizagem, apresentam diferentes resultados ao final de um programa de TD\&E?; iv) por que alguns aprendem e outros não?; v) por que uns são capazes de transferir aprendizagem e outros não?; vi) as necessidades de TD\&E são influenciadas pelas características da clientela? (Meneses, Abbad, Zerbini \& Lacerda, 2006). A resposta para essas e outras perguntas acerca da Característica da Clientela permitiriam a implementação bem-sucedidas de ações educacionais, bem como a adoção de estratégias de ensino e aprendizagem capazes de beneficiar a todos os participantes de tais ações (Meneses, Zerbini \& Martins, 2012). Pois, a partir de tais respostas seria possível estabelecer Estratégias de Aprendizagem para determinado público de modo a garantir o planejamento e o sucesso da ação educacional a partir da identificação do perfil da clientela para tal ação.

De acordo com Abbad, Corrêa e Meneses (2010), compreender o papel de determinadas variáveis, tais como: demográficas, experiência prévia em EAD, desenho do curso, efetividade do instrutor, características individuais, entre outras, é de fundamental importância para a orientação e direcionamento no planejamento de ações educacionais ofertadas a distância, e na efetividade de tais ações. Ainda segundo os autores, os cursos a distância pressupõem novos comportamentos dos alunos, entre eles: a capacidade de pensar e agir com independência; fazer escolhas corretas entre os diversos planos de estudo de um curso; reflexão sobre sua aprendizagem e controlar suas próprias atividades de aprendizagem.

O levantamento de informações sobre características individuais e situacionais é enfatizado por Zerbini (2007), pois tais informações podem orientar o delineamento de ações e de estratégias de ensino e aprendizagem mais adequados ao perfil do público-alvo, visto que tais características, a exemplo de Estratégias de Aprendizagem (autorregulatórias, cognitivas e comportamentais), parecem exercer maior influência no desenvolvimento de ações a distância do que em presenciais e podem determinar a maneira como o indivíduo estuda. Assim, é possível determinar Estratégias de Aprendizagem mais adequadas para uma ação educacional a partir do conhecimento prévio das características do seu público-alvo visando o alcance de resultados bem-sucedidos por tais ações.

$\mathrm{Na}$ apresentação do modelo MAIS, como discutido na seção 1.2., Borges-Andrade (1982 e 2006), apresenta um modelo integrado de avaliação de sistemas instrucionais, onde as variáveis presentes em seus componentes e subcomponentes (avaliação de necessidades, insumos, procedimentos, processos, resultados, suporte, disseminação e efeitos em longo prazo), podem ser identificadas e consideradas, além de especificar as relações que podem ser 
esperadas entre elas. Nesse contexto, as variáveis podem ser estudadas, analisadas e avaliadas individualmente como variáveis critérios.

O primeiro componente do modelo MAIS é o componente "insumos", que representa os fatores físicos e sociais, bem como os estados comportamentais associados aos participantes, anteriores à realização da ação educacional, que podem afetar seus resultados. Nesse componente, Borges-Andrade (1982 e 2006) apresenta alguns exemplos de variáveis de insumo, entre elas: o nível socioeconômico dos participantes do evento de TD\&E; o nível de escolaridade e idade dos participantes; cargo ocupado no trabalho pelos participantes; o uso de estratégias comportamentais, cognitivas, autorregulatórias e de transferência de aprendizagem no trabalho; domínio de competências como pré-requisito para a ação de TD\&E; motivação para aprender, entre outras. Pode-se perceber que todas variáveis do presente componente são referentes a variáveis remetidas as Características da Clientela, entre elas, variáveis Sociodemográficas (nível socioeconômico e de escolaridade, idade etc.) e de Estratégias de Aprendizagem (estratégias comportamentais, cognitivas e autorregulatórias), variáveis estas, de interesse do presente estudo. Assim, como exposto, tanto as variáveis Sociodemográficas podem predizer Estratégias de Aprendizagem como Estratégias de Aprendizagem podem predizer determinadas variáveis Sociodemográficas.

As Características da Clientela no modelo IMPACT de avaliação de treinamento de Abbad (1999), agrupam variáveis demográficas, cognitivas, motivacionais e funcionais dos participantes de ações educacionais. Meneses et al. (2006) classifica em cinco categorias as variáveis, a saber:

1. Repertório de entrada: conjunto de conhecimentos, habilidades, atitudes, expectativas e experiências adquiridas pelo participante antes do treinamento;

2. Sociodemográficas: perfil fisionômico da clientela (sexo, idade, escolaridade, condição socioeconômica) e perfil profissional e funcional do participante (profissão, tempo de serviço, função, cargo, lotação);

3. Psicossociais: variáveis autorreferentes tais quais: locus de controle (forma como os indivíduos delegam a responsabilidade pelo sucesso ou fracasso de suas ações), autoeficácia (crenças do indivíduo em suas próprias capacidades para mobilizar motivação, recursos cognitivos e cursos de ação necessários ao sucesso das ações em que se engajam), comprometimento (sentido de apego a uma organização de trabalho), prazer e sofrimento no trabalho; 
4. Motivacionais: motivação para aprender e para transferir aprendizagens e valor instrumental da ação educacional;

5. Cognitivo-comportamentais: estratégias cognitivas, comportamentais e autorregulatórias utilizadas pelo participante para aprender.

A variável repertório de entrada, a partir da identificação das suas características, permite definir turmas de acordo o nível de entrada dos participantes do treinamento; evita que ingressem participantes que já detêm os conhecimentos pretendidos por determinado curso, prevenindo gastos desnecessários com a ação educacional; garante que as necessidades e as expectativas dos participantes em relação às competências e aos conteúdos previstos na ação sejam efetivamente satisfeitas. Por meio das características sociodemográficas é possível identificar as necessidades e disponibilidade dos participantes para o treinamento. As características psicossociais indicam as percepções do indivíduo sobre a capacidade de exercer controle sobre: atitudes, comportamentos e outros eventos, e está relacionada aos efeitos de programas instrucionais. A motivação influencia os processos de aquisição, retenção e transferência da aprendizagem ao trabalho. Estudos comprovam que a aquisição, a melhor retenção de conhecimentos, e a sua transferência para o trabalho acontecem com indivíduos que são motivados a aprender e a participar de programas de TD\&E (Meneses, Zerbini \& Martins, 2012). E finalmente, as características cognitivo-comportamentais da clientela, envolvem a análise dos hábitos de estudo, de estratégias e estilos de aprendizagem, que são de extrema importância para que o desenho da ação educacional e sua entrega sejam realizados de forma efetiva. As informações sobre as preferências do aluno podem auxiliar na adaptação dos procedimentos utilizados no evento instrucional, bem como, desenvolver ações em conjunto com o aluno para melhorar seu aproveitamento durante o curso, evitando a mudança dos procedimentos (Meneses et al., 2006). Dessa forma, Estratégias de Aprendizagem podem se tornar critério para ações educacionais a partir da predefinição de determinadas características cognitivo-comportamental dos possíveis participantes de tais ações com o objetivo de garantir o sucesso da ação educacional.

Ainda como Características da Clientela na EAD, o conhecimento prévio do uso de ferramentas eletrônicas pelos participantes de ações educacionais nessa modalidade de ensino é de extrema importância para o sucesso de tais ações. De acordo com Mourão, Abbad e Zerbini (2013), a EAD mesmo praticada há muito tempo, nas últimas décadas, ganhou novos contornos com o desenvolvimento tecnológico dos computadores e das redes de computação proporcionado pela internet. Assim, segundo as autoras, indivíduos com maior dificuldade em 
relação ao uso de elementos eletrônicos dos cursos ofertados a distância podem apresentar maior chance de evadir de tais cursos, assim como, indivíduos com maior habilidade no uso de ferramentas on-line percebem a EAD como promotora de aprendizagem a assim tendem a estar mais satisfeitas com tal modalidade de ensino. Achados em estudos de Abbad, Carvalho e Zerbini (2006) indicam que indivíduos participantes de ações educacionais a distância com poucos acessos aos chats, ao mural de notícias e ao ambiente eletrônico do curso foram aqueles que também tenderam a abandonar o curso. De acordo com as autoras, tais resultados sugerem que os evadidos, no período de realização do curso, provavelmente ainda não dominavam o uso dos recursos baseados nas NTICs e/ou não se sentiram estimulados a utilizá-los.

Guimarães e Abbad (2015) realizaram estudo bibliográfico sobre a autoeficácia no uso do computador (crença que o indivíduo possui sobre a sua própria capacidade do uso do computador e seus recursos com sucesso). Os achados apontaram para uma correlação entre a autoeficácia e o uso do computador e conhecimentos anteriores sobre informática, experiência prévia ou frequência de uso pessoal do computador anterior a avaliação do indivíduo. Segundo as autoras, o estudo apontou que a experiência prévia e a participação anterior em um curso de informática se comportaram como variáveis positivamente correlacionadas com o nível de autoeficácia percebido pelos pesquisados. Dessa forma, o conhecimento prévio do indivíduo referente ao uso de computador se torna imprescindível para bons resultados em ações educacionais ofertadas a distância, já que tais ações são mediadas pelas NTICs em suas Estratégias de Aprendizagem. Assim, estratégias de aprendizagem que necessitam do uso de ferramentas eletrônicas, largamente utilizadas na EAD, terão maior probabilidade de sucesso com indivíduos que possuem conhecimento prévio do uso de computadores, multimídias e internet. A inclusão e a análise das características individuais em pesquisas podem auxiliar na compreensão do processo de aprendizagem em adultos, identificar aquelas que podem melhorar o desempenho em atividades e contribuir para o desenvolvimento de modelos teóricos de treinamento e de avaliação (Warr \& Allan, 1998; Warr \& Downing, 2000). Além das características já estudadas em pesquisas científicas, tais como: gênero, idade, motivação, ansiedade e autoeficácia, devem-se também fazer parte da investigação as variáveis cognitivocomportamentais, tais como as estratégias de aprendizagem utilizadas pelos alunos durante ações educacionais de natureza diferentes (Meneses et al., 2006; Warr \& Allan, 1998; Warr \& Downing, 2000).

As informações sobre a clientela permitem conhecer o perfil dos participantes de diferentes modalidades de ensino e quais estratégias são utilizadas para o alcance da 
aprendizagem, oferece subsídios para o ajuste dos programas instrucionais de acordo com as características e necessidades individuais. Dessa forma, segundo Zerbini (2007), evita-se o uso indevido de dados sobre personalidade, motivação, nível de inteligência e aptidões em contextos organizacionais.

A partir do que foi exposto, a identificação das variáveis relacionadas a Características da Clientela são de extrema importância para o resultado de ações em EAD. Tal reconhecimento pode auxiliar planejadores, docentes e gestores a administrar mais eficazmente as ações educacionais ofertadas em tal modalidade de ensino, bem como elevar as reações dos participantes de tais ações, como será apresentado e discutido na próxima seção.

\subsection{Reações}

Na literatura, a Reação tem sido denominada como a satisfação do aluno com o curso, ou seja, se refere a satisfação relacionada aos procedimentos instrucionais do curso, bem como a sua aplicabilidade, ao desempenho dos instrutores e a interface gráfica do curso (Carvalho \& Abbad, 2006; Martins \& Zerbini, 2015; Zerbini \& Abbad, 2010). As reações podem ser consideradas indicadores da qualidade de entrega de uma ação instrucional por uma instituição de ensino ou organização, e reflete a satisfação do aprendiz com o ritmo, o formato, a organização e o quanto foi aprendido durante tal ação, e ainda, pode representar os resultados afetivos de um curso (Klein, Noe \& Wang, 2006) como também podem ser uma medida da utilidade do mesmo (Morgan \& Casper, 2000).

O nível de avaliação reações, segundo Hamblim (1978), tem como objetivo mensurar a opinião dos participantes sobre diversos aspectos do treinamento e sua satisfação com o mesmo. Para Zerbini e Abbad (2010c) a mensuração e a coleta de informações sobre a satisfação dos treinandos possibilitam melhorar os métodos e as estratégias instrucionais, visando facilitar o alcance de resultados de aprendizagem e o desempenho desejado por uma organização.

Abbad (1999) define Reação a partir dos estudos de Borges-Andrade (1982) e Lima e Borges-Andrade (1985), como a opinião dos participantes do treinamento sobre a programação, apoio ao desenvolvimento do módulo, aplicabilidade e utilidade do treinamento, resultados, suporte organizacional e desempenho do instrutor. Assim, os participantes de ações educacionais julgam os aspectos relacionados à qualidade do plano instrucional ou de sua programação (objetivos, sequência, estratégias, meios, duração), à qualidade de sua execução (desempenho do tutor) e ao apoio oferecido à execução do treinamento (instalações e materiais didáticos). 
De acordo com autores da área de TD\&E as avaliações no nível de Reação devem considerar múltiplas variáveis, tanto no campo instrucional quanto administrativo, visando a maior confiabilidade da pesquisa e, portanto, dos resultados, tais como: insumos, procedimentos, processos, resultados e ambiente. Assim, a construção de itens de mensuração das reações segue o Modelo de Avaliação Integrado e Somativo - MAIS de Borges-Andrade (2006), pois a base teórica contempla aspectos instrucionais e administrativos que estão associados às Reações nos treinandos e aos cinco componentes do modelo (Borges-Andrade, 2002; Pilati \& Borges-Andrade, 2006).

Para Martins e Zerbini (2015) o alcance de bons resultados ao final da ação educacional e o sucesso do curso pode estar relacionado a reações favoráveis dos participantes aos procedimentos instrucionais e ao desempenho do tutor, pois são aspectos caracterizadores de um curso ou treinamento específico, configurando-se como uma das variáveis influentes no processo de aprendizagem. Pesquisas apontam que os fatores relativos ao sistema (funcionalidade, interação e resposta) e ao instrutor (atitude, habilidades técnicas e método de ensino) influenciam positivamente a efetividade do e-learning (Tien-Chen, 2012).

Para acompanhar as tendências de ações educacionais ofertadas a distância, Carvalho e Abbad (2006) e Zerbini e Abbad (2005) propuseram medidas especíificas de Reação para cursos mediados pelas NTICs, via internet, considerando as descobertas em pesquisas (Laaser, 1997; De Paula e Silva, 2004) quanto às novas competências e habilidades exigidas do tutor (exercer seu papel de mediação e orientação direcionado ao objetivo do curso), bem como com o ambiente virtual mais complexo e que interfere nos efeito das ações educacionais e, portanto, na qualificação do profissional envolvido. As medidas são: a) Reações aos procedimentos tradicionais: satisfação dos participantes com a qualidade dos objetivos de ensino, conteúdos, sequência, avaliações de aprendizagem, estratégias e meios; b) Reação aos procedimentos web: satisfação dos participantes com a qualidade das ferramentas da web, tais como, links, fóruns, banco de perguntas mais frequentes (FAQ), mural de notícias virtual, chats; c) Reação ao desempenho do tutor: percepção do treinando sobre a qualidade da interação do tutor com os alunos, domínio do conteúdo e uso de estratégias de ensino; d) Reação à interface gráfica: satisfação do treinando quanto à ergonomia do software e quanto à navegabilidade e usabilidade do ambiente na internet e; e) Reação aos resultados e aplicabilidade: autoavaliação sobre a capacidade de transmitir os conhecimentos adquiridos a outras pessoas, aplicar o aprendido em diferentes situações e trabalhar em conjunto com outros profissionais, além da percepção sobre o enfrentamento de dificuldades a partir do aprendido no curso. 
Recentes pesquisas revalidaram instrumentos de Reação. Martins e Zerbini (2015) verificaram evidências de validade dos instrumentos de Reação aos Desempenho do Tutor (Zerbini \& Abbad, 2009a) e de Reação aos Procedimentos Instrucionais (Zerbini \& Abbad, 2009b) em contexto de IES, sendo estes de interesse do presente estudo. As autoras justificam que a necessidade de verificar novamente as evidências de validade das escalas, ocorre pelo fato dos instrumentos em questão terem sido aplicados em contextos diferentes de suas aplicações (cursos de graduação ou híbridos), assim como o crescente aumento de cursos a distância ofertados no Brasil, também motivou a reaplicação das escalas.

Os procedimentos instrucionais são formados por diferentes estratégias e princípios de ensino, como: ferramentas, métodos e o próprio contexto que são combinados e integrados visando criar uma abordagem de entrega do curso, pois a forma como este treinamento foi planejado, organizado e estruturado influenciam no seu resultado e, consequentemente, no seu sucesso (Salas et al., 2012). Os procedimentos instrucionais são adequados quando escolhidos de acordo com resultados prévios que demonstraram vínculos com o processo de transferência (Burke \& Hutchins, 2007).

A estratégia para a coleta de dados sobre a satisfação dos participantes em ações educacionais deve ser diferenciada nos cursos ofertados a distância, podendo ser realizada via internet ou intranet (Zerbini \& Abbad, 2010c). Os instrumentos são normalmente digitalizados e hospedados em sites, e os participantes digitam suas respostas que são, automaticamente, enviadas para o arquivo de dados para posterior análise.

Zerbini e Abbad (2010c) realizaram revisão da literatura, nacional e estrangeira no período de 1990 a 2009, sobre o nível de avaliação Reação em cursos ofertados a distância, e apontam que a mensuração das informações sobre a satisfação dos participantes em relação às ações educacionais tem como foco o aprimoramento dos métodos e estratégias instrucionais utilizadas em tais ações, visando o alcance dos resultados de aprendizagem, a partir da sua transferência para o local de trabalho e, portanto, do desempenho esperado pela organização.

A integração das NTICs no processo de ensino e aprendizagem e os novos contextos educacionais a distância modificam os procedimentos instrucionais e promovem influências na atividade docente, onde são requeridas competências diferenciadas e novas condições para sua atuação, o que resulta na mudança do seu perfil profissional (Martins \& Zerbini, 2015). O tutor desempenha papel fundamental no processo de entrega de conteúdos por meio de tecnologias em ambientes virtuais de aprendizagem, já que tais tecnologias ainda não são capazes de realizar a total integração e efetividade instrucional, bem como as necessidades dos usuários 
(treinandos) sem que haja um auxilio por parte de uma equipe conteudista, desenhistas instrucionais e especialistas em tecnologia (Bedwell \& Salas, 2010). Diante deste contexto, o tutor representa um dos principais atores em contextos EAD ao facilitar o processo de transferência do conhecimento, atuando como mediador entre o conhecimento e o educando, auxiliando nas necessidades educacionais do aprendiz e o conduzindo para os fatores da aprendizagem eficaz, como a motivação e a autorregulação, além dos estritamente cognitivos (Martins \& Zerbini, 2015; Mauri \& Onrubia, 2010).

Entre as pesquisas levantadas, observa-se percepções favoráveis em relação a modalidade de ensino a distância como forma de colaboração no processo de aprendizagem (Morgan \& Casper, 2000; Vaughan \& MacVicar, 2004; Zerbini \& Abbad, 2010a) bem como satisfação favorável dos treinandos em relação ao treinamento, a aprendizagem e a transferência de treinamento na EAD (Brow, 2005; Giangreco, Carugati, Sebastiano \& Della Bella, 2010; Teo \& Wong 2013; Womble, 2008). Contudo, faz-se necessário o desenvolvimento de pesquisas que não somente confirmem os aspectos já encontrados, mas também avancem com novas contribuições ao estudo desta temática em outros contextos.

Com o objetivo de discutir conceitos, definições e medidas, e apresentar resultados de pesquisas, com ênfase em cursos ofertados a distância, Martins (2015) apresenta uma revisão da literatura sobre o nível de avalição Reação. O trabalho da autora serviu como ponto de partida para uma análise das pesquisas nacionais e internacionais sobre a relação entre as Estratégias de Aprendizagem utilizadas por aprendizes na modalidade a distância e o nível de satisfação em relação aos cursos. A seguir é apresentada a análise dos achados da pesquisa realizada pela autora, e no Anexo B se encontra um resumo dos resultados da pesquisa da autora.

Alguns resultados das pesquisas apontaram uma relação entre o êxito no processo de aprendizagem com as percepções favoráveis e satisfação positiva em relação ao curso (Giangreco, Carugati, Sebastiano \& Della Bella, 2010; Gunawardena, Linder-VanBerschot, LaPointe \& Rao, 2010; Morgan \& Casper, 2000; Vaugham \& MacVicar, 2004; Womble, 2008). Percebe-se as Estratégias de Aprendizagem, quando bem usadas, influenciam em muito na satisfação do aluno em relação ao curso.

O estudo de Morgam e Casper (2000) visava examinar a estrutura fatorial de reações de participantes ao treinamento. As reações dos participantes ao treinamento apontaram uma estrutura multidimensional entre a afetividade e utilidade. Assim, os diferentes aspectos das reações dos participantes podem influenciar de forma distinta variáveis como a aprendizagem, a transferência de treinamento, o desempenho e os resultados. Tal resultado indica a 
necessidade de pesquisas que apontem de que forma as reações dos treinandos afetam as Estratégias de Aprendizagem aplicadas no treinamento que levem ao êxito da ação educacional.

Vaugham e MacVicar (2004) visavam identificar as atitudes dos participantes em relação ao treinamento a distância em seu estudo. Os achados apontam que $76 \%$ dos participantes tiveram percepções favoráveis no processo de aprendizagem contínua na modalidade a distância, com destaque para a disponibilidade e facilidade de acesso aos conteúdos de estudo.

O estudo de Womble (2008) buscava avaliar satisfação do aprendiz e verificar a sua correlação com à utilidade em um contexto de e-learning e à autoeficácia. Os participantes do treinamento a distância que acreditavam na utilidade do treinamento e acreditavam que o mesmo iria melhorar seu desempenho no trabalho ficaram também satisfeitos com o treinamento.

Gunawardena, Linder-VanBerschot, LaPointe e Rao (2010) investigaram os fatores preditores de satisfação do aprendiz e da transferência de aprendizagem para o trabalho e os achados da pesquisa apontaram que o mais forte preditor de satisfação do aprendiz foi a autoeficácia online e, no que se refere a transferência de aprendizagem (impacto do treinamento em profundidade), o fator determinante foi o apoio de pares o que mostra a relação entre Reação, aprendizagem e satisfação dos participantes do treinamento.

Nos estudos de Giangreco, Caraguati, Sebastiano e Della Bella (2010), as variáveis antecedentes utilidade do treinamento, desempenho do instrutor e eficiência do treinamento tiveram satisfação total dos treinandos com o treinamento, bem como a participação feminina mostrou efeito positivo sobre a moderação da relação satisfação total e desempenho do instrutor.

Vários estudos apontam a contribuição da variável Reação aos procedimentos instrucionais como preditora de aprendizagem (Martins, 2012), bem como, com o processo de transferência de treinamento ou impacto do treinamento em profundidade (Carvalho \& Abbad, 2006; Zerbini \& Abbad, 2005 e 2010b; Zerbini, 2007).

Quando se trata de ambientes universitários, achados de pesquisas, apontam que a interação entre instrutor e aluno pode influenciar a efetividade da aprendizagem no contexto do ensino a distancia (Marks, Sibley \& Arbaugh, 2005), assim como o do grau de satisfação dos treinandos com o e-learning está relacionado de forma positiva à atuação profissional do tutor (Özkan, Köseler \& Baykal, 2009). 
Mesmo que em alguns estudos os resultados não tenham sido semelhantes, devido as reações positivas não se associarem a melhores níveis de aprendizagem (Martins, 2012), nem ao impacto de treinamento no trabalho (Borges-Ferreira \& Abbad, 2009; Zerbini \& Abbad, 2010b), a avaliação da satisfação dos participantes em relação ao desempenho do tutor e com os procedimentos instrucionais devem permanecer nas pesquisas futuras para testar relacionamento entre variáveis em contextos de EAD com as Estratégias de Aprendizagem, pois vários aspectos das reações dos participantes podem influenciar de forma diferenciada as variáveis: aprendizagem, transferência de treinamento, desempenho e resultado (Morgan \& Casper, 2000). Diante deste contexto, nota-se uma grande lacuna e uma área muito fértil para investigação no que se refere à Estratégias de Aprendizagem em ações educacionais no contexto universitário ofertadas à distância, portanto, faz-se necessário estudos que busquem compreender quais os fatores de Reação que contribuem para as Estratégias de Aprendizagem que levam à satisfação do aluno com a ação educacional.

A Tabela 8 ilustra os principais resultados de pesquisas nacionais e internacionais sobre o nível de Reações encontradas por Martins (2015). 
Tabela 8. Resumo resultados revisão bibliográfica Reações (Martins, 2015).

\begin{tabular}{|c|c|c|}
\hline Variável & Autores & Resultados \\
\hline \multirow{5}{*}{ Reações } & Morgam e Casper (2000) & $\begin{array}{l}\text { Os diferentes aspectos das reações dos participantes } \\
\text { podem influenciar de forma distinta variáveis como a } \\
\text { aprendizagem; }\end{array}$ \\
\hline & Vaugham e MacVicar (2004) & $\begin{array}{l}\text { Os achados apontam que } \mathbf{7 6 \%} \text { dos participantes } \\
\text { tiveram percepções favoráveis no processo de } \\
\text { aprendizagem continua na modalidade a distância }\end{array}$ \\
\hline & Womble (2008) & $\begin{array}{l}\text { Os participantes do treinamento a distância que } \\
\text { acreditavam na utilidade do treinamento e que o } \\
\text { mesmo iria melhorar seu desempenho no trabalho, } \\
\text { ficaram também satisfeitos com o treinamento. }\end{array}$ \\
\hline & $\begin{array}{l}\text { Linder-VanBerschot, LaPointe e } \\
\text { Rao (2010) }\end{array}$ & $\begin{array}{l}\text { O mais forte preditor de satisfação do aprendiz foi a } \\
\text { autoeficácia online e, no que se refere a } \\
\text { transferência de aprendizagem (impacto do } \\
\text { treinamento em profundidade), o fator determinante } \\
\text { foi o apoio de pares. }\end{array}$ \\
\hline & $\begin{array}{l}\text { Giangreco, Caraguati, Sebastiano e } \\
\text { Della Bella (2010) }\end{array}$ & $\begin{array}{l}\text { Variáveis antecedentes: utilidade do treinamento, } \\
\text { desempenho do instrutor e eficiência do treinamento } \\
\text { tiveram satisfação total dos treinandos com o } \\
\text { treinamento, bem como a participação feminina } \\
\text { mostrou efeito positivo sobre a moderação da relação } \\
\text { satisfação total e desempenho do instrutor. }\end{array}$ \\
\hline
\end{tabular}

Objetivando a atualização e sistematização de resultados de trabalhos científicos sobre o nível de Reações nos últimos anos, como citado anteriormente na seção descrição do percurso metodológico para busca bibliográfica, foram realizadas buscas bibliográficas nas bases de dados eletrônicas: a biblioteca eletrônica SciELO, as bases de dados ProQuest, bem como os bancos de dados da Universidade de São Paulo (USP), considerando os estudos produzidos no período de 2011 a 2015, a partir da estrutura de percurso de revisão desenvolvida por Martins (2012). A revisão da literatura encontrou o total de 829 artigos. Dentre eles foram selecionados os artigos das áreas de Psicologia, Educação e Administração, resultando em 72 artigos, dos quais 8 (oito) estavam disponíveis para download. Dos 8 artigos lidos, 3 (três) discutem ações educacionais ofertadas pela internet, contudo o foco não foi a Reação dos participantes em relação a tais ações, totalizando 5 (cinco) o número de produções analisadas no presente estudo.

O acervo levantado dos estudos publicados possibilitou situar a variável Reação no campo, com contribuições de outras áreas e suas diferentes perspectivas e objetivos. O levantamento das produções cientificas realizado na base de dados SciELO apontou um total de 53 resumos, onde os cruzamentos das palavras conduziram aos mesmos estudos, assim foram selecionados 5 resumos ao final, contudo os estudos se referiam a outras áreas do conhecimento e fora dos critérios para análise.

A base de dados ProQuest Academic Research Library apresenta trabalhos nas áreas de Negócios, Artes, Educação, Saúde, Humanidades, Internacional, Direito, Psicologia, Ciência e 
Ciências Sociais. Os trabalhos levantados sobre a temática pesquisada nesta revisão estavam reunidos nas áreas de Negócios, Contabilidade, Finanças, Economia e Administração, Psicologia e Educação. No processo de levantamento de dados foram utilizadas palavras em português e inglês com o objetivo de levantar os estudos realizados sobre a temática em questão no mundo. Muitos trabalhos são estudos de caso e pesquisas focadas na gestão de empresas nas áreas de conhecimento citadas.

Estudos sobre a temática do EAD têm sido realizados em todo o mundo (EUA, Reino Unido, China, Austrália, Canadá, Irã, Malásia, Hong Kong, entre outros). Os trabalhos levantados referentes a produção nacional sobre a temática pesquisada nesta revisão apontaram 621 resumos, resultando em 39 selecionados. Muitos artigos se apresentaram em diversos cruzamentos de palavras, assim foram computados apenas uma vez dentro dos resultados selecionados. No que se refere as produções internacionais o levantamento apontou 71 resumos sobre a temática pesquisada, dos quais 26 foram selecionados por ser das áreas pesquisadas. Abaixo, a Tabela 9 apresenta os principais achados da revisão de literatura acerca do nível de Reação. 
Tabela 9. Revisão de literatura para Reação.

\begin{tabular}{|c|c|c|c|c|c|}
\hline Autores & Título & Área e País & Objetivos & Instrumento e amostra & Resultados \\
\hline $\begin{array}{l}\text { Rafferty e } \\
\text { Anderson (2013) }\end{array}$ & $\begin{array}{l}\text { Os alunos são } \\
\text { executivos satisfeitos } \\
\text { com experiências de } \\
\text { aprendizagem } \text { on-line? } \\
\text { Implicações para a } \\
\text { formação on-line e } \\
\text { educação executiva. }\end{array}$ & $\begin{array}{l}\text { Administração } \\
\text { EUA }\end{array}$ & $\begin{array}{l}\text { Apresentar uma exploração de } \\
\text { como os estudantes em um } \\
\text { ambiente de aprendizagem } \\
\text { on-line comparam com esses em } \\
\text { um ambiente tradicional- } \\
\text { aprendizagem com respeito a } \\
\text { sentimentos de satisfação para a } \\
\text { experiência de aprendizagem } \\
\text { deles/dela. }\end{array}$ & $\begin{array}{l}\text { Instrumento: } \\
\text { Estudo descritivo que usa pesquisa } \\
\text { dirigida com } 34 \text { questões múltipla } \\
\text { escolha e } 5 \text { abertas onde os } \\
\text { entrevistados comparavam os } \\
\text { cursos on-line com o tradicional } \\
\text { Amostra: } \\
\text { Programa de MBA executivo com } \\
\text { uma concentração dentro da } \\
\text { indústria farmacêutica e de } \\
\text { cuidado médico com } 200 \\
\text { participantes }\end{array}$ & $\begin{array}{l}\text { - Alinhamento entre a satisfação dos } \\
\text { alunos para o ambiente on-line e o } \\
\text { convencional. } \\
\text { - A aprendizagem pode ser assegurada } \\
\text { no ambiente on-line pelo } \\
\text { relacionamento com instrutores, } \\
\text { comunidade com os colegas e } \\
\text { compromisso com o aprender. } \\
\text { - A satisfação com a aprendizagem é a } \\
\text { mesma no ambiente on-line como em } \\
\text { um ambiente em sala de aula. } \\
\text { - O desenvolvimento de habilidades } \\
\text { com o ambiente virtual, bem como a } \\
\text { comunicação ativa do instrutor está } \\
\text { relacionado com aprendizagem e a } \\
\text { satisfação do aluno. }\end{array}$ \\
\hline
\end{tabular}


Tabela 9. Revisão de literatura para Reação (Continuação).

\begin{tabular}{|c|c|c|c|c|c|}
\hline Autores & Título & Área e País & Objetivos & Instrumento e amostra & Resultados \\
\hline $\begin{array}{l}\text { Pinto e Anderson } \\
(2013)\end{array}$ & $\begin{array}{l}\text { Um pouco } \\
\text { conhecimento vai um } \\
\text { longo caminho: } \\
\text { Expectativa e } \\
\text { satisfação de estudantes } \\
\text { com a aprendizagem } \\
\text { híbrida }\end{array}$ & $\begin{array}{l}\text { Pedagogia, } \\
\text { EUA }\end{array}$ & $\begin{array}{l}\text { Responder as perguntas seguintes: } \\
\text { (1) o que estão considerando as } \\
\text { expectativas preconcebidas e } \\
\text { informadas de estudantes } \\
\text { aprendizagem híbrida? } \\
\text { (2) como satisfeito os estudantes } \\
\text { estão com o curso híbrido? } \\
\text { (3) que fatores são relacionados a } \\
\text { satisfação com este curso híbrido? }\end{array}$ & $\begin{array}{l}\text { Instrumento: } \\
\text { Expectativas preconcebidas e } \\
\text { informadas estavam medidas no } \\
\text { estudo com o uso de um jogo de } \\
\text { quarenta e um artigos de } \\
\text { expectativa que cobrem seis fatores: } \\
\text { tecnologia, administração de tempo, } \\
\text { conteúdo de curso, atitudes de } \\
\text { estudante, comunicação e } \\
\text { comunidade de curso. } \\
\text { Amostra: } \\
\text { Estudantes universitário de nível } \\
\text { superior que curso de marketing de } \\
\text { varejo ofertado em uma } \\
\text { universidade publicados Estados } \\
\text { Unidos. Um total de } 44 \text { estudantes } \\
\text { (20 homens e } 24 \text { mulheres). }\end{array}$ & $\begin{array}{l}\text { - Satisfação nivelada com o formato } \\
\text { de curso híbrido foi relativamente } \\
\text { baixo; } \\
\text { - A satisfação global de estudantes } \\
\text { era uma média de } 2.98 \\
\text { - Os seis fatores medidos } \\
\text { (comunidade de curso, tecnologia, } \\
\text { administração de tempo, conteúdo } \\
\text { de curso, atitudes de estudante e } \\
\text { comunicação) mostraram } \\
\text { correlação significante com } \\
\text { satisfação. }\end{array}$ \\
\hline $\begin{array}{l}\text { Almeida, Marroig } \\
\text { e Pinto (2014) }\end{array}$ & $\begin{array}{l}\text { Competências e } \\
\text { Habilidades do tutor } \\
\text { virtual que influenciam } \\
\text { na aprendizagem dos } \\
\text { alunos. }\end{array}$ & $\begin{array}{l}\text { Administração } \\
\text { Brasil }\end{array}$ & $\begin{array}{l}\text { Investigar as competências e } \\
\text { habilidades do tutor de EAD que } \\
\text { melhor influenciam a } \\
\text { aprendizagem dos alunos. }\end{array}$ & $\begin{array}{l}\text { Instrumento: } \\
\text { Construído um questionário } \\
\text { contendo questões relacionadas } \\
\text { com as competências e habilidades } \\
\text { do tutor. } \\
\text { Amostra: } \\
\text { Formada por } 153 \text { Tutores virtuais e } \\
\text { alunos de EAD de um curso de } \\
\text { MBA em Gestão Empreendedora } \\
\text { na Educação, na modalidade } \\
\text { semipresencial, ofertado aos } \\
\text { Gestores de Escolas Públicas dos } \\
\text { Estados do Rio de Janeiro e São } \\
\text { Paulo. }\end{array}$ & $\begin{array}{l}\text { Entre as competência e } \\
\text { habilidades do tutor que mais } \\
\text { representou para os alunos e } \\
\text { predizem a satisfação dos mesmos } \\
\text { são: conhecer o conteúdo da } \\
\text { disciplina e estimular perguntas, } \\
\text { troca de experiência e de } \\
\text { informações. }\end{array}$ \\
\hline
\end{tabular}


Tabela 9. Revisão de literatura para Reação (Continuação).

\begin{tabular}{|c|c|c|c|c|c|}
\hline Autores & Título & Área e País & Objetivos & Instrumento e amostra & Resultados \\
\hline $\begin{array}{l}\text { Mohelska e } \\
\text { Sokolava (2014) }\end{array}$ & $\begin{array}{l}\text { Eficácia do uso de } \\
\text { e-learning para } \\
\text { disciplinas de negócios: } \\
\text { O caso do curso de } \\
\text { Introdução de Gestão. }\end{array}$ & $\begin{array}{l}\text { Administração e } \\
\text { Economia, } \\
\text { Republica } \\
\text { Checa }\end{array}$ & $\begin{array}{l}\text { Verificar se o uso apropriado de } \\
\text { e-learning diante a um } \\
\text { desempenho comparável de } \\
\text { estudantes na área de } \\
\text { aprendizagem cognitiva. }\end{array}$ & $\begin{array}{l}\text { Instrumento: } \\
\text { Experimento - o método principal, } \\
\text { testes educacionais - a verificação } \\
\text { de hipótese, entrevista (para uma } \\
\text { extensão limitada),observação (para } \\
\text { uma extensão limitada) } \\
\text { Amostra: } \\
\text { estudantes universitários } \\
\text { (Universidade de FlradecKralove, } \\
\text { Faculdade de Informáticas e } \\
\text { Administração) }\end{array}$ & $\begin{array}{l}\text { - No curso em questão o e-learning } \\
\text { não é possível em todos os casos. } \\
\text { - O treinamento em habilidades } \\
\text { administrativas básicas no } \\
e \text {-learning é tão eficiente quanto } \\
\text { no presencial; } \\
\text { - A diferença entre o e-learning e o } \\
\text { ensino tradicional é irrelevante e } \\
\text { leva a satisfação e a aprendizagem } \\
\text { dos participantes. } \\
\text { - Importante levar em consideração } \\
\text { o perfil dos participantes. }\end{array}$ \\
\hline $\begin{array}{l}\text { Martins e Zerbini } \\
(2015)\end{array}$ & $\begin{array}{l}\text { Evidências de validade } \\
\text { de instrumentos de } \\
\text { reações } \\
\text { no ensino superior à } \\
\text { distância. }\end{array}$ & $\begin{array}{l}\text { Psicologia, } \\
\text { Brasil }\end{array}$ & $\begin{array}{l}\text { Verificar as evidências de } \\
\text { validade de dois instrumentos de } \\
\text { medida: Reação aos } \\
\text { Procedimentos Instrucionais e } \\
\text { Reação ao Desempenho do Tutor. }\end{array}$ & $\begin{array}{l}\text { Instrumento: } \\
\text { Reação aos procedimentos } \\
\text { instrucionais e Reação ao } \\
\text { desempenho do tutor, } \\
\text { questionários que avaliaram o nível } \\
\text { de satisfação com os procedimentos } \\
\text { instrucionais adotados e a atuação } \\
\text { profissional do tutor. } \\
\text { Amostra: } \\
\text { Alunos de graduação de uma } \\
\text { universidade particular no interior } \\
\text { paulista, que realizavam cursos a } \\
\text { distancia ou disciplinas hibridas. }\end{array}$ & $\begin{array}{l}\text { - Validação dos instrumentos } \\
\text { propostos, propondo escalas que } \\
\text { apresentam evidencias de validade } \\
\text { estrutural, portanto úteis ao } \\
\text { alcance de informações relevantes } \\
\text { a avaliação de reações de } \\
\text { participantes de diversificados } \\
\text { eventos instrucionais a distancia, } \\
\text { tanto de instituições de ensino, } \\
\text { como de organizações de trabalho, } \\
\text { que ofertam cursos EAD. }\end{array}$ \\
\hline
\end{tabular}


Rafferty e Anderson (2013) verificaram que há um alinhamento entre a satisfação dos alunos com os ambientes on-line e o convencional, bem como a aprendizagem quando estimulada pelos instrutores e formação de grupos entre colegas eleva o compromisso com o aprender e a satisfação do curso. Os autores apontam, ainda, que a postura ativa do instrutor se relaciona com a aprendizagem e a satisfação do aluno. Mesmo com a baixa satisfação apontada nos estudos de Pinto e Anderson (2013), a satisfação dos estudantes com a ação educacional on-line está relacionada a seis fatores, a saber: comunidade de curso, tecnologia, administração de tempo, conteúdo de curso, atitudes de estudante e comunicação.

Ao investigar as competências e habilidades do tutor de EAD que melhor influenciam a aprendizagem dos alunos, Almeida, Marroig e Pinto (2014), identificaram em seu estudo que as características do tutor predizem aprendizagem e satisfação dos alunos com a ação educacional, entre elas: conhecer o conteúdo da disciplina e estimular perguntas, troca de experiência e de informações. O estudo de Mohelska e Sokolava (2014) indicou que no curso em questão o e-learning não é possível em todos os casos e deve ser considerado o perfil dos participantes (idade, conhecimentos e experiência em informática). Contudo, o treinamento em habilidades administrativas básicas no e-learning é tão eficiente quanto no ensino presencial, bem como a diferença entre o e-learning e o ensino tradicional não é irrelevante e eleva a satisfação e a aprendizagem dos participantes. Martins e Zerbini (2015), com o objetivo de verificar as evidências de validade de dois instrumentos de medida: Reação aos Procedimentos Instrucionais e Reação ao Desempenho do Tutor, validaram os instrumentos propostos, com escalas que apresentam evidências de validade estrutural, portanto, úteis ao alcance de informações relevantes a avaliação de reações de participantes de diversificados eventos instrucionais a distância, tanto de instituições de ensino, como de organizações de trabalho, que ofertam cursos EAD.

Dos achados da presente pesquisa pode-se apontar que estudos nacionais e estrangeiros foram realizados, entre os anos de 2013 e 2015, com o objetivo de investigar a satisfação dos participantes em ações educacionais ofertadas com o uso das NTICs, pela internet (Rafferty \& Anderson, 2013; Mohelská \& Sokolava, 2014; Pinto \& Anderson, 2014; Almeida, Marroig \& Pinto, 2013; Martins \& Zerbini, 2015). Os achados dos estudos de Rafferty e Anderson (2013) e Pinto e Anderson (2013) mostram que a satisfação dos estudantes com a ação educacional online está relacionada aos fatores: comunidade de curso, tecnologia, administração de tempo, conteúdo de curso, atitudes de estudante e comunicação, aprendizagem estimulada pelos instrutores, formação de grupos entre colegas e postura ativa do instrutor. O estudo de Almeida, 
Marroig e Pinto (2014), também indica as características do tutor como preditoras de aprendizagem e satisfação dos alunos com ação educacional, entre elas: conhecer o conteúdo da disciplina e estimular perguntas, troca de experiência e de informações. Tais achados vão de encontro aos estudos da revisão de Martins (2015), principalmente no que diz respeito ao desempenho do tutor como preditor de satisfação do aluno com o curso ofertado a distância (Marks, Sibley \& Arbaugh, 2005; Özkan, Köseler \& Baykal, 2009). De acordo com o estudo de Mohelská e Sokolava (2014) o e-learning pode ser tão eficiente quanto no ensino presencial quando as características da clientela forem consideradas no planejamento da ação educacional, bem como a diferença entre as modalidades presencial e a distância é irrelevante e o EAD pode elevar a satisfação e a aprendizagem dos participantes.

O estudo de Martins e Zerbini (2015) se volta para a preocupação do levantamento da satisfação de participantes em ações educacionais a distância ao validar os instrumentos de medida: Reação aos Procedimentos Instrucionais e Reação ao Desempenho do Tutor. A mesma preocupação pode-se encontrar nos estudos de Morgane e Casper (2000) e Giangreco, Carugati, Sebastiano e Della Bella (2010) levantados na revisão de Martins (2015). A Tabela 10 apresenta, resumidamente, os principais achados relacionados as Estratégias de Aprendizagem e a satisfação dos alunos em relação ao curso.

Tabela 10. Resumo achados revisão da literatura sobre Reações dos últimos 5 anos (2011 a 2015).

\begin{tabular}{|c|c|c|}
\hline Variáve & Autores & Resultados \\
\hline \multirow{4}{*}{ Reações } & $\begin{array}{l}\text { Rafferty e Anderson (2013), } \\
\text { Pinto e Anderson ( } 2013\end{array}$ & $\begin{array}{l}\text { Satisfação dos estudantes com a ação educacional on-line } \\
\text { está relacionada a alguns fatores como: tecnologia, } \\
\text { administração de tempo, conteúdo de curso, atitudes de } \\
\text { estudante e comunicação, aprendizagem estimulada pelos } \\
\text { instrutores, postura ativa do instrutor }\end{array}$ \\
\hline & Almeida, Marroig e Pinto (2014) & $\begin{array}{l}\text { Características } \\
\begin{array}{l}\text { aprendizagem e tutor } \\
\text { e }\end{array} \text { satisfação } \\
\text { educacional. }\end{array}$ \\
\hline & Mohelská e Sokolava (2014) & $\begin{array}{l}\text { O e-learning pode ser tão eficiente quanto ao ensino } \\
\text { presencial quando as características da clientela for } \\
\text { considerada no planejamento da ação educacional. }\end{array}$ \\
\hline & Martins e Zerbini (2015) & $\begin{array}{l}\text { Validação dos instrumentos de medida: Reação aos } \\
\text { Procedimentos Instrucionais e Reação ao Desempenho do } \\
\text { Tutor. }\end{array}$ \\
\hline
\end{tabular}

Tendo sido descritas e caracterizadas as variáveis do presente estudo, o próximo capítulo se encarrega de apresentar a metodologia proposta para a investigação nessa pesquisa. 


\section{CAPÍTULO 4. CARACTERÍSTICAS METODOLÓGICAS DA PESQUISA}

\section{Objetivo do capítulo 4}

O presente capítulo visa apresentar a delimitação do problema, a justificativa e os objetivos da pesquisa, retratar o modelo de investigação, e apresentar as características da instituição de ensino superior participante, instrumentos de medida, assim como dos procedimentos de coleta e análise estatística dos dados.

\subsection{Delimitação do problema, objetivos de pesquisa e modelo de investigação}

Tendo como base a análise das questões empíricas que permeiam o campo literário nacional e estrangeiro em TD\&E, com foco no subsistema de avaliação de treinamento e em agendas de pesquisas de investigações anteriores que se voltaram a essa temática, o problema de pesquisa desse estudo foi delimitado (Abbad et al., 2006; Martins \& Zerbini, 2014; 2015; Sales, 2009).

Constata-se, a partir da revisão de literatura, que apesar dos benefícios e do crescimento experimentado pelos programas de EAD, especificamente aqueles oferecidos pela internet, ainda são poucos os estudos que se dedicam a investigar de forma sistemática a efetividade de treinamentos a distância (Abbad et al., 2006; Guimarães \& Abbad, 2015; Martins \& Zerbini, 2014; 2015; Sales, 2009). A lacuna encontrada pela escassez de estudos nessa temática sugere a necessidade de investigações com maior profundidade nesse método de ensino, que busquem estabelecer quais variáveis podem influenciar os resultados e a aplicabilidade dos eventos educacionais ofertados a distância, bem como avançar nesta discussão, ao analisar como outras variáveis (características da clientela e reação) podem influenciar nas estratégias de aprendizagem. Nesse sentido, a presente pesquisa objetiva propor e testar um modelo de avaliação de ações educacionais ofertadas a distância, buscando identificar variáveis preditoras de Estratégias de Aprendizagem relacionadas ao perfil da clientela (dados sociodemográficos e uso de ferramentas eletrônicas) e reações (desempenho do tutor e procedimentos instrucionais). $\mathrm{Na}$ Figura 7, segue a representação gráfica do conjunto de relações entre os construtos do modelo de investigação proposto. 


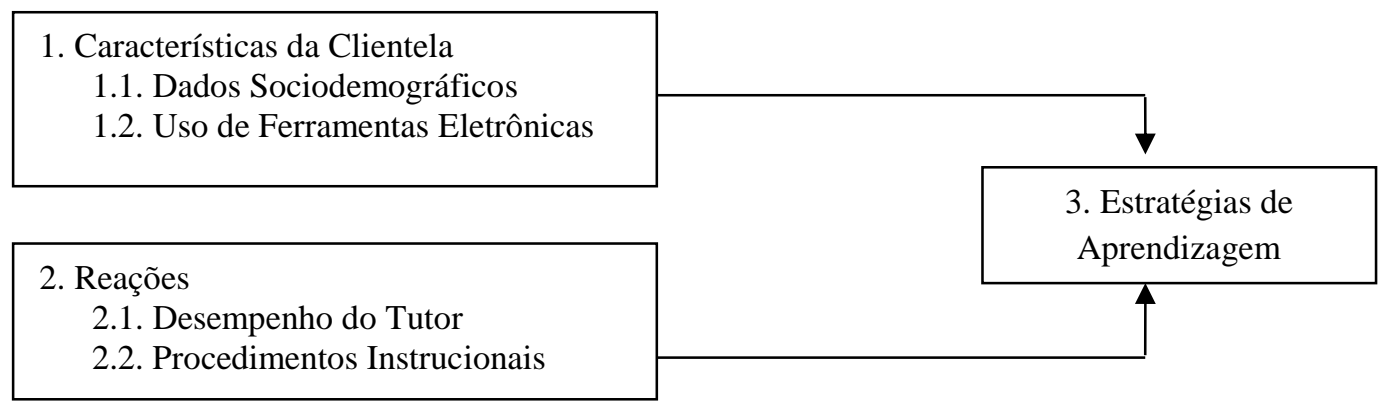

Figura 7. Modelo de investigação proposto.

Em função do modelo acima apresentado, são propostos os seguintes problemas de pesquisa:

1) Quais são as estratégias de aprendizagem utilizadas pelos alunos universitários em cursos a distância?

2) Reações favoráveis dos alunos aos procedimentos instrucionais e ao desempenho do tutor, bem como determinadas características da clientela estão relacionadas com a utilização de Estratégias de Aprendizagem adequadas em ações educacionais ofertadas a distância?

Com a finalidade de responder às questões empíricas acima descritas, foram traçados os objetivos da pesquisa, apresentados a seguir.

\section{Objetivo Geral}

Propor e testar um modelo de avaliação de ações educacionais ofertadas a distância, ao identificar variáveis preditoras de Estratégias de Aprendizagem relacionadas às Características da Clientela (perfil sociodemográficos e uso de ferramentas eletrônicas) e as Reações ao curso (Procedimentos Instrucionais e Desempenho do Tutor).

\section{Objetivos Específicos:}

- Verificar evidências de validade dos instrumentos de medida "Estratégias de Aprendizagem" (Martins \& Zerbini, 2014), "Reação aos Procedimentos Instrucionais" (Zerbini \& Abbad, 2009a), e "Reação ao Desempenho do Tutor" (Zerbini \& Abbad, 2009b).

- Identificar e analisar as Estratégias de Aprendizagem utilizadas pelos estudantes ao longo da ação educacional a distância.

- Analisar o perfil sociodemográficos da clientela e a frequência do uso de ferramentas eletrônicas disponibilizadas no ambiente eletrônico do curso. 
- Analisar as Reações dos alunos quanto aos procedimentos instrucionais e ao desempenho do tutor;

- Adaptar e verificar evidências de validade do Instrumento Roteiro de Análise de Cursos EAD, através de validação semântica e por juízes;

- Analisar os cursos ofertados pelas instituições parceiras pelo instrumento Roteiro de Análise de Cursos - EAD.

\subsection{Características da instituição-alvo}

Para a viabilização da presente pesquisa, foi estabelecida parceria com um polo da Universidade Aberta do Brasil (UAB). Para atender a crescente demanda por qualificação dos professores da educação básica, a partir do ano 2000, o sistema de ensino brasileiro estrutura a formação superior de tais professores por meio da modalidade EAD. Assim, visando a qualificação e valorização dos professores a um baixo custo, no ano de 2005 é criado o Sistema Universidade Aberta do Brasil. Com o objetivo de garantir a melhoria do desempenho da educação no país, aumentar e interiorizar a oferta de cursos e programas de educação superior, bem como fomentar a modalidade EAD nas IES públicas parceiras nos três níveis governamentais (federal, estadual e municipal) a UAB é apresentada como uma política pública para a formação inicial e continuada de professores, por meio do decreto lei $\mathrm{n}^{0} 5.800$ de 8 de junho de 2006 (Souza, 2012).

Participam do sistema UAB universidades federais, estaduais e municipais, bem como os Institutos Federais de Educação, Ciência e Tecnologia, tais instituições têm como responsabilidade a criação de projetos pedagógicos dos cursos ofertados e seguem os Referenciais de Qualidade para Educação Superior a Distância (2007), cujo documento é apresentado pela Secretaria da Educação a Distância (SEED), do Ministério da Educação (Souza, 2012).

Atualmente, as instituições participantes do sistema UAB e presentes no polo da cidade de Serrana são: Universidade Federal de Juiz de Fora (UFJF), Universidade Federal de São João Del Rei (UFSJ), Universidade Federal de Itajubá (UNIFEI), e Universidade Federal de São Paulo (UNIFESP). O contato com o polo se deu por meio do Coordenador de Polo e foi agendada uma reunião, na qual foram detalhados os objetivos da pesquisa e os procedimentos que seriam empregados. O material utilizado para tal apresentação, juntamente com o projeto de pesquisa, foi encaminhado ao referido profissional, o qual concordou com a realização do estudo. 
Para dar início ao desenvolvimento das atividades de pesquisa, foi firmada em outubro de 2015 uma parceria acadêmica entre a Universidade de São Paulo e o polo de Serrana, da Universidade Aberta do Brasil. Tal parceria teve por objeto a cooperação acadêmica na área de pesquisa, visando a conjugação de esforços entre os partícipes mediante a utilização de seus recursos humanos científicos, tecnológicos e materiais disponíveis para a implementação da presente pesquisa e na autorização para o levantamento e a utilização de dados referentes a cursos a distância via internet oferecidos pela $\mathrm{UAB}$, e seus efeitos sobre as Estratégias de Aprendizagem relacionadas às Características da Clientela bem como a satisfação.

O polo de Serrana oferece 13 cursos, sendo 4 (quatro) cursos de graduação (Educação Física, Administração Pública, Matemática e Pedagogia) ofertados pela UFJF e 9 (nove) cursos de especialização: Esportes e Atividades Físicas Inclusivas para Pessoas com Deficiências; Tecnologias Digitais de Informação e Comunicação para o Ensino Básico; Educação Empreendedora; Gestão em Saúde; Mídias na Educação; Práticas de Letramento e Alfabetização, ofertados pela UFSJ; Design Instrucional para EAD Virtual, ofertado pela UNIFEI; e Gestão em Enfermagem e Informática em Saúde ofertados pela UNIFESP. Inicialmente, para o desenvolvimento da presente pesquisa foram escolhidos os cursos de graduação por estar em acordo com os objetivos de pesquisa inicialmente traçados. Contudo, no decorrer do processo de coleta de dados, o baixo índice de retorno dos questionários encaminhados aos alunos, fez com que ocorresse a inclusão dos cursos de especialização, visando o alcance dos objetivos propostos pelo presente estudo. Assim, o desenvolvimento do trabalho e ações de pesquisa foram desenvolvidos em três Instituições de Ensino Superior sendo: quatro cursos de graduação e quatro cursos de especialização.

A instituição Universidade Federal de Juiz de Fora (UFJF), de acordo com seu site, possui sua gestão estratégica de EAD coordenada pelo Centro de Educação a Distância (Cead) que é responsável por coordenar, supervisionar e dar apoio às atividades de ensino, pesquisa extensão, cultura e desenvolvimento institucional, cientifico e tecnológico relativos a EAD da UFSJ, e oferece o curso Licenciatura em Educação Física no polo UAB de Serrana. O curso mencionado prevê quinzenalmente encontros presenciais para o desenvolvimento de atividades físicas necessárias, além dos encontros para avaliação prevista na legislação EAD.

A segunda instituição, Universidade Federal de São João Del Rei (UFSJ), segundo seu site, em 2008, foi criado o Núcleo de Educação a Distância da UFSJ (NEAD). Atualmente o NEAD/UAB oferece cursos de níveis de graduação, pós-graduação lato sensu, mestrado, extensão e aperfeiçoamento. No polo da UAB de Serrana são oferecidos três cursos de 
graduação, além de cursos de especialização. Os cursos de graduação em questão são: o curso de Administração Pública que se destina ao preparo de indivíduos que desejam se tornar aptos para atuar na Administração Pública nos âmbitos federal, estadual e municipal; o curso de Licenciatura em Matemática é voltado aos professores que lecionam Matemática na Educação Básica na rede pública, contudo, não possuem formação superior; e o curso de Pedagogia que é ofertado para suprir a demanda por formação de professores que se encontram em exercício nas redes públicas de ensino no Brasil, porém, sem formação específica, se destinando à formação de profissionais para o exercício da docência na Educação Infantil e Séries Iniciais do Ensino Fundamental. Já os cursos de especialização são: Educação Empreendedora, que procura dar resposta para a formação de profissionais da educação para lidar com a necessidade de formar pessoas autônomas e empreendedoras, capazes de reagir proativamente diante de novos desafios e mudanças, de modo criativo e inovador; o curso Mídias na Educação, está voltado para a formação de profissionais da educação frente as novas exigências das NTIcs no processo educacional; o curso Práticas de Letramento e Alfabetização capacita profissionais da educação para atuarem em espaços educativos formais e não-formais a partir dos conhecimentos em Práticas de Letramento e Alfabetização.

E por fim, a instituição Universidade Federal de São Paulo (UNIFESP), segundo seu site, oferece cursos de níveis de graduação, pós-graduação lato sensu (especialização). No polo de Serrana são oferecidos três cursos, sendo um de aperfeiçoamento e dois de especialização. Entre os cursos ofertados pela a UNIESP está o curso Gestão em Enfermagem, voltado para profissionais graduados em enfermagem com interesse em compreender estudos fundamentados na história, teorias, conceitos e instrumentos da administração aplicados à gestão de serviços, ao gerenciamento de recursos, aos processos de trabalho da enfermagem.

Na sequência são descritos os principais aspectos desses cursos, objetivando descrevêlos em termos de seus elementos formais.

\subsection{Características dos cursos}

Tal como já exposto, os cursos de graduação ofertados durante o desenvolvimento do presente estudo são: Licenciatura em Educação Física, ofertado pela UFJF; e os cursos de Administração Pública, Licenciatura em Matemática e Pedagogia, todos ofertados pela UFSJ. A Tabela 11 apresenta algumas características específicas dos cursos de graduação. 
Tabela 11. Características dos cursos de graduação ofertados pelas IES parceiras e avaliados na pesquisa

\begin{tabular}{|c|c|c|c|c|c|c|}
\hline Instituição & Curso & Modalidade & Objetivo Geral & Duração & Estrutura & Público-Alvo \\
\hline $\begin{array}{l}\text { Universidade Federal de } \\
\text { Juiz de Fora } \\
(U F J F)\end{array}$ & $\begin{array}{l}\text { Licenciatura em } \\
\text { Educação Física }\end{array}$ & EAD & $\begin{array}{l}\text { Formar professores capazes de atuar na docência da } \\
\text { Educação Física em todos os segmentos da educação } \\
\text { básica, estimulados a pesquisar e qualificar } \\
\text { permanentemente sua própria prática pedagógica. }\end{array}$ & $\begin{array}{l}4 \text { anos / } \\
2.865 \mathrm{~h}\end{array}$ & 8 períodos & $\begin{array}{l}\text { Egressos do ensino médio, ou } \\
\text { equivalente, bem como } \\
\text { professores em exercício nas } \\
\text { escolas públicas estaduais e } \\
\text { municipais sem formação } \\
\text { adequada à LDB. }\end{array}$ \\
\hline \multirow{3}{*}{$\begin{array}{l}\text { Universidade Federal de } \\
\text { São João Del Rei } \\
\text { (UFSJ) }\end{array}$} & $\begin{array}{l}\text { Administração } \\
\text { Pública }\end{array}$ & EAD & $\begin{array}{l}\text { Formar profissionais com amplo conhecimento de } \\
\text { Administração Pública, capazes de atuarem no } \\
\text { âmbito federal, estadual e municipal, administrando } \\
\text { com competência as organizações governamentais e } \\
\text { não-governamentais, de modo pró-ativo, } \\
\text { democrático e ético, tendo em vista a transformação } \\
\text { e o desenvolvimento da sociedade e do país. }\end{array}$ & $\begin{array}{l}4 \text { anos / } \\
3.000 \mathrm{~h}\end{array}$ & 8 módulos & $\begin{array}{l}\text { Concluintes do segundo } \\
\text { grau, que residam nas regiões } \\
\text { dos municípios Polos de } \\
\text { Apoio Presencial do Curso } \\
\text { de Administração Pública da } \\
\text { UAB }\end{array}$ \\
\hline & $\begin{array}{l}\text { Licenciatura em } \\
\text { Matemática }\end{array}$ & EAD & $\begin{array}{l}\text { Propiciar a formação profissional inicial de } \\
\text { professores de Matemática para o Ensino Básico } \\
\text { (Fundamental }-6^{\circ} \text { ao } 9^{\circ} \text { anos }- \text { e Médio); } \\
\text { Possibilitar uma visão ampla do conhecimento } \\
\text { matemático e pedagógico, de modo que este } \\
\text { profissional possa especializar-se posteriormente } \\
\text { em áreas afins, como em Educação ou Educação } \\
\text { Matemática, em Matemática, ou nas áreas de } \\
\text { Administração Escolar; Desenvolver valores como a } \\
\text { busca constante pelo saber, o bom relacionamento } \\
\text { pessoal e trabalhos em equipe, por meio do } \\
\text { aprimoramento de habilidades de comunicação, } \\
\text { organização e planejamento de suas atividades. }\end{array}$ & $\begin{array}{l}4 \text { anos / } \\
3.240 \mathrm{~h}\end{array}$ & $\begin{array}{l}8 \\
\text { semestres }\end{array}$ & $\begin{array}{l}\text { O curso será direcionado aos } \\
\text { professores que lecionam } \\
\text { Matemática na Educação } \\
\text { Básica na rede pública e que } \\
\text { não concluíram um curso } \\
\text { superior. }\end{array}$ \\
\hline & Pedagogia & EAD & $\begin{array}{l}\text { Formar profissionais para o exercício da docência na } \\
\text { Educação Infantil e Séries Iniciais do Ensino } \\
\text { Fundamental e em outras áreas nas quais seja } \\
\text { previsto conhecimento pedagógico }\end{array}$ & $\begin{array}{l}4 \text { anos / } \\
3.294 \mathrm{~h}\end{array}$ & 8 períodos & $\begin{array}{l}\text { Professores que atuam na } \\
\text { Educação Infantil e nas séries } \\
\text { iniciais do Ensino } \\
\text { Fundamental, nas redes } \\
\text { públicas de ensino de Minas } \\
\text { Gerais. }\end{array}$ \\
\hline
\end{tabular}


A partir da análise da tabela anterior, é possível verificar a homogeneidade entre os cursos de Licenciatura em Educação Física, ofertado pela UFJF, e os cursos Licenciatura em Matemática e Pedagogia, ofertados pela UFSJ, no campo de conhecimento cientifico, todos com objetivos geral comum, voltados para a formação de professores para a educação básica e ensino fundamental, bem como às características próprias aos mesmos, tal como, tempo de duração, número de módulos ou períodos, e carga horária. O curso Administração Pública, também ofertado pela UFSJ, apesar de ser voltado para a formação de profissionais para atuarem na administração das esferas federal, estadual e municipal, possui o mesmo tempo de duração, carga horária e número de módulos semelhantes aos demais cursos avaliados. Assim, de modo geral, os cursos considerados pelo presente estudo são alocados nos campos de concentração: Humanas e Gestão.

Tal como já foi explicitado, o evento instrucional ministrado pela UFJF, Licenciatura em Educação Física, encontra-se organizado em 8 (oito) períodos (semestres), sendo que cada um deles apresenta duração de um semestre e é constituído por disciplinas ou temas de interesse. As atividades formativas previstas - atividades web, leitura e encontros presenciais contabilizam uma carga horária total de 2.865 horas, compreendendo:

- 400 horas ao Estágio Curricular Supervisionado;

- 435 horas de Prática Pedagógica

- 200 horas destinadas às Atividades Acadêmico-Científico-Culturais;

- 1830 horas de atividades relacionadas com os Conteúdos Curriculares de Natureza Científico-Cultural, sendo 1586 horas desenvolvidas a distância.

A Tabela abaixo apresenta de forma mais detalhada as temáticas desenvolvidas em cada período, assim como as respectivas cargas horárias.

Tabela 12. Estrutura e Organização do curso "Licenciatura em Educação Física".

\begin{tabular}{llc}
\hline \multicolumn{1}{c}{ Atividade } & \multicolumn{1}{c}{ Tema } & Carga Horária \\
\hline Capacitação Tutor & Capacitação geral do tutor no ambiente Moodle (AVA); & 40h \\
\hline $\begin{array}{l}\text { Capacitação } \\
\text { Tutor/Disciplina }\end{array}$ & $\begin{array}{l}\text { Capacitação específica do tutor na disciplina com professor da } \\
\text { disciplina/tema; }\end{array}$ & $120 \mathrm{~h}$ \\
\hline Capacitação Alunos & Capacitação dos alunos no Ambiente AVA; & - \\
\hline & Introdução a EAD e ao Ambiente Virtual de Aprendizagem; & $330 \mathrm{~h}$ \\
& Introdução à Educação Física; \\
& História da Educação Física e do Esporte; \\
& Iniciação ao Atletismo I; \\
& Expressão Rítmica e Corporal; \\
& Iniciação ao Handebol; \\
& Iniciação ao Futebol;
\end{tabular}


Tabela 12. Estrutura e Organização do curso "Licenciatura em Educação Física" (continuação)

\begin{tabular}{|c|c|c|}
\hline Atividade & Tema & Carga Horária \\
\hline Período/Semestre 2 & $\begin{array}{l}\text { Fundamentos da Ginástica; } \\
\text { Estudos do Lazer; } \\
\text { Iniciação ao Atletismo II; } \\
\text { Iniciação a Dança; } \\
\text { Iniciação ao Basquetebol } \\
\text { Bases Anátomo-cinesiológicas do Movimento Humano; }\end{array}$ & $315 \mathrm{~h}$ \\
\hline Período/Semestre 3 & $\begin{array}{l}\text { Ginástica para Todos; } \\
\text { Iniciação à Ginástica Artística; } \\
\text { Iniciação à Natação; } \\
\text { Iniciação ao Voleibol; } \\
\text { Educação Física Inclusiva; } \\
\text { Biomecânica; } \\
\text { Bases Fisiológicas do Exercício Físico; }\end{array}$ & $345 \mathrm{~h}$ \\
\hline Período/Semestre 4: & $\begin{array}{l}\text { Iniciação à Ginástica Rítmica; } \\
\text { Processos de Ensino-aprendizagem; } \\
\text { Recreação e Jogos; } \\
\text { Educação Física Adaptada; } \\
\text { Libras; } \\
\text { Metodologia do Ensino da Educação Física; } \\
\text { Crescimento e Desenvolvimento; }\end{array}$ & $300 \mathrm{~h}$ \\
\hline Período/Semestre 5: & $\begin{array}{l}\text { Introdução ao Estudo da Corporeidade; } \\
\text { Socorros de Urgência; } \\
\text { Artes Marciais e Lutas; } \\
\text { Metodologia de Ensino; } \\
\text { Aprendizagem Motora; } \\
\text { Pensamento Pedagógico da Educação Física; } \\
\text { Prática Escolar I; }\end{array}$ & $315 \mathrm{~h}$ \\
\hline Período/Semestre 6 & $\begin{array}{l}\text { Educação Física na Saúde; } \\
\text { Planejamento e Organização de Eventos F-E na Escola; } \\
\text { Saberes da Educação Física Escolar; } \\
\text { Estado, Sociedade e Educação; } \\
\text { Prática Escolar II; } \\
\text { Metodologia do Trabalho Científico; }\end{array}$ & $315 \mathrm{~h}$ \\
\hline Período/Semestre 7 & $\begin{array}{l}\text { Políticas Públicas e Gestão do Espaço Escolar; } \\
\text { Avaliação em Educação Física; } \\
\text { Prática Escolar III; } \\
\text { Projeto de Pesquisa em Educação Física; } \\
\text { Estágio Supervisionado em Docência da Educação Física I }\end{array}$ & $395 \mathrm{~h}$ \\
\hline \multirow[t]{2}{*}{ Período/Semestre 8} & $\begin{array}{l}\text { Experiências Projetos Educativos Contemporâneos; } \\
\text { Questões Filosóficas Aplicadas à Educação; } \\
\text { Orientação do Projeto de Pesquisa em Educação Física; } \\
\text { Estágio Supervisionado em Docência da Educação Física II; }\end{array}$ & $350 \mathrm{~h}$ \\
\hline & Atividades Complementares; & $200 \mathrm{~h}$ \\
\hline
\end{tabular}

Segundo informações constantes no Projeto Político Pedagógico (PPP) do referido curso e disponível no site (www.ufjf.br/eadfaefid/curso), as ferramentas do ambiente virtual utilizadas no curso são:

- Dinâmica do curso - Com informações sobre o curso, entre elas: objetivo, justificativa, programa, cronograma, metodologia e avaliação;

- Agenda - Programação detalhada de cada unidade do curso.

- Atividades - Local onde são propostos os trabalhos a serem realizados. 
- Material de apoio - Com os textos relacionados à temática do curso.

A instituição mantém em seu ambiente virtual de aprendizagem, ferramentas de comunicação que permitem as interações entre os pares, tais como:

- Mural - Espaço dedicado à divulgação de eventos sobre a temática do curso: congressos, seminários, notícias e outros.

- Fórum de discussão - Tem por objetivo registrar dúvidas sobre cada unidade. São mantidos em aberto os fóruns da unidade atual e da unidade anterior. Os demais são encerrados, ficando disponíveis somente para consulta. Além dos fóruns por unidades serão mantidos alguns fóruns permanentes que serão apresentados no decorrer do curso.

- Bate papo - Permite uma conversa em tempo real entre os participantes do curso. Ao término de uma sessão as informações são registradas e ficam disponíveis para conhecimento dos que não puderam participar. As sessões têm por objetivo tirar dúvidas sobre as atividades propostas para a semana. Os tutores aguardarão quinze minutos, se ninguém comparecer neste período, a sessão é encerrada e as dúvidas poderão ser encaminhadas no fórum.

- Correio - É um sistema de correio eletrônico, interno ao ambiente, para troca de mensagens entre os participantes do curso.

As atividades individuais à distância estão voltadas para o estudo sistemático dos conteúdos. Tais atividades são orientadas por um Guia de Estudo, contendo: a) textos básicos e outras indicações para leitura, b) roteiros para o estudo dos textos e a discussão sobre os vídeos; c) orientações para trabalhos na Internet. Para o desenvolvimento das atividades são necessárias, no mínimo, 8 (oito) horas semanais. Além das atividades individuais os alunos participam de atividades coletivas em reuniões de grupos com os respectivos tutores, com o objetivo de criar um espaço de trabalho coletivo onde a fim de promover situações sociointerativas que favoreçam não apenas à aprendizagem dos conteúdos específicos, mas também à reflexão sobre a prática, a participação e o trabalho conjunto.

Por fim, no que diz respeito às atividades avaliativas - produtos/resultados de ações efetuadas, enviadas por intermédio da Plataforma Moodle (textos individuais, relatórios sobre filmes e vídeos assistidos, fóruns de discussão, bate-papo, exercícios) e produções derivadas de trabalhos presenciais. Assim, o processo avaliativo de uma disciplina deve ser composto por, no mínimo, exercícios avaliativos via Plataforma Moodle e uma avaliação presencial por período e quando necessário, uma avaliação suplementar presencial.

Quanto ao evento instrucional Administração Pública, ofertado pela UFJF, encontra-se organizado em 8 módulos, sendo que cada um deles apresenta duração de um semestre e é 
constituído por disciplinas ou temas de interesse. As atividades formativas previstas atividades web, leitura e encontros presenciais - contabilizam uma carga horária total de 3.000 horas, compreendendo:

- 300 horas ao Estágio Curricular Supervisionado;

- 120 horas destinadas às Atividades Acadêmico-Científico-Culturais;

- 2580 horas de atividades relacionadas com os Conteúdos Curriculares, sendo 2400 horas de natureza obrigatória, que garantem o perfil desejado do egresso e 180 horas optativas relativas as disciplinas de Informática para Administradores, Redação Oficial ou Língua Brasileira de Sinais (LIBAS) e disciplinas que integram uma das linhas de formação específica do curso. Das 2580 horas 2.420 horas desenvolvidas a distância e 160 horas são destinadas aos encontros presenciais.

Informações mais detalhadas sobre as temáticas desenvolvidas em cada módulo, assim como as respectivas cargas horárias são apresentadas na Tabela 13 abaixo.

Tabela 13. Estrutura e Organização do curso "Bacharelado em Administração Pública".

\begin{tabular}{|c|c|c|}
\hline Atividade & Tema & $\begin{array}{l}\text { Carga } \\
\text { Horária }\end{array}$ \\
\hline Capacitação Tutor & Capacitação geral do tutor no ambiente Moodle (AVA); & - \\
\hline $\begin{array}{l}\text { Capacitação } \\
\text { Tutor/Disciplina }\end{array}$ & $\begin{array}{l}\text { Capacitação específica do tutor na disciplina com professor da } \\
\text { disciplina/tema; }\end{array}$ & - \\
\hline Capacitação Alunos & Capacitação dos alunos no Ambiente AVA; & - \\
\hline Módulo/Semestre 1 & $\begin{array}{l}\text { Filosofia e Ética; } \\
\text { Teoria da Administração I; } \\
\text { Introdução à Economia; } \\
\text { Psicologia Organizacional; } \\
\text { Metodologia de Estudo e de Pesquisa em Administração; } \\
\text { Seminário Integrador; } \\
\text { Matemática Básica; }\end{array}$ & $390 \mathrm{~h}$ \\
\hline Módulo/Semestre 2 & $\begin{array}{l}\text { Ciência Política; } \\
\text { Teorias da Administração II; } \\
\text { Macroeconomia; } \\
\text { Contabilidade Geral; } \\
\text { Matemática para Administradores; } \\
\text { Seminário Temático I; } \\
\text { Redação Oficial; }\end{array}$ & $390 \mathrm{~h}$ \\
\hline
\end{tabular}


Tabela 13. Estrutura e Organização do curso "Bacharelado em Administração Pública" (continuação).

\begin{tabular}{|c|c|c|}
\hline Atividade & Tema & $\begin{array}{c}\text { Carga } \\
\text { Horária }\end{array}$ \\
\hline Módulo/Semestre 3 & $\begin{array}{l}\text { Teorias da Administração Pública; } \\
\text { Sociologia Organizacional; } \\
\text { Economia Brasileira; } \\
\text { Contabilidade Pública; } \\
\text { Instituições de Direito Público e Privado; } \\
\text { Seminário Temático II } \\
\text { Informática para Administradores; }\end{array}$ & $390 \mathrm{~h}$ \\
\hline Módulo/Semestre 4: & $\begin{array}{l}\text { Teorias das Finanças Públicas; } \\
\text { Organização, Processos e Tomada de Decisão; } \\
\text { Sistemas de Informação e Comunicação no Setor Público; } \\
\text { Estatística Aplicada à Administração } \\
\text { Direito Administrativo; } \\
\text { Seminário Temático III }\end{array}$ & $330 \mathrm{~h}$ \\
\hline Módulo/Semestre 5: & $\begin{array}{l}\text { Planejamento e Programação na Administração Pública; } \\
\text { Gestão de Pessoas no Setor Público; } \\
\text { Gestão de Operações Logísticas I; } \\
\text { Matemática Financeira e Análise de Investimento; } \\
\text { Legislação Tributária e Comercial; } \\
\text { Seminário Temático I na LFE I/ LFE II/ LFE III; } \\
\text { Estágio Curricular Supervisionado I }\end{array}$ & $330 \mathrm{~h}$ \\
\hline Módulo/Semestre 6 & $\begin{array}{l}\text { Orçamento Público; } \\
\text { Administração Estratégica; } \\
\text { Gestão de Operações Logísticas II; } \\
\text { Elaboração e Gestão de Projetos; } \\
\text { Eletiva I Marketing Governamental; } \\
\text { Seminário Temático II na LFE I/ LFE II/ LFE III; } \\
\text { Estágio Curricular Supervisionado II; }\end{array}$ & $300 \mathrm{~h}$ \\
\hline Módulo/Semestre 7 & $\begin{array}{l}\text { Auditoria e Controladoria; } \\
\text { Negociação e Arbitragem; } \\
\text { Tecnologia e Inovação; } \\
\text { Eletiva II Empreendedorismo Governamental; } \\
\text { Gestão da Regulação; } \\
\text { Seminário Temático III na LFE I/ LFE II/ LFE III; } \\
\text { Estágio Curricular Supervisionado III; }\end{array}$ & $300 \mathrm{~h}$ \\
\hline \multirow[t]{2}{*}{ Módulo/Semestre 8} & $\begin{array}{l}\text { Políticas Públicas e Sociedade; } \\
\text { Gestão Ambiental e Sustentabilidade; } \\
\text { Relações Internacionais; } \\
\text { Eletiva III Gestão de Redes de Cooperação na Esfera Pública; } \\
\text { Seminário Temático IV na LFE I/ LFE II/ LFE III; } \\
\text { Estágio Curricular Supervisionado IV; }\end{array}$ & $270 \mathrm{~h}$ \\
\hline & Estágio Curricular Supervisionado I, II, III e IV & $300 \mathrm{~h}$ \\
\hline
\end{tabular}

De acordo com as informações do PPP do referido curso, são disponíveis no site (www.grad.nead.ufsj.edu.br/AdmP/site/sobreocurso/projetopedagogico), as ferramentas utilizadas para interlocução entre tutoria e alunos são: a) Ambiente Virtual, com recursos de fórum, chat, biblioteca virtual, agenda, repositório de tarefas, questionários, recursos de acompanhamento e controle de cada estudante, entre outros; b) Videoaulas; c) Telefone; d) Email; e e) Material Impresso. Ainda de acordo com o documento, os encontros presenciais são planejados para envolver os atores pedagógicos e administrativos dos subsistemas do Curso, e entre as atividades que são desenvolvidas incluem-se avaliação do desempenho discente, 
apresentação de palestras, aulas, pesquisas desenvolvidas, defesa de TCC, visitas técnicas e integração social da comunidade acadêmica. Normalmente, os Encontros Presenciais acontecem no último mês do semestre e tem duração de 20 horas. Para o desenvolvimento das atividades das disciplinas os alunos recebem apoio da equipe do multidisciplinar do curso, no AVA e no apoio dos tutores presenciais.

No processo de avaliação de aprendizagem é analisado a capacidade de reflexão crítica do aluno frente a suas próprias experiências, a fim de que possa atuar dentro de seus limites sobre o que o impede de agir para transformar aquilo que julga limitado no campo da Administração Pública. O desempenho do aluno é avaliado em três situações distintas de acordo com os artigos $4^{\circ}$ e 24 do Decreto $\mathrm{n}^{\circ} 5622$ de 19 de dezembro de 2005 que regulamenta $\mathrm{o}$ artigo 80 da lei de Diretrizes e Bases da Educação Nacional nº 9394 de 20 de dezembro de 1996, a avaliação de desempenho do estudante se dará mediante:

I. O cumprimento das atividades programadas, ou seja, estudo do conteúdo e realização de atividades propostas pelo professor de cada disciplina, que devem ser enviadas e avaliadas posteriormente pelos tutores, seguindo critérios previamente determinados pelos professores especialistas;

II. Realização de exames presenciais através de avaliação escrita, ao final de cada semestre;

III. Trabalho de Conclusão que será desenvolvido pelo aluno durante o transcorrer dos estudos sob orientação de seu respectivo tutor acadêmico e sob a supervisão de um professor especialista.

Assim, no processo de avaliação os tutores e os professores formadores realizam a observação e registro dos seguintes aspectos: a) produção escrita do estudante; b) o método de estudo utilizado pelo aluno; c) a participação nos Encontros Presenciais, nos fóruns e nos bate papos; d) o acompanhamento e compreensão do conteúdo proposto em cada uma das disciplinas; e e) capacidade de posicionamentos crítico-reflexivos frente às abordagens trabalhadas e frente à sua prática profissional (dimensão cognitiva) bem como, na realização de estudos de caso e de pesquisa, a partir de proposições temáticas relacionadas ao seu campo de formação profissional, entre outros fatores. A nota final é composta por avaliações na plataforma $40 \%$ (quarenta por cento) e avaliações presenciais $60 \%$ (sessenta por cento).

No tocante ao curso Licenciatura em Matemática, ofertados pela instituição parceira UFSJ, encontra-se organizado em 8 semestres, e é constituído por disciplinas ou temas de interesse. As atividades formativas previstas - atividades web, leitura e encontros presenciais contabilizam uma carga horária total de 3.240 horas, compreendendo: 
- 432 horas ao Estágio Curricular Supervisionado;

- 200 horas destinadas às Atividades Acadêmico-Complementares;

- 2608 horas de atividades relacionadas com os Conteúdos Curriculares, sendo 2500 horas de natureza obrigatória, que garantem o perfil desejado do egresso e 108 horas relativas às disciplinas de nivelamento (Introdução a Educação a Distância e Matemática Elementar). Das 2608 horas 2.480 horas desenvolvidas a distância e 128 horas são destinadas aos encontros presenciais.

Informações mais detalhadas sobre as temáticas desenvolvidas em cada módulo, assim como as respectivas cargas horárias são apresentadas na Tabela abaixo.

Tabela 14. Estrutura e Organização do curso "Licenciatura em Matemática".

\begin{tabular}{|c|c|c|}
\hline Atividade & Tema & $\begin{array}{c}\text { Carga } \\
\text { Horária }\end{array}$ \\
\hline Capacitação Tutor & Capacitação geral do tutor no ambiente Moodle (AVA); & - \\
\hline $\begin{array}{l}\text { Capacitação } \\
\text { Tutor/Disciplina }\end{array}$ & $\begin{array}{l}\text { Capacitação específica do tutor na disciplina com professor da } \\
\text { disciplina/tema; }\end{array}$ & - \\
\hline Capacitação Alunos & $\begin{array}{l}\text { Introdução a Educação a Distância; } \\
\text { Matemática elementar. }\end{array}$ & $108 \mathrm{~h}$ \\
\hline Semestre 1 & $\begin{array}{l}\text { Fundamentos da Matemática Elementar 1; } \\
\text { Geometria Analítica; } \\
\text { Introdução ao Cálculo; } \\
\text { Laboratório de Ensino de Matemática. }\end{array}$ & $360 \mathrm{~h}$ \\
\hline Semestre 2 & $\begin{array}{l}\text { Álgebra Linear; } \\
\text { Cálculo 1; } \\
\text { Fundamentos da Matemática Elementar 2; } \\
\text { Geometria Plana e Desenho Geométrico. }\end{array}$ & $360 \mathrm{~h}$ \\
\hline Semestre 3 & $\begin{array}{l}\text { Cálculo 2; } \\
\text { Didática da Matemática; } \\
\text { Informática e Ensino de Matemática; } \\
\text { Modelagem Matemática. }\end{array}$ & $360 \mathrm{~h}$ \\
\hline Semestre 4: & $\begin{array}{l}\text { Cálculo 3; } \\
\text { Geometria Espacial; } \\
\text { Metodologia da Pesquisa em Educação Matemática } \\
\text { Política e Gestão da Educação. }\end{array}$ & $360 \mathrm{~h}$ \\
\hline Semestre 5: & $\begin{array}{l}\text { Cálculo Numérico; } \\
\text { Estágio de Prática Pedagógica 1; } \\
\text { Estatística da Educação Básica ao Ensino Superior; } \\
\text { Introdução a Teoria dos Números; } \\
\text { Tendências em Educação Matemática. }\end{array}$ & $432 \mathrm{~h}$ \\
\hline Semestre 6 & $\begin{array}{l}\text { Estágio de Prática Pedagógica 2; } \\
\text { Estruturas Algébricas; } \\
\text { História da Educação Matemática; } \\
\text { Metodologia do Ensino de Matemática; } \\
\text { Oficina de Prática Pedagógica. }\end{array}$ & $432 \mathrm{~h}$ \\
\hline
\end{tabular}


Tabela 14. Estrutura e Organização do curso "Licenciatura em Matemática" (continuação)

\begin{tabular}{|c|c|c|}
\hline Atividade & Tema & $\begin{array}{c}\text { Carga } \\
\text { Horária }\end{array}$ \\
\hline Semestre 7 & $\begin{array}{l}\text { Análise dos Livros Didáticos; } \\
\text { Estágio de Prática Pedagógica 3; } \\
\text { Introdução a Análise; } \\
\text { Tecnologias de Informação e Comunicação no Ensino de } \\
\text { Matemática; } \\
\text { Trabalho de Conclusão de Curso } 1\end{array}$ & $432 \mathrm{~h}$ \\
\hline Semestre 8 & $\begin{array}{l}\text { Educação a Diversidade; } \\
\text { Ensino de Matemática por meio de Problemas; } \\
\text { Estágio de Prática Pedagógica } 4 \text {; } \\
\text { História da Matemática; } \\
\text { Trabalho de Conclusão de Curso } 2 \text {. }\end{array}$ & $414 \mathrm{~h}$ \\
\hline
\end{tabular}

De acordo com o PPP do curso Licenciatura em Matemática, que se encontra disponível no site (www.grad.nead.ufsj.edu.br/mat/site/sobreocurso/projetopedagogico), o estudo a distância é realizado pelo estudante por meio de leituras individuais, bem como pela participação nas videoconferências, na interação em fóruns e chats; pela realização de atividades, individuais e coletivas, além do AVA. Os recursos da Internet são destinados para disseminar informações sobre o curso, desenvolver funções de apoio ao processo de aprendizagem, além de proporcionar acesso as ferramentas: correio eletrônico, fóruns e chats. As videoconferências e as vídeo aulas também são utilizadas como ferramenta para a interlocução professor e aluno.

Os encontros presenciais são realizados nos polos, e são previstos dois encontros com carga horária total de 16 horas por semestre. Esses momentos são destinados para o desenvolvimento de atividades diversificadas, a saber:

- Palestras que abordem em forma de síntese os conteúdos das diferentes disciplinas ou da formação e atuação profissional do aprendiz de forma mais ampla;

- Apresentação dos resultados das pesquisas temáticas ou por meio de comunicações orais ou de outra forma de participação;

- Avaliações escritas, englobando todos os conteúdos de todas as áreas trabalhadas no semestre.

O processo de avaliação do referido curso prevê o acompanhamento passo a passo do processo de ensino e aprendizagem pelo docente e deve cumprir a função didático pedagógica. Os instrumentos de avaliação ficam a critério do professor, contudo são realizados em pelo menos duas modalidades distintas, sendo obrigatoriamente a primeira, provas presenciais, onde se enquadram testes discursivos, testes práticos, elaboração de redações, artigos de revisão bibliográfica, relatórios, memoriais e especialmente a pesquisa científica. Para esta avaliação a 
representação do total de pontos equivale a $60 \%$ da nota final do aluno. A segunda modalidade de avaliação acontece via plataforma de aprendizagem, correspondendo no máximo a $40 \%$ do total de pontos atribuídos a cada disciplina.

E por fim, o curso de Pedagogia, ofertado também pela instituição parceira UFSJ, encontra-se organizado em 8 (oito) períodos, sendo que cada um deles apresenta duração de um semestre e é constituído por disciplinas ou temas de interesse e é constituído por disciplinas ou temas de interesse. As atividades formativas previstas - atividades web, leitura e encontros presenciais - contabilizam uma carga horária total de 3.294 horas, compreendendo:

- 360 horas ao Estágio Curricular Supervisionado;

- 306 horas de Trabalho de Conclusão de Curso - TCC (Monografia)

- 108 horas destinadas às Atividades Acadêmicas, Científicas e Culturais;

- 2520 horas de atividades relacionadas com os Conteúdos Curriculares, sendo 2.360 horas desenvolvidas a distância e 160 horas são destinadas aos encontros presenciais.

Informações mais detalhadas sobre as temáticas desenvolvidas em cada módulo, assim como as respectivas cargas horárias são apresentadas na Tabela 15.

Tabela 15. Estrutura e Organização do curso "Pedagogia".

\begin{tabular}{|c|c|c|}
\hline & Tema & $\begin{array}{c}\text { Carga } \\
\text { Horária }\end{array}$ \\
\hline Semestre 1 & $\begin{array}{l}\text { Fundamentos da Educação a Distância; } \\
\text { Psicologia da educação; } \\
\text { História da educação; } \\
\text { Filosofia da educação; } \\
\text { Arte-Educação }\end{array}$ & $360 \mathrm{~h}$ \\
\hline Semestre 2 & $\begin{array}{l}\text { Organização da Educação Brasileira; } \\
\text { Sociologia da Educação; } \\
\text { Desenvolvimento e aprendizagem; } \\
\text { Teorias do Currículo; } \\
\text { Didática. }\end{array}$ & $360 \mathrm{~h}$ \\
\hline Semestre 3 & $\begin{array}{l}\text { História do Ensino; } \\
\text { Alfabetização e letramento; } \\
\text { Ludicidade e desenvolvimento infantil; } \\
\text { Pesquisa em Educação; } \\
\text { Educação Ambiental; } \\
\text { Prática Pedagógica. }\end{array}$ & $360 \mathrm{~h}$ \\
\hline Semestre 4: & $\begin{array}{l}\text { Gestão Educacional; } \\
\text { Literatura Infantil; } \\
\text { Geografia e ensino; } \\
\text { Língua Portuguesa e ensino; } \\
\text { Estágio Supervisionado. }\end{array}$ & $378 \mathrm{~h}$ \\
\hline
\end{tabular}


Tabela 15. Estrutura e Organização do curso "Pedagogia" (continuação)

\begin{tabular}{|c|c|c|}
\hline Atividade & Tema & $\begin{array}{c}\text { Carga } \\
\text { Horária }\end{array}$ \\
\hline Semestre 5: & $\begin{array}{l}\text { Alfabetização e letramento Matemático; } \\
\text { Políticas de atendimento à infância; } \\
\text { Avaliação educacional1; } \\
\text { Educação Inclusiva; } \\
\text { Disciplina eletiva; } \\
\text { Prática Pedagógica II }\end{array}$ & $396 \mathrm{~h}$ \\
\hline Semestre 6 & $\begin{array}{l}\text { Currículo e planejamento na EI; } \\
\text { Matemática e ensino; } \\
\text { Jogos e recreação; } \\
\text { Avaliação educacional II; } \\
\text { Pratica pedagógica III; } \\
\text { Estágio supervisionado II. }\end{array}$ & $414 \mathrm{~h}$ \\
\hline Semestre 7 & $\begin{array}{l}\text { Currículo e Planejamento nos anos iniciais do EF; } \\
\text { Fundamento s e Didática da Educação de Jovens e Adultos; } \\
\text { Ciências Naturais e ensino; } \\
\text { Disciplina eletiva; } \\
\text { Pratica pedagógica IV; } \\
\text { Estágio supervisionado III. }\end{array}$ & $378 \mathrm{~h}$ \\
\hline \multirow[t]{2}{*}{ Semestre 8} & $\begin{array}{l}\text { Libras; } \\
\text { Seminários de Pesquisa e Trabalho de Conclusão de Curso; } \\
\text { Disciplina eletiva; } \\
\text { Estágio Supervisionado IV; } \\
\text { TCC (monografia) }\end{array}$ & $540 \mathrm{~h}$ \\
\hline & Atividades Acadêmicas, Científicas e Culturais & $108 \mathrm{~h}$ \\
\hline
\end{tabular}

Segundo o PPP do curso, disponível no site do curso de Pedagogia (www.grad.nead.ufsj.edu.br/pedag/site/sobreocurso/projetopedagogico), a interlocução entre o aluno e o tutor são utilizados os seguintes recursos: Ambiente Virtual, com recursos de fórum, chat, biblioteca virtual, agenda; repositório de tarefas, questionários, recursos de acompanhamento e controle de cada estudante, entre outros; Videoaulas; Telefone; E-mail; Material Impresso.

Nos encontros presenciais são realizadas atividades que incluem: avaliação do desempenho discente; apresentação de palestras; aulas, pesquisas desenvolvidas, defesa de TCC, visitas técnicas e integração social da comunidade acadêmica. Tais encontros estão previstos para acontecer no último mês de cada semestre com duração de 20 horas cada, totalizando 160 horas presenciais no curso

No tocante ao processo de avaliação, de acordo com o PPP, a ênfase está no processo e não nos produtos. Assim, a avaliação adotada no curso de Pedagogia da UFSJ não está voltada para o controle e sim como um instrumento de aperfeiçoamento de processos em vista dos fins almejados pelo PPP e pelo Plano de Ensino do Professor. Dessa forma, como o curso Administração Pública, no curso de Pedagogia a avaliação de desempenho do estudante acontece em três situações distintas de acordo com a legislação da educação vigente, a saber: 
I. O cumprimento das atividades programadas, ou seja, estudo do conteúdo e realização de atividades propostas pelo professor de cada disciplina, que devem ser enviadas e avaliadas posteriormente pelos tutores, seguindo critérios previamente determinados pelos professores especialistas;

II. Realização de exames presenciais através de avaliação escrita, ao final de cada semestre;

III. Trabalho de Conclusão que será desenvolvido pelo aluno durante o transcorrer dos estudos sob orientação de seu respectivo tutor acadêmico e sob a supervisão de um professor especialista.

Durante o processo de avaliação os tutores e os professores formadores realizam a observação e registro dos seguintes aspectos: a) produção escrita do estudante; b) o método de estudo utilizado pelo aluno; c) a participação nos Encontros Presenciais, nos fóruns e nos batepapos; d) o acompanhamento e compreensão do conteúdo proposto em cada uma das disciplinas; e e) capacidade de posicionamentos crítico-reflexivos frente às abordagens trabalhadas e frente à sua prática profissional (dimensão cognitiva) bem como, na realização de estudos de caso e de pesquisa, a partir de proposições temáticas relacionadas ao seu campo de formação profissional, entre outros fatores. A nota final é composta por avaliações na plataforma $40 \%$ (quarenta por cento) e avaliações presenciais $60 \%$ (sessenta por cento).

Os cursos pós-graduação lato senso (especialização) ofertados durante o desenvolvimento do presente estudo são: Educação Empreendedora, Mídias na Educação e Práticas de Letramento e Alfabetização, ofertados pela UFJF; e Gestão em Enfermagem, ofertado pela UNIESP. A Tabela 16 apresenta algumas características específicas dos cursos de especialização. 
Tabela 16. Características dos cursos de especialização ofertados pelas IES parceiras e avaliados na pesquisa.

\begin{tabular}{|c|c|c|c|c|c|c|}
\hline Instituição & Curso & Modalidade & Objetivo Geral & Duração & Estrutura & $\begin{array}{l}\text { Público-Alvo } \\
\end{array}$ \\
\hline $\begin{array}{l}\text { Universidade Federal de } \\
\text { São Paulo } \\
\text { (UNIFESP) }\end{array}$ & $\begin{array}{l}\text { Gestão em } \\
\text { Enfermagem }\end{array}$ & EAD & $\begin{array}{l}\text { Capacitar enfermeiros para atuarem de forma crítica } \\
\text { e competente na administração da assistência de } \\
\text { enfermagem nos serviços de saúde }\end{array}$ & $\begin{array}{l}13 \text { meses } \\
486 \mathrm{~h}\end{array}$ & $\begin{array}{l}13 \\
\text { disciplinas }\end{array}$ & $\begin{array}{l}\text { Enfermeiros que estão } \\
\text { atuando nos serviços e que } \\
\text { ainda não tiveram } \\
\text { possibilidade de cursar uma } \\
\text { especialização. }\end{array}$ \\
\hline \multirow{3}{*}{$\begin{array}{l}\text { Universidade Federal de } \\
\text { São João Del Rei } \\
(\text { UFSJ) }\end{array}$} & $\begin{array}{l}\text { Educação } \\
\text { Empreendedora }\end{array}$ & EAD & $\begin{array}{l}\text { Ampliar a visão conceitual e metodológica dos } \\
\text { profissionais participantes, no campo da educação } \\
\text { empreendedora }\end{array}$ & $\begin{array}{l}18 \text { meses } \\
360 \mathrm{~h}\end{array}$ & $\begin{array}{l}4 \text { Etapas } \\
13 \\
\text { disciplinas }\end{array}$ & $\begin{array}{l}\text { Profissionais da educação, } \\
\text { graduados e a e áreas afins } \\
\text { interessados na Educação } \\
\text { Empreendedora. }\end{array}$ \\
\hline & $\begin{array}{l}\text { Mídias na } \\
\text { Educação }\end{array}$ & EAD & $\begin{array}{l}\text { Contribuir para a formação continuada de } \\
\text { profissionais em Educação, em especial professores } \\
\text { da Educação Básica, incluindo aqueles de Educação } \\
\text { de Jovens e Adultos, de Educação Especial e de } \\
\text { Educação Profissional, para o uso dos recursos } \\
\text { tecnológicos no cotidiano da escola, de forma } \\
\text { articulada à proposta pedagógica e a uma concepção } \\
\text { interacionista de aprendizagem. }\end{array}$ & $\begin{array}{l}24 \text { meses } \\
425 \mathrm{~h}\end{array}$ & $\begin{array}{l}4 \text { módulos } \\
16 \\
\text { disciplinas }\end{array}$ & $\begin{array}{l}\text { Professores da rede pública } \\
\text { de ensino, graduados nas } \\
\text { diversas áreas, e } \\
\text { profissionais graduados que } \\
\text { trabalhem com educação, } \\
\text { comunicação e áreas afins }\end{array}$ \\
\hline & $\begin{array}{l}\text { Práticas de } \\
\text { Letramento e } \\
\text { Alfabetização }\end{array}$ & EAD & $\begin{array}{l}\text { Atender à demanda da comunidade na qual a } \\
\text { Universidade Federal de São João del- Rei se insere, } \\
\text { propiciando a continuidade da formação acadêmica } \\
\text { do profissional da educação básica, especificamente, } \\
\text { com aqueles envolvidos com a temática da } \\
\text { alfabetização e letramento }\end{array}$ & $\begin{array}{l}18 \text { meses } \\
360 \mathrm{~h}\end{array}$ & $\begin{array}{l}13 \\
\text { disciplinas }\end{array}$ & 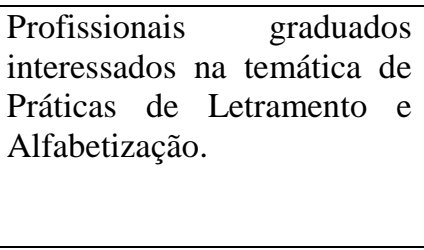 \\
\hline
\end{tabular}


A partir da análise da tabela 16 é possível verificar uma grande heterogeneidade entre os cursos avaliados, no que tange aos campos de conhecimento científico, bem como às características próprias aos mesmos, tal como: tempo de duração, número de módulos e eixos temáticos trabalhados. De modo geral, os cursos considerados pelo presente estudo podem ser alocados em 3 grandes campos de concentração, a saber: Humanas; Educação e Gestão e Negócios.

O evento instrucional ministrado pela UNIFESP, Gestão em Enfermagem, encontrase organizado em 13 (treze) disciplinas. As atividades formativas previstas - atividades web, leitura e encontros presenciais - contabilizam uma carga horária total de 486 horas, compreendendo:

A Tabela abaixo apresenta as disciplinas desenvolvidas, bem como as respectivas cargas horárias.

Tabela 17. Estrutura e Organização do curso "Gestão em Enfermagem".

\begin{tabular}{|c|c|c|}
\hline Disciplina & Tema & $\begin{array}{c}\text { Carga } \\
\text { Horária }\end{array}$ \\
\hline 1 & Adaptação ao Ambiente de aprendizagem & 30 \\
\hline 2 & Introdução a Administração Geral & 30 \\
\hline 3 & Competências Gerenciais & 30 \\
\hline 4 & Gerenciamento de Enfermagem & 30 \\
\hline 5 & Gestão de Recursos Humanos & 30 \\
\hline 6 & Gestão da Informação em Saúde & 30 \\
\hline 7 & Gestão de Recursos Financeiros & 30 \\
\hline 8 & Gestão de Recursos Físicos e Materiais & 30 \\
\hline 9 & Qualidade e Segurança nos Serviços de Saúde & 30 \\
\hline 10 & Gestão e Sustentabilidade nos Serviços de Saúde & 30 \\
\hline 11 & Marketing e Empreendedorismo em Saúde & 30 \\
\hline 12 & Elaboração do Trabalho de Conclusão do Curso & 30 \\
\hline \multirow[t]{3}{*}{13} & TCC & 98 \\
\hline & Encontros Presenciais & 28 \\
\hline & Total & 486 \\
\hline
\end{tabular}


De acordo com o PPP do curso, disponível no site do curso de Gestão em Enfermagem (http://www.unifesp.br/reitoria/sead/uab1), para a interlocução entre o aluno e o tutor são utilizados os seguintes recursos: Ambiente Virtual, com recursos de fórum, chat, biblioteca virtual, agenda; repositório de tarefas, questionários, recursos de acompanhamento e controle de cada estudante, entre outros; Videoaulas; Telefone; E-mail; Material Impresso.

Nos encontros presenciais são realizadas atividades que incluem: avaliação do desempenho discente; apresentação de palestras; aulas, pesquisas desenvolvidas, defesa de TCC, visitas técnicas e integração social da comunidade acadêmica. Tais encontros estão previstos para acontecer uma vez por mês com duração total de 28 horas cada, totalizando $6 \%$ das horas do curso, onde o aluno deve manter a frequência de $85 \%$ nestas atividades práticas presenciais.

No que se refere a avaliação, as disciplinas são organizadas em conteúdos semanais, que são avaliados por meio das postagens nos fóruns de discussão e provas de autocorreção, ou atividade equivalente. Assim, a avaliação adotada no curso de Gestão em Enfermagem não está voltada para o controle e sim como um instrumento de aperfeiçoamento de processos em vista dos fins almejados pelo PPP e pelo Plano de Ensino do Professor.

Quanto ao evento instrucional Educação Empreendedora, ofertado pela UFSJ, encontrase organizado em 4 etapas, envolvendo o total de 13 disciplinas, com duração de 18 meses e uma carga horária total de 360 horas. A Tabela 18 apresenta as disciplinas desenvolvidas, bem como as respectivas cargas horárias. 
Tabela 18. Estrutura e Organização do curso "Educação Empreendedora".

\begin{tabular}{|c|c|c|c|}
\hline Disciplina & Tema & $\begin{array}{c}\text { Carga } \\
\text { Horária }\end{array}$ & Etapas \\
\hline 1 & Fundamentos da Educação a Distância & 15 & \multirow{4}{*}{$1^{\mathrm{a}}$ Etapa } \\
\hline 2 & Didática do Ensino Superior & 30 & \\
\hline 3 & Pedagogia Empreendedora & 30 & \\
\hline 4 & Elaboração e Gestão de Projetos Educacionais & 30 & \\
\hline 5 & Educação Ambiental na Escola & 30 & \multirow{4}{*}{$2^{\mathrm{a}}$ Etapa } \\
\hline 6 & Educação Empreendedora e Redes de cooperação & 30 & \\
\hline 7 & Estratégias Educacionais & 30 & \\
\hline 8 & Comportamento Organizacional & 30 & \\
\hline 9 & Trabalho e Saúde na Educação & 30 & \multirow{4}{*}{$3^{\mathrm{a}}$ Etapa } \\
\hline 10 & Metodologia de Pesquisa & 30 & \\
\hline 11 & Planejamento e Avaliação educacional & 30 & \\
\hline 12 & Gestão de Mudanças e Conflitos & 30 & \\
\hline \multirow[t]{2}{*}{13} & TCC - Seminários e tópicos Especiais & 15 & $4^{\circ}$ Etapa \\
\hline & Total & 360 & \\
\hline
\end{tabular}

De acordo com o PPP do curso, disponível no site do curso de Educação Empreendedora (http://pos.nead.ufsj.edu.br/EE/EE2014/site/index.php), na interlocução entre o aluno e o tutor são utilizados os seguintes recursos: Ambiente Virtual, com recursos de fórum, chat, biblioteca virtual, agenda; hipertextos, textos audiovisuais, recursos de acompanhamento e controle de cada estudante, entre outros; Videoaulas; Telefone; E-mail; Material Virtual e Impresso.

São previstos quatro encontros presenciais onde são realizadas atividades que incluem: avaliação do desempenho discente; apresentação de disciplinas, pesquisas desenvolvidas, defesa de TCC, visitas técnicas e integração social da comunidade acadêmica. Tais encontros estão previstos para acontecer ao final de cada etapa, totalizando 40 horas. As atividades complementares se caracterizarão pela participação do aluno em fóruns de debates a distância, videoconferências, chats para discussões, seminários e congressos da área de Educação a Distância e Educação Empreendedora. 
No que se refere a avaliação, as disciplinas são organizadas em conteúdos semanais, que são avaliados por meio das postagens nos fóruns de discussão e provas de autocorreção, ou atividade equivalente, além da realização de exames presenciais através de avaliação escrita, ao final de cada semestre, elaborada pelo conjunto de professores das disciplinas cursadas no semestre, observando-se o caráter interdisciplinar dos conteúdos. O processo de avaliação também conta com o trabalho de conclusão de curso (TCC), que é elaborado e apresentado individualmente, com acompanhamento do professor orientador. A apresentação será pública e avaliada por uma banca composta pelo orientador e mais dois convidados.

O curso Mídias na Educação, também ofertado pela UFSJ, encontra-se organizado em 4 módulos, envolvendo o total de 16 disciplinas, com duração de 24 meses e uma carga horária total de 425 horas, entre a carga horária das disciplinas e o TCC. A Tabela 19 apresenta as disciplinas desenvolvidas, bem como as respectivas cargas horárias.

Tabela 19. Estrutura e Organização do curso "Mídias na Educação".

\begin{tabular}{|c|c|c|c|}
\hline Disciplina & Tema & $\begin{array}{c}\text { Carga } \\
\text { Horária }\end{array}$ & \\
\hline 1 & Introdução à Educação a Distância & 15 & \multirow{5}{*}{ Módulo 1} \\
\hline 2 & Integração das Mídias na Educação & 30 & \\
\hline 3 & Introdução à informática e internet & 30 & \\
\hline 4 & Módulo TV e vídeo & 30 & \\
\hline 5 & Módulo Rádio & 30 & \\
\hline 6 & Módulo Gestão & 15 & \multirow{5}{*}{ Módulo 2} \\
\hline 7 & Educomunicação & 15 & \\
\hline 8 & Módulo Material Impresso & 30 & \\
\hline 9 & Convergência das Mídias & 30 & \\
\hline 10 & $\begin{array}{l}\text { Vivenciando o desenvolvimento de projetos com mídias } \\
\text { integradas na educação }\end{array}$ & 30 & \\
\hline 11 & A imagem na mídia impressa & 15 & \multirow{5}{*}{ Módulo 3} \\
\hline 12 & Uso de blogs, flogs e webquest na educação & 15 & \\
\hline 13 & Gêneros informativos na televisão & 30 & \\
\hline 14 & Serviços e Radiofusão & 30 & \\
\hline 15 & Metodologia Científica & 30 & \\
\hline \multirow[t]{2}{*}{16} & Elaboração da Monografia ou TCC (texto ou produto) & 50 & Módulo 4 \\
\hline & Total & 425 & \\
\hline
\end{tabular}


De acordo com o PPP do curso, disponível no site do curso de Mídias na Educação (http://pos.nead.ufsj.edu.br/Midias/Midias2012/site/imagens/enviadas/PROJETO_MID.pdf), na interlocução entre o aluno e o tutor são utilizados os seguintes recursos: ambiente virtual, com recursos de fórum, chat, biblioteca virtual, agenda; hipertextos, textos audiovisuais, recursos de acompanhamento e controle de cada estudante, videoaulas; telefone; e-mail; material virtual e impresso.

Para as atividades presenciais são previstos cinco encontros, onde são realizadas atividades que incluem: avaliação do desempenho discente; apresentação de disciplinas, apresentação de seminários e defesa de TCC. Tais encontros estão previstos para acontecer ao final de cada módulo 40 horas. As atividades complementares se caracterizarão pela participação do aluno em fóruns de debates a distância, videoconferências, chats para discussões, seminários e congressos da área de Educação a Distância e Educação Empreendedora

No que se refere a avaliação, como foi dito as disciplinas são organizadas em módulos e o que consta no PPP ao final de cada módulo, no encontro presencial, será realizado avaliação presencial, bem como, o cumprimento das atividades programadas ao longo das disciplinas, ou seja, estudo do conteúdo e realização de atividades propostas pelo professor de cada disciplina, que serão enviadas e avaliadas pelos tutores, conforme critérios previamente determinados pelos professores especialistas. O processo de avaliação também conta com o trabalho de conclusão de curso (TCC), que é elaborado e apresentado individualmente, com acompanhamento do professor orientador.

E por fim, o evento instrucional também ministrado pela UFSJ, Práticas de Letramento e Alfabetização, com duração de 18 meses e uma carga horária total de 360 horas, entre a carga horária das disciplinas e o TCC. As atividades formativas previstas - atividades web, leitura e encontros presenciais. A Tabela 20 apresenta as disciplinas desenvolvidas, bem como as respectivas cargas horárias. 
Tabela 20. Estrutura e Organização do curso "Práticas de Letramento e Alfabetização".

\begin{tabular}{|c|c|c|}
\hline Disciplina & Tema & $\begin{array}{c}\text { Carga } \\
\text { Horária }\end{array}$ \\
\hline 1 & Introdução a Educação a Distância & 15 \\
\hline 2 & Conceituação e história da alfabetização & 30 \\
\hline 3 & Psicogenética & 30 \\
\hline 4 & Métodos e técnicas de pesquisa & 30 \\
\hline 5 & Alfabetização Matemática & 30 \\
\hline 6 & Alfabetização de Jovens e Adultos & 30 \\
\hline 7 & Alfabetização geo-histórica & 30 \\
\hline 8 & Dificuldades de aprendizagem & 30 \\
\hline 9 & Leitura e produção de textos & 30 \\
\hline 10 & Literatura infantil e alfabetização & 30 \\
\hline 11 & Avaliação no processo de alfabetização & 30 \\
\hline 12 & Didática do Ensino Superior & 30 \\
\hline \multirow[t]{2}{*}{13} & Seminários e Tópicos especiais & 15 \\
\hline & Total & 360 \\
\hline
\end{tabular}

De acordo com o PPP do curso, disponível no site do curso de Práticas de Letramento e Alfabetização (http://pos.nead.ufsj.edu.br/PLA/site/images/pdf/ Projeto pedagógico), na interlocução entre o aluno e o tutor são utilizados mesmos recursos que o curso Mídias na Educação (ambiente virtual, com recursos de fórum, chat, biblioteca virtual, agenda; hipertextos, textos audiovisuais, videoaulas; e-mail, entre outros).

São previstos quatro encontros presenciais onde são realizadas atividades que incluem: apresentação do programa no primeiro encontro (15 horas); avaliação do desempenho discente referente as disciplinas de 1 a 8 (8 horas); avaliação do desempenho discente referente as disciplinas de 9 a 12 (12 horas) e apresentação das monografias (5 horas), totalizando 40 horas de atividades presenciais.

O processo de avaliação contempla dois momentos presenciais, na apresentação da monografia e o cumprimento das atividades programadas ao longo das disciplinas, ou seja, estudo do conteúdo e realização de atividades propostas pelo professor de cada disciplina, que 
serão enviadas e avaliadas pelos tutores, conforme critérios previamente determinados pelos professores especialistas.

\subsection{População e amostras}

O Polo da UAB da cidade de Serrana não forneceu os dados da população de alunos matriculados nas instituições parceiras, tendo justificado que não é realizada tal contabilização e controle sobre os dados sociodemográficos pelo polo. Assim, não foi possível coletar dados referentes à totalidade dos discentes atendidos pelas instituições participantes nem realizar, consequentemente, a comparação entre os perfis da amostra e da população, para verificar semelhanças e eventuais diferenças entre eles.

Durante o processo de coleta de dados foram encaminhados questionários para os 220 discentes matriculados nos cursos pesquisados no Polo da UAB na cidade de Serrana. Assim, a população da presente pesquisa é composta por 220 alunos, sendo: 48 alunos do curso de Administração Pública, 30 alunos do curso de Pedagogia, 20 alunos do curso de Licenciatura em Educação Física, 17 alunos do curso de Licenciatura em Matemática, 30 alunos do curso Gestão em Enfermagem, 25 alunos do curso de Mídias na Educação, 25 alunos do curso Práticas de Letramento e 25 alunos do curso Educação Empreendedora. A amostra considerada para a presente pesquisa é composta pelos estudantes matriculados nos diversos cursos supracitados, que responderam ao questionário sociodemográfico, totalizando 94 alunos (43\% da população) conforme é descrito na tabela 21.

Tabela 21. Composição da População e Amostra por curso.

\begin{tabular}{lccc}
\hline \multirow{2}{*}{ Curso } & \multirow{2}{*}{$\begin{array}{c}\text { Alunos } \\
\text { matriculados }\end{array}$} & \multicolumn{2}{c}{ Questionários respondidos } \\
\cline { 3 - 4 } & & Quantidade & \% \\
\hline Administração Pública & 48 & 24 & $50 \%$ \\
Pedagogia & 30 & 16 & $53 \%$ \\
Educação Física & 20 & 9 & $45 \%$ \\
Matemática & 17 & 0 & $0 \%$ \\
Gestão em Enfermagem & 30 & 13 & $43 \%$ \\
Mídias na Educação & 25 & 16 & $64 \%$ \\
Práticas de Letramento e Alfabetização & 25 & 6 & $24 \%$ \\
Educação Empreendedora & 25 & 10 & $40 \%$ \\
\hline \multicolumn{1}{c}{ Total } & 220 & 94 & $43 \%$ \\
\hline
\end{tabular}

A partir das respostas do questionário sociodemográfico disponibilizado aos participantes do estudo ( $\mathrm{N}=94)$, foi possível delinear um perfil da amostra. Tais dados estão descritos na Tabela 22. 
Tabela 22. Perfil da amostra de alunos dos Cursos de Graduação e Pós-Graduação.

\begin{tabular}{|c|c|c|c|c|c|}
\hline Variável & $\mathbf{F}$ & $\%$ & Variável & $\mathbf{F}$ & $\%$ \\
\hline Curso & & & Renda* & & \\
\hline Administração Pública & 24 & 25,5 & Até 1 & 1 & 1,1 \\
\hline Pedagogia & 16 & 17,0 & 2 a 3 & 37 & 39,4 \\
\hline Educação Física & 9 & 9,6 & 4 a 5 & 27 & 28,7 \\
\hline Gestão em Enfermagem & 13 & 13,8 & 6 a 7 & 19 & 20,2 \\
\hline Mídias na Educação & 16 & 17,0 & Acima de 7 & 10 & 10,6 \\
\hline Práticas de Letramento & 6 & 6,4 & Estado civil & & \\
\hline Educação Empreendedora & 10 & 10,6 & Solteiro (a) & 29 & 30,9 \\
\hline Sexo & & & Casado (a) & 52 & 55,3 \\
\hline Feminino & 62 & 66,0 & Divorciado (a) & 5 & 5,3 \\
\hline Masculino & 32 & 34,0 & Separado (a) & 2 & 2,1 \\
\hline Escolaridade & & & Outro (a) & 6 & 6,4 \\
\hline Ensino Médio Completo & 4 & 4,3 & Composição familiar & & \\
\hline Superior Incompleto & 21 & 22,3 & Tem filhos & 62 & 66,0 \\
\hline Superior Completo & 69 & 73,4 & Não tem filhos & 32 & 8,5 \\
\hline $\begin{array}{l}\text { Idade } \\
20 \text { a } 29\end{array}$ & 10 & 10,6 & $\begin{array}{l}\text { Experiência anterior } \\
\text { com EAD }\end{array}$ & & \\
\hline 30 a 39 & 37 & 39,4 & Sim & 54 & 57,4 \\
\hline 40 a 49 & 34 & 36,2 & Não & 40 & 42,6 \\
\hline Acima de 50 & 13 & 13,8 & Média & 40 & \\
\hline Experiência anterior no & & & Desvio-padrão & 7,89 & \\
\hline uso da internet & & & Moda & 31 & \\
\hline Sim & 86 & 91,5 & Mínimo & 26 & \\
\hline 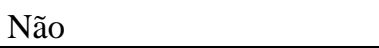 & 8 & 8,5 & Máximo & 57 & \\
\hline
\end{tabular}

A partir das informações coletadas é possível observar que o curso de Administração Pública representa 25,5\% dos alunos que responderam ao questionário em questão. Ainda, as informações mostram que a maioria dos alunos é do sexo feminino $(66,0 \%)$, casados $(55,3 \%)$ e com filhos (66,0\%). Em média, a amostra considerada possui 40 anos de idade (DP =7,89), sendo 31 anos a idade que apareceu com mais frequência, 57 anos a máxima e 26 anos a mínima.

Quanto ao nível de escolaridade, 73,4\% responderam ter o Ensino Superior Completo categoria que pode ter sido mais vezes considerada em razão da metade dos cursos pesquisados serem de pós-graduação com exigência de nível superior para cursá-los. Contudo, essa classificação foi incluída no questionário para elucidar aqueles que já iniciaram um curso universitário, mas não o concluíram. Previa-se que eles escolheriam a alternativa "Ensino Superior Completo", por ser o grau educacional compatível com os requisitos de entrada para a pós-graduação. Esse resultado reforça a hipótese de que profissionais já graduados buscam novas formações como meio de incrementar ou atualizar suas competências laborais e encontram na modalidade EAD a oportunidade de realização já que possuem diversas atribuições e responsabilidades e estão inseridos no mercado de trabalho.

A grande maioria dos respondentes relataram possuir experiência prévia no uso da internet $(91,5 \%)$, demonstrando domínio das ferramentas e instrumentais utilizados nos 
ambientes virtuais, bem como já tiveram experiência anterior com o EAD (57,4\%). A maioria dos respondentes $(39,4 \%)$ declararam contar com uma renda financeira entre dois e três salários mínimos.

Após a apresentação da população e amostra, na próxima seção, serão apresentados os instrumentos de medida da presente pesquisa

\subsection{Instrumentos de medida}

Os instrumentos de medida empregados na investigação são: 1) Estratégias de Aprendizagem (Martins \& Zerbini, 2014); 2) Reação aos Procedimentos Instrucionais em EAD (Martins \& Zerbini, 2015); e 3) Reação de Desempenho ao Tutor (Zerbini \& Abbad, 2009b). Tais instrumentos foram desenvolvidos e validados em estudos precedentes. A seguir, são apresentadas as informações referentes aos dados empíricos obtidos nos estudos correspondentes (Tabela 23).

Tabela 23. Resumo das informações sobre os instrumentos a serem utilizados na pesquisa.

\begin{tabular}{|c|c|c|c|c|c|}
\hline \multirow[b]{2}{*}{ Instrumentos } & \multirow[b]{2}{*}{ Escalas obtidas } & \multirow{2}{*}{$\begin{array}{c}\mathbf{N}^{\mathbf{o}} \\
\text { de } \\
\text { itens }\end{array}$} & \multirow[b]{2}{*}{ Alfa } & \multicolumn{2}{|c|}{ Cargas fatoriais } \\
\hline & & & & Mín. & Máx. \\
\hline \multirow{4}{*}{$\begin{array}{l}\text { Estratégias de aprendizagem } \\
\text { (Martins \& Zerbini, 2014) }\end{array}$} & Estratégias cognitivas & 15 & 0,90 & 0,33 & 0,72 \\
\hline & Controle da emoção & 4 & 0,77 & 0,46 & 0,76 \\
\hline & Estratégias autorregulatórias & 7 & 0,86 & $-0,50$ & $-0,69$ \\
\hline & Busca de ajuda interpessoal & 3 & 0,68 & 0,45 & 0,69 \\
\hline $\begin{array}{l}\text { Reação aos procedimentos } \\
\text { instrucionais em EAD (Martins } \\
\& \text { Zerbini, 2015) }\end{array}$ & $\begin{array}{l}\text { Procedimentos instrucionais em } \\
\text { EAD }\end{array}$ & 17 & 0,96 & 0,67 & 0,88 \\
\hline $\begin{array}{l}\text { Reação ao desempenho do tutor } \\
\text { (Zerbini \& Abbad, 2009b) }\end{array}$ & Desempenho do tutor & 27 & 0,98 & 0,69 & 0,88 \\
\hline
\end{tabular}

Os três questionários acima citados sofreram modificações visando a adequação a contextos de educação superior a distância, especificamente, cursos de graduação, já que nos estudos de origem, Zerbini et al. (2005) e Zerbini (2007), os instrumentos foram aplicados em cursos profissionalizantes e gratuitos, de alcance nacional (Martins, 2012). No Capítulo 5 são presentados os resultados das adequações dos instrumentos para a presente pesquisa.

\subsection{Considerações éticas}

O projeto de pesquisa foi submetido à aprovação do Comitê de Ética em Pesquisa da Faculdade de Filosofia, Ciências e Letras de Ribeirão Preto (FFCLRP-USP). Após a aprovação, o polo de Serrana da UAB foi contatado, sendo seu coordenador esclarecido sobe os objetivos da pesquisa e os procedimentos que seriam utilizados. Mediante sua autorização, foi possível a 
realização da pesquisa e iniciou-se os procedimentos de coleta de dados junto a instituição parceira.

Devido a pesquisa ser realizada online, previamente à aplicação dos questionários, era apresentado aos participantes um Termo de Consentimento Livre e Esclarecido (Anexo C), aprovado pelo Comitê de Ética em questão, que assegurava a manutenção de sigilo e anonimato acerca de sua identidade, o caráter de sua participação voluntária, bem como solicitava a autorização do uso de suas informações no estudo. Para prosseguir com as respostas dos questionários, o participante deveria assinalar "Eu concordo". Caso ele optasse pela opção "Não concordo", uma nova tela aparecia, agradecendo e encerrando sua participação na pesquisa.

\subsection{Procedimentos de coleta de dados}

O desenvolvimento da presente pesquisa inclui a apresentação e a testagem de um modelo de avaliação de ações educacionais ofertadas a distância com o objetivo de identificar variáveis preditoras de estratégias de aprendizagem relacionadas às características clientela e às reações ao curso. Para o cumprimento de tal objetivo, foram aplicados questionários aos estudantes matriculados em variados programas de EAD (cursos de graduação e extensão) das instituições de ensino superior parceiras. Tais questionários foram utilizados como instrumentos de medida, destinados ao levantamento das características sociodemográficas dos discentes, das estratégias de aprendizagem utilizados por eles durante o desenvolvimento do curso, e a satisfação com os procedimentos instrucionais e com o desempenho do tutor.

Devido a diferença nos calendários institucionais das instituições parceiras, não foi possível realizar a coleta de dados em um único momento. Em razão do encerramento das atividades do curso de Administração Pública da USFJ, a coleta de dados do referido curso foi realizada no período entre 11 e 31 de dezembro de 2015. A aplicação dos questionários aos demais cursos (Licenciatura em Educação Física e Matemática, Pedagogia, Mídias na Educação, Educação Empreendedora, Gestão em Enfermagem e Práticas de Letramento) ocorreu durante os dias 01 e 31 de março de 2016.

O procedimento de coleta de dados foi realizado parcialmente a distância, por meio da internet, através da qual os instrumentos digitalizados ficaram hospedados em uma página da internet (Google Docs) e disponível para os discentes nos períodos acima citados. Os questionários foram disponibilizados por meio de um link (endereço eletrônico) para os tutores, acompanhado por uma carta de apresentação do questionário (Anexo D) explicando o objetivo da pesquisa e as orientações para a coleta de dados, bem como a importância da participação 
dos alunos para o desenvolvimento da pesquisa. O coordenador do polo encaminhou aos discentes, por e-mail, o link para o acesso ao questionário acompanhado por uma carta (Anexo E) que informava sobre a parceria de pesquisa, o objetivo e importância da sua participação. Para responder o questionário, o aluno, bastava clicar no link que acompanhava o $e$-mail e este encaminhava o aluno ao questionário hospedado em uma página da internet (Google Docs) para a coleta eletrônica dos dados. As instruções, aos alunos, para o preenchimento do questionário foram realizadas pelos tutores dos cursos, pelo coordenador do polo, bem como na apresentação do questionário disponível na referida página da internet. Ao clicar sobre o link indicado e este redirecionava o estudante diretamente aos questionários $-1^{\mathrm{a}}$ Etapa: Questionário 1 "Sociodemográfico"; 2a Etapa: Questionário 2 "Estratégias de Aprendizagem"; 3" Etapa: Questionário 3 "Procedimentos Instrucionais"; e 4 Etapa: Questionário 4 "Desempenho do Tutor". Automaticamente as informações dos questionários respondidos eram armazenadas em uma planilha eletrônica que, posteriormente, deu subsídios para a tabulação dos dados da pesquisa.

Com o objetivo de aumento dos índices de retorno dos questionários, foram empregados esforços para aprimorar os procedimentos de coleta de dados pela internet. Neste sentido, houve investimento nos contatos com o Coordenador do Polo da UAB de Serrana, o qual semanalmente, durante os períodos de coleta de dados, encaminhou e-mails para os alunos solicitando a participação na pesquisa por meio do preenchimento dos questionários hospedados em endereço da internet. Bem como, em dois momentos de atividade presencial, os instrumentos foram aplicados pelo coordenador do polo, na forma impressa, para alunos que participaram de avaliação de aprendizagem presencial. Posteriormente as respostas aos instrumentos de medida foram digitalizadas e integradas ao banco de dados pelo pesquisador. A coleta de dados presencial resultou na participação de 12 alunos, sendo seis alunos do curso de Administração Pública, coletados no dia 12 de março de 2016 e seis alunos do curso de Mídias na Educação, coletados no dia 19 de março de 2016. O índice de retorno dos questionários respondidos pode ser visualizado na Tabela 24 e na Figura 8. 
Tabela 24. Índice de retorno dos questionários na coleta de dados

\begin{tabular}{|c|c|c|c|c|c|c|c|c|c|}
\hline \multirow[b]{2}{*}{ Curso } & \multirow{2}{*}{$\begin{array}{c}\text { Alunos } \\
\text { matriculados }\end{array}$} & \multicolumn{8}{|c|}{ Retorno Questionários (Instrumentos) } \\
\hline & & $\begin{array}{l}\text { Sóciodemo- } \\
\text { gráficos }\end{array}$ & $\begin{array}{c}\% \\
\text { Retorno } \\
\end{array}$ & $\begin{array}{c}\text { Estratégias } \\
\text { Aprendizagem }\end{array}$ & $\begin{array}{c}\% \\
\text { Retorno }\end{array}$ & $\begin{array}{l}\text { Desempenho } \\
\text { Tutor } \\
\end{array}$ & $\begin{array}{c}\% \\
\text { Retorno }\end{array}$ & $\begin{array}{l}\text { Procedimentos } \\
\text { Instrucionais }\end{array}$ & $\begin{array}{c}\% \\
\text { Retorno }\end{array}$ \\
\hline Adm. Pública & 48 & 24 & $50 \%$ & 21 & $44 \%$ & 21 & $44 \%$ & 20 & $42 \%$ \\
\hline Matemática & 17 & 0 & $0 \%$ & 0 & $0 \%$ & 0 & $0 \%$ & 0 & $0 \%$ \\
\hline Pedagogia & 30 & 16 & $53 \%$ & 14 & $47 \%$ & 14 & $47 \%$ & 13 & $43 \%$ \\
\hline Educação Física & 20 & 9 & $45 \%$ & 11 & $55 \%$ & 9 & $45 \%$ & 10 & $50 \%$ \\
\hline Gestão Enfermagem & 30 & 13 & $43 \%$ & 11 & $37 \%$ & 10 & $33 \%$ & 9 & $30 \%$ \\
\hline Mídias na Educação & 25 & 16 & $64 \%$ & 15 & $60 \%$ & 14 & $56 \%$ & 14 & $56 \%$ \\
\hline Práticas de Letramento & 25 & 6 & $24 \%$ & 5 & $20 \%$ & 5 & $20 \%$ & 5 & $20 \%$ \\
\hline Educação Empreendedora & 25 & 10 & $40 \%$ & 6 & $24 \%$ & 5 & $20 \%$ & 6 & $24 \%$ \\
\hline Total & 220 & 94 & $43 \%$ & 83 & $38 \%$ & 78 & $35 \%$ & 77 & $35 \%$ \\
\hline
\end{tabular}

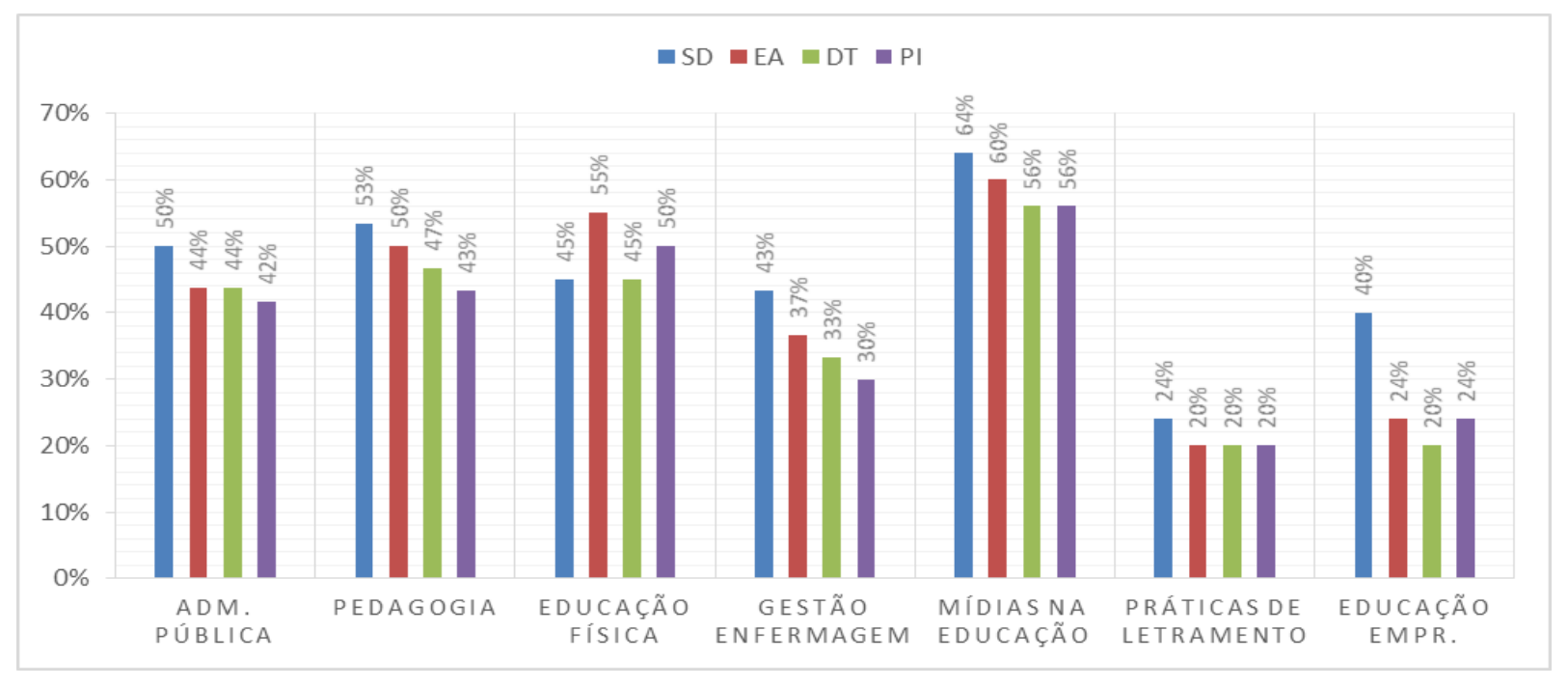

Figura 8. Porcentagem de questionários respondidos por curso na coleta de dados. 
Considerando a entrada de 880 questionários (quatro por aluno), contemplados pelas escalas de Estratégias de Aprendizagem, Reações ao Desempenho do Tutor e Procedimentos Instrucionais e aos Dados Sociodemográficos, o retorno foi de 332 questionários, o que representa um índice de retorno total de $38 \%$.

A variação do retorno entre os questionários respondidos foi entre $35 \%$ e $43 \%$. Foi possível perceber que o questionário de dados sociodemográficos foi o que apresentou maior número de respondentes (94 questionários, 43\%), seguido dos questionários Estratégias de Aprendizagem (83 questionários, 38\%), de Reação ao Desempenho do Tutor (78 questionários, $35 \%$ ) e Procedimentos Instrucionais (77 questionários, 35\%). Provavelmente o ocorrido se deu pela ordem de disponibilização dos questionários no formato online, ordem esta que seguia a sequência de questionários descrita anteriormente, do maior número de respostas para o menor. Possivelmente, os respondentes consideraram a existência de muitos itens nos questionários em sequência, bem como o aumento do nível de complexidade dos mesmos, deixando de responder os últimos. Os questionários Desempenho do Tutor e Procedimentos Instrucionais foram os menos respondidos, o que pode sugerir que os alunos evitam avaliar formalmente o tutor, com receio de identificação. O mesmo fenômeno foi observado em pesquisas anteriores (Carvalho \& Abbad, 2006; Martins, 2012; Zerbini \& Abbad, 2005; 2010b).

As respostas aos instrumentos de medida foram digitalizadas e integradas ao banco de dados. Finalizado o processo de coleta de dados, e obtida uma amostra estatisticamente significativa, as informações foram enviadas para o SPSS (Statistical Package for the Social Science) versão 21.0 - software que viabilizou as análises do material coletado. Após o pareamento das respostas de cada discente aos respectivos questionários, teve início os procedimentos de análise de dados, expostos a seguir

\subsection{Procedimentos de análise de dados}

Primeiramente, foram realizadas análises descritivas (média, desvio-padrão, moda, mínimo e máximo) e exploratórias com o objetivo de investigar a exatidão da entrada dos dados, a presença de casos extremos, a distribuição de frequência das variáveis e o tamanho das amostras. Vale ressaltar que devido a obrigatoriedade de responder todos os itens do instrumento não houve casos omissos. Após esse momento, foram realizadas as análises 
diretamente relacionadas ao alcance dos objetivos desta pesquisa. A seguir, apresentam-se os procedimentos das análises ${ }^{1}$.

\subsubsection{Procedimentos de análises exploratórias das estruturas empíricas dos questionários}

Para a validação dos instrumentos foram realizadas análises no SPSS versão 21.0. Foram realizadas análises exploratórias para identificação de casos extremos; univariados e multivariados, multicolinearidade, singularidade e linearidade, de acordo com as orientações de Tabachnick e Fidell (2007), vale lembrar que não houve casos omissos devido a obrigatoriedade de responder todos os itens do questionário para o seu envio via internet. Os testes de normalidade das distribuições de frequência não foram realizados, de acordo com Pasquali (2004), a normalidade não é um problema grave na análise fatorial exploratória, pois essa técnica é robusta à violação desse pressuposto, suportando desvios da normalidade.

Tabachnick e Fidell (2007) orientam que todas as variáveis sejam transformadas em escores Z para a identificação de casos extremos univariados. De acordo com os autores, os casos extremos univariados são respostas que destoam do conjunto de respostas em uma única variável. Assim, para a identificação dos casos extremos univariados, todas as variáveis foram transformadas em escores $\mathrm{Z}$, e foram excluídas aquelas respostas cujos escores padronizados eram iguais ou superiores a 3,29 ( $\mathrm{p}<0,001$, two-tailed $)$. Os casos extremos multivariados são definidos pelos autores como valores resultantes de uma combinação anormal de escores em duas ou mais variáveis. Os mesmos foram identificados a partir da distância Mahalanobis distância de um caso do centro do restante dos casos, quando o centro é o ponto criado pelas médias de todas as variáveis $-(\alpha=0,001)$ e, posteriormente, excluídos.

Na sequência, iniciaram-se as análises fatoriais exploratórias dos dois instrumentos, seguindo as orientações de Pasquali (2004), a saber: a) coleta da informação através de pesquisa empírica; b) elaboração da matriz de covariância; c) análise da matriz de covariância em termos de fatorabilidade e do número de fatores; d) extração inicial dos fatores; e) rotação dos fatores para uma estrutura final; f) interpretação dos fatores; g) construção dos escores fatoriais para uso em análises futuras.

Para elaborar a matriz de covariância foram seguidas as orientações de Pasquali (2004), que recomenda:

\footnotetext{
${ }^{1}$ Os procedimentos de análises de dados, bem como os autores supracitados, são retirados de Zerbini (2007), que que descreve detalhadamente as informações necessárias para nortear cada etapa do processo de análise de dados, conferindo rigor aos procedimentos adotados.
} 
a) Tipos de coeficientes de correlação: utilizar as correlações bivariadas paramétricas de Pearson, pois é o tipo mais adequado de matriz de covariâncias para análise fatorial;

b) Tamanho da amostra: considerar 10 casos para cada variável observável;

c) Normalidade e Linearidade: como dito anteriormente, não é um problema grave na análise fatorial exploratória, uma vez que a análise é robusta contra este problema e suporta desvios da normalidade, assim, não foi realizado teste de normalidade. Já a linearidade afeta a análise fatorial, uma vez que as correlações consistem em medidas de relações lineares. Para a análise da linearidade foram realizadas correlações bivariadas, considerando o coeficiente de correlação produto-momento de Pearson - valores diferentes de 0 (zero) e significativos indicam a presença de uma relação linear, considerada forte quanto mais próxima de 1 (um) for o coeficiente obtido;

d) Multicolinearidade e Singularidade - as variáveis com multicolinearidade são tão correlacionadas que parecem sinônimos. Nesse caso, uma das variáveis deve ser eliminada da análise. Já as variáveis que apresentam singularidade são redundantes, ou seja, uma variável é a combinação de duas ou mais variáveis. Para a analisar a multicolinearidade e singularidade, verifica-se a existência de correlações superiores a 0,90 .

Para a análise da matriz de covariância em termos de fatorabilidade, ou seja, verificar se de fato tem covariância, e do número de fatores, foi realizado os seguintes passos:

a) Análise do tamanho das correlações - foi considerado uma correlação importante quando o valor obtido estava acima de 0,30 , positivo ou negativo. A matriz podia ser fatorizável quando os valores de correlações acima de 0,30 ultrapassavam 50\% dos casos;

b) Teste de adequação da amostra de Kaiser-Meyer-Olkin (KMO) - foi analisado as correlações parciais das variáveis, que quanto mais próximo do valor 1 for esta estatística, mais a matriz é fatorável, pois indica que as variáveis têm muita variância em comum.

A extração inicial dos fatores foi realizada a partir da análise dos componentes principais (Principal Components - PC). A PC tem como objetivo reduzir o número de variáveis em componentes que expliquem a maior parte da variância original das variáveis. Essa técnica analisa os componentes mais importantes e define o número mínimo de fatores a serem 
inicialmente extraídos. Para definir o número de componentes na PC, foram utilizados os seguintes critérios:

a) Critérios convencionais - foram considerados apenas os valores próprios (eigenvalues) superiores a 1 (um); e foi analisada a distribuição visual dos valores próprios, o scree plot, nessa análise é possível avaliar o ponto de corte por meio da forma de curva resultante, os pontos que representam os componentes passam de uma inclinação acentuada para uma inclinação quase horizontal; é nesse ponto de mudança que se considera o número máximo de fatores a serem extraídos;

b) Critérios estatísticos (testes de significância) - foi realizada a análise paralela de Horn, nessa análise foram comparados valores próprios empíricos, obtidos pela análise da PC, com valores próprios aleatórios, obtidos com o auxílio do software RanEign, em função da quantidade de variáveis e do tamanho da amostra. Os fatores são retirados da estrutura quando apresentam valor próprio empírico igual ou menor que os valores aleatórios. De acordo com Laros (2004), a análise apresenta índice de precisão de $92 \%$ de indicação correta do número de fatores, sendo o melhor método para definição de número de fatores de uma matriz de respostas a questionários;

c) Critérios de relevância do fator - foram realizadas análises de interpretabilidade, importância e consistência dos fatores após a rotação dos fatores. A importância do fator é definida pela variância que consegue explicar após a rotação da matriz fatorial. $\mathrm{O}$ critério de Harman considera um fator irrelevante aquele que explica menos do que $3 \%$ da variância total das variáveis. A validade do fator é expressa pelo tamanho das cargas fatoriais, ou seja, quanto maiores elas forem, mais a variável é representativa do fator. Contudo, um fator pode ser válido, porém pode não ser consistente, por isso, também foram feitas análises de consistência dos fatores, por meio da análise de Alfa de Cronbach.

Com o objetivo de confirmar as estruturas fatoriais, foram realizadas análises fatoriais utilizando o método de fatoração dos eixos principais (Principal Axis Factoring - PAF). Tal método verifica a covariância entre as variáveis, ou seja, a variabilidade que as variáveis possuem em comum. A PAF, apesar de utilizar os mesmos procedimentos da PC, substitui o valor 1 da PC por uma estimativa das comunalidades na diagonal da matriz, uma vez que a variabilidade que interessa para esse método é a variabilidade que as variáveis têm em comum, isto é, a covariância entre elas (modelo causal). 
A análise da estabilidade foi realizada por meio da verificação de quanto os itens eram bons representantes do fator, pelo tamanho da carga fatorial, que é a correlação entre o item com o conjunto dos outros itens do fator (quanto mais próxima de 1 for esta carga, melhor representa o fator). Para analisar a interpretabilidade, identificou-se o traço latente que é considerado a causa do agrupamento das variáveis, por meio da análise da literatura da área. Os escores fatoriais foram produzidos pela média dos escores das variáveis originais que pertencem ao fator.

\subsubsection{Procedimentos de análise dos testes de Regressão Múltipla, ANOVA e Testes $t$.}

Após as análises fatoriais exploratórias, foram produzidos os escores fatoriais a partir da média das variáveis originais dos fatores. Tais escores foram utilizados para nas análises de regressão múltipla padrão, realizada com o intuito de identificar e investigar os principais preditores da variável Estratégias de Aprendizagem, medida em termos da média das respostas dos participantes aos itens que compõem a escala de elementos ligados às estratégias de aprendizagens utilizadas pelo discente de cursos em EAD. As ANOVAS e Testes $t$ foram realizadas para complementar as informações obtidas no processo de validação estatísticas das escalas utilizadas.

De acordo com as recomendações de Tabachnick e Fidell (2007) as análises de regressão devem respeitar os seguintes critérios de inclusão para análise: amostra maior ou igual a 50 casos mais oito vezes o número de variáveis antecedentes $(\mathrm{N} \geq 50+8 \mathrm{~m})$ para testar correlações múltiplas e $\mathrm{N} \geq 104+\mathrm{m}$, para testar preditores individuais. No presente estudo, conforme citado no item 4.7, somente 77 casos permaneceram no banco de dados, o que limitou as análises de regressão. Mais detalhes sobre o tamanho da amostra são descritos no capitulo 5.

Para essa etapa de análise foi utilizado o arquivo de dados completo, contendo o modelo multivariado com as seguintes variáveis pareadas: sociodemográficas, estratégias de aprendizagem, reação aos procedimentos instrucionais e reação ao desempenho do tutor. O banco de dados obtido foi submetido a análises exploratórias, sendo observados os casos extremos univariados e multivariados, multicolinearidade, singularidade e linearidade segundo orientações de Tabachnick e Fidell (2007). Como explicado anteriormente não se encontra casos omissos no presente estudo. Para identificação dos casos extremos univariados todas as variáveis foram transformadas em escores $\mathrm{Z}$ e excluídas todas as respostas cujos escores padronizados eram iguais ou superiores a 3,29 ( $\mathrm{p}<0,001$, two-tailed). Os casos extremos multivariados foram identificados a partir da distância Mahalanobis $(\alpha=0,001)$ e, 
posteriormente, excluídos. Após obtidos os escores fatoriais dos instrumentos, os mesmos foram submetidos à uma correlação bivariada, sendo consideradas para análise as correlações significativas, considerando $\mathrm{p}<0,01$. Foram consideradas as correlações maiores que 0,30 . $\mathrm{O}$ mesmo banco de dados foi utilizado para o cálculo da ANOVA e do Teste t.

Os critérios relativos à normalidade univariada e cálculos utilizados para definição do tamanho da amostra diferem dos usados nas análises fatoriais exploratórias. Diferente da análise fatorial exploratória, as análises multivariadas são afetadas pelo pressuposto da normalidade, que deve ser avaliada por meio de índices estatísticos ou métodos gráficos (frequências com histogramas e curva normal), sendo os dois componentes de análise, a assimetria (skewness) e a curtose (kurtosis). Uma vez que não foram encontradas diferenças nas análises com e sem transformação das variáveis com assimetria/curtose em algumas pesquisas (Tamayo, 2002; Sant'anna, 2002; Lacerda \& Abbad, 2003; Meneses \& Abbad, 2003; Zerbini \& Abbad, 2005; Carvalho \& Abbad, 2006), decidiu-se por não realizar transformações dessas variáveis.

Seguindo os mesmos critérios referidos na seção anterior os casos extremos univariados e multivariados foram retirados do arquivo de dados, foram identificadas relações lineares entre as variáveis utilizadas nas regressões (linearidade), e não houve singularidade e multicolinearidade entre elas, bem como se seguiu as recomendações de Tabachnick e Fidell (2007) nas análises de regressão (critérios de inclusão para análise: amostra maior ou igual a 50 casos mais oito vezes o número de variáveis antecedentes $-\mathrm{N} \geq 50+8 \mathrm{~m}$ ).

Após ser apresentado o método utilizada no presente estudo, o próximo capítulo trata da apresentação os resultados de adaptação e validação dos instrumentos, análises descritivas, exploratórias fatoriais e de relacionamento entre as variáveis. 


\section{CAPÍTULO 5. RESULTADOS}

\section{Objetivos do capítulo 5}

O objetivo deste capítulo é apresentar os resultados do presente estudo, resultante do processo de adaptação dos instrumentos de medida, bem como, e a adaptação e a validação semântica e por juízes do Instrumento Roteiro de Análise de Cursos - EAD; das análises descritivas e validação estatística dos Instrumentos Estratégias de Aprendizagem, Reações aos Procedimentos Instrucionais e Reações ao Desempenho do Tutor e da aplicação dos testes de Regressão Múltipla, ANOVA e Teste t.

\subsection{Adaptação e validação dos instrumentos de medida}

Entre os instrumentos que foram aplicados à amostra do presente estudo, o instrumento "Estratégias de Aprendizagem" (Anexo G) de Martins e Zerbini (2014) foi derivado da escala proposta por Zerbini et al. (2005). As autoras efetuaram modificações na referida ferramenta a fim de também adaptá-la a cenários educacionais de nível superior na modalidade de ensino a distância, assim, se apresenta no mesmo contexto do presente estudo e não necessitou de adaptação ou alteração, sendo utilizado sem alterações.

O instrumento Reação aos Procedimentos Instrucionais de Zerbini e Abbad (2009a) foi alterado por Martins (2012) (Anexo H), com o objetivo de adequação das terminologias utilizadas no contexto universitário e o instrumento que original que continha 15 itens, ficou com 17 ao final do processo de adaptação. No presente estudo o instrumento de Martins (2012) passou pelas seguintes alterações: o termo unidades dos itens: "3. Sequência de apresentação das unidades"; "8. Atividades/tarefas propostas ao final de cada unidade"; "10. Quantidade de conteúdo para cada unidade"; e "11. Quantidade de horas de estudo sugerida para cada unidade" foi substituído pelo termo disciplinas, por se tratar de avaliação de curso e não de disciplinas. Do mesmo modo, no instrumento de Reação ao Desempenho do Tutor (Anexo I) de Zerbini e Abbad (2009b) teve a substituição do termo chats e listas de discussão para fóruns, como sugerido por Martins (2012), o instrumento permaneceu com o mesmo número, ou seja, 27 itens. Martins e Zerbini (2014) realizaram a verificação das evidências de validade de dois instrumentos de medida. As autoras realizaram Análises Fatoriais Exploratórias e de consistência interna. Os escores analisados apontaram para as evidências de validade estrutural em ambas escalas, que apresentam estruturas empíricas unifatoriais: 1) "Procedimentos Instrucionais em EAD" ( 17 itens, $\alpha=0,96$ e cargas fatoriais entre 0,60 e 0,86); e 2) "Desempenho do Tutor" (27 itens, $\alpha=0,98$ e cargas fatoriais entre 0,67 e 0,88). Ainda as autoras recomendam 
a aplicação dos instrumentos em contextos e amostras diferentes, em futuras pesquisas. Para levantar os dados pessoais dos participantes da pesquisa foi construído um instrumento com o objetivo de caracterizar e traçar um perfil da amostra de estudantes que participam de cursos de graduação a distância (Anexo J).

Os cursos ofertados pela instituição parceira foram analisados a partir do Instrumento Roteiro de Análise de Cursos de Graduação - EAD (Anexo F). Tal instrumento foi adaptado do "Roteiro de Análise do Material Didático - EAD" desenvolvido por Zerbini (2003) e Carvalho (2003) utilizado para avaliar a qualidade dos materiais instrucionais de disciplinas e cursos de curta duração, para que fosse possível avaliar cursos de graduação ofertados a distância.

Para a adaptação, foram consultados trabalhos científicos na literatura especializada e documentos oficiais de normatização para cursos superiores. O Instrumento de Zerbini e Carvalho (2003), com 39 itens, sofreu alterações na redação dos itens, novos foram incluídos e outros excluídos e a nova versão para análise de cursos ficou com 31 itens e foi submetida à validação semântica e por juízes.

\section{Validação semântica e por juízes}

Os itens foram submetidos à validação semântica por sete alunos de graduação que avaliaram os itens quanto à precisão, clareza e objetividade, bem como a adequação das instruções do roteiro. A partir da análise e avaliação das sugestões os itens foram reelaborados. A versão final do Roteiro de Análise de Cursos de Graduação - EAD foi submetida à validação por juízes, que consistiu na avaliação por dois coordenadores de cursos de graduação, sendo um de uma IES pública e outro de uma IES privada na adequação do instrumento produzido quanto: a revisão dos itens e análise da necessidade de incluir ou excluir itens. A seguir são apresentados os resultados da validação semântica e por juízes do instrumento em questão, pertencente a cada grupo de itens do instrumento: 1) características do curso; 2) objetivos instrucionais; 3) adequação das estratégias instrucionais, 4) exercícios; 5) planejamento de atividades; 6) sequenciação do ensino; 7) fontes de informações (bibliografia e outros meios) e, por fim, 8) informações gerais sobre o curso. 


\section{Características do curso}

$\mathrm{Na}$ caracterização do curso, o item cuja grafia original era " Carga horária diária sugerida" foi alterado para "Carga horária mínima sugerida pelas DCNs (Diretriz Curricular Nacional) do curso" visto que todo curso possui uma carga horária mínima sugerida pela legislação vigente. Na sequência o item "Carga horária total sugerida” foi alterado para "Carga horária do curso", com o objetivo de adequação do item para análise de curso, bem como analisar a carga horária ofertada no curso com a carga horária mínima sugerida pela legislação vigente.

\section{Objetivos Instrucionais}

Os itens que remetiam a análise dos objetivos instrucionais não sofreram alterações e forma mantidos tanto pela validação semântica e por juízes.

\section{Adequação das Estratégias Instrucionais}

Pequenos ajustes foram realizados no item 6 "Adequação das estratégias instrucionais às características da clientela (escolaridade, cargo) ", a palavra cargo foi excluída, pois o instrumento objetiva a análise de curso de graduação devendo estar adequado somente a escolaridade mínima exigida e foi questionado a palavra cargo. Após a exclusão o item fícou “Adequação das estratégias instrucionais às características da clientela (escolaridade)". O item 11 "Formação de exemplos que ilustrem, dentro do contexto de trabalho dos participantes, os conteúdos apresentados", foi reformulado visando a adequação do mesmo ao ensino superior para "Formação de exemplos que ilustrem, na atuação profissional dos participantes no curso oferecido".

\section{$\underline{\text { Exercícios }}$}

Os Itens que se referem a análise dos exercícios foram excluídos porque, de acordo com os especialistas, não se aplicam a análise de curso e sim ao material didático.

\section{Planejamento de Atividades}

O título dos itens "Planejamento de Atividades" foi alterado para "Planejamento de Curso" por se tratar da análise de curso não realizando a análise das atividades das disciplinas. Os itens que compõe a análise do "Planejamento de Curso" foi o que mais apresentou necessidade de ajustes e adaptação, três itens foram ajustados e dois excluído. A partir deste 
item, a numeração dos itens foi alterada devido a exclusão dos itens que remetiam a análise de exercícios. Assim, a numeração aqui apresentada já se encontra no instrumento adaptado.

O item 16 (anterior 22) “Adequação da carga horária sugerida com relação ao volume dos conteúdos apresentados” sofreu alteração na redação passando para “Adequação da carga horária sugerida com relação ao volume das disciplinas apresentadas". A palavra participante foi questionada pelos especialistas nos itens 17 e 18 (anterior 23 e 24), sugerindo a alteração para a palavra aluno por ser mais adequada para cursos de formação acadêmica, assim, o item 17 "Informação ao participante da estimativa de tempo a ser gasto em cada módulo" passou para "informação ao aluno da estimativa de tempo a ser gasto em cada módulo/período por disciplina.", e também foi sugerido a complementação das palavras periodo por disciplina, no item 18 além da alteração da palavra participante para aluno, foi inserido as palavras teóricas e disciplinas ("Informação ao aluno da estimativa de tempo a ser gasto com as atividades teóricas e práticas de cada disciplina”).

Os itens originais, 29 "Adequação das avaliações de aprendizagem aos conteúdos" e 30 "Exigência de uma menção final mínima para a conclusão do curso" foram excluídos, o primeiro por não se aplicar a avaliação de curso e o segundo por ser exigido uma nota mínima para conclusão de cursos de graduação e especialização.

\section{$\underline{\text { Sequenciação do Ensino }}$}

Nos itens: 25 (anterior 33) "Seqüenciação adequada dos conteúdos dentro de cada módulo" e 26 (anterior 34) "Seqüenciação adequada dos conteúdos atinge o nível de complexidade dos objetivos do curso" a palavra conteúdos foi substituída por disciplina pois o instrumento analisará disciplinas e não conteúdo.

\section{Fontes de Informação: Bibliografia e outros meios}

No item 27 (anterior 36) "Utilização de bibliografia atualizada (década de $90 \mathrm{em}$ diante)", foi inserido a palavra básica e o período foi questionando pelos especialistas, sugerindo uma bibliografia mais recente dos últimos 5 anos, portanto o item foi alterado para “Utilização de bibliografia básica atualizada (últimos cinco anos)”.

No item 28 (anterior 37) "Indicação de fontes alternativas de informações sobre os temas tratados no treinamento (livros, periódicos, sites, etc.)" foi alterado para "indicação de bibliografia complementar sobre os temas tratados na disciplina (livros, periódicos, sites etc.)" por se tratar de curso de formação acadêmica e não de treinamento. 


\section{Informações gerais sobre o curso}

Os especialistas sugeriram a inclusão de um item sobre o Projeto Político Pedagógico do curso, assim foi incluído o item 31 "Acesso ao PPP (Projeto Político Pedagógico) do curso"

A partir da análise do curso por meio do roteiro de análise de cursos a cima citado, foi possível avaliar os seguintes aspectos no conjunto de disciplinas dos cursos: os objetivos instrucionais, a adequação das estratégias instrucionais, o planejamento do curso, a sequenciação do ensino, as fontes de informações (bibliografia e outros meios) e as informações gerais sobre o curso. Vale ressaltar que todas as informações para o roteiro de análise dos cursos foram extraídas do Projeto Político Pedagógico (PPP) e nos sites dos cursos em questão, bem como em documentos oficiais.

No que se refere aos objetivos instrucionais, em todos os cursos analisados, estão descritos em termos de desempenhos observáveis, há precisão na escolha do verbo de ação quanto à descrição do comportamento esperado do aluno, clareza na descrição do objeto, bem como a definição clara das condições para realização dos comportamentos esperados, destacando-se os cursos de Matemática e Educação Física.

As estratégias instrucionais se apresentam adequadas às características da clientela (nível médio para os cursos de graduação e nível superior para os cursos de extensão), à natureza dos objetivos instrucionais (todos do domínio cognitivo) e ao nível de complexidade dos objetivos instrucionais. Segundo a taxonomia proposta por Bloom e cols. (1972a e 1972b), descrita também em Rodrigues Jr. (2006), grande parte dos objetivos do curso enquadra-se nos três primeiros níveis da taxonomia do domínio cognitivo: conhecimento, compreensão e aplicação. Em todas as disciplinas, são utilizados recursos de apoio à aprendizagem (fórum, chats, plantões de dúvidas).

Os programas de ensino são disponibilizados com a carga horária das disciplinas e as avaliações de aprendizagem. Assim, a carga horária se apresenta adequada ao volume das disciplinas apresentadas nos quatro cursos analisados. O programa, contém informações sobre os meios de interação e a descrição das avaliações de aprendizagem. Na análise do PPP verificou-se diversidade nas avaliações de aprendizagem e a possibilidade de integração entre os alunos dos cursos.

A sequenciação do ensino é adequada na maioria dos casos, as disciplinas se apresentam por ordem de complexidade e bem articuladas entre os módulos ou períodos. As $\underline{\text { fontes bibliográficas }}$ das disciplinas são disponibilizadas nos PPP e se apresentam 
desatualizadas na maioria dos cursos, sendo inferior aos últimos cincos anos. Todos os cursos apresentam informações gerais e dão acesso ao PPP por meio dos sites.

A Tabela 25 apresenta de forma resumida o resultado da análise dos cursos ofertados pelas instituições parceiras a partir do Instrumento Roteiro de Análise de Cursos de Graduação - EAD.

Tabela 25. Resumo análise dos cursos ofertados pelas IES parceiras.

\begin{tabular}{c|l}
\hline Itens & \multicolumn{1}{c}{ Análise } \\
\hline \hline Objetivos Instrucionais & $\begin{array}{l}\text { Grande parte dos objetivos instrucionais está descrita em termos de } \\
\text { desempenhos observáveis e há clareza na descrição e precisão do verbo de ação; }\end{array}$ \\
\hline $\begin{array}{c}\text { Estratégias } \\
\text { Instrucionais }\end{array}$ & $\begin{array}{l}\text { Se apresentam adequadas às características da clientela, à natureza dos objetivos } \\
\text { instrucionais e ao seu nível de complexidade; }\end{array}$ \\
\hline $\begin{array}{c}\text { Programas de Ensino } \\
\text { Aequenciação de } \\
\text { Ensino }\end{array}$ & $\begin{array}{l}\text { A carga horaria se apresenta adequada ao volume de disciplinas e o programa } \\
\text { Administração Pública; }\end{array}$ \\
\hline $\begin{array}{c}\text { Fontes de Informação } \\
\text { Adormaços sobre os meios de interação e avaliação; }\end{array}$ & $\begin{array}{l}\text { Em menos da metade dos casos as fontes bibliográficas são dos últimos cinco } \\
\text { anos; }\end{array}$ \\
\hline
\end{tabular}

A partir da construção do Instrumento Roteiro de Análise de Cursos de Graduação EAD foi possível realizar a análise dos cursos ofertados pela UAB no polo de Serrana, por meio da coleta de dados em documentos dos referidos cursos (PPP), documentos oficiais (DCN), no site das IES e informações institucionais. A próxima seção apresenta as análises descritivas das variáveis do presente estudo.

\subsection{Análises descritivas}

Nesta seção, são apresentados os resultados descritivos de cada variável do modelo de investigação. São discutidos o valor das médias, desvio-padrão, modas, mínimo, máximo e a concentração das respostas dadas pelos participantes às variáveis estudadas.

\subsubsection{Estratégias de aprendizagem}

O questionário Estratégias de Aprendizagem mensura a frequência de uso de capacidades cognitivas, habilidades comportamentais, monitoramento da compreensão e controle da ansiedade e da motivação pelos alunos, para controlar os próprios processos psicológicos de aprendizagem durante o curso. O instrumento é formado por 29 itens associados a uma escala de frequência de varia de 0 (Nunca) a 10 (Sempre). Os valores máximo e mínimo 
foram omitidos, uma vez que todos os itens apresentaram valores iguais a dez e zero, respectivamente. Os resultados descritivos de seus itens podem ser visualizados na Tabela 26.

Tabela 26. Resultados descritivos de Estratégias de Aprendizagem.

\begin{tabular}{|c|c|c|c|c|c|c|c|c|}
\hline \multirow[t]{2}{*}{ Itens } & \multirow[t]{2}{*}{ Média } & \multirow{2}{*}{$\begin{array}{l}\text { Desvio } \\
\text { Padrão }\end{array}$} & \multirow[t]{2}{*}{ Moda } & \multirow[t]{2}{*}{ Mín. } & \multirow[t]{2}{*}{ Máx. } & \multicolumn{3}{|c|}{$\begin{array}{l}\text { Concentração de } \\
\text { Respostas }(\%)^{*}\end{array}$} \\
\hline & & & & & & $0-4$ & $5-7$ & $8-10$ \\
\hline $\begin{array}{l}\text { 27.Associei os conteúdos do curso aos meus } \\
\text { conhecimentos anteriores. }\end{array}$ & 9,36 & 0,97 & 10 & 7 & 10 & 0,0 & 7,2 & 92,8 \\
\hline $\begin{array}{l}\text { 29.Identifiquei situações diárias em que eu } \\
\text { pudesse aplicar os conteúdos do curso. }\end{array}$ & 9,07 & 1,10 & 10 & 6 & 10 & 0,00 & 14,5 & 85,5 \\
\hline $\begin{array}{l}\text { 10.Busquei solucionar minhas dúvidas ao } \\
\text { consultar as apostilas do curso. }\end{array}$ & 8,88 & 1,24 & 10 & 5 & 10 & 0,0 & 12,0 & 88,0 \\
\hline $\begin{array}{l}\text { 5.Esforcei-me mais quando percebi que estava } \\
\text { perdendo a concentração. }\end{array}$ & 8,72 & 1,29 & 10 & 5 & 10 & 0,0 & 13,2 & 86,8 \\
\hline $\begin{array}{l}\text { 16.Busquei sites relacionados ao conteúdo do } \\
\text { curso para me ajudar a aprender. }\end{array}$ & 8,64 & 1,87 & 10 & 1 & 10 & 1,2 & 21,6 & 77,2 \\
\hline $\begin{array}{l}\text { 11.Busquei compreender melhor os conteúdos } \\
\text { ao estudá-los nas apostilas do curso. }\end{array}$ & 8,60 & 1,54 & 10 & 3 & 10 & 1,2 & 19,2 & 79,6 \\
\hline $\begin{array}{l}\text { 26.Busquei desenvolver uma ideia global sobre } \\
\text { como os conteúdos do curso se relacionavam } \\
\text { entre si. }\end{array}$ & 8,58 & 1,59 & 10 & 0 & 10 & 1,2 & 15,7 & 80,7 \\
\hline $\begin{array}{l}\text { 2.Repeti a mim mesmo, quando me senti } \\
\text { ansioso, que tudo sairia bem ao final do curso. }\end{array}$ & 8,55 & 1,96 & 10 & 0 & 10 & 2,4 & 16,8 & 80,8 \\
\hline $\begin{array}{l}\text { 9.Esforcei-me para verificar minha } \\
\text { compreensão sobre o que estava sendo } \\
\text { ensinado. }\end{array}$ & 8,51 & 1,63 & 10 & 0 & 10 & 1,2 & 19,2 & 79,6 \\
\hline $\begin{array}{l}\text { 6.Forcei-me a manter a atenção nos estudos } \\
\text { quando me senti desinteressado. }\end{array}$ & 8,48 & 1,56 & 10 & 4 & 10 & 2,4 & 18,0 & 79,6 \\
\hline 21.Fiz anotações sobre o conteúdo do curso. & 8,46 & 1,76 & 10 & 0 & 10 & 1,2 & 27,2 & 71,1 \\
\hline $\begin{array}{l}\text { 28.Diferenciei, ao analisar os conteúdos do } \\
\text { curso, os aspectos mais importantes dos menos } \\
\text { importantes. }\end{array}$ & 8,41 & 1,53 & 10 & 3 & 10 & 1,2 & 25,3 & 73,5 \\
\hline $\begin{array}{l}\text { 25.Refleti sobre as implicações que os } \\
\text { conteúdos aprendidos poderiam ter. }\end{array}$ & 8,37 & 1,81 & 10 & 0 & 10 & 1,2 & 18,1 & 80,7 \\
\hline $\begin{array}{l}\text { 7.Esforcei-me mais quando percebi que estava } \\
\text { perdendo o interesse no assunto. }\end{array}$ & 8,34 & 1,73 & 10 & 2 & 10 & 3,6 & 21,7 & 74,7 \\
\hline 1. Mantive a calma quando tive dificuldades. & 8,22 & 1,76 & 10 & 4 & 10 & 3,6 & 24,0 & 72,4 \\
\hline $\begin{array}{l}\text { 15.Busquei outras fontes de pesquisa, fora da } \\
\text { internet, relacionadas ao curso para me ajudar a } \\
\text { aprender. }\end{array}$ & 8,20 & 2,26 & 10 & 0 & 10 & 6,0 & 22,9 & 71,1 \\
\hline $\begin{array}{l}\text { 18.Revisei os conteúdos relativos aos } \\
\text { exercícios em que cometi erros. }\end{array}$ & 8,01 & 1,84 & 10 & 2 & 10 & 3,6 & 28,9 & 67,5 \\
\hline $\begin{array}{l}\text { 4.Mantive a calma diante dos erros que cometi } \\
\text { ao realizar atividades do curso. }\end{array}$ & 7,96 & 1,68 & 8 & 1 & 10 & 2,4 & 31,3 & 66,3 \\
\hline $\begin{array}{l}\text { 8.Revisei a matéria para verificar o quanto eu } \\
\text { dominava o conteúdo. }\end{array}$ & 7,96 & 1,98 & 10 & 0 & 10 & 4,8 & 28,8 & 66,4 \\
\hline 22.Fiz resumos do conteúdo do curso. & 7,86 & 2,72 & 10 & 0 & 10 & 8,4 & 24,1 & 67,5 \\
\hline
\end{tabular}


Tabela 26. Resultados descritivos de Estratégias de Aprendizagem (continuação).

\begin{tabular}{|c|c|c|c|c|c|c|c|c|}
\hline \multirow[t]{2}{*}{ Itens } & \multirow[t]{2}{*}{ Média } & \multirow{2}{*}{$\begin{array}{l}\text { Desvio } \\
\text { Padrão }\end{array}$} & \multirow[t]{2}{*}{ Moda } & \multirow[t]{2}{*}{ Mín. } & \multirow[t]{2}{*}{ Máx. } & \multicolumn{3}{|c|}{$\begin{array}{l}\text { Concentração de } \\
\text { Respostas }(\%)^{*}\end{array}$} \\
\hline & & & & & & $0-4$ & $5-7$ & $8-10$ \\
\hline $\begin{array}{l}\text { 23.Li o conteúdo do curso várias vezes como } \\
\text { método para aprender. }\end{array}$ & 7,67 & 2,51 & 10 & 0 & 10 & 7,2 & 32,6 & 60,2 \\
\hline $\begin{array}{l}\text { 3.Mantive a calma com a possibilidade de ter } \\
\text { um rendimento abaixo do esperado. }\end{array}$ & 7,61 & 2,01 & 10 & 0 & 10 & 7,2 & 37,3 & 55,5 \\
\hline $\begin{array}{l}\text { 17.Tentei entender o conteúdo ao aplicá-lo na } \\
\text { prática, ao invés de dedicar tempo lendo ou } \\
\text { pedindo ajuda a alguém. }\end{array}$ & 7,45 & 2,42 & 10 & 0 & 10 & 8,4 & 33,8 & 57,8 \\
\hline $\begin{array}{l}\text { 24.Fiz esquemas do conteúdo do curso como } \\
\text { método para aprender. }\end{array}$ & 7,37 & 2,54 & 8 & 0 & 10 & 8,4 & 31,4 & 60,2 \\
\hline $\begin{array}{l}\text { 12.Busquei auxílio do tutor para esclarecer } \\
\text { minhas dúvidas sobre o conteúdo. }\end{array}$ & 7,34 & 2,52 & 10 & 1 & 10 & 13,2 & 32,5 & 54,3 \\
\hline $\begin{array}{l}\text { 20.Repeti mentalmente os conteúdos do curso } \\
\text { que gostaria de aprender. }\end{array}$ & 7,27 & 2,82 & 8 & 0 & 10 & 10,8 & 25,2 & 64,0 \\
\hline $\begin{array}{l}\text { 19.Aprendi conteúdos ao mentalizá-los } \\
\text { repetidamente até perceber que havia } \\
\text { entendido. }\end{array}$ & 6,99 & 2,86 & 8 & 0 & 10 & 12,0 & 31,3 & 56,7 \\
\hline $\begin{array}{l}\text { 14.Troquei mensagens com os colegas para } \\
\text { esclarecer dúvidas sobre o conteúdo do curso. }\end{array}$ & 6,29 & 3,38 & 10 & 0 & 10 & 25,2 & 27,7 & 47,1 \\
\hline $\begin{array}{l}\text { 13.Busquei auxílio de colegas nos fóruns para } \\
\text { esclarecer minhas dúvidas. }\end{array}$ & 6,23 & 3,29 & 10 & 0 & 10 & 25,2 & 32,5 & 42,3 \\
\hline
\end{tabular}

$\mathrm{N}=83$ casos.

* 0-4: comportou-se pouco da maneira descrita no item; 5-7: comportou-se com frequência razoável da maneira descrita no item; 8-10: comportou-se com muita frequência da maneira descrita no item.

A análise descritiva do instrumento de Estratégias de Aprendizagem demonstra que, nessa amostra, a média de uso das Estratégias de Aprendizagem descritas nos itens teve uma variação de 6,23 a 9,36. Os 29 itens presentes no questionário apresentaram maior concentração de respostas nos pontos mais altos da escala (entre $42,3 \%$ e 92,8\%). Os valores da moda confirmaram este resultado concentrando as respostas nos valores de 8 e 10 pontos. Não houve casos omissos devido a forma de preenchimento do questionário, que só era encerrado e enviado quando todos os itens fossem preenchidos.

Os desvios padrão apresentados pela amostra são altos na sua grande maioria, o que já era esperado, pois ao longo do curso os alunos utilizam-se de diferentes Estratégias de Aprendizagem. Ou seja, uma determinada Estratégia pode ser extremamente utilizada por um certo aluno, e pouco usada por outro.

Das dez médias mais altas - $27(\mathrm{M}=9,36$ e $\mathrm{DP}=0,97) ; 29(\mathrm{M}=9,07$ e $\mathrm{DP}=1,10) ; 10$ $(\mathrm{M}=8,88$ e $\mathrm{DP}=1,24) ; 5(\mathrm{M}=8,72$ e $\mathrm{DP}=1,29) ; 16(\mathrm{M}=8,64$ e $\mathrm{DP}=1,87) ; 11 \quad(\mathrm{M}=8,60$ e $\mathrm{DP}=1,54) ; 26(\mathrm{M}=8,58$ e $\mathrm{DP}=1,59) ; 2(\mathrm{M}=8,55$ e $\mathrm{DP}=1,96) ; 9(\mathrm{M}=8,51$ e DP 1,63) e $6(\mathrm{M}=8,48$ e DP=1,56) - cinco itens correspondem ao fator “Estratégias Autorregulatórias" encontrado por Martins (2012) (Itens, 5, 6, 9, 10 e 11), tal fator relaciona estratégias ligadas ao controle da motivação e ao monitoramento da compreensão. Ainda, 4 itens representam o fator "Estratégias 
Cognitivas" (Itens 16, 26, 27e 29). O fator representa estratégias de reflexão ativa (repetição, organização e elaboração mental da informação que foi apresentada), bem como de estratégias comportamentais (busca de ajudo no material didático e aplicação prática). O item restante (2) corresponde a estratégias ligadas ao "Controle da Emoção"

Entre os cinco itens que apresentaram as médias mais baixas, 3 deles são os itens que compõe o fator "Busca da Ajuda Interpessoal" de Martins (2012). São eles os itens 12 (M=7,32 e $\mathrm{DP}=2,52), 13(\mathrm{M}=6,23$ e $\mathrm{DP}=3,29)$ e $14(\mathrm{M}=6,29$ e $\mathrm{DP}=3,38)$. Os demais itens $19(\mathrm{M}=6,99$ e $\mathrm{DP}=2,86)$ e $20(\mathrm{M}=7,27$ e $\mathrm{DP}=2,82)$ são referentes a "Estratégias Cognitivas"

Ao analisar os resultados descritivos do instrumento Estratégias de Aprendizagem, percebe-se que a maior ocorrência de médias altas se concentra nos itens dos fatores 1 e 3 do presente estudo, respectivamente, Estratégias Cognitivas e Estratégias Autorregulatórias, indicando que tais estratégias foram as mais utilizadas pela amostra, enquanto as médias mais baixas apresentam-se no fator 4, "Busca de Ajuda Interpessoal". Esse resultado indica que os alunos pouco utilizaram de interação com outras pessoas (pares e tutores) para auxiliar no seu aprendizado, pois o uso da Estratégia Busca de Ajuda Interpessoal considera que o aluno busca ajuda de tutores e seus pares no ambiente virtual para tirar possíveis dúvidas.

\subsubsection{Reação aos procedimentos instrucionais}

A satisfação dos alunos com relação aos procedimentos utilizados no curso é mensurada pelo questionário de Reação aos Procedimentos Instrucionais. A qualidade dos mesmos foi avaliada segundo uma escala de intensidade que varia de 0 (Péssimo) a 10 (Excelente) associada aos 17 itens presentes no instrumento. Os resultados descritivos de seus itens podem ser visualizados na Tabela 27.

Tabela 27. Resultados descritivos de Reação aos Procedimentos Instrucionais.

\begin{tabular}{|c|c|c|c|c|c|c|c|c|}
\hline \multirow[t]{2}{*}{ Itens } & \multirow{2}{*}{ Média } & \multirow{2}{*}{$\begin{array}{l}\text { Desvio } \\
\text { Padrão }\end{array}$} & \multirow{2}{*}{ Moda } & \multirow[t]{2}{*}{ Mín. } & \multirow[t]{2}{*}{ Máx. } & \multicolumn{3}{|c|}{$\begin{array}{l}\text { Concentração de } \\
\text { Respostas }(\%)^{*}\end{array}$} \\
\hline & & & & & & $0-4$ & $5-7$ & 8-10 \\
\hline $\begin{array}{l}\text { 1. Ligação entre o conteúdo proposto e os } \\
\text { objetivos do curso. }\end{array}$ & 9,08 & 1,44 & 10 & 0 & 10 & 1,3 & 9,1 & 89,6 \\
\hline $\begin{array}{l}\text { 2. Ligação entre o conteúdo do curso e os } \\
\text { seus objetivos pessoais. }\end{array}$ & 9,06 & 1,20 & 10 & 3 & 10 & 1,3 & 3,9 & 94,8 \\
\hline 5. Leituras recomendadas. & 9,00 & 1,10 & 10 & 5 & 10 & 0,0 & 10,4 & 89,6 \\
\hline 4. Linguagem utilizada no material do curso. & 8,96 & 1,46 & 10 & 0 & 10 & 1,3 & 9,1 & 89,6 \\
\hline 3. Sequência de apresentação das disciplinas. & 8,92 & 1,24 & 10 & 5 & 10 & 0,0 & 13,0 & 87,0 \\
\hline 15. Fóruns de discussão. & 8,77 & 1,56 & 10 & 0 & 10 & 1,3 & 13,3 & 85,7 \\
\hline $\begin{array}{l}\text { 11. Quantidade de horas de estudo sugerida } \\
\text { para cada disciplina }\end{array}$ & 8,74 & 1,67 & 10 & 0 & 10 & 1,3 & 14,3 & 84,4 \\
\hline
\end{tabular}


Tabela 27. Resultados descritivos de Reação aos Procedimentos Instrucionais (continuação)

\begin{tabular}{|c|c|c|c|c|c|c|c|c|}
\hline \multirow[t]{2}{*}{ Itens } & \multirow{2}{*}{ Média } & \multirow{2}{*}{$\begin{array}{l}\text { Desvio } \\
\text { Padrão }\end{array}$} & \multirow{2}{*}{ Moda } & \multirow[t]{2}{*}{ Mín. } & \multirow[t]{2}{*}{ Máx. } & \multicolumn{3}{|c|}{$\begin{array}{l}\text { Concentração de } \\
\text { Respostas }(\%)^{*}\end{array}$} \\
\hline & & & & & & $0-4$ & $5-7$ & 8-10 \\
\hline 12. Fóruns de apresentação. & 8,70 & 1,69 & 10 & 0 & 10 & 1,3 & 18,2 & 80,5 \\
\hline 16. Guias das disciplinas. & 8,70 & 1,51 & 10 & 4 & 10 & 2,6 & 10,4 & 87,0 \\
\hline $\begin{array}{l}\text { 10. Quantidade de conteúdo para cada } \\
\text { disciplina. }\end{array}$ & 8,64 & 1,53 & 10 & 0 & 10 & 1,3 & 13,0 & 85,7 \\
\hline $\begin{array}{l}\text { 7. Links disponibilizados no ambiente virtual } \\
\text { de aprendizagem (AVA). }\end{array}$ & 8,61 & 1,47 & 10 & 3 & 10 & 3,9 & 11,7 & 84,4 \\
\hline $\begin{array}{l}\text { 6. Novidades e lembretes divulgados no } \\
\text { ambiente virtual de aprendizagem (AVA). }\end{array}$ & 8,57 & 1,75 & 10 & 0 & 10 & 1,3 & 20,8 & 77,9 \\
\hline $\begin{array}{l}\text { 8. Atividades/tarefas propostas ao final de } \\
\text { cada disciplina. }\end{array}$ & 8,55 & 1,29 & 8 & 4 & 10 & 1,3 & 16,9 & 81,8 \\
\hline 13. Fóruns de dúvidas. & 8,44 & 1,71 & 10 & 0 & 10 & 1,3 & 19,5 & 79,2 \\
\hline 14. Fóruns de notícias. & 8,06 & 1,79 & 8 & 0 & 10 & 1,3 & 28,6 & 70,1 \\
\hline 17. Troca de mensagens entre os alunos. & 8,06 & 2,50 & 10 & 0 & 10 & 5,2 & 22,1 & 72,1 \\
\hline $\begin{array}{l}\text { 9. Orientação para solução de erros nas } \\
\text { atividades/tarefas. }\end{array}$ & 8,03 & 1,99 & 10 & 0 & 10 & 5,2 & 29,9 & 64,9 \\
\hline
\end{tabular}

$\mathrm{N}=77$ casos.

*0-4: qualidade ruim dos procedimentos instrucionais; 5-7: qualidade razoável dos procedimentos instrucionais; 8-10: qualidade excelente dos procedimentos instrucionais.

De forma geral, observa-se que os alunos ficaram muito satisfeitos com a qualidade dos procedimentos instrucionais utilizados ao longo do curso, uma vez que as médias variam entre 8,03 e 9,08. Como os valores dos desvios-padrão não foram altos na maioria dos itens, pode-se considerar que houve concordância de opiniões entre os respondentes quanto aos aspectos avaliados. Contudo, como os valores mínimos e máximos variam de 0 a 10, alguns participantes não julgaram os procedimentos instrucionais tão bons (ou ruins) quanto outros. Vale ressaltar, que não houve casos omissos devido a forma de preenchimento do questionário, que só era encerrado e enviado quando todos os itens fossem preenchidos. Os itens apresentaram concentração de respostas superior a $60 \%$ nos pontos mais altos da escala, esse dado se confirma com o valor da moda na maioria dos itens iguais a 10 - com exceção dos itens 8 e 14 que são iguais a 8 .

Os itens que receberam as melhores avaliações foram os seguintes: $1(\mathrm{M}=9,08 \mathrm{e}$ $\mathrm{DP}=1,44) ; 2(\mathrm{M}=9,06$ e $\mathrm{DP}=1,20) ; 5(\mathrm{M}=9,00$ e $\mathrm{DP}=1,10) ; 4(\mathrm{M}=8,96$ e $\mathrm{DP}=1,46)$ e $3(\mathrm{M}=8,92$ e $\mathrm{DP}=1,24)$. Vale enfatizar que os valores das modas obtidas para estes itens foram 10 , indicando grande satisfação dos respondentes. Os itens mais bem avaliados referem-se, respectivamente, ligação entre o conteúdo proposto e os objetivos do curso, ligação entre o conteúdo proposto do curso e os objetivos pessoais, a leituras recomendadas, linguagem utilizada no material do curso e à sequência de apresentação das disciplinas. Todos esses itens 
podem ser considerados procedimentos instrucionais tradicionais, já que medem a satisfação dos participantes com as características do curso presentes em qualquer tipo de evento instrucional, presencial ou não.

Em relação aos itens com avaliações mais baixas foram os seguintes itens: 9 “Orientação para solução de erros nas atividades/tarefas" (M=8,03 e DP=1,99); 17 "Troca de mensagens entre os alunos" $(\mathrm{M}=8,06$ e $\mathrm{DP}=2,50) ; 14$ "Fóruns de notícias" $(\mathrm{M}=8,06$ e $\mathrm{DP}=1,79)$; e 13 "Fóruns de dúvidas" $(\mathrm{M}=8,44$ e $\mathrm{DP}=1,71)$. Os valores das modas para os quatro itens de avaliações mais baixas foram, respectivamente, 10, 8, 10 e 10. As médias mais baixas relacionam-se aos itens que podem ser agrupados em procedimentos instrucionais específicos para web, que avalia a satisfação dos participantes com fóruns de notícias e dúvidas troca de mensagens entre pares e tutores. Assim, verifica-se que os alunos julgaram que os fóruns de dúvidas e notícias e as orientações prestadas pelo tutor apresentam algumas deficiências. O segundo item diz respeito às trocas de mensagens entre os alunos feitas no próprio ambiente de aprendizagem, indicando que os alunos utilizaram pouco essa ferramenta, como verificado nos resultados descritivos do questionário de estratégias de aprendizagem.

A partir análise dos resultados descritivos do questionário de Procedimentos Instrucionais, percebe-se que as médias mais altas pertencem aos itens relacionados aos procedimentos tradicionais, já as médias mais baixas estão concentradas nos itens que tratam de recursos do AVA e que envolvem diretamente a participação ativa do tutor e alunos (mensagens, fóruns, orientações para a execução das tarefas). Tais achados podem ser explicados considerando-se alguns pontos de discussão ou a sua combinação: a) os alunos podem não ter utilizado com frequência as ferramentas da web, e dificultou uma opinião sobre a qualidade das mesmas; b) tais procedimentos de fato não foram bem avaliados pois possuem falhas segundo os usuários.

\subsubsection{Reação ao desempenho do tutor}

O questionário de Reação ao Desempenho do Tutor mensura a satisfação dos alunos quanto ao desempenho didático e domínio do conteúdo do tutor e uso de estratégias motivacionais e de incentivo aos alunos. O instrumento é composto por 27 itens, associados a uma escala que varia de 0 (Nunca) a 10 (Sempre), que medem a frequência de comportamento do tutor. Os resultados descritivos de seus itens podem ser visualizados na Tabela 28 - foram omitidos desta os valores mínimo e máximo, já que apresentam valor igual a zero e dez, respectivamente. 
Tabela 28. Resultados descritivos de Reação ao Desempenho do Tutor.

\begin{tabular}{|c|c|c|c|c|c|c|c|c|}
\hline \multirow{2}{*}{ Itens } & \multirow{2}{*}{ Média } & \multirow{2}{*}{$\begin{array}{l}\text { Desvio } \\
\text { Padrão }\end{array}$} & \multirow{2}{*}{ Moda } & \multirow[t]{2}{*}{ Mín. } & \multirow[t]{2}{*}{ Máx. } & \multicolumn{3}{|c|}{$\begin{array}{l}\text { Concentração de } \\
\text { Respostas }(\%)^{*}\end{array}$} \\
\hline & & & & & & $0-4$ & $5-7$ & 8-10 \\
\hline 14. Utiliza linguagem de fácil compreensão. & 8,91 & 1,55 & 10 & 0 & 10 & 1,3 & 10,2 & 88,5 \\
\hline 19. Comunica-se sem erros de português. & 8,91 & 1,72 & 10 & 1 & 10 & 3,8 & 10,3 & 85,9 \\
\hline $\begin{array}{l}\text { 1. Utiliza os fóruns para estimular a interação } \\
\text { entre os participantes. }\end{array}$ & 8,79 & 1,75 & 10 & 0 & 10 & 2,6 & 17,9 & 79,5 \\
\hline $\begin{array}{l}\text { 26. Cria oportunidades para os participantes } \\
\text { manifestarem suas ideias. }\end{array}$ & 8,46 & 2,15 & 10 & 0 & 10 & 5,1 & 16,7 & 78,2 \\
\hline $\begin{array}{l}\text { 10. Leva em consideração as ideias dos } \\
\text { participantes. }\end{array}$ & 8,42 & 1,76 & 10 & 0 & 10 & 1,3 & 24,3 & 74,4 \\
\hline $\begin{array}{l}\text { 20. Utiliza todos os recursos de interação } \\
\text { disponibilizados pelo curso. }\end{array}$ & 8,41 & 2,15 & 10 & 0 & 10 & 3,8 & 23,1 & 73,1 \\
\hline $\begin{array}{l}\text { 12. Utiliza sua experiência profissional ao } \\
\text { orientar os participantes. }\end{array}$ & 8,38 & 2,48 & 10 & 0 & 10 & 6,4 & 19,2 & 74,4 \\
\hline $\begin{array}{l}\text { 2. Encoraja os participantes a discutirem } \\
\text { coletivamente suas dúvidas e } \\
\text { questionamentos. }\end{array}$ & 8,36 & 1,97 & 10 & 0 & 10 & 5,1 & 20,5 & 74,4 \\
\hline $\begin{array}{l}\text { 5. Utiliza expressões afetuosas ao se dirigir } \\
\text { aos participantes. }\end{array}$ & 8,32 & 2,01 & 10 & 0 & 10 & 3,8 & 15,4 & 80,8 \\
\hline $\begin{array}{l}\text { 11. Elogia os participantes pelo desempenho } \\
\text { no decorrer do curso. }\end{array}$ & 8,29 & 2,24 & 10 & 0 & 10 & 5,1 & 21,8 & 73,1 \\
\hline $\begin{array}{l}\text { 13. Fornece respostas que esclarecem } \\
\text { completamente as dúvidas dos participantes. }\end{array}$ & 8,29 & 1,81 & 10 & 2 & 10 & 3,8 & 21,8 & 74,4 \\
\hline 6. Elogia a participação nos fóruns. & 8,27 & 2,22 & 10 & 0 & 10 & 5,1 & 15,4 & 79,5 \\
\hline $\begin{array}{l}\text { 25. Direciona as discussões nos fóruns, } \\
\text { evitando conversas que fujam do tema. }\end{array}$ & 8,22 & 2,42 & 10 & 0 & 10 & 9,0 & 14,4 & 76,9 \\
\hline $\begin{array}{l}\text { 27. Indica diversas fontes de pesquisa sobre } \\
\text { os temas do curso. }\end{array}$ & 8,22 & 2,33 & 10 & 0 & 10 & 5,1 & 23,1 & 71,8 \\
\hline $\begin{array}{l}\text { 9. Respeita o ritmo de aprendizagem dos } \\
\text { participantes. }\end{array}$ & 8,21 & 2,20 & 10 & 0 & 10 & 5,1 & 20,5 & 74,4 \\
\hline $\begin{array}{l}\text { 15. Participa, do início ao fim, das discussões } \\
\text { nos fóruns. }\end{array}$ & 8,19 & 2,36 & 10 & 0 & 10 & 6,4 & 24,4 & 69,2 \\
\hline $\begin{array}{l}\text { 21. Apresenta exemplos que ilustram bem o } \\
\text { tema discutido. }\end{array}$ & 8,19 & 2,10 & 10 & 0 & 10 & 3,8 & 24,4 & 71,8 \\
\hline 8. Está disponível nas horas marcadas. & 8,09 & 2,50 & 10 & 0 & 10 & 7,7 & 19,2 & 73,1 \\
\hline $\begin{array}{l}\text { 23. Aproveita os acertos dos participantes } \\
\text { para enfatizar os aspectos mais importantes } \\
\text { do tema discutido }\end{array}$ & 8,05 & 2,34 & 10 & 0 & 10 & 6,4 & 23,1 & 70,5 \\
\hline $\begin{array}{l}\text { 18. Indica caminhos ao invés de dar respostas } \\
\text { prontas. }\end{array}$ & 8,04 & 2,40 & 10 & 0 & 10 & 7,7 & 25,6 & 66,7 \\
\hline 7. Faz críticas construtivas. & 8,03 & 2,36 & 10 & 0 & 10 & 7,7 & 25,6 & 66,7 \\
\hline $\begin{array}{l}\text { 3. Envia mensagens de incentivo aos } \\
\text { participantes. }\end{array}$ & 8,01 & 2,38 & 10 & 0 & 10 & 7,7 & 23,7 & 69,2 \\
\hline $\begin{array}{l}\text { 24. Integra teoria e prática em suas } \\
\text { explicações. }\end{array}$ & 7,95 & 2,51 & 10 & 0 & 10 & 9,0 & 23,1 & 67,9 \\
\hline $\begin{array}{l}\text { 16. Cria situações de aprendizagem em que } \\
\text { os participantes sintam-se capazes de } \\
\text { resolver. }\end{array}$ & 7,92 & 2,26 & 10 & 0 & 10 & 7,7 & 26,9 & 65,4 \\
\hline $\begin{array}{l}\text { 17. Ressalta os benefícios práticos do curso } \\
\text { nos contatos com os participantes. }\end{array}$ & 7,88 & 2,37 & 10 & 0 & 10 & 9,0 & 20,5 & 70,5 \\
\hline $\begin{array}{l}\text { 22. Muda a forma de explicar até que os } \\
\text { participantes compreendam os conteúdos. }\end{array}$ & 7,78 & 2,41 & 9 & 0 & 10 & 6,4 & 26,9 & 66,7 \\
\hline $\begin{array}{l}\text { 4. Procura compreender os motivos que estão } \\
\text { dificultando a participação no curso. }\end{array}$ & 7,73 & 2,39 & 10 & 0 & 10 & 9,0 & 28,2 & 62,8 \\
\hline
\end{tabular}
$\mathrm{N}=78$ casos. 
*0-4: comportou-se pouco da maneira descrita no item; 5-7: comportou-se razoavelmente da maneira descrita no item; 8-10: comportou-se com muita frequência da maneira descrita no item.

De forma geral, observa-se que a maioria dos participantes avaliou positivamente o desempenho dos tutores, o que demonstra a satisfação com a frequência de comportamento emitida pelos mesmos, uma vez que as médias variam de 7,73 a 8,91 ; a concentração de respostas foi superior a $60 \%$ nos pontos mais altos da escala; e os valores da moda foi 10 para todos os itens, com exceção do item 22 "Muda a forma de explicar até que os participantes compreendam os conteúdos" que apresentou moda 9. Os valores de desvios-padrão foram baixos, indicando concordância de opiniões quando aos aspectos avaliados. Contudo, apesar de todos os indícios de alta satisfação por parte dos alunos, ao analisar os valores mínimos, observa-se a maioria dos itens há com valores iguais a 0 (zero), assim, alguns alunos não ficaram satisfeitos com o desempenho do tutor. Como foi comentado anteriormente, devido a formatação do questionário não houve casos omissos.

Os itens $14(\mathrm{M}=8,91$ e $\mathrm{DP}=1,55) ; 19(\mathrm{M}=8,91$ e $\mathrm{DP}=1,72) ; 1(\mathrm{M}=8,79$ e $\mathrm{DP}=1,75) ; 26$ $(\mathrm{M}=8,46$ e $\mathrm{DP}=2,15) ; 10(\mathrm{M} 8,42$ e $\mathrm{DP}=1,76)$ e $20(\mathrm{M}=8,41$ e $\mathrm{DP}=3,8)$ receberam as melhores avaliações e apresentaram concentração de respostas superior a $70 \%$ entre os pontos de 8 a 10 na escala. Vale enfatizar que os valores das modas obtidas para estes itens foram 10. Dessa forma, os alunos mostram-se satisfeitos com o uso de linguagem de fácil compreensão, a comunicação sem erros de português, a criação de oportunidades para os participantes manifestarem suas ideias, bem como considerar as ideias dos mesmos e utilizar todos os recursos de interação disponibilizados pelo curso. Os itens com as médias mais altas agruparam comportamentos relativos ao domínio do conteúdo e desempenho didático dos tutores.

Em contrapartida, os itens cujas avaliações foram mais baixas são: 24 "Integra teoria e prática em suas explicações" ( $M=7,95$ e $\mathrm{DP}=2,51)$; 16 "Cria situações de aprendizagem em que os participantes sintam-se capazes de resolver" $(\mathrm{M}=7,92$ e $\mathrm{DP}=2,26) ; 17$ "Ressalta os benefícios práticos do curso nos contatos com os participantes" (M=7,88 e DP=2,37); 22 "Muda a forma de explicar até que os participantes compreendam os conteúdos" $(\mathrm{M}=7,78$ e $\mathrm{DP}=2,41)$ e 4 "Procura compreender os motivos que estão dificultando a participação no curso" (M=7,73 e DP=2,39). Os valores das modas para os quatro itens de avaliações mais baixas foram 9 e 10 . Apesar de esses itens apresentarem valores de médias mais baixos, os valores de concentração nos pontos mais altos da escala estão acima de $60 \%$, indicando que os participantes estão satisfeitos com a frequência de comportamento demonstrado pelos tutores em tais aspectos.

No questionário de Reação ao Desempenho do Tutor houve uma queda no retorno do questionário em relação aos demais. Isso pode ter ocorrido por ser o quarto e último instrumento 
a ser respondido na sequência de questionários, após os dados sociodemográficos, o de estratégias de aprendizagem e de procedimentos instrucionais. Os alunos podem também ter evitado avaliar formalmente o tutor, temendo serem identificados ou repreendidos.

\subsection{Análises das evidências de validade dos questionários}

Esta seção descreve os resultados das análises das evidências de validade dos questionários de Estratégias de Aprendizagem, Reação aos Procedimentos Instrucionais e Reação ao Desempenho do Tutor. Estas análises estão relacionadas ao alcance dos objetivos específicos de adaptação e verificação de evidências de validade dos instrumentos de medida mencionadas em contextos de ações educacionais ofertadas a distância.

\subsubsection{Estratégias de aprendizagem}

Antes de iniciar a explanação dos resultados das análises de evidências de validade do instrumento de Estratégias de Aprendizagem, é necessário descrever o percurso que levou a esses resultados. Devido ao baixo retorno do instrumento, o questionário de Estratégias de Aprendizagem conta com 83 respostas válidas em seus 29 itens, o que não atende parte dos critérios exigidos para realização da análise fatorial exploratória (AFE), no que diz respeito à extração dos fatores pela análise de componentes principais (Principal Componentes $-P C$ ) e confirmação da estrutura fatorial de fatoração dos eixos principais (Principal Axis Factoring $P A F)$. Nessas análises, é recomendado por Pasquali (2004), o mínimo de 5 casos por variável. Sendo assim, seria necessário o retorno mínimo de 145 respostas válidas para o instrumento. Contudo, para a verificação de evidências de validade do instrumento, foram realizadas análises de consistência interna (Alfa de Cronbach) levando em conta os fatores encontrados por Martins (2012), estudo que foi realizado no mesmo contexto do presente estudo (cursos superiores ofertados na modalidade EAD). Após as devidas análises, a autora apresenta o instrumento de Estratégias de Aprendizagem, composto por 29 itens e formado por 4 fatores denominados: Fator 1 "Estratégias Cognitivas", Fator 2 "Controle da Emoção", Fator 3 "Estratégias Autorregulatórias", Fator 4 "Busca de Ajuda Interpessoal”. A Tabela 29 apresenta a definição de cada fator de acordo com Martins (2012). 
Tabela 29. Definição dos Fatores de Estratégias de Aprendizagem.

\begin{tabular}{|c|c|c|}
\hline Fator & Itens & Análise \\
\hline 1. Estratégias Cognitivas & $\begin{array}{c}15 \text { itens } \\
(15 \text { ao } 29)\end{array}$ & $\begin{array}{l}\text { Dos } 15 \text { itens pertencentes a esse fator, } 12 \text { são referentes as } \\
\text { estratégias cognitivas de repetição, organização e elaboração } \\
\text { (reflexão ativa), dois itens provêm das estratégias de busca de } \\
\text { ajuda ao material didático e um de aplicação prática, ambas } \\
\text { comportamentais. }\end{array}$ \\
\hline 2. Controle da Emoção & $\begin{array}{l}4 \text { itens } \\
(1 \text { ao } 4)\end{array}$ & $\begin{array}{l}\text { São estratégias que demonstram o controle da ansiedade e } \\
\text { prevenção de dispersões de concentração causadas por } \\
\text { sentimentos de ansiedade no momento de estudo. }\end{array}$ \\
\hline $\begin{array}{l}\text { 3. Estratégias } \\
\text { Autorregulatórias }\end{array}$ & $\begin{array}{l}7 \text { itens } \\
(5 \text { a } 11)\end{array}$ & $\begin{array}{l}\text { As estratégias autorregulatórias de controle da motivação e } \\
\text { monitoramento da compreensão, propostas por Warr e Allan } \\
\text { (1998), uniram-se em um mesmo fator. Tais estratégias } \\
\text { auxiliam na autorregulação da aprendizagem (Boruchovitch \& } \\
\text { Santos, 2004) }\end{array}$ \\
\hline $\begin{array}{l}\text { 4. Busca de Ajuda } \\
\text { Interpessoal }\end{array}$ & $\begin{array}{c}3 \text { itens } \\
(12,13 \text { e } 14)\end{array}$ & $\begin{array}{l}\text { Expressam a busca ativa, por iniciativa do próprio aluno, pela } \\
\text { ajuda de outros indivíduos (tutores ou pares) para tirar dúvidas. } \\
\text { De acordo com Warr e Allan (1998), tais estratégias } \\
\text { comportamentais representam um comportamento proativo do } \\
\text { indivíduo de buscar auxílio, ao invés de obter informações do } \\
\text { material do curso. }\end{array}$ \\
\hline
\end{tabular}

Fonte: Martins (2012)

O resultado da análise da consistência interna (Alfa de Cronbach) do instrumento Estratégias de Aprendizagem, aplicado na amostra do presente estudo a partir dos quatro fatores encontrados por Martins (2012) é demonstrado na Tabela 30.

Tabela 30. Consistência Interna (Alfa de Cronbach) da escala de Estratégias de Aprendizagem.

\begin{tabular}{lccccc}
\hline \multirow{2}{*}{ Descrição } & \multicolumn{4}{c}{ Fatores } \\
\cline { 2 - 5 } & & 1 & 2 & 3 & 4 \\
\hline $\mathrm{N}$ & 83 & 83 & 83 & 83 \\
No. de itens & 15 & 4 & 7 & 3 \\
Alfa $(\alpha)$ & 0,85 & 0,80 & 0,91 & 0,74 \\
\hline
\end{tabular}

O Fator 1, Estratégias Cognitivas, apresenta um total de 15 itens (15 ao 29), e apresenta um índice bom de consistência interna $(\alpha=0,85)$. Dos 15 itens pertencentes a esse fator, 12 são provenientes das estratégias cognitivas de repetição, organização e elaboração (reflexão ativa), dois itens reverem-se a estratégias de busca de ajuda ao material didático e um de aplicação prática, ambas comportamentais, de acordo com Warr e Allan (1998).

O Fator 2, Controle da Emoção, é composto por 4 itens (1 ao 4), e também apresenta um bom índice de consistência interna $(\alpha=0,80)$. Os 4 itens permaneceram em um mesmo fator, e pertencem ao Controle da Emoção, que de acordo com Warr e Allan (1998), representam estratégias que demonstram o controle de ansiedade no momento do estudo, e assim corrobora com literatura anterior. 
O Fator 3, Estratégias Autorregulatórias, possui 7 itens (5 ao 11) e apresenta um excelente índice de consistência interna $(\alpha=0,91)$. As estratégias autorregulatórias de controle da motivação e monitoramento da compreensão uniram-se em um mesmo fator nos estudos de Martins (2012) e estão de acordo com a proposta de Warr e Allan (1998). Para os alunos do presente estudo, o controle da motivação e atenção atrelado à avaliação do processo de aquisição de aprendizagem parecem ocorrer em conjunto, e portanto, não são identificados como distintos. Para Boruchovitch e Santos (2004) tais estratégias auxiliam na autorregulação da aprendizagem, dessa forma, é justificável estarem presentes no mesmo fator.

O Fator 4, Busca de Ajuda Interpessoal, com 3 itens (12, 13 e 14) e índice razoável de consistência interna $(\alpha=0,74)$. Os itens desse fator expressam a busca ativa, por iniciativa do próprio aluno, pela ajuda de outras pessoas (tutores ou pares) para tirar dúvidas. De acordo com Warr e Allan (1998), essas estratégias comportamentais representam um comportamento proativo do indivíduo de buscar auxílio, ao invés de obter informações do material do curso. A partir da análise dos resultados descritivos, percebe-se que a maior ocorrência de médias baixas se concentra nos itens desse fator, ou seja, os alunos pouco utilizaram estratégias mediadas por tecnologias, já que os itens descrevem o esclarecimento de dúvidas através das ferramentas web: AVA, fóruns e mensagens. Como os alunos da amostra possuem encontros presenciais regulares previstos no calendário do curso, o ato de tirar dúvidas normalmente pode ser realizado pessoalmente em tais encontros.

\subsubsection{Reação aos procedimentos instrucionais}

O questionário de Reação aos Procedimentos Instrucionais apresenta 77 casos válidos. Mesmo não atendendo as recomendações de Pasquali (2004) (número mínimo de 5 casos por variável, ou seja, seria necessário o retorno mínimo de 85 respostas válidas para o instrumento), decidiu-se por realizar a análise fatorial exploratória (AFE) devido o retorno estar bem próximo do exigido e atender ao objetivo de verificar evidências de validade do instrumento Reação aos Procedimentos Instrucionais em EAD (Martins \& Zerbini, 2015). As respostas aos questionários válidos não apresentaram casos extremos univariados e casos extremos multivariados.

A partir da elaboração e análise da matriz de correlação foram identificados 5 pares de itens altamente correlacionados entre si, indicando multicolinearidade: 
- Par 1: 1 "Ligação entre o conteúdo proposto e os objetivos do curso" e 4 "Linguagem utilizada no material do curso." ( $\mathrm{r}=0,81, \mathrm{p}<0,01)$;

- Par 2: 6 "Novidades e lembretes divulgados no ambiente virtual de aprendizagem (AVA)" e 7 "Links disponibilizados no ambiente virtual de aprendizagem (AVA)" $(r=0,82, p<0,01)$;

- Par 3: 4 "Linguagem utilizada no material do curso." e 10 "Quantidade de conteúdo para cada unidade." $(r=0,86, p<0,01)$;

- Par 4: 10 "Quantidade de conteúdo para cada unidade." e 11.Quantidade de horas de estudo sugerida para cada unidade." $(r=0,82, p<0,01)$;

- Par 5: 12 "Fóruns de apresentação." e 13 "Fóruns de dúvidas.” $(r=0,81, p<0,01)$.

Em relação ao par 1 encontrado, constatou-se que os conteúdos medidos por esses itens são distintos, o primeiro diz respeito a relação entre os conteúdos trabalhados pelas disciplinas com os objetivos do curso. Já o segundo item refere-se a linguagem utilizada no material didático do curso, se a mesma está adequada ao nível de complexidade e às características dos alunos (nível médio ou graduado).

Nos itens que compõem o par 2, os conteúdos são distintos, já que o primeiro referese às novidades e lembretes divulgados pelo tutor no AVA com o objetivo de avisar os alunos com relação a aspectos programáticos da disciplina, como: prazos de entrega de atividades, datas dos encontros e provas presenciais, etc. O item que trata dos links fornecidos no AVA diz respeito à indicação de conteúdos complementares (sites ou vídeos) disponibilizados para auxiliar no entendimento de determinado assunto abordado na disciplina. Assim, o item 6 está voltado para informações do curso enquanto que o item 7 possui um papel de auxiliar o aluno no seu processo de aprendizagem.

O par 3, constatou-se que os conteúdos medidos por esses itens são distintos. Como explicado no par 1, o item 4 refere-se a linguagem utilizada no material didático do curso, já o item o item 10 refere-se à quantidade de conteúdo trabalhada em cada unidade ou disciplina, se a mesma está adequada a carga horária proposta pelas mesmas.

Ao analisar os itens que compõem o par 4 constatou-se que os conteúdos medidos por eles são distintos. O primeiro mede a quantidade de conteúdo para cada unidade, já o segundo mede a quantidade de horas disponíveis para cada unidade. Devido ao item 10 ter sido correlacionado nos pares 3 e 4, em posteriores aplicações, deve-se atentar para o 
aperfeiçoamento da redação dos mesmos, para que possa ser diferenciado dos demais itens, já que os itens apresentam papeis diferentes no AVA.

O par 5 aborda itens sobre diferentes fóruns utilizados no AVA durante as disciplinas. Tais fóruns possuem objetivos diferenciados: os fóruns de apresentação são utilizados no início da disciplina para que os alunos possam se apresentar para os demais alunos que formam a turma de determinada disciplina; já os fóruns de dúvidas são destinados para que os alunos possam tirar dúvidas com seus pares (tutor e alunos) referentes ao conteúdo trabalhado durante a disciplina. Sendo assim, optou-se por manter todos os itens do instrumento neste primeiro momento.

Para a análise da matriz de correlação em relação a fatorabilidade, foram analisados o tamanho das correlações e a adequação da amostra. Em mais de 50\% dos casos foram encontrados valores de correlação superiores a 0,30 indicando que a matriz é provavelmente fatorável. A partir da análise da matriz também foi possível verificar que não houve relacionamentos não lineares (linearidade), nem a presença de singularidade. $\mathrm{O}$ teste de KMO também foi realizado e obteve-se um valor de 0,88 , considerado um excelente índice de adequação da amostra.

A extração inicial de fatores foi realizada a partir da análise dos componentes principais, seguindo os critérios convencionais já descritos anteriormente. A análise dos componentes principais, sugere uma estrutura empírica com 2 componentes que explicam, em conjunto, $68,47 \%$ da variância total das respostas dos participantes aos itens do questionário - segundo critério dos eigenvalues (valores próprios) maiores ou iguais a um. Quanto à importância do fator, cada componente deveria explicar no mínimo 3\% da variância total. Assim, poderiam ser extraídos dois fatores, no máximo. A análise do scree plot, confirmou a existência de 2 componentes, como pode ser observado na Figura 9. 


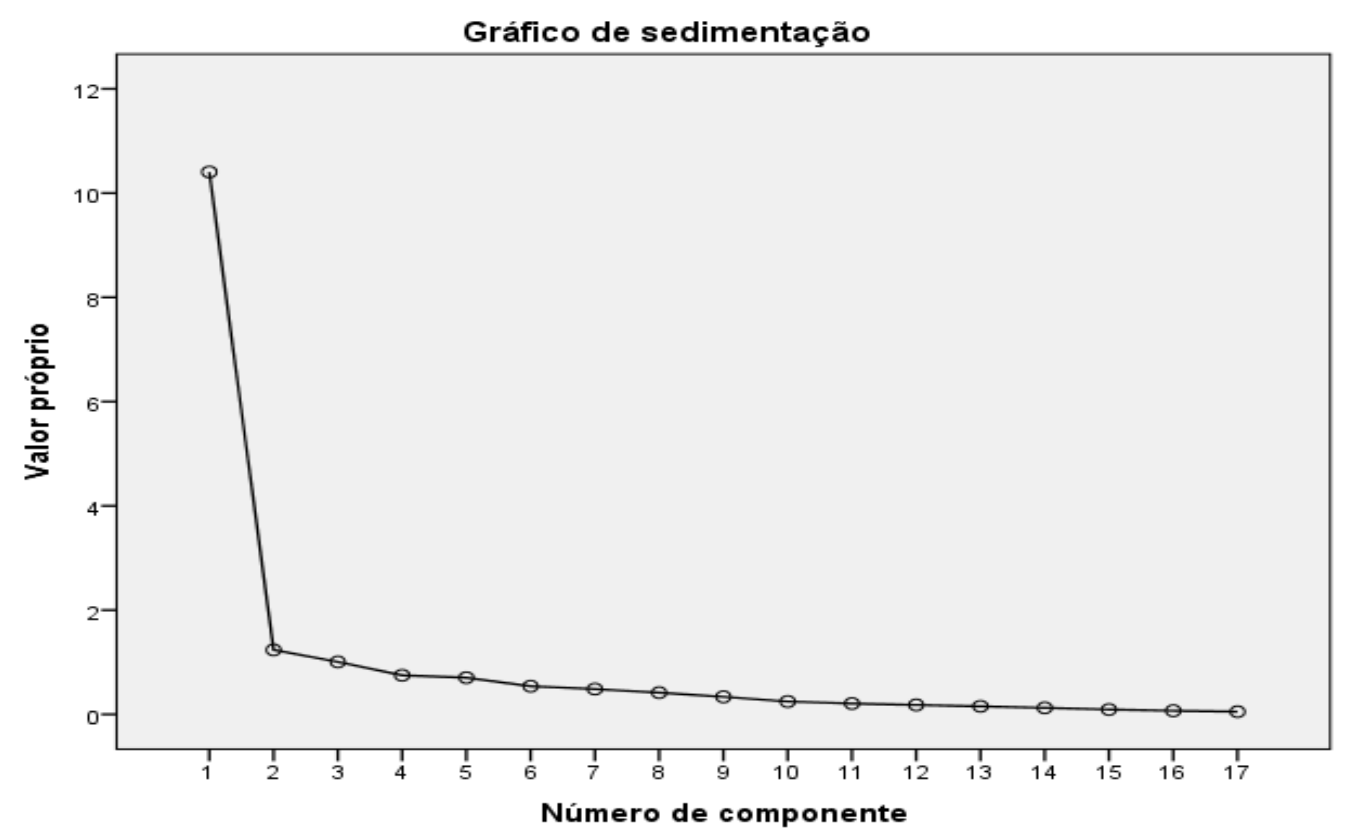

Figura 9. Distribuição dos valores próprios (scree plot) da escala de Reação aos Procedimentos Instrucionais.

A análise paralela de Horn possibilita a retenção de componentes cujos autovalores empíricos são superiores àqueles encontrados através de matrizes de variáveis randômicas não correlacionadas, com tamanho análogo de amostra e número de variáveis (Laros, 2004). A interpretação da análise indicou apenas um fator para este instrumento, ao passo que os fatores com valores empíricos menores ou iguais aos valores aleatórios são retirados da estrutura, como mostra a Tabela 31.

Tabela 31. Valores próprios empíricos e aleatórios dos primeiros dez componentes de Procedimentos Instrucionais.

\begin{tabular}{lcccccccccc}
\hline Valores & \multicolumn{10}{c}{ Componentes } \\
\cline { 2 - 12 } Próprios & 1 & 2 & 3 & 4 & 5 & 6 & 7 & 8 & 9 & 10 \\
\hline Empírico & $\mathbf{1 0 , 4 0 5}$ & 1,236 & 1,006 & 0,749 & 0,704 & 0,539 & 0,435 & 0,415 & 0,336 & 0,246 \\
\hline Aleatório & $\mathbf{1 , 9 2 6}$ & 1,708 & 1,555 & 1,423 & 1,309 & 1,205 & 1,108 & 1,020 & 0,937 & 0,851 \\
\hline
\end{tabular}

No. de itens (17); $\mathrm{N}=77$

A partir da análise da Tabela 31 observa-se que somente o primeiro fator explica o maior número de variância do que o fator correspondente nos dados aleatórios. Assim, a análise paralela de Horn admite apenas uma estrutura fatorial.

Para a confirmação final da estrutura fatorial do instrumento foi realizada a PAF, considerando apenas as cargas fatoriais superiores ou iguais a 0,30. Dessa análise foi extraído um fator único que explica $61,20 \%$ da variância total das respostas aos itens do instrumento. 
A estrutura empírica da escala é apresentada na Tabela 32, as cargas fatoriais, as comunalidades $\left(\mathrm{h}^{2}\right)$ dos itens, as médias e desvios-padrão, os índices de consistência interna e os valores próprios e percentuais de variância explicada de cada fator.

Tabela 32. Estrutura empírica da Escala de Reação aos Procedimentos Instrucionais.

\begin{tabular}{|c|c|c|c|c|}
\hline \multirow[t]{2}{*}{ Descrição dos Itens } & $\begin{array}{l}\text { Cargas } \\
\text { fatoriais }\end{array}$ & \multirow[t]{2}{*}{$\mathrm{h}^{2}$} & \multirow[t]{2}{*}{$X$} & \multirow[t]{2}{*}{ DP } \\
\hline & Fator 1 & & & \\
\hline 1. Ligação entre o conteúdo proposto e os objetivos do curso. & 0,85 & 0,77 & 9,08 & 1,44 \\
\hline 2. Ligação entre o conteúdo do curso e os seus objetivos pessoais. & 0,69 & 0,74 & 9,06 & 1,20 \\
\hline 3. Sequência de apresentação das disciplinas. & 0,79 & 0,76 & 8,92 & 1,24 \\
\hline 4. Linguagem utilizada no material do curso. & 0,88 & 0,81 & 8,96 & 1,46 \\
\hline 5. Leituras recomendadas. & 0,59 & 0,54 & 9,00 & 1,10 \\
\hline $\begin{array}{l}\text { 6. Novidades e lembretes divulgados no ambiente virtual de } \\
\text { aprendizagem (AVA). }\end{array}$ & 0,80 & 0,77 & 8,57 & 1,75 \\
\hline $\begin{array}{l}\text { 7. Links disponibilizados no ambiente virtual de aprendizagem } \\
\text { (AVA). }\end{array}$ & 0,73 & 0,71 & 8,61 & 1,47 \\
\hline 8. Atividades/tarefas propostas ao final de cada disciplina. & 0,75 & 0,70 & 8,55 & 1,29 \\
\hline 9. Orientação para solução de erros nas atividades/tarefas. & 0,79 & 0,76 & 8,03 & 1,99 \\
\hline 10. Quantidade de conteúdo para cada disciplina. & 0,88 & 0,81 & 8,64 & 1,53 \\
\hline 11. Quantidade de horas de estudo sugerida para cada disciplina & 0,80 & 0,75 & 8,74 & 1,67 \\
\hline 12. Fóruns de apresentação. & 0,79 & 0,68 & 8,70 & 1,69 \\
\hline 13. Fóruns de dúvidas. & 0,85 & 0,82 & 8,44 & 1,71 \\
\hline 14. Fóruns de notícias. & 0,80 & 0,71 & 8,06 & 1,79 \\
\hline 15. Fóruns de discussão. & 0,83 & 0,84 & 8,77 & 1,56 \\
\hline 16. Guias das disciplinas. & 0,77 & 0,62 & 8,70 & 1,51 \\
\hline $\mathrm{N}($ listwise $)$ & 77 & & & \\
\hline Eigenvalue (Valor próprio) & 10,41 & & & \\
\hline \% da Variância Explicada & 61,20 & & & \\
\hline No. de itens & 16 & & & \\
\hline Alfa $(\alpha)$ & 0,96 & & & \\
\hline
\end{tabular}

O fator único denominado "Procedimentos Instrucionais em EAD” é composto por 16 itens que se referem aos procedimentos instrucionais e dos recursos de interação. Tais itens avaliam a satisfação dos alunos relacionada aos aspectos instrucionais da disciplina, como as trocas de informações, discussões nos fóruns e informações disponíveis para auxílio na organização e planejamento das atividades (links, lembretes e guias). O fator apresentou um alto índice de consistência interna $(\alpha=0,96)$, com itens cujas cargas fatoriais variaram entre 0,59 e 0,88 . O item 17 "Troca de mensagens entre os alunos" por não possuir carga fatorial igual ou maior que 0,30 , positiva ou negativa, não permaneceu na estrutura. $O$ item está relacionado a interação com os demais alunos da disciplina, bem como pode-se relacionar aos itens referentes a Busca por Ajuda Interpessoal do instrumento Estratégias de Aprendizagem que também apresentaram baixas cargas fatoriais como explicado anteriormente.

Assim como nos estudos de Martins (2012), a solução unifatorial mostra a não diferenciação dos procedimentos instrucionais, considerados tradicionais, pelos alunos da 
referida amostra, comuns nos cursos ofertados nas modalidades presenciais e a distância, tais como: objetivos, planejamento e sequenciação dos conteúdos, linguagem utilizada, carga horária, entre outros; daqueles que são específicos do EAD, como: fóruns, chats, informações disponíveis no AVA (links, avisos, etc.) e troca de mensagens via internet. Talvez esse fato ocorra devido as contínuas atividades presenciais previstas pelos cursos.

\subsubsection{Reação ao desempenho do tutor}

O questionário de Ração ao Desempenho do Tutor apresenta 78 casos válidos. Assim como o instrumento Estratégias de Aprendizagem, o baixo retorno das respostas ao instrumento em questão não atende aos critérios da análise fatorial exploratória (AFE) no que diz respeito à extração dos fatores pela análise de componentes principais (Principal Componentes $-P C$ ) e confirmação da estrutura fatorial de fatoração dos eixos principais (Principal Axis Factoring $P A F$ ), para os quais Pasquali (2004) recomenda o mínimo de 5 casos por variável. Sendo assim, seria necessário o retorno mínimo de 135 respostas válidas para o instrumento. Dessa forma, para verificação de evidências de validade do instrumento, foram realizadas análises de consistência interna (Alfa de Cronbach) considerando os fatores encontrados por Martins (2012), a qual, como dito anteriormente, realizou seus estudos no mesmo contexto do presente estudo (cursos superiores ofertados na modalidade EAD). Após as devidas análises, a autora apresenta o instrumento de Reação ao Desempenho do Tutor $(\alpha=098$, cargas fatoriais entre 0,69 e 0,88 ), composto por 27 itens e formado por um único fator denominado Desempenho do Tutor. Os itens presentes em tal fator avaliam a satisfação dos alunos com a atuação profissional do tutor, a saber: desempenho didático, domínio do conteúdo, incentivo e respeito aos alunos.

O resultado da análise da consistência interna (Alfa de Cronbach) do instrumento Reação ao Desempenho do Tutor, aplicado na amostra do presente estudo a partir do único fator encontrado por Martins (2012) é demonstrado na Tabela 33.

Tabela 33. Consistência Interna (Alfa de Cronbach) da escala de Reação ao Desempenho do Tutor.

\begin{tabular}{lc}
\hline Descrição & Fator 1 \\
\hline $\mathrm{N}$ (listwise) & 78 \\
No. de itens & 27 \\
Alfa $(\alpha)$ & 0,98 \\
\hline
\end{tabular}

O fator único "Desempenho do Tutor” é composto por 27 itens. Tais itens avaliam a satisfação dos alunos relacionada com a atuação profissional do tutor: desempenho didático, 
domínio do conteúdo, incentivo e respeito aos alunos. O fator apresentou um alto índice de consistência interna $(\alpha=0,98)$.

\subsubsection{Síntese dos resultados: verificação de evidências de validade dos instrumentos}

A Tabela 34 apresenta um resumo dos dados dos instrumentos utilizados na presente pesquisa, os quais passaram por análises que visaram a verificação de evidências de validade dos mesmos. Pode-se observar que os índices de confiabilidade variaram de 0,74 a 0,98, indicando que as escalas dos instrumentos apresentam consistência interna.

Tabela 34. Resumo das informações sobre os instrumentos utilizados nesta pesquisa.

\begin{tabular}{llcc}
\hline \multicolumn{1}{c}{ Instrumento } & \multicolumn{1}{c}{ Escalas Obtidas } & $\begin{array}{c}\mathbf{N}^{\mathbf{0}} \mathbf{d e} \\
\text { Itens }\end{array}$ & Alfa \\
\hline \multirow{3}{*}{ Estratégias de Aprendizagem } & Estratégias cognitivas & 15 & 0,85 \\
& Controle da emoção & 4 & 0,80 \\
& Estratégias autorregulatórias & 7 & 0,91 \\
& Busca de ajuda interpessoal & 3 & 0,74 \\
\hline Reação aos Procedimentos & Procedimentos Instrucionais em EAD & 16 & 0,96 \\
Instrucionais & & 27 & 0,98 \\
\hline Reação ao Desempenho do Tutor & Desempenho do Tutor & & \\
\hline \hline
\end{tabular}

\subsection{Análises complementares sobre as escalas: ANOVA e Testes $t$}

Com o objetivo de complementar os resultados obtidos nas análises exploratórias das estruturas empíricas das escalas, e investigar um pouco mais a fundo sobre o perfil dos alunos participantes no presente estudo, foram realizados testes de diferença de médias (ANOVA e Teste $t$ ). Nestas análises, as médias das respostas dos participantes às escalas de Estratégias de Aprendizagem, Reação aos Procedimentos Instrucionais e ao Desempenho do Tutor foram transformadas na variável-critério dos modelos. As variáveis inseridas separadamente nos modelos foram: sexo, idade, curso e experiência anterior em EAD.

Com o objetivo de estudar dois grupos homogêneos, foi selecionada uma amostra dos quatro fatores da variável critério Estratégias de Aprendizagem (Estratégias Cognitivas, Controle da Emoção, Estratégias Autorregulatórias e Busca de Ajuda Interpessoal) do mesmo tamanho da amostra das variáveis sociodemograficas (sexo, idade, e experiência anterior em EAD). Sendo assim, ficaram dois grupos de 28 participantes para a variável sexo, dois grupos de 40 participantes para a variável idade e dois grupos de 31 participantes para a variável experiência anterior em EAD. Para essas análises foi realizado o Test $t$, contudo, apenas na variável idade, os resultados apresentaram diferenças significativas em comparação com as 
médias dos fatores de Estratégias de Aprendizagem Autorregulatória e Busca de Ajuda Interpessoal. A variável idade foi recategorizada para agrupar um número de participantes menos desigual entre as categorias. Tais resultados podem ser visualizados na Tabela 35 .

Tabela 35. Teste de diferença entre médias (Teste $t$ ), segundo idade dos participantes.

\begin{tabular}{|c|c|c|c|c|c|}
\hline Idade* & Média & Desvio-Padrão & $t$ & $g l$ & $P * *$ \\
\hline \multicolumn{6}{|c|}{ Média Estratégias de Aprendizagem - Autorregulatórias (EA3) } \\
\hline De 20 a 39 anos & 8,81 & 0,97 & 2,57 & 78 & 0,03 \\
\hline Acima de 40 anos & 8,11 & 1,44 & & & \\
\hline \multicolumn{6}{|c|}{ Média Estratégias de Aprendizagem - Busca de Ajuda Interpessoal (EA4) } \\
\hline De 20 a 39 anos & 7,01 & 2,20 & 1,66 & 78 & 0,04 \\
\hline Acima de 40 anos & 6,08 & 2,75 & & & \\
\hline
\end{tabular}

* De 20 a 39 anos $\mathrm{N}=40$; Acima de 40 anos $\mathrm{N}=40$.

$* *$ Considerando $\mathrm{p}<0,05$.

Verificou-se que existem diferenças significativas entre as médias dos grupos definidos a partir da idade em comparação com as médias obtidas da utilização de estratégias de aprendizagem que envolve de controle da motivação e monitoramento da compreensão que auxiliam na autorregulação da aprendizagem, bem como estratégias de aprendizagem voltadas para a busca por ajuda de outros indivíduos (tutores ou colegas) para tirar dúvida. Assim, é possível afirmar que os alunos entre 20 e 39 anos utilizam mais estratégias autorregulatórias $(\mathrm{p}=0,03)$ e busca de ajuda interpessoal $(\mathrm{p}=0,04)$.

Para as demais variáveis sociodemograficas citadas, os resultados não mostraram diferenças significativas em comparação com as médias dos fatores da variável critério, demonstrando que não há relação entre o sexo e experiências anteriores com a modalidade de ensino à distância e as estratégias de aprendizagem utilizadas pelos alunos que compõem a presente amostra. As mesmas análises foram realizadas com as variáveis Procedimentos Instrucionais e Desempenho do Tutor. Assim como a variável critério Estratégias de Aprendizagem, os resultados não mostraram diferenças significativas em comparação com as médias dos dois fatores e as variáveis sociodemográficas citadas.

Para realizar a comparação dos cursos em relação à médias dos escores das escalas, também foi realizado o teste de diferença entre médias ANOVA. Na Tabela 36 são apresentados os resultados, segundo os cursos dos participantes, considerando $\mathrm{p}<0,05$. 
Tabela 36. Teste de diferença entre médias (ANOVA), segundo o curso dos participantes.

\begin{tabular}{|c|c|c|c|c|c|}
\hline Curso & Média & Desvio-Padrão & $\boldsymbol{F}$ & $g l$ & $P * *$ \\
\hline \multicolumn{6}{|c|}{ Média de Estratégias Cognitivas (EA1) } \\
\hline Administração Pública (18) & 7,33 & 1,47 & 2,88 & 82 & 0,01 \\
\hline Pedagogia (16) & 8,44 & 1,06 & & & \\
\hline Educação Física (9) & 8,44 & 1,07 & & & \\
\hline Gestão em Enfermagem (13) & 8,32 & 0,87 & & & \\
\hline Mídias na Educação (12) & 8,75 & 0,94 & & & \\
\hline Práticas de Letramento e Alfabetização (6) & 7,36 & 1,56 & & & \\
\hline Educação Empreendedora (9) & 8,13 & 0,79 & & & \\
\hline \multicolumn{6}{|c|}{ Média de Procedimentos Instrucionais (PI) } \\
\hline Administração Pública (18) & 7,78 & 1,73 & 2,97 & 76 & 0,01 \\
\hline Pedagogia (16) & 9,33 & 0,82 & & & \\
\hline Educação Física (9) & 8,90 & 1,23 & & & \\
\hline Gestão em Enfermagem (13) & 8,92 & 0,77 & & & \\
\hline Mídias na Educação (12) & 8,92 & 0,56 & & & \\
\hline Práticas de Letramento e Alfabetização (6) & 8,65 & 0,44 & & & \\
\hline Educação Empreendedora (9) & 8,46 & 1,15 & & & \\
\hline
\end{tabular}

**Considerando $\mathrm{p}<0,05$.

Verificou-se que existem diferenças significativas entre as médias dos grupos definidos a partir do curso em comparação com as médias obtidas da utilização de estratégias de aprendizagem cognitivas e percepção dos participantes relacionada aos procedimentos tradicionais. É possível afirmar, a partir da análise do teste Post Hoc, que o grupo de participantes dos cursos Mídias na Educação $(\mathrm{M}=8,75$; $\mathrm{DP}=0,94)$, seguido por Pedagogia $(\mathrm{M}=8,44 ; \mathrm{DP}=1,06)$ e Educação Física $(\mathrm{M}=8,44 ; \mathrm{DP}=1,07)$ utilizam com mais frequência as estratégias de aprendizagem cognitivas $(\mathrm{p}=0,01)$. O grupo de alunos dos cursos de Pedagogia $(M=9,33 ; D P=0,82)$, Gestão em Enfermagem $(M=8,92 ; D P=0,77)$ e Mídias na Educação $(\mathrm{M}=8,92 ; \mathrm{DP}=0,56)$ avaliaram mais favoravelmente os procedimentos instrucionais do que os alunos dos demais cursos $(\mathrm{p}=0,01)$. O resumo dos achados nos Testes $t$ e ANOVA são apresentados de maneira resumida na Tabela 37 abaixo:

Tabela 37. Resumo dos resultados das análises de diferenças de médias (Teste $t$ e ANOVA).

\begin{tabular}{l|l}
\multicolumn{1}{c|}{ Variável } & \multicolumn{1}{c}{ Resultado } \\
\hline $\begin{array}{l}\text { O participante que pertence ao grupo de } \\
\text { participantes com idade entre 20 e 39 anos... }\end{array}$ & $\begin{array}{l}\text { Utilizou mais Estratégias Autorregulatórias (EA3) e Busca } \\
\text { de Ajuda Interpessoal (EA4). }\end{array}$ \\
\hline $\begin{array}{l}\text { Os participantes dos cursos: Mídias na } \\
\text { Educação, Pedagogia e Educação Física... }\end{array}$ & $\begin{array}{l}\text { Utilizaram com mais frequência Estratégias Cognitivas } \\
\text { (EA1) }\end{array}$ \\
\hline $\begin{array}{l}\text { Os participantes dos cursos: Pedagogia, Gestão } \\
\text { em enfermagem e Mídias na Educação... }\end{array}$ & $\begin{array}{l}\text { Avaliaram mais favoravelmente os Procedimentos } \\
\text { Instrucionais; }\end{array}$ \\
\hline
\end{tabular}

\subsection{Análises de regressão múltipla}

As análises de regressão múltipla foram realizadas visando cumprir o objetivo de testagem do modelo proposto. As variáveis que compõem o modelo sofreram análises 
exploratórias, de acordo com os critérios de Tabachnick e Fidell (2007). As análises de regressão devem respeitar os seguintes critérios de inclusão: amostra maior ou igual a 50 casos mais oito vezes o número de variáveis antecedentes $(\mathrm{N} \geq 50+8 \mathrm{~m})$ para testagem de correlações múltiplas e $\mathrm{N} \geq 104+\mathrm{m}$ para testagem de preditores individuais (Tabachnick \& Fidell, 2007). $\mathrm{Na}$ análise stepwise, uma amostra maior é necessária (razão de 40 casos para cada variável antecedente). Portanto, para testar o modelo, foi possível realizar a regressão padrão com apenas 3 variáveis antecedentes $(\mathrm{N} \geq 50+8.3=\mathrm{N} \geq 74)$.

A presente pesquisa buscou identificar as variáveis preditoras de Estratégias de Aprendizagem relacionadas ao perfil da clientela (dados sociodemográficos e uso de ferramentas eletrônicas) e reações (desempenho do tutor e procedimentos instrucionais) a partir de um modelo de avaliação de ações educacionais ofertadas a distância. Para isso 4 modelos foram testados, um para cada fator do instrumento Estratégias de Aprendizagem, a saber: EA1 - "Estratégias Cognitivas", EA2 - "Controle da Emoção", EA3 - "Estratégias Autorregulatórias" e EA4 - "Busca da Ajuda Interpessoal". Nos modelos foram as variáveis antecedentes que apresentaram maior correlação com a variável critério.

Para a testagem do Modelo A, foram incluídas as seguintes variáveis antecedentes: média das respostas aos itens do instrumento de variáveis sociodemográficas (idade), média das respostas aos itens do fator único do instrumento Reação aos Procedimentos Instrucionais (PI); média das respostas aos itens do fator único do instrumento Reação ao Desempenho do Tutor (DT). A variável critério estudada, EA1 (estratégias cognitivas), é composta pela média das respostas dos participantes ao uso de estratégias cognitivas de repetição, organização e elaboração, bem como estratégias de busca de ajuda ao material didático e aplicação prática. Na Figura 10 é possível visualizar o modelo A.

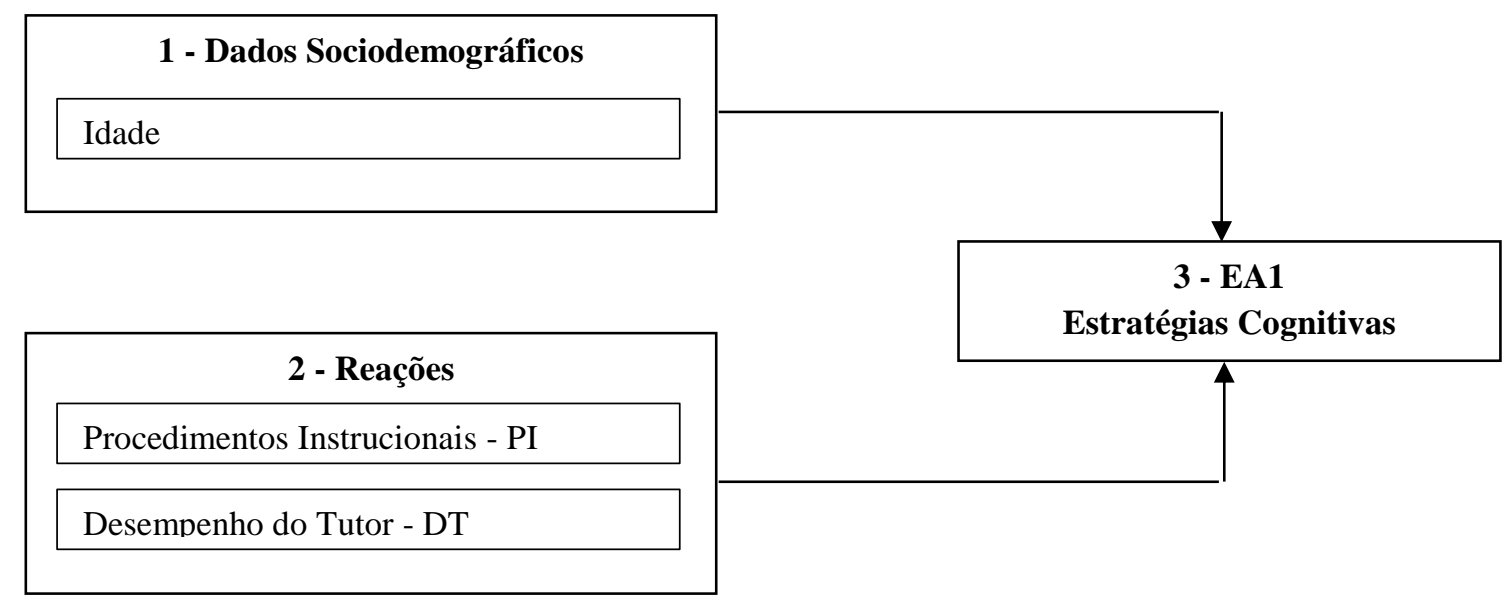

Figura 10. Modelo de Análise de predição de EA1 - Estratégias Cognitivas. 
A Tabela 38 apresenta as relações entre as variáveis, os coeficientes de regressão não padronizados (B), os coeficientes de regressão padronizados $(\beta)$, a contribuição individual de cada variável $\left(\mathrm{Sr}^{2}\right)$, as médias das variáveis $(\mathrm{X})$, os desvios-padrão (DP), a constante, o $\mathrm{R}^{2}$ (correlação entre todas as variáveis antecedentes com a variável critério - variância individual e compartilhada das variáveis antecedentes em relação à variável critério), o $\mathrm{R}^{\mathbf{2}}$ ajustado (estimativa do $\mathrm{R}^{2}$ da população) e o $\mathrm{R}$ (correlação entre a variável critério e as variáveis antecedentes).

Tabela 38. Regressão Múltipla padrão para o modelo de investigação A.

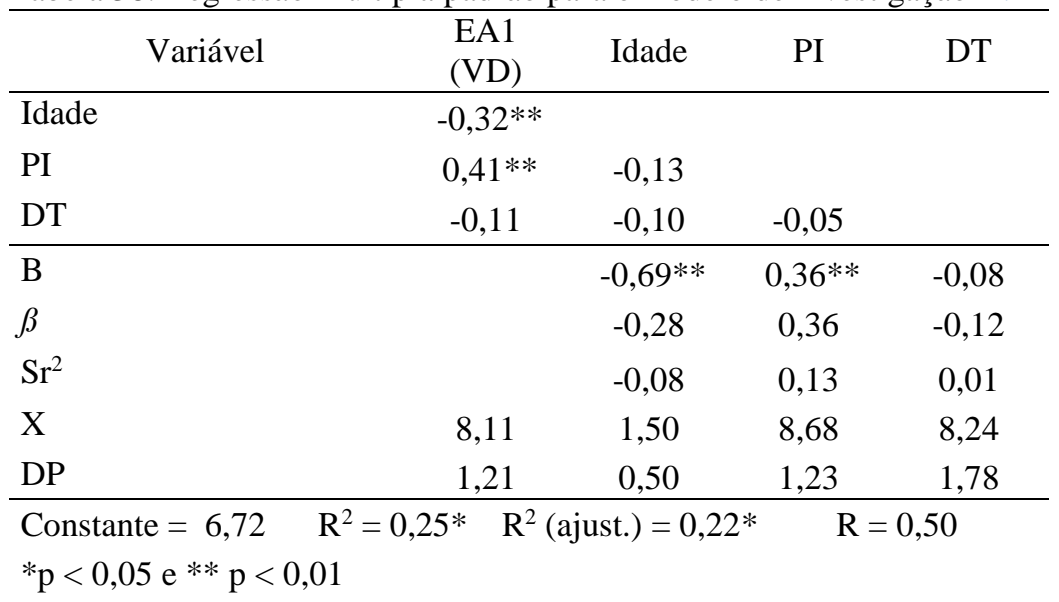

$\mathrm{O}$ coeficiente de regressão múltipla $\mathrm{R}$ foi significativamente diferente de zero, $\mathrm{F}(8,139)=5,58,<0,001$, com limites de confiança de 95\%. As variáveis antecedentes que contribuíram significativamente para a explicação de Estratégias Cognitivas de Aprendizagem, tendo considerado o intervalo de confiança de 95\%, foram: Idade $(\beta=-0,28), \operatorname{PI}(\beta=0,36)$ e DT $(\beta=-0,12)$. Agrupadas, as 3 variáveis iniciais, explicam 25\% (22\% ajustado) da variabilidade de Estratégias Cognitivas de Aprendizagem. A Figura 11 esquematiza os relacionamentos somente entre as variáveis que indicaram maior poder preditivo com a variável critério.

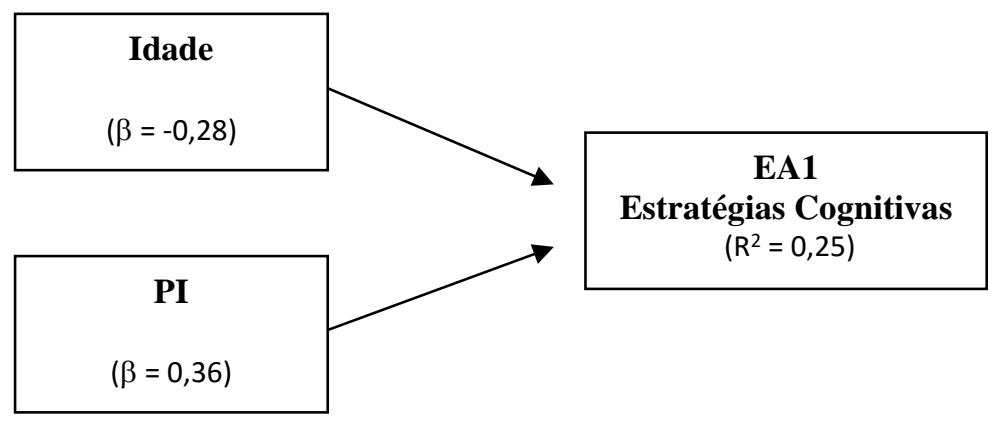

Figura 11. Representação do modelo de regressão múltipla para EA1 como variável critério. 
Em suma os alunos que mais utilizaram as estratégias cognitivas de repetição, organização e elaboração são os alunos que avaliaram favoravelmente os procedimentos instrucionais dos cursos avaliados, por existir uma relação positiva entre as Estratégias Cognitivas e os Procedimentos Instrucionais. Em relação a idade, o modelo mostra uma correlação inversa (negativa) entre o fator Idade e Estratégias Cognitivas, ou seja, quanto menor a idade da amostra, mais estratégias cognitivas são utilizadas.

No Modelo B, foram incluídas as seguintes variáveis antecedentes: média das respostas aos itens do instrumento de variáveis sociodemográficas (Idade e experiência anterior em EAD - ExpEAD), e média das respostas aos itens do fator único do instrumento Reação aos Procedimentos Instrucionais (PI). A variável critério estudada foi a média das respostas que compõe o fator EA2 (controle emoção), que são estratégias voltadas para o controle da ansiedade e prevenção de dispersões de concentração causadas por sentimentos de ansiedade no momento de estudo pelos participantes. O Modelo B é apresentado na Figura 12 .

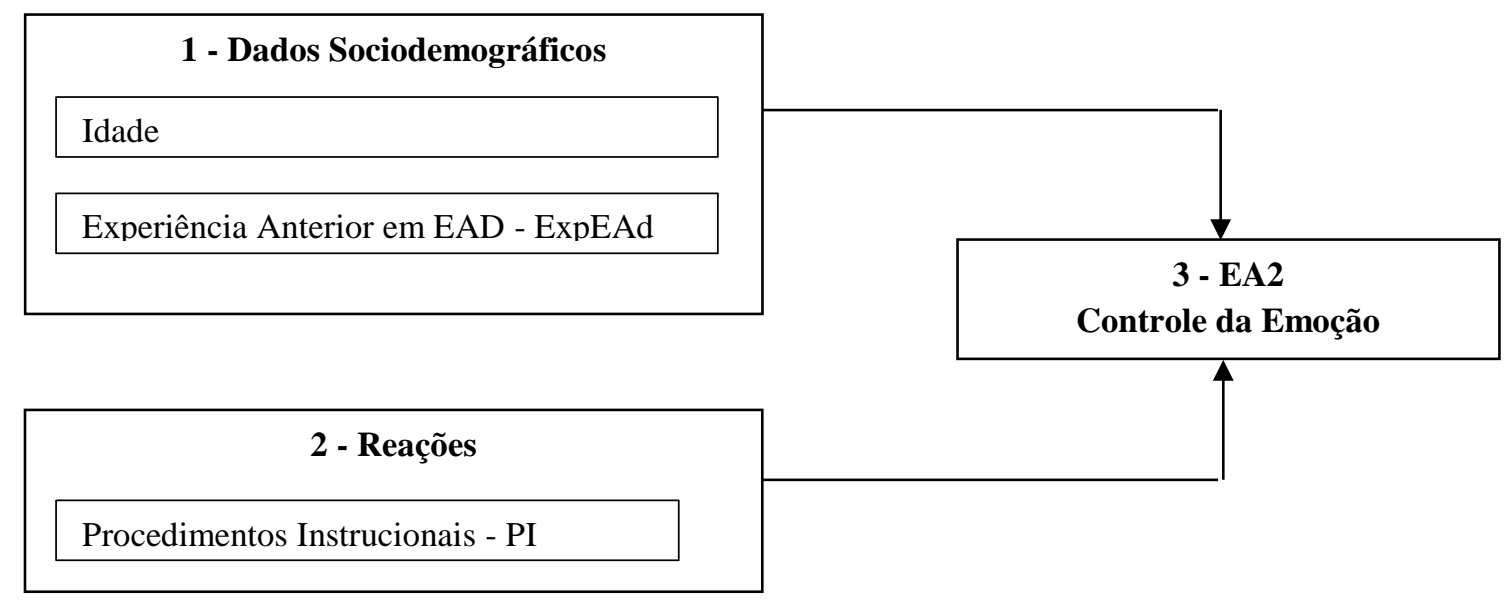

Figura 12. Modelo de Análise de predição de EA2 - Controle da Emoção.

Na Tabela 39 são apresentadas as relações entre as variáveis, os coeficientes de regressão não padronizados $(B)$, os coeficientes de regressão padronizados $(\beta)$, a contribuição individual de cada variável $\left(\mathrm{Sr}^{2}\right)$, as médias das variáveis $(\mathrm{X})$, os desvios-padrão (DP), a constante, o $\mathrm{R}^{\mathbf{2}}$ (correlação entre todas as variáveis antecedentes com a variável critério variância individual e compartilhada das variáveis antecedentes em relação à variável critério), o $\mathrm{R}^{2}$ ajustado (estimativa do $\mathrm{R}^{2}$ da população) e o $\mathrm{R}$ (correlação entre a variável critério e as variáveis antecedentes). 
Tabela 39. Regressão Múltipla padrão para o modelo de investigação B.

\begin{tabular}{lcccc}
\hline Variável & $\begin{array}{c}\text { EA2 } \\
\text { (VD) }\end{array}$ & Idade & ExpEAD & PI \\
\hline Idade & $-0,19$ & & & \\
ExpEAD & $-0,19$ & $-0,13$ & & \\
$\mathrm{PI}$ & $0,43 * *$ & $-0,12$ & $-0,06$ & \\
\hline $\mathrm{B}$ & & $-0,48$ & $-0,56$ & 0,48 \\
$\beta$ & & $-0,16$ & $-0,19$ & 0,40 \\
$\mathrm{Sr}^{2}$ & & $-0,03$ & $-0,04$ & 0,16 \\
$\mathrm{X}$ & & 1,43 & 1,45 & 8,68 \\
$\mathrm{DP}$ & 8,09 & 0,50 &, 49 & 1,23 \\
\hline Constante $=4,92 \quad \mathrm{R} 2=0,24$ & $\mathrm{R} 2$ (ajust.) $=0,21$ & $\mathrm{R}=0,49$ & \\
$* \mathrm{p}<0,05 \mathrm{e} * * \mathrm{p}<0,01$ & \multicolumn{5}{c}{} & \\
\end{tabular}

Foi significativamente diferente de zero o coeficiente de regressão múltipla $\mathrm{R}, \mathrm{F}(7,62)$ $=4,02<0,001$, sendo considerados limites de confiança de $95 \%$. As variáveis antecedentes que contribuíram significativamente para a explicação de Estratégias de Aprendizagem de Controle da Emoção, tendo considerado o intervalo de confiança de $95 \%$, foram: Idade $(\beta=-0,16)$, $\operatorname{ExpEAD}(\beta=-0,19)$ e PI $(\beta=0,40)$. Agrupadas, as 3 variáveis iniciais, explicam $24 \%(21 \%$ ajustado) da variabilidade de Estratégias de Aprendizagem com Controle da Emoção. A Figura 13 esquematiza o relacionamento identificado entre as variáveis que indicaram maior poder preditivo com a variável critério

\begin{tabular}{|c|c|}
\hline \multirow{2}{*}{ PI } \\
\cline { 2 - 3 }$(\beta=0,40)$
\end{tabular}$\stackrel{\begin{array}{c}\text { EA2 } \\
\text { Controle da Emoção } \\
\left(R^{2}=0,24\right)\end{array}}{\longrightarrow}$

Figura 13. Representação do modelo de regressão múltipla para EA2 como variável critério.

Em síntese, os alunos que demonstraram maior frequência o controle da ansiedade, bem como a prevenção de dispersões de concentração com causa na ansiedade durante o estudo, são os alunos que apresentaram satisfação favorável em relação aos procedimentos instrucionais dos cursos avaliados. Assim, os procedimentos instrucionais podem influenciar tais estratégias de forma significativa. Contudo, para a presente amostra, as variáveis idade e experiência anterior com EAD, não influenciaram significativamente o uso de estratégias do controle da emoção.

Para a testagem do Modelo C, foram consideradas as seguintes variáveis antecedentes: média das respostas aos itens do instrumento de variáveis sociodemográficas (Idade), média das respostas aos itens do fator único do instrumento Reação aos Procedimentos Instrucionais 
(PI); média das respostas aos itens do fator único do instrumento Reação ao Desempenho do Tutor (DT). A variável critério estudada foi a média das respostas que compõe o fator EA3 (estratégias autorregulatórias), voltadas para o controle da motivação e monitoramento da compreensão. A Figura 14 apresenta o Modelo C.

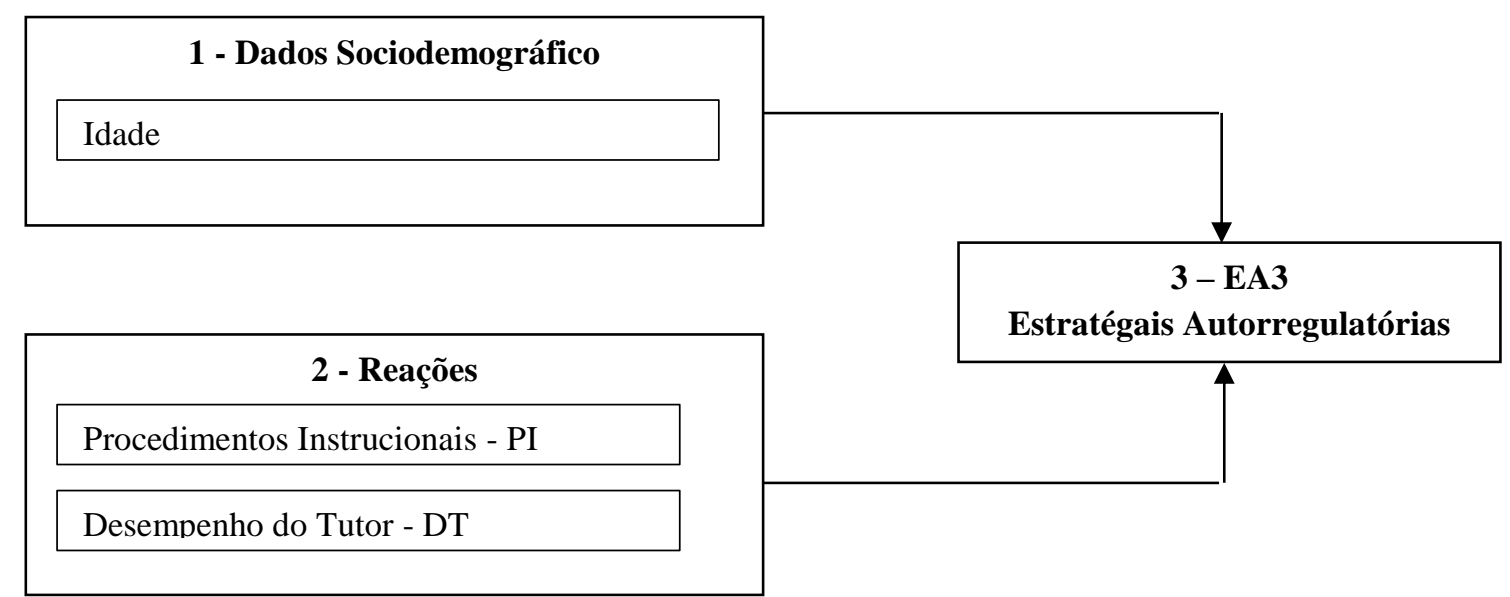

Figura 14. Modelo de Análise de predição de EA3 - Estratégias Autorregulatórias.

A Tabela 40 apresenta as relações entre as variáveis, os coeficientes de regressão não padronizados (B), os coeficientes de regressão padronizados $(\beta)$, a contribuição individual de cada variável $\left(\mathrm{Sr}^{2}\right)$, as médias das variáveis (X), os desvios-padrão (DP), a constante, o $\mathrm{R}^{2}$ (correlação entre todas as variáveis antecedentes com a variável critério - variância individual e compartilhada das variáveis antecedentes em relação à variável critério), o $\mathrm{R}^{2}$ ajustado (estimativa do $\mathrm{R}^{2}$ da população) e o $\mathrm{R}$ (correlação entre a variável critério e as variáveis antecedentes).

Tabela 40. Regressão Múltipla padrão para o modelo de investigação C.

\begin{tabular}{|c|c|c|c|c|}
\hline Variável & $\begin{array}{l}\text { EA3 } \\
\text { (VD) }\end{array}$ & Idade & PI & DT \\
\hline Idade & $-0,25^{*}$ & & & \\
\hline PI & $0,43 * *$ & $-0,13$ & & \\
\hline DT & $-0,05$ & $-0,10$ & $-0,05$ & \\
\hline B & & $-0,52$ & 0,42 & $-0,03$ \\
\hline$\beta$ & & $-0,21$ & 0,41 & $-0,05$ \\
\hline $\mathrm{Sr}^{2}$ & & 0,04 & 0,16 & 0,00 \\
\hline$X$ & 8,50 & 1,50 & 8,68 & 8,24 \\
\hline DP & 1,27 & 0,50 & 1,23 & 1,78 \\
\hline
\end{tabular}

O coeficiente de regressão múltipla $R$ foi significativamente diferente de zero, $F(7,21)$ $=4,66,<0,001$, com limites de confiança de 95\%. As variáveis antecedentes que contribuíram 
significativamente para a explicação de Estratégias Autorregulatórias de aprendizagem, tendo considerado o intervalo de confiança de $95 \%$, foram: Idade $(\beta=-0,21)$, PI $(\beta=0,41)$ e DT $(\beta$ $=-0,05)$. Agrupadas, as 3 variáveis iniciais, explicam 23\% (20\% ajustado) da variabilidade das Estratégias de Aprendizagem Autorregulatórias.

A Figura 15 esquematiza os relacionamentos somente entre as variáveis que indicaram maior poder preditivo com a variável critério.

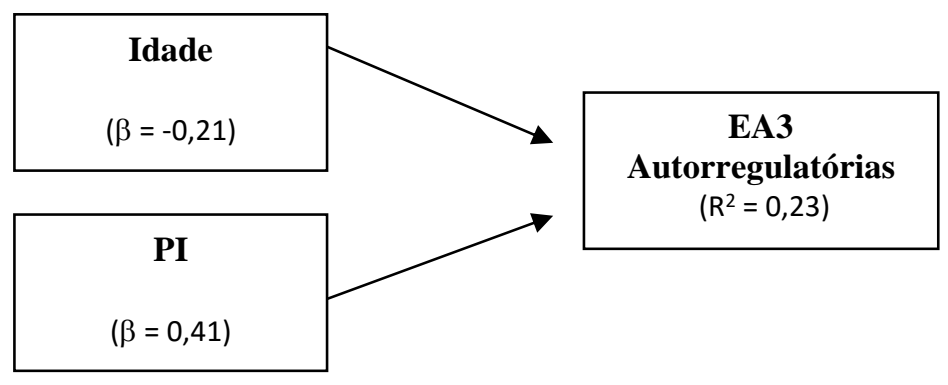

Figura 15. Representação do modelo de regressão múltipla para EA3 como variável critério.

Assim como as Estratégias Cognitivas (EA1), os alunos que mais utilizaram as Estratégias Autorregulatórias (EA3) de controle da motivação e monitoramento da compreensão que auxiliam na autorregulação da aprendizagem são os alunos que avaliaram favoravelmente os procedimentos instrucionais dos cursos avaliados, por existir uma relação positiva entre as Estratégias Autorregulatórias e os Procedimentos Instrucionais. Considerando que as estratégias de aprendizagem cognitivas e autorregulatórias, são decorrentes de um complexo conjunto de capacidades cognitivas desenvolvidas pelo indivíduo ao longo de sua vida, é compreensível que estudantes que utilizam de tais estratégias tenham maior compreensão dos procedimentos instrucionais utilizados pelas IES, se beneficiando do processo de aprendizagem e consequentemente tendo uma maior satisfação pelos mesmos. Em relação a idade, o modelo mostra uma relação inversa (negativa) entre o fator Idade e Estratégias Autorregulatórias, ou seja, quanto menor a idade da amostra, mais estratégias autorregulatórias são utilizadas.

Por fim, no Modelo D foram consideradas as seguintes variáveis antecedentes: média das respostas aos itens do instrumento de variáveis sociodemográficas (Idade e experiência anterior em EAD), e média das respostas aos itens do fator único do instrumento Reação aos Procedimentos Instrucionais (PI). A variável critério estudada foi a média das respostas que compõe o fator EA4 (busca ajuda interpessoal), medida em termos do comportamento proativo 
do indivíduo de buscar auxilio com seus pares (tutores e colegas). O Modelo D é apresentado na Figura 16.

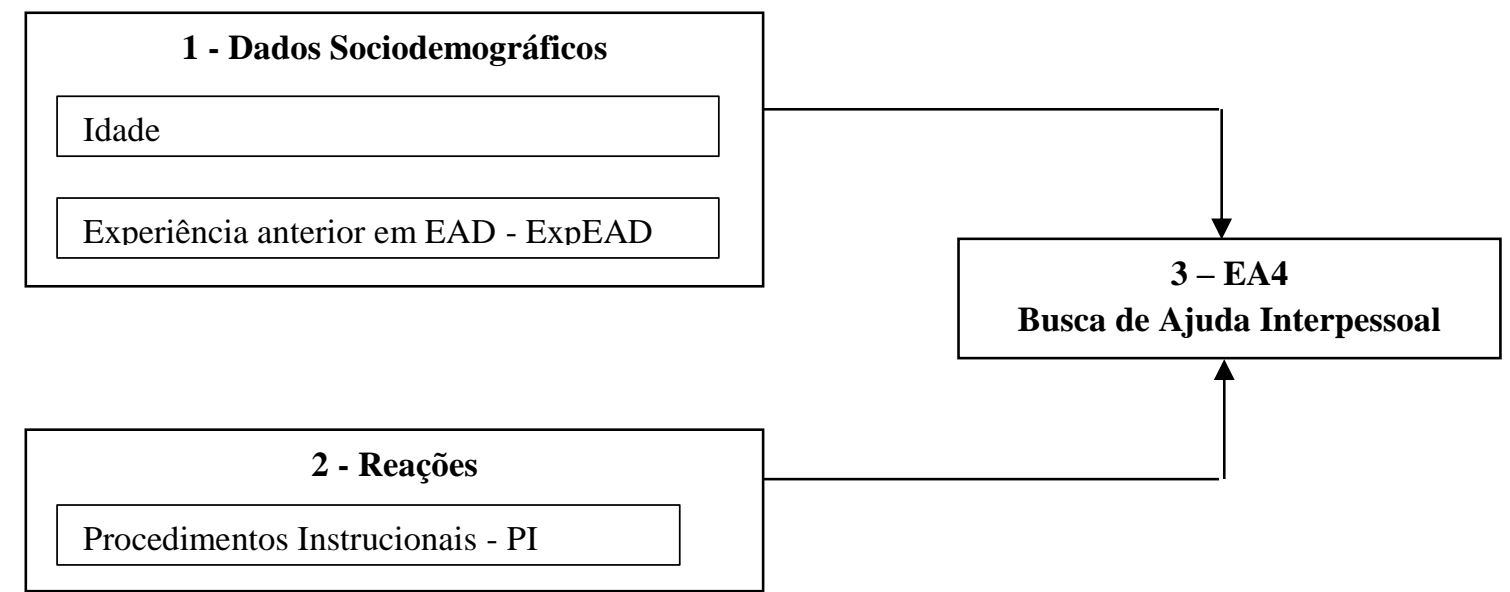

Figura 16. Modelo de Análise de predição de EA4 - Busca Ajuda Interpessoal.

$\mathrm{Na}$ Tabela 41 encontram-se descritas as relações entre as variáveis, os coeficientes de regressão não padronizados $(\mathrm{B})$, os coeficientes de regressão padronizados $(\beta)$, a contribuição individual de cada variável $\left(\mathrm{Sr}^{2}\right)$, as médias das variáveis $(\mathrm{X})$, os desvios-padrão (DP), a constante, o $\mathrm{R}^{\mathbf{2}}$ (correlação entre todas as variáveis antecedentes com a variável critério variância individual e compartilhada das variáveis antecedentes em relação à variável critério), o $\mathrm{R}^{2}$ ajustado (estimativa do $\mathrm{R}^{2}$ da população) e o $\mathrm{R}$ (correlação entre a variável critério e as variáveis antecedentes).

Tabela 41. Regressão Múltipla padrão para o modelo de investigação D.

\begin{tabular}{lcccc}
\hline Variável & $\begin{array}{c}\text { EA4 } \\
\text { (VD) }\end{array}$ & Idade & ExpEAD & PI \\
\hline Idade & $-0,17$ & & & \\
ExpEAD & $-0,03$ & $-0,13$ & & \\
PI & $0,23^{*}$ & $-0,12$ & $-0,06$ & \\
\hline $\mathrm{B}$ & & $-0,77$ & $-0,20$ & 0,42 \\
$b$ & & $-0,15$ & $-0,04$ & 0,20 \\
$\mathrm{Sr}^{2}$ & & $-0,02$ & 0,00 & 0,04 \\
$\mathrm{X}$ & & 1,50 & 8,68 & 8,24 \\
$\mathrm{DP}$ & 6,62 & 0,50 & 1,23 & 1,78 \\
\hline Constante $=4,45$ & $\mathrm{R} 2=0,07$ & $\mathrm{R} 2$ (ajust.) $=0,04$ & $\mathrm{R}=0,27$ & \\
$* \mathrm{p}<0,05 \mathrm{e} * * \mathrm{p}<0,01$ & & & &
\end{tabular}

$\mathrm{O}$ coeficiente de regressão múltipla $\mathrm{R}$ foi diferente de zero, $\mathrm{F}(1,94)=1,75<0,001$, sendo considerados limites de confiança de $95 \%$. As variáveis antecedentes que contribuíram significativamente para a explicação das Estratégias de Busca Ajuda Interpessoal pelos alunos foram, Idade $(\beta=-0,15), \operatorname{ExpEAD}(\beta=-0,04)$ e PI $(\beta=0,20)$. Agrupadas, as 3 variáveis iniciais, 
explicam 7\% (4\% ajustado) da variabilidade de Estratégias de Aprendizagem com Busca da Ajuda Interpessoal. A Figura 17 demostra o relacionamento identificado entre as variáveis que indicaram maior poder preditivo com a variável critério

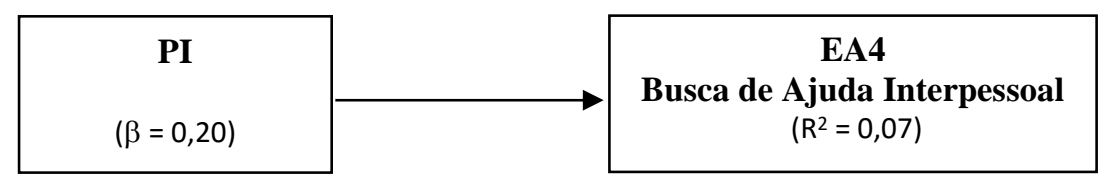

Figura 17, Representação do modelo de regressão múltipla para EA4 como variável critério.

Em suma, os alunos que demonstraram a busca ativa por iniciativa própria, busca pela a ajuda de outros indivíduos (tutores ou colegas) para tirar dúvida, são os alunos que avaliaram favoravelmente os procedimentos instrucionais das disciplinas avaliadas, mesmo sendo estas as estratégias menos utilizadas pela amostra do presente estudo como demonstra a análise descritiva do instrumento Estratégias de Aprendizagem.

A Figura 18 apresenta o resumo dos resultados dos modelos de regressão aplicados no presente estudo.

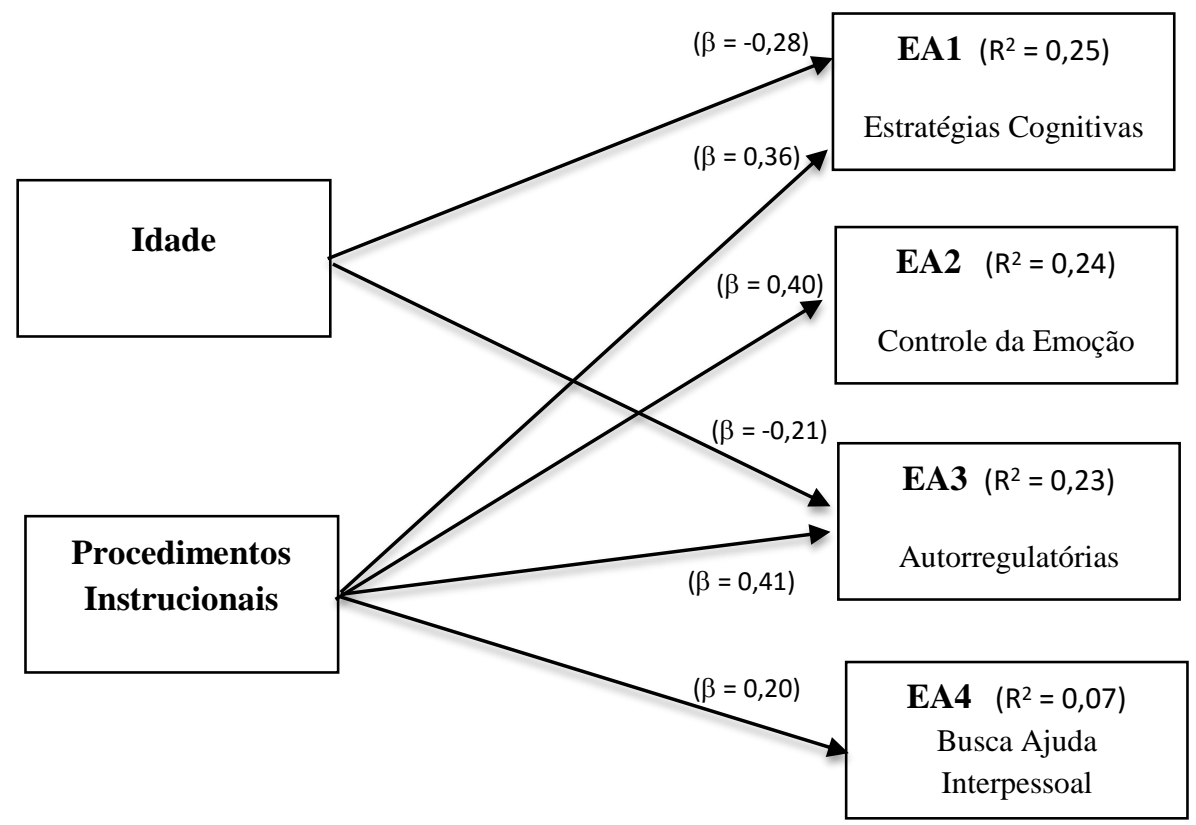

Figura 18. Resumo dos resultados dos modelos de regressão.

Percebe-se que os Procedimentos Instrucionais foi a variável relacionada a satisfação (reação) que se manteve presente nos quatro modelos aqui apresentados, como a variável de maior poder preditivo com a variável critério Estratégias de Aprendizagem nos seus quatro fatores (EA1 - Estratégias Cognitivas; EA2 - Controle da Emoção; EA3 - Estratégias Autorregulatórias e EA4 - Busca Ajuda Interpessoal). Esse resultado demonstra a satisfação 
dos participantes com a qualidade dos objetivos de ensino, o conteúdo trabalhado nas disciplinas, bem como a sequenciação dos mesmos, as avaliações de aprendizagem, as estratégias utilizadas no curso e os meios e seu impacto nas estratégias de aprendizagem utilizadas pelos mesmos. Dessa forma, pode-se dizer que os procedimentos instrucionais da ação educacional influenciam nas estratégias de aprendizagem utilizadas pelos alunos ao longo de tal ação. Assim, os procedimentos instrucionais devem ser pensados e elaborados estrategicamente na fase de planejamento da ação educacional de forma que motive os alunos visando os bons resultados da ação educacional.

A única variável sociodemográficas que aparecem como variável preditiva foi a variável Idade e ainda nos modelos A e C (Estratégias Cognitivas e Autorregulatórias), ou seja, os alunos entre 20 e 39 anos usaram com maiores frequências tais estratégias de aprendizagem. Após a apresentação todos os resultados do presente estudos, a próxima seção trata da discussão, relacionando os resultados com os achados da literatura. 


\section{CAPÍTULO 6. DISCUSSÃO}

O objetivo deste capítulo é discutir os principais resultados obtidos na presente pesquisa, relacionando-os com os objetivos propostos e com resultados de pesquisa encontrados na revisão de literatura.

\subsection{Discussões dos resultados de análises fatoriais exploratórias dos instrumentos}

Os objetivos específicos de verificar evidências de validade dos instrumentos utilizados: "Estratégias de aprendizagem", "Reação aos procedimentos instrucionais" e "Reação ao desempenho do tutor", em contexto de IES foram parcialmente atingidos. Devido ao baixo índice de retorno dos instrumentos aplicados na presente pesquisa, somente no instrumento Reação aos Procedimentos Instrucionais foi possível realizar a AFE. Nos demais instrumentos: Estratégias de Aprendizagem e Reação ao Desempenho do Tutor, foram realizadas apenas análises de consistência interna, com base nos fatores encontrados por Martins (2012). A seguir são apresentas as discussões referente aos referidos instrumentos.

\section{Estratégias de Aprendizagem}

O instrumento Estratégias de Aprendizagem foi adaptado e aplicado em contexto de graduação a distância por Martins (2012), que recomendou sua aplicação e consequente validação estatística em outras amostras, no mesmo contexto (EAD em IES). Na literatura nacional e internacional, é possível encontrar diversos autores que buscaram mensurar Estratégias de Aprendizagem. Assim, vários contextos escolares foram utilizados para a aplicação de instrumentos voltados ao construto, entre eles, as séries iniciais no nível fundamental (Boruchovitch \& Santos, 2004; Boruchovitch et al., 2006; Costa \& Boruchovitch, 2009), e o nível superior (Ribeiro \& Silva, 2000). Warr e Dowming (2000) focaram as Estratégias de Aprendizagem utilizadas em ambientes de trabalho e cursos técnicos profissionalizantes. Outros autores investigaram as Estratégias de Aprendizagem utilizadas em treinamentos ofertados no contexto a distância (Zerbini et al., 2005), bem como cursos de qualificação profissional a distância (Borges-Ferreira, 2005; Zerbini \& Abbad, 2008).

Como explicado anteriormente, devido ao baixo retorno dos questionários, no presente estudo, foram utilizados para as análises os quatro fatores encontrados por Martins (2012) a saber: 1) Estratégias cognitivas; 2) Controle da emoção; 3) Estratégias autorregulatórias e 4) Busca de ajuda interpessoal. O primeiro fator, Estratégias cognitivas, é composto por 15 itens (15 ao 29) e apresentou um índice bom de consistência interna $(\alpha=0,85)$. Conforme explicado 
anteriormente, dos 15 itens pertencentes a esse fator, 12 são provenientes das estratégias cognitivas de repetição, organização e elaboração (reflexão ativa), dois itens reverem-se a estratégias de busca de ajuda ao material didático e um de aplicação prática, ambas comportamentais (Warr \& Allan, 1998).

O Fator Controle da emoção, também apresentou um bom índice de consistência interna $(\alpha=0,80)$, e é formado por 4 itens ( 1 ao 4 ). Tais itens representam estratégias que demonstram o controle de ansiedade no momento do estudo (Warr \& Allan, 1998), e assim corrobora com a literatura anterior.

O Fator 3, Estratégias Autorregulatórias, é formado por 7 itens (5 ao 11) e apresentou um excelente índice de consistência interna $(\alpha=0,91)$. De acordo com Martins (2012), as estratégias autorregulatórias de controle da motivação e monitoramento da compreensão uniram-se em um mesmo fator e estão de acordo com a proposta de Warr e Allan (1998).

Por fim, o Fator 4, Busca de Ajuda Interpessoal, apresentou um índice razoável de consistência interna $(\alpha=0,74)$ e é formado por 3 itens (12, 13 e 14). Tais itens expressam a busca ativa, por iniciativa do próprio aluno, pela ajuda de outras pessoas (tutores ou pares) para tirar dúvidas. Essas estratégias comportamentais representam um comportamento proativo do indivíduo de buscar auxílio, ao invés de obter informações do material do curso (Warr \& Allan, 1998).

Os resultados das análises descritivas mostram que os itens que tiveram maior média foram: 27) “Associei os conteúdos do curso aos meus conhecimentos anteriores” (M=9,36 e $\mathrm{DP}=0,97)$; 29) "Identifiquei situações diárias em que eu pudesse aplicar os conteúdos do curso" ( $\mathrm{M}=9,07$ e $\mathrm{DP}=1,10)$ e 10) "Busquei solucionar minhas dúvidas ao consultar as apostilas do curso" (M=8,88 e DP=1,24). Os dois primeiros itens pertencem ao fator Estratégias Cognitivas e o terceiro ao fator Estratégias Autorregulatórias. Assim, conclui-se que tais fatores foram os mais utilizados pelos alunos que compõem a presente amostra. Os itens 27 e 29 são considerados estratégia cognitiva, sendo o primeiro de elaboração e o segundo comportamental de aplicação prática, o item 10 (Warr \& Allan, 1998), é considerado uma Estratégia Comportamental, por se tratar da busca de ajuda ao Material Didático e foi agrupado no fator de Estratégias Autorregulatórias de Martins (2012).

Os itens que apresentaram as médias mais baixas nas análises descritivas foram: 13) "Busquei auxílio de colegas nos fóruns para esclarecer minhas dúvidas" (M=6,23 e DP=3,29); 14) "Troquei mensagens com os colegas para esclarecer dúvidas sobre o conteúdo do curso" $(\mathrm{M}=6,29$ e $\mathrm{DP}=3,38)$ e 19) "Aprendi conteúdos ao mentalizá-los repetidamente até perceber 
que havia entendido" ( $\mathrm{M}=6,99$ e $\mathrm{DP}=2,86)$. Dos 3 itens, os dois (13 e 14) com médias mais baixas são os itens que compõe o fator "Busca da Ajuda Interpessoal" de Martins (2012) e o item 14 é referente a "Estratégias Cognitivas". A partir da análise dos resultados descritivos, percebe-se que a maior ocorrência de médias baixas concentra-se nos itens fator 4, "Busca de Ajuda Interpessoal", ou seja, os alunos pouco utilizaram de interação com outras pessoas (pares e tutores) para auxiliar no seu aprendizado, pois o uso da Estratégia Busca de Ajuda Interpessoal considera que o aluno busca ajuda no ambiente virtual de tutores e seus pares para tirar possíveis dúvidas, bem como pouco utilizaram estratégias mediadas por tecnologias, já que os itens descrevem o esclarecimento de dúvidas através das ferramentas web: AVA, fóruns e mensagens. Como dito anteriormente, uma explicação possível para a baixa ocorrência do uso de tal estratégia é o fato dos alunos da amostra participarem de encontros presenciais regulares, previstos no calendário do curso, e o ato de tirar dúvidas normalmente pode ser realizado pessoalmente em tais encontros.

Os resultados corroboram para estudos sobre o planejamento instrucional das ações educacionais. Vários resultados de pesquisas apresentados na revisão da literatura (Martins, 2012; Marks, Sibley \& Arbaugh, 2005; Morgan \& Carsper, 2000) indicaram uma relação direta entre as estratégias de aprendizagem utilizadas pelos alunos e as reações aos procedimentos instrucionais e desempenho de tutor. Portanto, tutores e planejadores instrucionais devem atentar-se para: 1) Estratégias de Busca por Ajuda Interpessoal, mesmo sendo estratégias que expressam a busca ativa, por iniciativa do próprio aluno, pela ajuda de outros indivíduos (tutores ou pares) para tirar dúvidas, devem ser estimuladas durante o processo de ensino e aprendizagem (Almeida, Marroig \& Pinto, 2014; Marks, Sibley \& Arbaugh, 2005; Mohelska \& Sokolava, 2014; Raffarty \& Anderson, 2013), e 2) Estratégias cognitivas ao incentivar os alunos a verificarem sua concentração, atenção e motivação durante os estudos, bem como na construção e disponibilização de materiais completos, com qualidade na redação e sequência de exposição dos conteúdos; fornecer exemplos que auxiliem os alunos a associarem os conteúdos aprendidos aos conhecimentos já adquiridos e situações cotidianas; planejar situações que estimulem os alunos a ler, resumir e anotar pontos importantes dos conteúdos ensinados.

A análise da consistência interna (Alfa de Cronbach) do instrumento Estratégias de Aprendizagem apontou bons resultados para os quatro fatores (EA1 $\alpha=0,85$; EA $2 \alpha=0,80$; EA3 $\alpha=0,91$ e EA4 $\alpha=0,74)$. Por fim, foi possível extrair os escores fatoriais utilizados nas análises de regressão múltipla. 


\section{Reação aos procedimentos instrucionais}

O instrumento de Reação aos procedimentos instrucionais, no presente estudo, passou por alterações de nomenclaturas para se adequar ao contexto de EAD e à amostra participante. A partir das análises fatoriais exploratórias da estrutura empírica do instrumento foi possível encontrar 5 pares de itens altamente correlacionados entre si.

Os itens que compõem o par 1 (1 "Ligação entre o conteúdo proposto e os objetivos do curso" e 4 "Linguagem utilizada no material do curso."), tratam de diferentes conteúdos e devem ser mantidos para a avaliação de cada um. No par 2 (6 "Novidades e lembretes divulgados no ambiente virtual de aprendizagem (AVA)" e 7 "Links disponibilizados no ambiente virtual de aprendizagem (AVA)"), o item 6 esta é voltado para informações do curso enquanto que o item 7 possui um papel de auxiliar o aluno no seu processo de aprendizagem, para confirmação da distinção entre os itens foi contatado o coordenador do polo participante sobre o tipo de leitura disponível no AVA e o mesmo confirmou a existência de um espaço destinado para informações aos alunos, medido pelo item 6 , bem como outro espaço onde o aluno encontra leituras especificas sobre conteúdos de aprendizagem e links que o remetem a leituras com o mesmo objetivo, desta forma os dois itens foram mantidos, pois se tratam de diferentes tipos de leituras e possibilitam a avaliação especifica de cada um. Em relação aos itens presentes no par 3 (4 "Linguagem utilizada no material do curso." e 10 "Quantidade de conteúdo para cada unidade.") constatou-se que os conteúdos medidos por esses itens são distintos e por essa razão foram mantidos no instrumento. No par 4 (10 "Quantidade de conteúdo para cada unidade." e 11.Quantidade de horas de estudo sugerida para cada unidade."), constatou-se que os conteúdos medidos por esses itens são distintos, contudo, o item 10 está correlacionado nos pares 3 e 4, em posteriores aplicações, deve-se atentar para o aperfeiçoamento da redação dos mesmos, para que possa ser diferenciado dos demais itens, já que os itens apresentam papeis diferentes no AVA. Por fim, os itens que compõem o par 5 (12 "Fóruns de apresentação." e 13 "Fóruns de dúvidas."), tratam dos diferentes tipos de fóruns utilizados durante as disciplinas, portanto devem ser mantidos para possibilitar a avaliação específica de cada um, assim como no par 2, foi confirmado com o coordenador do polo sobre a distinção dos fóruns e segundo o responsável tais fóruns possuem objetivos diferenciados: o fóruns de apresentação é utilizado no início da disciplina para que os alunos possam se apresentar para os demais alunos que formam a turma de determinada disciplina; já o fóruns de dúvidas é destinado para que os alunos possam tirar dúvidas com seus pares (tutor e alunos) 
referentes ao conteúdo trabalhado durante a disciplina, portanto, a decidiu-se pela não exclusão de nenhum deles itens.

O item 17 "Troca de mensagens entre os alunos" por não possuir carga fatorial igual ou maior que 0,30, positiva ou negativa, não permaneceu na estrutura. Assim, a escala apresentou um único fator denominado "Procedimentos Instrucionais em EAD” (16 itens, $\alpha=0,96$ e as cargas fatoriais variaram entre 0,59 e 0,88 ) que se referem aos procedimentos instrucionais e dos recursos de interação. Conforme explicado anteriormente, tais itens avaliam a satisfação dos alunos relacionada aos aspectos instrucionais da disciplina, com as trocas de informações, discussões nos fóruns e informações disponíveis para auxílio na organização e planejamento das atividades (links, lembretes e guias). Sugere-se a aplicação do instrumento em questão em contextos e amostras diferentes, sobretudo, em ensino superior essencialmente a distância. Futuros estudos devem aprofundar as discussões sobre a influência dos procedimentos instrucionais nas estratégias de aprendizagem utilizadas pelos alunos em contextos de IES e EAD, já que no presente estudo se apresentou uma predição entre tais variáveis.

A análise descritiva do instrumento indica que a amostra ficou muito satisfeita com a qualidade dos procedimentos instrucionais utilizados ao longo do curso (variação de média entre 8,03 e 9,08). Os itens com maior avaliação (1, 2, 5, 4 e 3) são itens ligados ao conteúdo proposto e os objetivos do curso e objetivos pessoais, bem como as leituras recomendadas, a linguagem utilizada no material do curso e a sequência de apresentação das disciplinas. Os itens que apresentaram avaliação baixa $(9,13,14$ e 17) são itens relacionados aos procedimentos instrucionais específicos para a web (fóruns e troca de mensagens entre pares e tutores). Assim como o instrumento Estratégias de Aprendizagem, o instrumento Procedimentos Instrucionais aponta a atenção para a comunicação entre os alunos e principalmente os tutores na presente amostra, pois os itens com baixa avaliação indica que os alunos pouco utilizaram os procedimentos instrucionais da web para se comunicar com pares e tutores, o que poderia contribuir para as estratégias de aprendizagem utilizadas pelos discentes durante o processo de aprendizagem, já que o tutor possui papel fundamental no processo de entrega de conteúdos em ambientes virtuais de aprendizagem (Almeida, Marroig \& Pinto, 2014; Marks, Sibley \& Arbaugh, 2005; Mohelska \& Sokolava, 2014; Raffarty \& Anderson, 2013), bem como pode influenciar a efetividade da aprendizagem, por meio de tecnologias, no contexto EAD (Bedwell \& Sallas, 2010; Marks, Sibley \& Arbaugh, 2005). 
Por fim, outros instrumentos são encontrados na literatura nacional para mensurar a reação dos participantes aos procedimentos instrucionais do curso (De Paula e Silva, 2004; Borges-Ferreira, 2005; Zerbini \& Abbad, 2005, 2009b, 2010b). Contudo, a escala foi aplicada em cursos técnicos e profissionalizantes ofertados no contexto a distância. A solução unifatorial também foi encontrada por Zerbini (2003) - 19 itens, $\alpha=0,93$ e cargas fatoriais entre 0,56 e 0,77; Borges-Ferreira (2005) - 12 itens, $\alpha=0,89$ e cargas fatoriais entre 0,52 e 0,73; e Martins (2012) - 17 itens, $\alpha=0,96$ e cargas fatoriais entre 0,60 e 0,86. Dessa forma, no contexto EAD, os recursos da web compõem os procedimentos instrucionais, portanto, é coerente as AFEs apresentarem o agrupamento dos itens em um mesmo fator para representar tais procedimentos, em geral, utilizados durante o curso ou disciplina.

\section{Reação ao desempenho do tutor}

O instrumento de Reação ao desempenho do tutor passou por algumas alterações para sua reaplicação no contexto específico desta pesquisa (nos itens que continham os termos unidades foram substituídos por disciplinas). Em contextos mediados por tecnologias, a avaliação da reação (satisfação) dos alunos com relação ao desempenho e apoio do tutor se torna de grande importância, pois seus comportamentos podem influenciar nos resultados dos participantes da ação educacional, no que diz respeito ao comprometimento com as tarefas e na aquisição de aprendizagem (Martins, 2012).

Assim como os demais instrumentos, o questionário de Reação ao Desempenho do Tutor teve um baixo índice de retorno impossibilitando a AFE, sendo possível, apenas, realizar a análise de consistência interna com base no fator unico encontrado por Martins (2012) denominado Desempenho do Tutor com 27 itens ( $\alpha=0,98$ e cargas fatoriais entre 0,67 e 0,88) que avalia a satisfação dos alunos com a atuação profissional do tutor e foi aplicado no mesmo contesto deste estudo (IES e EAD). Outros estudos foram realizados em diversos contextos e corroboram com a solução unifatorial (Borges-Ferreira, 2005; De Paula e Silva, 2004; Carvalho \& Abbad, 2006; Zerbini \& Abbad, 2005; Zerbini \& Abbad, 2009a; Zerbini \& Abbad, 2010b). Em todos estudos encontrados na literatura, o instrumento apresentou excelentes índices de consistência interna, sendo igualmente confiável e válido. Assim, a escala de Reação ao Desempenho do Tutor pode ser reaplicada em variadas situações de ensino a distância (organizações, cursos, etc.), como uma ferramenta apropriada e fidedigna para avaliar a satisfação dos participantes de tais ações quanto à qualidade da interação aluno-tutor, domínio do conteúdo e uso de estratégias de ensino pelo tutor. 
No presente estudo o resultado da análise da consistência interna (Alfa de Cronbach) do instrumento apresentou um alto índice $(\alpha=0,98)$. Assim, o fator único "Desempenho do Tutor" é composto por 27 itens. Os itens que compõem o referido instrumento avaliam a satisfação dos alunos relacionada com a atuação profissional do tutor: desempenho didático, domínio do conteúdo, incentivo e respeito aos alunos. A consistência interna (Alfa de Cronbach) do instrumento Reações ao Desempenho do Tutor foi de 0,98 , sendo possível extrair o escore fatorial necessário para a análise de regressão múltipla.

\subsection{Discussões dos resultados das análises de regressão: teste do modelo multivariado}

A presente pesquisa alcançou parcialmente o objetivo geral, a saber: propor e testar um modelo de avaliação de ações educacionais ofertadas a distância, visando identificar variáveis preditoras de estratégias aprendizagem relacionadas às características da clientela (estratégias de aprendizagem e frequência nos recursos da web) e às reações aos procedimentos instrucionais e ao tutor. Como exposto anteriormente, o baixo índice de retorno dos questionários, influenciou na composição dos modelos multivariados da variável critério Estratégias de Aprendizagem, De acordo com a literatura as análises de regressão devem respeitar os seguintes critérios de inclusão: amostra maior ou igual a 50 casos mais oito vezes o número de variáveis antecedentes $(\mathrm{N} \geq 50+8 \mathrm{~m})$ para testagem de correlações múltiplas e $\mathrm{N}$ $\geq 104+\mathrm{m}$ para testagem de preditores individuais (Tabachnick \& Fidell, 2007). A amostra para as análises de regressão do presente estudo é composta por um $\mathrm{N}=77$. Portanto, foi possível testar um modelo para cada fator de Estratégia de Aprendizagem (EA1) Estratégias cognitivas; EA2) Controle da emoção; EA3) Estratégias autorregulatórias e EA4) Busca de ajuda interpessoal), com apenas 3 variáveis antecedentes $(\mathrm{N} \geq 50+8.3=\mathrm{N} \geq 74)$, apresentando assim, uma limitação do presente estudo, onde outras variáveis poderiam fazer parte das análises corroborando para os resultados do estudo.

O modelo de avaliação de ações educacionais a distância proposto e testado foi composto por variáveis individuais e sociodemográficas, e fatores ligados à reação aos procedimentos instrucionais e desempenho do tutor, visando reconhecer quais variáveis apresentavam maior poder preditivo e mensurar aquelas que contribuíram significativamente para a explicação da variável critério Estratégias de Aprendizagem. Assim, para exame do modelo foram consideradas as seguintes variáveis antecedentes: média das respostas aos itens da escala de dados sociodemográficos (idade e/ou experiência anterior em EAD); média das 
respostas aos itens do único fator Procedimentos Instrucionais; e média das respostas aos itens do único fator de Desempenho do Tutor.

Nos quatro modelos de predição de fatores relacionados às Estratégias de Aprendizagem (Modelo A - Estratégias Cognitivas, Modelo B - Estratégias de Controle da Emoção, Modelo C - Estratégias Autorregulatórias e Modelo D - Estratégias de Busca de Ajuda Interpessoal), diferentes variáveis apresentaram contribuição significativa na explicação da variável critério. Nos modelos foram incluídas nas análises empreendidas, apenas as variáveis antecedentes que apresentaram relação com a variável critério, já que, como descrito anteriormente, não havia $\mathrm{N}$ suficiente para inserir todas as variáveis previstas inicialmente.

No Modelo A, as variáveis que revelaram predição com fatores ligados as estratégias de aprendizagem utilizados pelos alunos da amostra foram Idade $(\beta=-0,28)$ e Procedimentos Instrucionais $(\beta=0,36)$. A variância compartilhada e individual das variáveis antecedentes agrupadas, em relação à variável critério, foi de $\mathrm{R}^{2}=25 \%$. Os alunos que mais utilizaram as Estratégias Cognitivas de repetição, organização e elaboração são os alunos que avaliaram favoravelmente os procedimentos instrucionais dos cursos avaliados, bem como são os alunos entre 20 a 39 anos, pois o modelo mostra uma relação inversa entre o fator Idade e Estratégias Cognitivas, ou seja, quanto menor a idade da amostra, mais estratégias cognitivas são utilizadas.

A variável no Modelo B que apresentou relação de predição com Estratégias de Controle da Emoção foi: Procedimentos Instrucionais $(\beta=0,40)$. A variância compartilhada e individual das variáveis antecedentes agrupadas, em relação à variável critério, foi de $\mathrm{R}^{2}=24 \%$. Tal resultado indica que os discentes que demonstraram maior frequência o controle da ansiedade, bem como a prevenção de dispersões de concentração com causa na ansiedade durante o estudo, são os alunos que apresentaram satisfação favorável em relação aos procedimentos instrucionais dos cursos avaliados.

$\mathrm{Na}$ testagem do Modelo $\mathrm{C}$, as variáveis que apresentaram relação de predição com as Estratégias Autorregulatórias foram: foram: Idade $(\beta=-0,21)$, e Procedimentos Instrucionais $(\beta=0,41)$. Agrupadas, as 3 variáveis iniciais, explicam 23\% (20\% ajustado) da variabilidade das Estratégias de Aprendizagem Autorregulatórias. Os alunos que mais utilizaram as Estratégias Autorregulatórias de controle da motivação e monitoramento da compreensão que auxiliam na autorregulação da aprendizagem são os alunos que avaliaram favoravelmente os procedimentos instrucionais dos cursos avaliados. Como exposto anteriormente, ao longo da vida o indivíduo desenvolve um complexo conjunto de capacidades cognitivas que podem influenciar o uso de estratégias de aprendizagem cognitivas e autorregulatórias em ações 
educacionais, assim, é compreensível que estudantes que utilizam de tais estratégias tenham maior compreensão dos procedimentos instrucionais utilizados pelas IES e se beneficiam do processo de aprendizagem levando a uma maior satisfação pelos mesmos. O modelo também mostra uma relação inversa entre as variáveis Idade e Estratégias Autorregulatórias, ou seja, quanto menor a idade da amostra, mais estratégias autorregulatórias são utilizadas.

No modelo $\mathrm{D}$, as variáveis que apresentaram relação de predição com fatores ligados às Estratégias de Busca por Ajuda Interpessoal foi a variável Procedimentos Instrucionais $(\beta=$ 0,20). A variância compartilhada e individual das variáveis antecedentes agrupadas, em relação à variável critério, foi de $\mathrm{R}^{2}=7 \%$. Os alunos que demonstraram a busca ativa por iniciativa própria, busca pela a ajuda de outros indivíduos (tutores ou colegas) para tirar dúvida, são os alunos que avaliaram favoravelmente os procedimentos instrucionais dos cursos avaliados.

A variável antecedente Procedimentos Instrucionais se manteve presente nos quatro modelos de regressão como variável de maior poder preditivo da variável critério Estratégias de Aprendizagem nos seus quatro fatores (EA1 - Estratégias Cognitivas; EA2 - Controle da Emoção; EA3 - Estratégias Autorregulatórias e EA4 - Busca Ajuda Interpessoal). Tal resultado confirma que os procedimentos instrucionais formados por diferentes estratégias e princípios de ensino (métodos, ferramentas, etc.), quando planejados, organizados e estruturados influenciam os resultados da ação educacional (Burke \& Hutchins, 2007; Salas et al., 2012; Meneses, Zerbini \& Abbad, 2010).

O fator Estratégias Cognitivas representa estratégias voltadas à reflexão ativa, entre elas; repetição, organização e elaboração mental da informação que foi apresentada, tais estratégias estão entre as melhores médias obtidas nas respostas do instrumento Estratégias de Aprendizagem. Entre as medidas do instrumento Procedimentos Instrucionais estão a qualidade dos objetivos de ensino, conteúdos, sequencias e avaliações de aprendizagem (procedimentos tradicionais), tais processos quando bem planejados podem influenciar no uso de tal estratégia de aprendizagem. Tais achados corroboram com os estudos de Vaugham e MacVicar (2004) que indicam a disponibilidade e facilidade de acesso aos conteúdos de estudos na modalidade a distância prediz percepções favoráveis a aprendizagem contínua.

As estratégias presentes no fator Controle da Emoção envolve estratégias de controle da ansiedade, bem como a prevenção de dispersão da concentração no momento do estudo (Martins \& Zerbini, 2015; Warr \& Allan, 1998; Zerbini, 2007), a permanência das mesmas em um fator distinto das demais estratégias de aprendizagem mostra a importância de tais estratégias e a contribuição para o aprendizado de alunos no contexto $\mathrm{EAD}$, bem como é um 
diferencial para a aprendizagem com autogerenciamento pelos alunos que estudam a distância (Martins \& Zerbini, 2015). Alunos que estudam em ambientes mediados pelas NTICs se defrontam com desafios cognitivos, motivacionais, colaborativos e emocionais, e impõe a necessidade de controlar e gerir seus próprios esforções durante o processo de aprendizagem (Salovaara, 2005), Nesse sentido, o planejamento adequado dos procedimentos instrucionais para a ação educacional, bem como o estímulo do uso de tais ferramentas pelos tutores, entre eles: links, fóruns, acesso constante ao AVA, mural de notícias virtual, chats, podem favorecer o uso de estratégias de controle da emoção ao proporcionar segurança para o aluno durante a aprendizagem. No presente estudo é confirmada a influência dos procedimentos instrucionais no uso de estratégias de controle da emoção pelo modelo B, pois, os alunos que utilizaram com maior frequência estratégias voltadas para o controle da emoção apresentaram satisfação favorável em relação aos procedimentos instrucionais dos cursos avaliados.

As Estratégias Autorregulatórias, compostas por estratégias de monitoramento da compreensão, controle da motivação e busca de ajuda ao material didático (Martins, 2012), auxiliam na autorregulação da aprendizagem (Boruchovitch \& Santos, 2004). A variável antecedente Procedimento Instrucional apresentou relação de predição $(\beta=0,41)$ com a variável critério Estratégias Autorregulatórias, ou seja, os alunos que usaram com mais frequência estratégias de aprendizagem autorregulatórias, aquelas que auxiliavam no monitoramento da compreensão e no processo de autorregulação da aprendizagem; estavam satisfeitos com os procedimentos instrucionais adotados e utilizaram com mais frequência as ferramentas web disponíveis, como o acesso recorrente ao AVA. Tal resultado corrobora com os estudos de Martins (2012).

Por fim, o fator Estratégia Busca de Ajuda Interpessoal também apresentou relação de predição significativa com a variável Procedimentos Instrucionais $(\beta=0,20)$. Mesmo sendo a estratégia de aprendizagem menos utilizada pela amostra, de acordo com as análises descritivas, os alunos que buscaram auxilio com tutores e colegas, bem como trocaram mensagens com os mesmos, ou seja, alunos que utilizaram com mais frequência recursos previstos pelos procedimentos instrucionais (fóruns, chats e e-mail), avaliaram positivamente os mesmos.

Os resultados descritivos do instrumento Reação aos Procedimentos Instrucionais, apontaram, no geral, uma boa avaliação. Contudo, os alunos avaliaram melhor os procedimentos relacionados ao planejamento das disciplinas, adequação e linguagem do material e fontes de informação disponibilizadas; e os itens com médias mais baixas estão voltados para recursos do AVA que envolvem diretamente a participação ativa do tutor, entre 
eles: fóruns de dúvidas e notícias, troca de mensagens entre alunos e orientação para a solução de erros nas atividades ou tarefas. Tal situação se confirma com o retorno do instrumento Estratégias de Aprendizagem, com os itens que apresentaram menor média foram aqueles voltados para a troca de mensagens com colegas e busca de auxilio com tutor e colegas nos fóruns para esclarecer dúvidas. O baixo índice de satisfação dos alunos com os fóruns de dúvidas e notícias, orientações prestadas pelo tutor, e o pouco uso das ferramentas de comunicação entre aluno/tutor e seus pares, pode indicar presença de falhas no desenho dos cursos. No estudo de Zerbini (2007), os alunos da amostra também usaram pouco os recursos eletrônicos oferecidos pelo curso, entre eles: chats, lista de discurso e tira-dúvidas, tais recursos promoviam a interação entre aluno e tutor, bem com seus pares.

Dois modelos (A e C) apresentaram a variável Idade como preditiva para Estratégias Cognitivas e Autorregulatórias, alunos entre 20 e 39 anos usaram com maior frequência tais estratégias de aprendizagem. As Estratégias Cognitivas, envolvem a busca por fontes externas de estudo (internet). $\mathrm{O}$ uso dessa estratégia demonstra que alunos contemporâneos possuem maior facilidade para buscar informações disponíveis na web. Tais alunos estão mais familiarizados com o uso do computador, bem como o uso da internet, e, portanto, não apresentam dificuldades com o uso do AVA. Tal resultado corrobora com os achados de Martins (2012). A análise descritiva do instrumento Estratégias de Aprendizagem, apontou entre as maiores médias ( $\mathrm{M}$ entre 8,48 a 8,88) o uso das Estratégias Autorregulatórias, que por sua vez auxiliam no monitoramento da motivação e compreensão, bem como no processo de autorregulação da aprendizagem. Assim, alunos na faixa etária indicada são mais ativos no processo de aprendizagem.

A variável Desempenho do Tutor não se manteve como preditora em nenhum dos modelos realizados no presente estudo, contrariando pesquisas encontradas na revisão da literatura (Almeida, Marroig \& Pinto, 2014; Marks, Sibley \& Arbaugh, 2005; Martins, 2015; Mauri \& Onrubia, 2010). De acordo com a literatura, o tutor representa um dos principais atores em contextos EAD, por ser responsável pela mediação e facilitador do processo de transferência do conhecimento, bem como auxilia nas necessidades educacionais dos alunos e conduz fatores da aprendizagem eficaz, como: autorregulação e a motivação (Martins \& Zerbini, 2015; Mauri \& Onrubia, 2010). Diversos estudos apontam que no contexto EAD, a interação entre tutor e aluno pode influenciar a efetividade da aprendizagem, bem como características do tutor podem predizer a satisfação dos alunos com a ação educacional, entre elas: domínio do conteúdo das disciplinas, estimular perguntas, o uso de ferramentas do AVA, troca de informações e de 
experiências entre os alunos (Marks, Sibley \& Arbaugh, 2005; Martins, 2015; Almeida, Marroig \& Pinto, 2014). Desse modo, mesmo com as altas médias encontradas na análise descritiva do instrumento Reação ao Desempenho do Tutor $(M=8$, avaliação 7,73 a 8,91), fazse necessário aplicar o instrumento em outras amostras e no mesmo contex to do presente estudo (IES e EAD), e promover discussões acerca do papel do tutor/instrutor em cursos de graduação ofertados a distância.

Com o objetivo de aproveitar as respostas dadas pelos alunos dos cursos que participaram da pesquisa, foram realizadas análises que pudessem complementar as discussões dos resultados. Foram realizados Testes $t$ e ANOVA. Os resultados mostraram que houve diferença significativa entre as médias dos grupos definidos a partir do curso em comparação com as médias obtidas da utilização da aprendizagem cognitivas, entre os cursos que mais utilizaram tal estratégia foram: Mídias na Educação $(\mathrm{M}=8,75 ; \mathrm{DP}=0,94)$, seguido por Pedagogia ( $M=8,44 ; \mathrm{DP}=1,06)$ e Educação Física $(\mathrm{M}=8,44 ; \mathrm{DP}=1,07)$. Tal resultado, mesmo que não conclusivo, é interessante, por confirmar a Estratégia Cognitiva ser a mais utilizada pelos alunos da presente amostra.

Em resumo, os modelos testados e avaliados neste estudo apresentaram significativas relações entre as variáveis procedimentos instrucionais e idade no uso de estratégias de aprendizagem ao longo a ação educacional ofertada a distância. Os resultados encontrados indicam que quanto mais se utilizar diferentes estratégias e princípios de ensino, bem como quando mais se planejar, organizar e estruturar métodos, ferramentas, entre outros recursos, os resultados das ações educacionais podem ser influenciados (Burke \& Hutchins, 2007; Salas et al., 2012; Meneses, Zerbini \& Abbad, 2010), bem como o uso diversas estratégias de aprendizagem ao longo de tais ações objetivando o alcance de resultados acadêmicos positivos (Badia \& Monereo, 2010; Oliveira, Boruchovitch \& Santos, 2009; Zabalza, 2005; Warr \& Downing, 2000). Além disso, constatou-se o uso com maior frequência de estratégias cognitivas e autorregulatórias por estudantes entre 20 e 39 anos.

Os objetivos específicos de identificar e analisar as estratégias de aprendizagem utilizadas pelos estudantes ao longo da ação educacional a distância e analisar as Reações dos alunos quanto aos procedimentos instrucionais e ao desempenho do tutor também foram cumpridos. A partir das análises descritivas das respostas do instrumento Estratégias de Aprendizagem foi possível identificar as estratégias mais utilizadas pela amostra participante do presente estudo, bem analisar tais estratégias. As estratégias de aprendizagem mais utilizadas pela amostra, foram respectivamente: 1) Estratégias Cognitivas; 2) Estratégias 
Autorregulatórias; 3 ) Controle da Emoção e 4 ) Busca de Ajuda Interpessoal. Entre os 10 itens com maior média, quatro itens (16, 26, 27 e 29) correspondem ao fator Estratégias Cognitivas, sendo dois (Itens 27 e 29) deles com as maiores médias dos itens, outros cinco itens correspondem ao fator Estratégias Autorregulatórias (Itens, 5, 6, 9, 10 e 11) e apenas um item (2) corresponde a estratégias ligadas ao Controle da Emoção. Entre os cinco itens com menor média, estão os três itens do fator Busca de Ajuda Interpessoal. A Tabela 42 demonstra o resumo das estratégias utilizadas de acordo com as maiores médias obtidas.

Tabela 42. Estratégias mais utilizadas pela amostra.

\begin{tabular}{lcc}
\hline \multicolumn{1}{c}{ Estratégia por maior frequência } & Itens & Intervalo de Médias \\
\hline 1. Estratégias Cognitivas & 15 itens (15 ao 29) & 6,99 a $\underline{\mathbf{9 , 3 6}}$ \\
2. Estratégias Autorregulatórias & 7 itens (5 a 11) & 7,96 a $\underline{\mathbf{8 , 8 8}}$ \\
3. Controle da Emoção & 4 itens (1 ao 4) & 7,61 a $\underline{\mathbf{8 , 5 5}}$ \\
4. Busca de Ajuda Interpessoal & 3 itens (12,13 e 14) & 6,23 a $\underline{\mathbf{7 , 3 4}}$ \\
\hline
\end{tabular}

De acordo com Martins (2012), dos 15 itens que pertencem a estratégia cognitiva, 12 referem-se a estratégias de repetição, organização e elaboração, ou seja, reflexão ativa, dois deles provêm de estratégias de busca do material didático e um de aplicação prática. A partir da análise descritiva do instrumento Estratégias de Aprendizagem, é possível perceber que os alunos que responderam ao questionário, utilizaram com maior frequência estratégias de elaboração e aplicação prática, ao associar os conteúdos trabalhados no com seus conhecimentos anteriores (item 27, maior média, M=9,36) e identificação de conteúdos possíveis a aplicação em situações cotidianas (item 20, M=9,07), bem como relacionar os conteúdos entre si (item 26, M=8,58) e pesquisa dos mesmos em sites relacionados (item 16, $M=8,64)$ visando o processo de aprendizagem. Associado as estratégias cognitivas, tais alunos utilizaram estratégias autorregulatórias de controle da motivação e principalmente monitoramento da compreensão ao buscar solucionar duvidas com auxílio do material do curso (item 10, M=8,88), verificação da compreensão sobre o que estava sendo ensinado (item 9, $\mathrm{M}=8,51)$ e procuraram se esforçar quando percebiam que estavam perdendo a concentração (item 5, M=8,72). Assim, a maioria dos alunos da amostra, utilizaram tal estratégia para concluir os conteúdos e atividades propostas no decorrer dos cursos. A partir da análise ANOVA foi possível confirmar as informações das análises descritivas, ao identificar que houve diferença significativa entre as médias dos grupos definidos a partir dos cursos em comparação com as médias obtidas da utilização da aprendizagem cognitivas, sendo esta a mais utilizada pelos alunos dos cursos pesquisados. 
As estratégias que apresentaram menor média entre as respostas ao instrumento foi a Estratégia de Busca de Ajuda Interpessoal. Os itens que compõem tal estratégia expressam a busca ativa, por iniciativa do próprio aluno, pela ajuda de outros indivíduos inseridos na ação educacional (tutores ou pares) para tirar dúvidas, tais estratégias de cunho comportamental, representa comportamento proativo do indivíduo de buscar auxílio, ao invés de obter informações do material do curso (Warr \& Allan, 1998). A análise dos resultados descritivos demonstra que a maior ocorrência de médias baixas se concentra nos itens desse fator, ou seja, os alunos da amostra pouco utilizaram estratégias mediadas por tecnologias, visto que os itens que compõem tal estratégia, descrevem o esclarecimento de dúvidas mediante as ferramentas web: AVA, fóruns e mensagens. Tal situação foi confirmada na análise descritiva do instrumento Procedimentos Instrucionais, onde os itens com menores médias foram: fóruns de dúvidas e notícias, troca de mensagens entre alunos e orientação para solução de erros nas atividades ou tarefas. Verifica-se que os alunos julgaram que os fóruns de notícias e as orientações prestadas pelo tutor apresentam algumas deficiências e merece atenção.

Quanto a análise das Reações dos alunos aos procedimentos instrucionais, a partir da análise descritiva foi possível observar que de forma geral, os alunos ficaram muito satisfeitos com a qualidade dos procedimentos instrucionais utilizados ao longo do curso, uma vez que as médias variam entre 8,03 e 9,08. As médias mais altas pertencem aos itens relacionados aos procedimentos tradicionais presentes na modalidade presencial, já as médias mais baixas estão concentradas nos itens que tratam de recursos do AVA e que envolvem diretamente a participação ativa do tutor e alunos (mensagens, fóruns, orientações para a execução das tarefas). Tais achados corroboram com os estudos de Mohelska e Sokolava (2014) que apontaram o treinamento em habilidades administrativas básicas no e-learning é tão eficiente quanto no ensino presencial e a irrelevância nas diferenças entre o e-learning e o ensino tradicional e eleva a satisfação e a aprendizagem dos participantes. Quanto as médias mais baixas dos achados podem ser explicados considerando-se alguns pontos de discussão ou a sua combinação: a) devido os cursos do presente estudo prever encontros presenciais constantes, os alunos podem não ter utilizado com frequência as ferramentas da web, e dificultou uma opinião sobre a qualidade das mesmas; e b) tais procedimentos de fato não foram bem avaliados pois possuem falhas segundo os usuários.

Os resultados descritivos do instrumento Desempenho do Tutor indicaram que de forma geral, a maioria dos participantes avaliou positivamente o desempenho dos tutores, o que demonstra a satisfação com a frequência de comportamento emitida pelos mesmos, uma vez 
que as médias variam de 7,73 a 8,91. Os itens com as médias mais altas agruparam comportamentos relativos ao domínio do conteúdo e desempenho didático dos tutores. Dessa forma, os alunos mostraram-se satisfeitos com o uso de linguagem de fácil compreensão e a comunicação sem erros de português. Contudo, a analise descritiva dos instrumentos Estratégias de Aprendizagem e Procedimentos Instrucionais, indicaram baixas médias para os itens relacionados a participação ativa do tutor no processo de aprendizagem. A análise de regressão também não indicou o desempenho do tutor como variável antecedente às estratégias de aprendizagem. A literatura indica que o comportamento do tutor pode influenciar no rendimento dos participantes da ação educacional, no que diz respeito ao comprometimento com as tarefas, bem como na aquisição de aprendizagem (Almeida, Marroig \& Pinto 2014; Martins \& Zerbini, 2014). Diversos estudos apontaram a influência do tutor na efetividade da aprendizagem (Marks, Sibley \& Arbaugh, 2005) e na satisfação dos alunos com o e-learning (Almeida, Marroig \& Pinto, 2014; Özkan, Köseler \& Baykal, 2009). Dessa forma, faz-se necessários novos estudos com estudantes universitários em contexto EAD, para verificar a satisfação dos participantes em relação ao desempenho do tutor e sua influência nos processos de aprendizagem, bem como no uso de estratégias de aprendizagem em cursos ofertados a distância.

O objetivo específico analisar o perfil sociodemográficos da clientela e a frequência do uso de ferramentas eletrônicas disponibilizadas no ambiente eletrônico do curso foi parcialmente cumprido, em razão da falta de informação no polo de Serrana sobre a frequência do uso de ferramentas eletrônicas pelos alunos das instituições parceiras, prejudicando assim a análise. De acordo com o coordenador do polo, tais informações são de responsabilidade das instituições parceiras e não ter acesso as mesmas.

A partir das respostas $(\mathrm{N}=94)$ ao questionário sociodemográfico foi possível identificar o perfil da amostra do presente estudo como demonstrado no item 4.5, sendo: a maioria dos alunos é do sexo feminino $(66,0 \%)$, casados $(55,3 \%)$ e com filhos $(66,0 \%)$. Em média, a amostra considerada possui 40 anos de idade ( $\mathrm{DP}=7,89$ ), sendo 31 anos a idade que com mais frequência apareceu, 57 anos a máxima e 26 anos a mínima. A grande maioria dos alunos $(73,4 \%)$ responderam ter o Ensino Superior Completo, esse resultado já era esperado, devido $50 \%$ dos cursos pesquisados serem de pós-graduação, com pré-requisito do nível superior para cursá-los. A maioria dos respondentes $(39,4 \%)$ declararam contar com uma renda financeira entre dois e três salários mínimos. Quanto as experiências com internet, a grande maioria dos respondentes relataram possuir experiência prévia no uso da internet $(91,5 \%)$, 
demonstrando domínio das ferramentas e instrumentais utilizados nos ambientes virtuais, bem como já tiveram experiência anterior com o $\operatorname{EAD}(57,4 \%)$.

Ao relacionar a variável idade com os fatores da variável critério Estratégias de aprendizagem por meio dos modelos de regressão, foi possível identificar a variável Idade com preditiva para Estratégias Cognitivas e Autorregulatórias. A partir da análise sociodemografica, os achados indicaram que alunos entre 20 e $39 \operatorname{anos}(\mathrm{N}=37,39 \%$ da amostra) usaram com maior frequência tais estratégias de aprendizagem. Como já descrito anteriormente, as Estratégias Cognitivas, envolvem a busca por fontes externas de estudo (internet), o uso dessa estratégia demonstra que alunos contemporâneos possuem maior facilidade para buscar informações disponíveis na web. Tais alunos estão mais familiarizados com o uso do computador, bem como o uso da internet, e, portanto, não apresentam dificuldades com o uso do AVA. Tais resultados, mesmo não conclusivos, são interessantes e podem auxiliar no processo de planejamento da ação educacional. Outras pesquisas são necessárias para comparar esses achados, bem como avançar nas discussões acerca das estratégias de aprendizagem utilizadas por estudantes universitários na modalidade EAD, a característica da clientela, bem como as reações aos procedimentos instrucionais e desempenho do tutor.

Por fim, o objetivo específico: analisar os cursos ofertados pelas instituições parceiras pelo instrumento Roteiro de Análise de Cursos - EAD, foi cumprido por meio da adaptação do "Roteiro de Análise do Material Didático - EAD“ desenvolvido por Zerbini (2003) e Carvalho (2003), utilizado para avaliar a qualidade dos materiais instrucionais de disciplinas e cursos de curta duração. Tal adaptação resultou na construção do Instrumento Roteiro de Análise de Cursos de Graduação - EAD, para que fosse possível avaliar cursos de graduação ofertados a distância.

Os cursos ofertados pelas IES parceiras apresentaram de forma geral: a) objetivos instrucionais descritos em termos de desempenhos observáveis e com clareza na descrição, bem como precisão do verbo de ação; b) as estratégias instrucionais estão adequadas as características da clientela e a natureza dos objetivos instrucionais e complexidade; c) o programa de ensino apresenta carga horária adequada ao volume das disciplinas propostas; d) a sequenciação de ensino se apresenta adequada, com exceção do curso de Administração Pública, onde o aluno cursa disciplinas obrigatórias e optativas, sendo estas quando não orientadas pode prejudicar a sequência do conhecimento; e e) na maioria dos cursos a bibliografia não são dos últimos cinco anos. 
A seguir, são discutidas as principais contribuições e limitações do estudo, bem como propõe-se uma agenda de pesquisa. 


\section{CAPÍTULO 7. CONSIDERAÇÕES FINAIS}

\section{Objetivo do capítulo}

Este capítulo tem como objetivo concluir o estudo ao apresentar suas principais contribuiçõos e limitações, e propor uma agenda de pesquisa.

Nos últimos anos estudos foram realizados com esforços para a avaliação de cursos no nível superior de ensino ofertados na modalidade a distância (Martins, 2012; Umekawa, 2013). Contudo, a área carece de estudos sistemáticos que proponham modelos multivariados de avaliação com o uso de instrumentos de medida voltados para o contexto da modalidade EAD e este é um campo de conhecimento ainda em exploração, com pesquisas em andamento e instrumentos disponíveis na literatura, mas que precisam ser adaptados e aperfeiçoados por meio de análises estatísticas mais robustas (Martins, 2012). Dessa forma, foram verificadas evidências de validade dos instrumentos no presente estudo. Ainda assim, recomenda-se que as escalas utilizadas nesse estudo sejam aplicadas em diferentes contextos de IES e amostras que estudem essencialmente na modalidade EAD.

Vale ressaltar que durante o desenvolvimento do presente estudo foram enfrentadas inúmeras dificuldades, entre elas: firmar parceiras de pesquisas com instituições de ensino superior e o processo de coleta de dados, que acabou por afetar os resultados da pesquisa. Mesmo com os esforços empreendidos durante o processo de coleta de dados, entre eles: dois momentos para coleta de dados, devido a diferença nos calendários institucionais das instituições parceiras, e visando aumentar o número de questionários respondidos, o procedimento de coleta de dados foi realizado parcialmente a distância, por meio da internet, e em dois momentos de atividades presenciais, a participação dos alunos dos cursos das instituições participantes do presente estudo foi pequena, o que inviabilizou as análises fatoriais exploratórias (AFE) dos instrumentos Estratégias de Aprendizagem e Reação ao Desempenho do Tutor. Diante disso, para cumprir com os objetivos do estudo, realizaram-se apenas as análises de consistência interna.

Zerbini (2007) e Martins (2012) recomendam Análises Fatoriais Confirmatórias dos instrumentos, bem como a modelagem por equação estrutural (MEE) como análises mais robustas e rigorosas para o teste de relações entre variáveis de TD\&E e auxiliar no desenvolvimento do campo teórico da área de avaliação institucional. Em razão do baixo retorno dos questionários não foi possível realizar tais análises 
Os objetivos de pesquisa propostos foram atingidos, e sobre os problemas de pesquisa levantados, pode-se dizer:

Quais são as estratégias de aprendizagem utilizadas pelos alunos universitários em cursos a distância? Os alunos da amostra utilizaram com maior frequência as estratégias cognitivas e na sequência as estratégias autorregulatórias. Pode-se dizer que os indivíduos estão mais acostumados, ou talvez, mais estimulados, a utilizar estratégias cognitivas ao longo da vida, sendo estas consideradas mais comuns em diferentes ações educacionais. $\mathrm{O}$ uso das estratégias autorregulatórias de controle da motivação e monitoramento da compreensão, pode indicar maior autonomia do aluno no processo de aprendizagem, o que é esperado do aluno na modalidade EAD. O uso dessas estratégias pelos alunos indica a importância do desenvolvimento de estratégias de ensino, no processo de planejamento da ação educacional, que promovam o autogerenciamento da aprendizagem.

Reações favoráveis dos alunos aos procedimentos instrucionais e ao desempenho do tutor, bem como determinadas características da clientela estão relacionadas com a utilização de Estratégias de Aprendizagem adequadas em ações educacionais ofertadas a distância? Nesse estudo, apenas as reações favoráveis aos procedimentos instrucionais foram preditoras das estratégias de aprendizagem. Contudo, como dito anteriormente, a avaliação da satisfação dos estudantes como desempenho do tutor deve permanecer nos modelos de pesquisas futuras, visando testar o relacionamento entre variáveis em contextos $\mathrm{EAD}$, pois pesquisas indicam a relação entre a satisfação do aluno com o tutor e o resultado da aprendizagem no ensino a distância (Almeida, Marroig \& Pinto, 2014; Martins, 2012; Martins \& Zerbini, 2014; Marks, Sibley \& Arbaugh, 2005). Os modelos de predição testados nesse estudo, também indicaram a variável Idade, sendo esta uma característica da clientela, como uma variável preditora das estratégias de aprendizagem cognitivas e autorregulatórias. Os resultados apontaram o uso com maior frequência de estratégias cognitivas e autorregulatórias por estudantes entre 20 e 39 anos.

Dentre as contribuições deste estudo, destacam-se: (1) Atualização da revisão de literatura, durante o período de 2009 a 2015, sobre a variável "Estratégias de Aprendizagem" em diferentes campos de conhecimento (Educação, Filologia e Língua Portuguesa, Administração, Interfaces Sociais da Comunicação e Psicologia), a qual apoiou embasamento teórico do texto, contribuindo para o alcance dos resultados de pesquisa sobre a temática de interesse; (2) Adaptação e validação (semântica e por juízes) do instrumento Roteiro de Análise de Cursos de Graduação - EAD (3) Verificação de evidências de validade da escala de "Reação aos Procedimentos Instrucionais em EAD” de Martins e Zerbini (2015), que pode ser utilizada 
em futuras pesquisas da área de avaliação de ações educacionais a distância, em organizações de trabalho e instituições de ensino que ofertam cursos EAD; (4) Aprimoramento da estratégia de coleta de dados realizada pela internet em comparação a estudos anteriores (Brauer, 2005; Carvalho e Zerbini, 2006; Martins, 2012; Sales, 2009; Zerbini e Abbad, 2005); (5) O estudo da variável Estratégias de Aprendizagem como variável critério para outras variáveis de TD\&E em contexto EAD.

Quanto às limitações do estudo, pode-se citar:

1) Baixo índice de devolução dos instrumentos nos momentos de coleta de dados realizados por meio da internet;

2) O uso dos fatores de Martins (2012) para a elaboração dos escores fatoriais dos instrumentos Estratégias de Aprendizagem e Desempenho do Tutor, devido ao baixo retorno dos questionários;

3) Ainda sobre o baixo índice de retorno dos instrumentos, os modelos de regressão não puderam ser completamente testados como proposto inicialmente em função do tamanho da amostra. No presente estudo foi possível incluir apenas três variáveis antecedentes por modelo de regressão.

4) Não utilização de métodos estatísticos mais robustos, tais como a Análise Fatorial Confirmatória e Modelagem de Equação Estrutural, sendo que essas duas últimas poderiam colaborar na testagem de modelos de predição, como por exemplo, na influência dos Dados Sociodemográficos, Reação aos Procedimentos Instrucionais e Desempenho do Tutor no uso de determinadas Estratégias de Aprendizagem;

5) Não inclusão de diferentes variáveis individuais que poderiam elevar a explicação do modelo de predição de estratégias de aprendizagem, como hábitos de estudo, autoeficácia, variáveis motivacionais, entre outras;

6) Não inclusão de dados referentes à frequência de acesso aos recursos da web, que poderiam contribuir para a explicação dos modelos testados;

7) Impossibilidade de generalizar os resultados encontrados no presente estudo, pois foi avaliado apenas um polo das IES participantes da UAB. Além disso, não foi possível coletar dados sobre a população de alunos, não se pode afirmar se as características da amostra são semelhantes à da população;

Os resultados obtidos no presente estudo trazem implicações práticas que se referem ao uso das medidas de avaliação de cursos a distância em instituições de ensino superior e também em organizações de trabalho que oferecem ações educacionais EAD no que se refere 
características (Estratégias de Aprendizagem) e reações dos alunos (Procedimentos Instrucionais e Desempenho do Tutor). Por meio das análises das variáveis envolvidas nesses programas, é possível reunir informações pertinentes ao aprimoramento instrucional adotado, bem como os efeitos por ele produzidos. A busca pelo aperfeiçoamento dos cursos ofertados a distância contribui para a visibilidade da modalidade como uma alternativa educacional disponível, com aplicabilidade atestado por meio de pesquisas científicas, bem como tais pesquisas podem contribuir para que a modalidade não caia no descrédito, ao promover conhecimentos e discussões sobre o EAD, e quebra de preconceitos e comentários depreciativos sobre a sua qualidade e eficácia (Martins, 2012). A avaliação e a melhoria de cursos ofertados a distância, podem contribuir para a elaboração de objetivos educacionais mais complexos, resultando no delineamento de estratégias de ensino e avaliações de aprendizagem compatíveis aos mesmos (Martins, 2012; Zerbini, 2007; Zerbini, Borges-Ferreira \& Abbad, 2012).

Diante dos resultados e das discussões promovidas no presente estudo, a seguinte agenda de pesquisa é proposta:

1) Aprimorar procedimentos de coleta de dados pela internet, buscando aumentar os índices de retorno;

2) Aplicação dos instrumentos de medida utilizados nesta pesquisa em outros contextos e amostras, especialmente no ensino superior a distância;

3) Realizar análises confirmatórias das estruturas empíricas utilizadas nesta pesquisa;

4) Testar por meio de modelagem por equação estrutural, diferentes relacionamentos entre variáveis, incluindo relação de mediação e moderação;

5) Aprofundar as discussões sobre as estratégias de aprendizagem utilizadas pelos alunos em contextos de IES e EAD, por meio da construção e aplicação de um questionário semiestruturado, com uma abordagem qualitativa, a partir das respostas do instrumento Estratégias de Aprendizagem aplicado a amostra, visando avançar nas pesquisas e no conhecimento cientifico da área de TD\&E na busca da razão do uso de tais estratégias de aprendizagem pelos participantes da ação educacional;

6) Rever o impacto da variável Desempenho do Tutor nas Estratégias de Aprendizagem utilizadas por alunos em outras amostras.

$\mathrm{O}$ presente estudo pretendeu atender recomendações e agendas de pesquisas anteriormente propostas (Martins, 2012; Umekawa, 2014; Zerbini, 2007; entre outros) e espera ter contribuído com a área de área de avaliação de cursos a distância, especialmente, em relação às estratégias de aprendizagem e características do aluno em contexto de IES. 


\section{Referências}

Abbad, G. (1999). Um modelo integrado de avaliação de impacto de treinamento no trabalho. Tese Doutorado, Instituto de Psicologia, Universidade de Brasília.

Abbad, G., Pilati, R., \& Pantoja, M. J. (2003). Avaliação de treinamento: análise da literatura e agenda de pesquisa. Revista de Administração da USP, 38(3), 205-218.

Abbad, G., Borges-Ferreira, M. F., \& Nogueira, R. (2006). Medidas de aprendizagem em avaliação de TD\&E. In J. E. Borges-Andrade, G. Abbad, L. Mourão (Orgs.). Treinamento, desenvolvimento e educação em organizações e trabalho: fundamentos para a gestão de pessoas (pp. 469-488). Porto Alegre: Artmed.

Abbad, G. S., Carvalho, R. S., \& Zerbini, T. (2006). Evasão em curso via internet: explorando variáveis explicativas. Revista de administração de empresas eletrônica, 5(2), Art. 17, jul./dez.

Abbad, G., Zerbini, T., Carvalho, R. S., \& Meneses, P. P. M. (2006). Planejamento instrucional em TD\&E. In J. E. Borges-Andrade, G. Abbad, L. Mourão (Orgs.), Treinamento, desenvolvimento e educação em organizações e trabalho: fundamentos para a gestão de pessoas (pp. 289-321). Porto Alegre, RS: Artmed.

Abbad, G., Côrrea, V. P., \& Meneses, P. P. M. (2010). Avaliação de treinamentos a distância: relações entre estratégias de aprendizagem e satisfação com o treinamento. RAM - Revista de Administração Mackenzie, 11(2),43-67

Abbad, G.; Zerbini, T., \& Souza, D. B. L. (2010). Panorama das pesquisas em Educação a Distância no Brasil. Estudos de Psicologia (UFRN), 15, 291-298.

Abbad, G., \& Mourão, L. (2012) A avaliação de necessidades de TD\&E: proposição de um novo modelo. Revista de Administração Mackenzie, São Paulo, 13(6), ed. esp., 107-137. nov./dez.

Aguinis, H., \& Kraiger, K. (2009). Benefits of training and development for individuals and teams, organizations, and society. Annual Review of Psychology, 60, 451-474.

Almeida, N. L. O., Marroig, R., \& Pinto, V. R. R. (2014); Competências e habilidades do tutor virtual que influenciam na aprendizagem dos alunos. RPCA, 8(2), 144-166.

Alvarez, K., Salas, E., \& Garofano, C.M. (2004). An integrated model of training evaluation and effectiveness. Human Resource Development Review, 3(4), 385-416.

Alves, L. (2011). Educação a distância: conceitos e história no Brasil e no mundo. Revista Brasileira de Aprendizagem Aberta e a Distância, 10, 83-92.

Associação Brasileira de Educação a Distância (ABED) (2012).

Asmmann, H (1998). Reencantar a educação rumo à sociedade aprendente. Petrópolis/RJ: Editora Vozes.

Badia, A., \& Monereo, C. (2010). Ensino e aprendizagem de estratégias de aprendizagem em 
ambientes virtuais. In C. Coll \& C. Monereo (Orgs.). Psicologia da Educação virtual Aprender e ensinar com as tecnologias da informação e da comunicação. (pp. 311-328).

Bedwell, W. L., \& Salas, E. (2010). Computer-based training: capitalizing on lessons learned. International Journal of Training and Development, 14(3), 239-249.

Belloni, M. L. (2003). Educação a distância. Campinas, SP: Autores Associados.

Beluce, A. C., \& Oliveira, K. L. (2012). Ambientes virtuais de aprendizagem: das estratégias de ensino às estratégias de aprendizagem. In IX ANPED SUL, 1-14.

Bjork, R. A., Dunlosky, J., \& Kornell, N. (2013). Self-Regulated Learning: Beliefs, Techniques, and Illusions. Annu. Rev. Psychol., 64, 417-44.

Bohadana, E., \& Valle, L. (2009). O quem da educação a distância. Revista Brasileira de Educação. 14(42), 551-564.

Borges-Andrade, J. E. (1982). Avaliação somativa de sistemas instrucionais: integração de três propostas. Tecnologia Educacional, 11(46), 29-39

Borges-Andrade, J. E. (2006). Avaliação integrada e somativa em TD\&E. In J. E. BorgesAndrade, G. Abbad, L. Mourão (Orgs.), Treinamento, desenvolvimento e educação em organizações e trabalho: fundamentos para a gestão de pessoas (pp. 343-358). Porto Alegre: Artmed.

Borges-Andrade, J. E.; Zerbini, T.; Abbad, G. S. \& Mourão, L. (2013). Treinamento, desenvolvimento e educação: Um modelo para sua gestão. In Borges, L., Mourão, L. (Org). $O$ Trabalho e as Organizações. Atuações a partir da Psicologia (pp. 465-498). Porto Alegre: Editora Artmed.

Borges, L., \& Vilas-Boas, R. (Orgs). Medidas de Avaliação em TD\&E - Ferramentas para gestão de pessoas (pp. 226-243). Porto Alegre: Editora Artmed.

Boruchovitch, E., \& Santos, A. A. A. (2004). Escala de avaliação de estratégias de aprendizagem para crianças do ensino fundamental. Manuscrito não publicado, Universidade São Francisco, Bragança Paulista.

Boruchovitch, E., Santos, A. A. A., Costa, E. R., Neves, E. R. C., Cruvinel, M., Primi, R., \& Guimarães, S. E. R. (2006). A construção de uma escala de estratégias de aprendizagem para alunos do ensino fundamental. Psicologia: Teoria e Pesquisa, 22(3), 297-304.

Brandão, H. P., \& Borges-Andrade, J. E. (2011). Desenvolvimento e validação de uma escala de estratégias de aprendizagem no trabalho. Psicologia: Reflexão e Crítica, 24(3), 448-457.

Brasil. Decreto n. 2.494, de 10 de fevereiro de 1998. Regulamento da Educação a Distância no País. Diário Oficial da Republica Federativa do Brasil. Disponível em $<$ http://www.mec.gov.br. Acesso em 16/08/2015.

Brown, K. G. (2005). What does recent research tell us about "training satisfaction?" In: C. Saul \& B. Sugrue (Ed.). American Society for Training \& Development:Research-to-Practice 
Conference Proceedings (pp. 27 - 35). United States of America.

Bowman, J., \& Wilson, J. P. (2008). Different roles, different perspectives: perceptions about the purpose of training needs analysis. Industrial and Comercial Training, v. 1, n. 40, p. 38-41.

Bloom, B. S., Krathwohl, D. R., \& Masia, B.B. (1972). Taxonomia de objetivos educacionais, compêndio primeiro: domínio cognitivo. Porto Alegre: Globo.

Burke, L. A., \& Hutchins, H. M. (2007). Training transfer: an integrative literature review. HumanResourceDevelopmentReview, 6(3), 263-297.

Carvalho, R. S. (2003). Avaliação de treinamento a distância via internet: reação, suporte à transferência e impacto do treinamento no trabalho. Dissertação de Mestrado, Instituto de Psicologia, Universidade de Brasília.

Carvalho, R. S., \& Abbad, G. (2006). Avaliação de treinamento a distância: reação, suporte à transferência e impactos no trabalho. Revista de Administração Contemporânea, 10(1), 95-116.

Carswell, A. D., \& Venkatesh, V. (2002). Learner outcomes in an asynchronous distance education environment. International Journal of Human-Computer Studies, 56, 475-494.

Castro, M. N. M., \& Ferreira, L. D. V. (2006). TD\&E a distância: múltiplas mídias e clientelas. In J. E. Borges-Andrade, G. Abbad, L. Mourão (Orgs.). Treinamento, desenvolvimento e educação em organizações e trabalho: fundamentos para a gestão de pessoas (pp. 322-339). Porto Alegre: Artmed

Censo da Educação Superior 2010: Resumo Técnico. - Brasília : Instituto Nacional de Estudos e Pesquisas Educacionais Anísio Teixeira. Retirado de: http://download.inep.gov.br/download/superior/censo/2010/resumo_tecnico_censo_educacao _superior_2010.pdf

Censo da Educação Superior 2012: Resumo Técnico. - Brasília : Instituto Nacional de Estudos e Pesquisas Educacionais Anísio Teixeira, 2014. Retirado de: http://download.inep.gov.br/download/superior/censo/2012/resumo_tecnico_censo_educacao superior_2012.pdf

Cobo, C., \& Pardo, H. (2007). Planeta web 2.0. Inteligencia colectiva o médios fastfood. Grup de Recerca d'Interacciones Digitals, Universitat de Vic. Flacso México. Barcelona.

Coelho Jr., F. A. \& Borges-Andrade, J. E. (2008). Uso do conceito de aprendizagem em estudos relacionados ao trabalho e organizações. Paidéia, 18(40), 221-234.

Coll, C. (2004). Psicología de la educación y prácticas educativas mediadas por las tecnologias de la información y la comunicación. Sinéctica, 25, 1-24.

Coll, C., Mauri, T., \& Onrubia, J. (2010). A incorporação das tecnologias da informação e da comunicação na educação - do projeto pedagógico às práticas de uso. In C. Coll \&C. Monereo (Orgs.). Psicologia da Educação virtual - Aprender e ensinar com as tecnologias da informação e da comunicação (pp. 66-93). Porto Alegre: Artmed. 
Cunha, M. G. M, \& Boruchovitch, E. (2012).Estratégias de Aprendizagem e Motivação para Aprender na Formação de Professores. Revista Interamericana de Psicología/Interamerican Journal of Psychology (46)2, 247-254

De Paula e Silva, A (2004). Avaliação de uma disciplina semipresencial de graduação ofertada por meio da internet pela Universidade de Brasília. Dissertação (Mestrado em Psicologia) Instituto de Psicologia, Universidade de Brasília, Brasília.

Dean, A., \& Webster, L. (2000). Simulations in distance education-progress towards an evaluation instrument. Distance Education, 21(2), 344-360.

Freeze, R. D., Alshare, K. A., Lane, P. L. \& Wen, H. J. (2010). IS success model in e-learning context based on students' perceptions.Journal of Information Systems Education, 21(2), 173 184.

Garrison, D. R., \& Vaughan, N. D. (2008). Blended learning in higher education: framework, principles and guidelines. São Francisco: Jossey-Bass.

Giangreco, A., Carugati, A., Sebastiano, A., \& Della Bella D. (2010). Trainees' reactions to training: shaping groups and courses for happier trainees. The International Journal of Human Resource Management, 21(13), 2468-2487.

Gondin, S. M. G. \& Silva, N. (2004). Motivação no Trabalho. In J. C. Zanellie, J. E. BorgesAndrade \& A. V. B. Bastos (Orgs.), Psicologia, organizações e trabalho no Brasil (pp. 145176). Porto Alegre: Artmed.

Goldstein, I.L. (1991). Training in work organizations. Em: Dunnette\& Hough (Orgs.), Handbook of Industrial and Organizational Psychology (pp.507-619). California: Consulting Psychology Press.

Gonsalves, E. P. (2014). Educação e a Curva Pedagógica. Campinas: Alinea.

Guimarães, V. F., \& Abbad, G. (2015). Autoeficácia no uso do computador em situações de aprendizagem: uma análise da literatura internacional. Revista Psicologia: Organizações e Trabalho, 15(2), abr-jun 170-187.

Gunawardena, C. N., Linder-VanBerschot, J. A., LaPointe, D. K., \& Rao, L. (2010). Predictors of learner satisfaction and transfer of learning in a corporate online education program. American Journal of Distance Education, 24, 207-226.

Hair, J. F., Anderson, R. L., Tatham, R. L. \& Black, W. C. (2005). Análise Multivariada de dados (5a ed.). Porto Alegre: Bookman.

Hamblin, A. C. (1978). Avaliação e controle do treinamento. São Paulo: McGraw-Hill do Brasil.

Henderson, B.D (1998). As origens da Estratégia. Em Montgnomery, C. A, Porter, M. P. Estratégia: a busca da vantagem competitiva. $15^{\mathrm{a}}$ ed. Rio de Janeiro. Elsevier. 
Holman, D., Epitropaki, O., \& Fernie, S. (2001). Understanding learning strategies in the workplace: a factor analytic investigation. Journal of Occupational and Organizational Psychology, 74, 675-681.

Iglesias, M., \& Salgado, J. F. (2012). Effectiveness of Occupational Training Through Videoconferencing: Comparison with Classroom Training and Individual Differences. Revista de PsicologíadelTrabajo y de lasOrganizaciones, 28(3), 183-188.

Kirkpatrick, D. L. (1976). Evaluation of training. In R. L. Craig (Org.), Training and Development Handbook (pp. 18.1-18.27). New York: McGraw-Hill.

Klein, H. J., Noe, R. A., \& Wang, C. (2006). Motivation to learn and course outcomes: the impact of delivery mode, learning goal orientation, and perceived barriers and enablers. Personnel Psychology, 59, 665-702.

Laaser, W (1997). Manual de criação e elaboração de materiais para educação a distância. Brasília: CEAD, Editora Universidade de Brasília, 1997.

Lee, Y., Tseng, S., Liu, F., \& Liu, S. (2007). Antecedents of learner satisfaction toward elearning. Journal of American Academy of Business, 11(2), 161-168.

Laros, J. A. (2004). O uso da análise fatorial: algumas diretrizes para pesquisadores. Em: L. Pasquali (Org.). Análise fatorial para pesquisadores. Petrópolis: Vozes.

Lima, S. M. V., \& Borges-Andrade, J. E. (1985). Meta-análise de avaliação de treinamento. Revista de Administração, 20(3), 39-52.

Lu, H. P., \& Chiou, M. J. (2010). The impact of individual differences on e-learning system satisfaction: a contingency approach. British Journal of Educational Technology, 41(2), 307323.

Marks, R. B., Sibley, S. D., \& Arbaugh, J. B. (2005). A structural equation model of predictors for effective online learning. Journalof Management Education, 29(4), 531-563.

Martins, L. B. (2012). Aprendizagem em ações educacionais a distância: fatores influentes no desempenho acadêmico de universitário. Dissertação de Mestrado, Faculdade de Filosofia, Ciências e Letras de Ribeirão Preto, Universidade de São Paulo, São Paulo.

Martins, L. B. (2015). Impacto do treinamento no trabalho: determinantes individuais e contextuais em cursos a distância. Proforma da Tese apresentada para o Exame de Qualificação, Faculdade de Filosofia, Ciências e Letras de Ribeirão Preto, Universidade de São Paulo, São Paulo.

Martins, L. B., \& Zerbini, T. (2014). Educação a distância em instituições de ensino superior: uma revisão de pesquisas. Revista Psicologia: Organizações e Trabalho, 14(3), 271-282.

Martins, L. B., \& Zerbini, T. (2015). Evidências de validade de instrumentos de reações no ensino superior à distância. Revista: Estudos e Pesquisas em Psicologia. Rio de Janeiro, $15(1), 116-134$. 
Mauri, T., Onrubia, J., Coll, C., \& Columbia, R. (2005). La calidad de los contenidos educativos reutilizables: diseño, usabilidad y prácticas de uso. Revista de Educación a Distancia.

Mauri, T., \& Onrubia, J. (2010). O professor em ambientes virtuais: perfil, condições e competências. In C. Coll \& C. Monereo (Orgs.). Psicologia da Educação virtual-Aprender e ensinar com as tecnologias da informação e da comunicação.(pp. 118-135). Porto Alegre: Artmed.

McCormick, C. B. (2003). Metacognition and learning. In:W. M. Reynolds, G. E. Miller (Orgs.). Handbook of Psychology. Educational Psychology.

Meneses, P. P. M., Abbad, G, Zerbini, T., \& Lacerda, E. (2006). Medidas de características da clientela em avaliação de TD\&E. In J. E. Borges-Andrade, G. Abbad, L. Mourão (Orgs.). Treinamento, desenvolvimento e educação em organizações e trabalho: fundamentos para a gestão de pessoas (pp. 422-442). Porto Alegre: Artmed.

Meneses, P. P. M., Zerbini, T., \& Abbad, G. (2010). Manual de Treinamento Organizacional. Porto Alegre: Artmed.

Meneses, P. P. M., Zerbini, T., \& Martins, L. B. (2012). Determinantes situacionais e individuais da aprendizagem em ensino a distância: desenvolvimento de escala. PSICOPUCRS, 43(2), 208-218.

Ministério da Educação e Cultura (2010). Censo do Ensino Superior 2010.

Mintzberg, H., \& Quinn, J. B (2001). O processo da Estratégia. $3^{\text {a }}$ ed. Porto Alegre. Bookman.

Mohelská, H., \& Sokolová, M. (2014) Effectiveness of using e-learning for business disciplines: The case of introductory management course. Ekonomie a Management, 1, 82-92.

Morgan, R. B., \& Casper, W. J. (2000). Examining the factor structure of participant reactions to training: a multidimensional approach. HumanResourceDevelopmentQuarterly, 11(3), 301317.

Mourão, L., Abbad, G. \& Zerbini, T., (2013). Avaliação da efetividade e dos preditores de um treinamento a distância em uma instituição bancária de grande porte. Revista Administração, São Paulo, v.49 (3), 534-548, jul./ago./set.

Oliveira, K. L., Boruchovitch, E., \& Santos, A. A. A. (2009).Estratégias de aprendizagem e desempenho acadêmico: evidências de validade. Psicologia: teoria e pesquisa, 25(4), 531-536.

Özkan, S., Köseler, R., \& Baykal, N. (2009). Evaluating learning management systems; adoption of hexagonal e-learning assessment model in higher education. Transforming Government: People, Process and Policy, 3(2), 111-130.

Pantoja, M. J. (2004). Estratégias de aprendizagem no trabalho e percepções de suporte à aprendizagem - uma análise multinível. Tese de Doutorado, Instituto de Psicologia, Universidade de Brasília.

Pantoja, M. J. \& Borges-Andrade, J. E. (2009). Estratégia de Aprendizagem no Trabalho em 
Diferentes Ocupações Profissionais. Revista RAC-Eletrônica, 3(1), 41-62.

Pasquali, L. (2004). Análise fatorial para pesquisadores. Petrópolis: Vozes.

Perassinoto, M. G. M., Boruchovitch, E., \& Bzneck, J. A. (2013) Estratégias de aprendizagem emotivação para aprender de alunos do Ensino Fundamental. Avaliação Psicológica, 12(3), 351-359.

Pilati, R. (2006). História e importância de TD\&E. In J. E. Borges-Andrade, G. Abbad, L. Mourão (Orgs.), Treinamento, desenvolvimento e educação em organizações e trabalho: fundamentos para a gestão de pessoas (pp. 159-176). Porto Alegre: Artmed.

Pilati, R., \& Borges-Andrade, J. E. (2006). Construção de medidas e delineamentos em avaliação de TD\&E. In J. E. Borges-Andrade, G. Abbad, L. Mourão \& colaboradores. Treinamento, desenvolvimento e educação em organizações e trabalho: fundamentos para a gestão de pessoas (pp. 359-384). Porto Alegre: Artmed.

Pinto, M. B. \& Anderson, W. (2013) A little knowledge goes a long way: Student expectation and satisfaction with hybrid learning Journal of Instructional Pedagogies, 10, 1-12

Rafferty, P. D. \& Anderson, C. M. (2013) Are executive students satisfied with online-learning experiences? Implications for online training and executive education. Training \& Management Development Methods, 27(4), 673-684.

Reis, F. L. (2009). Do ensino presencial ao ensino a distância no contexto universitário na Península Ibérica. Revista Brasileira de Aprendizagem Aberta e a Distância, 8, 1-28.

Rodrigues Jr., J.F. (2006). Taxonomia de objetivos em TD\&E. Em: J. E. Borges-Andrade, G. Abbad, L. Mourão \& colaboradores. Treinamento, desenvolvimento e educação em organizações e trabalho: fundamentos para a gestão de pessoas (pp.282 - 288). Porto Alegre: Artmed.

Salas, E., \& Cannon-Bowers, J. A. (2001). The science of training: a decade of progress. Annual Review of Psychology, 52, 471-499.

Salas, E., Tannenbaum, S. I., Kraiger, K., \& Smith-Jentsch, K. A. (2012). The Science of Training and Development in Organizations: What Matters in Practice. Psychological Science in thePublicInterest, 13(2) 74-101.

Sales, P. A. O. (2009). Evasão em Cursos a Distância: Motivos Relacionados às Características do Curso, do Aluno e do Contexto de Estudo. Dissertação de Mestrado, Instituto de Psicologia, Universidade de Brasília, Brasília.

Salovaara, H, (2005). An exploration of students strategy use in inquiry based computersupported collaborative learning. Journal of Computer Assisted Learning, 21, 37-52.

Sahin, I., \& Shelley, M. (2008). Considering students' perceptions: the distance education student satisfaction model.Educational Technology \& Society, 11(3), 216-223. 
Santos, J. F. S. (2006). Avaliação no ensino a distância. Revista Iberoamericana de Educación, 38(4), 1-9.

Siritongthaworn, S., \& Krairit, D. (2006). Satisfaction in e-learning: the context of supplementary instruction. Campus - Wide Information Systems, 23(2), 76-91.

Souza, A. S. Q. (2012). Universidade Aberta do Brasil (UAB) como política de formação de professores. Revista: Educação em Questão, Natal, 42 (28), 119-148.

Tabachnick, B. G., \& Fidell, L. S. (2007). Using multivariate statistics. New York: HarperCollinsCollege Publishers.

Teo, T., \& Wong, S. L. (2013). Modeling key drivers of e-learning satisfaction among student teachers. Journal of Educational Computing Research, 48(1), 71-95.

Testa, M. G., \& Luciano, E. M. (2010). A influência da autorregulação dos recursos de aprendizagem na efetividade dos cursos desenvolvidos em ambientes virtuais de aprendizagem na Internet. Revista Eletrônica de Administração, 16(2), 176-208.

Tien-Chen, C. (2012). Computer self-efficacy and factors influencing e-learning effectiveness. European Journal of Training and Development, 36(7), 670-686.

Umekawa, E. E. R. (2014). Preditores de fatores relacionados à evasão e à persistência discente em ações educacionais a distância. Dissertação de Mestrado, Faculdade de Filosofia, Ciências e Letras de Ribeirão Preto, Universidade de São Paulo, São Paulo.

Umekawa, E. E. R., \& Zerbini, T. (2015). Evasão e persistência em ações educacionais a distância: análise do perfil discente. Revista Psicologia: Organizações e Trabalho, 15(2), abrjun, 188-200.

Vaughan, N. (2007). Perspectives on blended learning in Higher education. InternationalJournalon E-learning, 6, (1), 81-94.

Vaughan, K., \& MacVicar, A. (2004). Employees' pre-implementation attitudes and perceptions to e-learning: a banking case study analysis. Journal of European Industrial Training, 28(5), 400-413.

Vargas, M. R. M. (2003). Educação a distância no contexto da mudança organizacional. In S. M. V. Lima (Org.), Mudança organizacional: teoria e gestão (pp. 291-315). Rio de Janeiro: FGV.

Vargas, M. R. M. (2004). Barreiras à implantação de programas de educação e treinamento a distância. Tese de Doutorado, Instituto de Psicologia, Universidade de Brasília, Brasília.

Vargas, M. R. M., \& Abbad, G. (2006). Bases Conceituais em Treinamento, Desenvolvimento e Educação (TD\&E). In J. E. Borges-Andrade, G. Abbad, L. Mourão (Orgs.), Treinamento, desenvolvimento e educação em organizações e trabalho: fundamentos para a gestão de pessoas, 137-158. Porto Alegre: Artmed.

Veenman, M. V. J., Wilhelm, P., \& Beishuizen, J. J. (2004). The relation between intellectual 
and metacognitive skills from a developmental perspective. Learning and Instruction, 14, 89109.

Yukselturk, E., \& Inan, F. A. (2006). Examining the Factors Affecting Student Dropout in an Online Learning Environment. Turkish Online Journal of Distance Education, 7(2).

Walter, A. M. (2006). Variáveis Preditoras de Evasão em Cursos a Distância. Dissertação de Mestrado, Universidade de Brasília, Brasília.

Warr, P., \& Allan, C. (1998). Learning strategies and occupational training. Internacional Review of Industrial and Organizational Psychology, 13, 83-121.

Warr, P., \& Downing, J. (2000). Learning strategies, learning anxiety and knowledge acquisition. British JournalPsychology, 91, 311-333.

Womble, J. (2008). E-learning: the relationship among learner satisfaction, self-efficacy, and usefulness.The Business Review, Cambridge, 10(1), 182-188.

Zerbini, T. (2007). Avaliação da transferência de treinamento em curso a distância. Tese de Doutorado, Instituto de Psicologia, Universidade de Brasília.

Zerbini, T., \& Abbad, G. (2005). Impacto de treinamento no trabalho via internet. Revista de Administração de Empresas - RAE- eletrônica, 4(2).

Zerbini, T., Carvalho, R. S., \& Abbad, G. (2005). Treinamento a distância via internet: construção e validação de escala de estratégias de aprendizagem [CD-Rom]. Em Associação Nacional dos Programas de Pós-Graduação em Administração (Org.). Anais do XXIX ENANPAD. Brasília: ANPAD.

Zerbini, T., \& Abbad, G. (2008). Estratégias de aprendizagem em curso a distância: validação de uma escala. Psico-USF, 13, 177-187.

Zerbini, T., \& Abbad, G. (2009a). Reação aos procedimentos instrucionais de um curso via internet: validação de uma escala. Estudos de Psicologia (Campinas), 26(3), 363-371.

Zerbini, T., \& Abbad, G. (2009b). Reação ao desempenho do tutor em um curso a distância validação de uma escala. Estudos e Pesquisas em Psicologia, 9, 447-463.

Zerbini, T., \& Abbad, G. (2010). Qualificação profissional a distância: avaliação da transferência de treinamento. Paidéia, vol. 20, nº 47, 313-323.

Zerbini, T., \& Abbad, G. (2010b). Transferência de treinamento e impacto do treinamento no trabalho: análise crítica da literatura. Revista Psicologia: Organizações e Trabalho, 10(2), 97111

Zerbini, T., \& Abbad, G. (2010c). Reações em cursos a distância: revisão da literatura. Revista PSICO, 41, 192-200.

Zerbini, T., \& Pilati, R. (2012). Medidas de insumo: perfil cognitivo-comportamental da clientela de ações de TD\&E. In Abbad, G. Mourão, L., Meneses, P., Zerbini, T., 
Zerbini, T., Abbad, G., \& Mourão, L. (2012). Avaliação da efetividade de um curso a distância, via intranet: o caso do Banco do Brasil. Revista Psicologia: Organizações e Trabalho, 12(2), 155-170. 


\section{Anexos}

Anexo A. Pesquisa de Estratégias de Aprendizagem (Martins, 2015)

\begin{tabular}{|c|c|c|c|c|c|}
\hline Autores & Objetivo & Amostra/Contexto & $\begin{array}{c}\text { Procedimentos de } \\
\text { coleta de dados }\end{array}$ & $\begin{array}{l}\text { Procedimentos de } \\
\text { análise de dados }\end{array}$ & Resultados \\
\hline $\begin{array}{l}\text { Warr e } \\
\text { Downing } \\
(2000)\end{array}$ & $\begin{array}{l}\text { Validar uma escala de } \\
\text { Estratégias de Aprendizagem } \\
\text { e investigar a relação entre } \\
\text { Estratégias de Aprendizagem, } \\
\text { ansiedade para aprender e } \\
\text { aquisição de conhecimento }\end{array}$ & $\begin{array}{l}152 \text { participantes de } \\
\text { um curso de mecânica } \\
\text { básica }\end{array}$ & $\begin{array}{l}\text { Aplicação de } \\
\text { questionários }\end{array}$ & $\begin{array}{l}\text { Análise fatorial } \\
\text { exploratória }\end{array}$ & 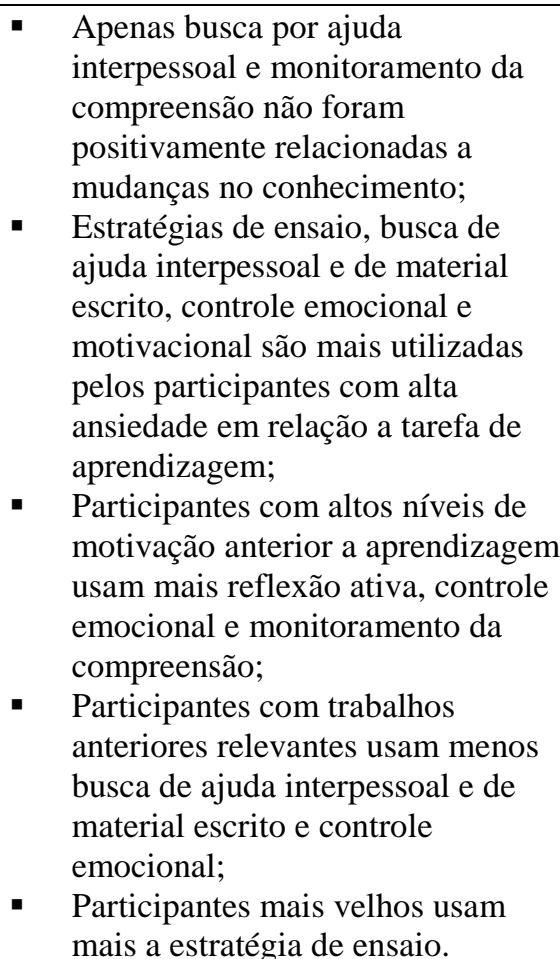 \\
\hline
\end{tabular}

Fonte: Martins (2015). 
Anexo A. Pesquisas sobre Estratégias de Aprendizagem (continuação).

Holman, Validar uma escala de 628 agentes de call

Epitropaki e Estratégias de Aprendizagem, center de um banco

provinda de ambiente (Reino Unido)

questionários

Análises fatoriais
exploratórias e

confirmatórias

ducacional, em um contexto

organizacional
- As Estratégias de Aprendizagem utilizadas por adultos em contextos de trabalho são similares às usadas em ambientes educacionais.

- 22 itens; 6 fatores divididos em 2 tipos de estratégias: cognitivas (reprodução, organização e elaboração) e comportamentais (busca de ajuda interpessoal, busca de ajuda ao material didático e aplicação prática)

\begin{tabular}{|c|c|c|c|c|c|c|}
\hline $\begin{array}{l}\text { Zerbini e } \\
\text { Abbad (2005) }\end{array}$ & $\begin{array}{l}\text { Relacionar o uso de } \\
\text { Estratégias de Aprendizagem } \\
\text { às reações aos procedimentos } \\
\text { instrucionais de um curso via } \\
\text { internet e reações ao tutor e } \\
\text { impacto do treinamento no } \\
\text { trabalho }\end{array}$ & $\begin{array}{l}188 \text { e } 354 \text { participantes } \\
\text { do curso a distância } \\
\text { IPGN (SEBRAE) }\end{array}$ & $\begin{array}{l}\text { Aplicação de } \\
\text { questionários online }\end{array}$ & $\begin{array}{l}\text { Análise fatorial } \\
\text { exploratória } \\
\text { Análise de regressão } \\
\text { múltipla }\end{array}$ & & $\begin{array}{l}\text { Apenas as estratégias de } \\
\text { elaboração e aplicação prática } \\
\text { explicaram o impacto do } \\
\text { treinamento no trabalho. }\end{array}$ \\
\hline Pantoja (2004) & $\begin{array}{l}\text { Investigar o relacionamento } \\
\text { entre Estratégias de } \\
\text { Aprendizagem, características } \\
\text { da organização e percepções } \\
\text { de suporte à aprendizagem } \\
\text { contínua }\end{array}$ & $\begin{array}{l}900 \text { trabalhadores de } \\
16 \text { categorias distintas } \\
\text { atuantes em diferentes } \\
\text { segmentos } \\
\text { organizacionais }\end{array}$ & $\begin{array}{l}\text { Aplicação de } \\
\text { questionários }\end{array}$ & $\begin{array}{l}\text { Teste de } 5 \text { modelos } \\
\text { multiníveis para } \\
\text { verificação do efeito } \\
\text { específico de } \\
\text { variáveis preditoras } \\
\text { nas Estratégias de } \\
\text { Aprendizagem no } \\
\text { local de trabalho } \\
\text { Análise fatorial } \\
\text { exploratória }\end{array}$ & & $\begin{array}{l}\text { Diferentes correlações encontradas } \\
\text { entre as variáveis individuais } \\
\text { (idade, gênero, anos de estudo, } \\
\text { categoria profissional) e a } \\
\text { utilização de Estratégias de } \\
\text { Aprendizagem no local de } \\
\text { trabalho; } \\
\text { Destaque para a estratégia } \\
\text { aplicação prática para a } \\
\text { aprendizagem dos indivíduos nos } \\
\text { contextos organizacionais } \\
\text { estudados; } \\
\text { Há diferenças significativas entre } \\
\text { as Estratégias de Aprendizagem } \\
\text { utilizadas no local de trabalho } \\
\text { conforme a categoria profissional. }\end{array}$ \\
\hline
\end{tabular}

Fonte: Martins (2015). 
Anexo A. Pesquisas sobre Estratégias de Aprendizagem (continuação)

\begin{tabular}{|c|c|c|c|c|c|}
\hline $\begin{array}{l}\text { Pantoja e } \\
\text { Borges- } \\
\text { Andrade (2009) }\end{array}$ & $\begin{array}{l}\text { Mapear Estratégias de } \\
\text { Aprendizagem no trabalho } \\
\text { com o objetivo de classificar } \\
\text { dezesseis ocupações } \\
\text { profissionais, em quatro } \\
\text { categorias de postos de } \\
\text { trabalho, bem como descrever } \\
\text { e comparar as estratégias } \\
\text { utilizadas pelos indivíduos } \\
\text { para aprenderem, em seu dia- } \\
\text { a-dia no trabalho, nessas } \\
\text { diferentes categorias } \\
\text { profissionais }\end{array}$ & $\begin{array}{l}12 \text { coordenadores de } \\
\text { RH e } 55 \text { representantes } \\
\text { das dezesseis } \\
\text { ocupações } \\
\text { profissionais estudadas }\end{array}$ & $\begin{array}{l}\text { Entrevistas } \\
\text { semiestruturadas } \\
\text { baseadas na técnica } \\
\text { de incidentes críticos }\end{array}$ & Análise de conteúdo & $\begin{array}{l}\text { As estratégias aplicação prática e } \\
\text { busca de ajuda interpessoal } \\
\text { exerceram papel primordial nos } \\
\text { processos de aquisição, retenção e } \\
\text { transferência de novas } \\
\text { competências em âmbito laboral; } \\
\text { Diferentes configurações de uso de } \\
\text { Estratégias de Aprendizagem } \\
\text { estiveram associadas às categorias } \\
\text { profissionais estudadas. }\end{array}$ \\
\hline $\begin{array}{l}\text { Zerbini e } \\
\text { Abbad (2008, } \\
\text { 2010) }\end{array}$ & $\begin{array}{l}\text { Identificar variáveis } \\
\text { explicativas da aplicação de } \\
\text { habilidades ensinadas aos } \\
\text { participantes de um curso de } \\
\text { qualificação profissional a } \\
\text { distância, via internet }\end{array}$ & $\begin{array}{l}4.719 / 470 \\
\text { participantes do curso } \\
\text { a distância IPGN } \\
\text { (SEBRAE) }\end{array}$ & $\begin{array}{l}\text { Aplicação de } \\
\text { questionários online }\end{array}$ & $\begin{array}{l}\text { Análise fatorial } \\
\text { exploratória } \\
\text { Análise de regressão } \\
\text { múltipla }\end{array}$ & $\begin{array}{l}\text { Participantes que utilizaram com } \\
\text { mais frequência as Estratégias de } \\
\text { Aprendizagem elaboração e } \\
\text { monitoramento da compreensão } \\
\text { foram os que relataram maior } \\
\text { ocorrência de impacto do } \\
\text { treinamento no trabalho; } \\
\text { Os participantes que elaboraram o } \\
\text { plano de negócios utilizaram com } \\
\text { mais frequência a estratégia de } \\
\text { aprendizagem busca de ajuda } \\
\text { interpessoal. }\end{array}$ \\
\hline $\begin{array}{l}\text { Abbad, Côrrea } \\
\text { e Meneses } \\
(2010)\end{array}$ & $\begin{array}{l}\text { Analisar as relações entre } \\
\text { Estratégias de Aprendizagem } \\
\text { e satisfação com treinamentos } \\
\text { a distância }\end{array}$ & $\begin{array}{l}216 \text { participantes de } \\
\text { cinco cursos realizados } \\
\text { a distância }\end{array}$ & $\begin{array}{l}\text { Aplicação de } \\
\text { questionários }\end{array}$ & $\begin{array}{l}\text { Análise fatorial } \\
\text { exploratória } \\
\text { Análises de } \\
\text { correlações bivariadas }\end{array}$ & $\begin{array}{l}\text { - Padrões de associação entre } \\
\text { determinadas estratégias cognitivas } \\
\text { de aprendizagem e satisfação com } \\
\text { o desempenho da tutoria, com os } \\
\text { procedimentos e os resultados e } \\
\text { com a interface gráfica do curso }\end{array}$ \\
\hline
\end{tabular}

Fonte: Martins (2015). 
Anexo A. Pesquisas sobre Estratégias de Aprendizagem (continuação)

Testa e Luciano Investigar o papel Participantes: 28

(2010)

desempenhado pelas

Estratégias de Aprendizagem

utilizadas na regulação de

recursos de aprendizagem em

ambientes virtuais de ensino (questionários)

Entrevistas

semiestruturadas e

abertas; análise de

documentos e de

registros; observação

direta; e pesquisa

survey (entrevistados) e 104

Análise de conteúdo
Análise fatorial
exploratória

- Participantes que mais frequentemente estabeleceram

interações com pares e professores, para tirar dúvidas ou buscar auxílio, atingiram as mais elevadas médias nos itens interesse,

persistência, percepção de autoconfiança e gestão do ambiente social da escala MSLQ

(Motivated Strategies for Learning Questionnaire);

- Correlações significativas entre as elevadas taxas de satisfação com o estudo e desempenho acadêmico e a utilização de estratégias para gestão do tempo e esforço.

- Implicações práticas: estabelecer prazos curtos e frequentes para a conclusão das tarefas; fixar nos critérios avaliativos elementos que tratem do gerenciamento de tempo; investir em interações viabilizadas pelo recurso do chat ou por meio de videoconferências; sugerir atividades não formais nas quais os estudantes partilhem preferências, opiniões, etc.

\begin{tabular}{|c|c|c|c|c|c|}
\hline $\begin{array}{l}\text { Brandão \& } \\
\text { Borges- } \\
\text { Andrade (2011) }\end{array}$ & $\begin{array}{l}\text { Desenvolver uma escala de } \\
\text { Estratégias de Aprendizagem } \\
\text { no trabalho e verificar a } \\
\text { frequência com que estas são } \\
\text { utilizadas por gestores de um } \\
\text { banco público }\end{array}$ & $\begin{array}{l}881 \text { gestores de } \\
\text { agências bancárias } \\
\text { brasileiras }\end{array}$ & $\begin{array}{l}\text { Levantamento } \\
\text { documental, } \\
\text { entrevistas e } \\
\text { questionários }\end{array}$ & $\begin{array}{l}\text { Análises descritivas e } \\
\text { fatoriais exploratórias }\end{array}$ & $\begin{array}{l}\text { As Estratégias de Aprendizagem } \\
\text { busca de ajuda interpessoal e } \\
\text { reflexão ativa foram as mais } \\
\text { utilizadas pela amostra. }\end{array}$ \\
\hline
\end{tabular}

Fonte: Martins (2015) 5). 
Anexo B. Pesquisa de Reações (Martins, 2015)

\begin{tabular}{|c|c|c|c|c|c|}
\hline Autores & Objetivo & Amostra/Contexto & $\begin{array}{l}\text { Procedimentos de } \\
\text { coleta de dados }\end{array}$ & $\begin{array}{c}\text { Procedimentos } \\
\text { de análise de } \\
\text { dados }\end{array}$ & Resultados \\
\hline $\begin{array}{l}\text { Morgan \& Casper } \\
(2000)\end{array}$ & $\begin{array}{l}\text { Examinar a estrutura } \\
\text { fatorial de reações de } \\
\text { participantes ao } \\
\text { treinamento }\end{array}$ & $\begin{array}{l}9.128 \text { funcionários de } \\
\text { uma agência } \\
\text { governamental com } \\
750.000 \text { membros }\end{array}$ & $\begin{array}{l}\text { Aplicação de } \\
\text { questionários }\end{array}$ & $\begin{array}{l}\text { Análises } \\
\text { fatoriais } \\
\text { exploratórias e } \\
\text { confirmatórias }\end{array}$ & 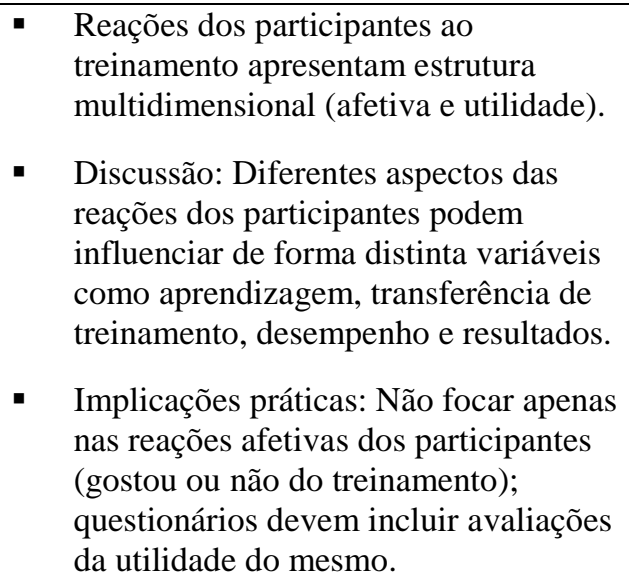 \\
\hline $\begin{array}{l}\text { Vaughan \& } \\
\text { MacVicar (2004) }\end{array}$ & $\begin{array}{l}\text { Identificar as atitudes dos } \\
\text { participantes com relação } \\
\text { ao treinamento a distância }\end{array}$ & 58 funcionários & $\begin{array}{l}\text { Respostas a questões: } \\
\text { sensibilização para o } e \text { - } \\
\text { learning; } \\
\text { oportunidades para } \\
\text { treinamento; suporte } \\
\text { de chefes; barreiras } \\
\text { para o } e \text {-learning; } \\
\text { contato pessoal; } \\
\text { mecanismos de apoio; } \\
\text { métodos de avaliação; } \\
\text { motivação e } \\
\text { autodisciplina; estilos } \\
\text { e atitudes de }\end{array}$ & $\begin{array}{l}\text { Estatísticas } \\
\text { descritivas }\end{array}$ & 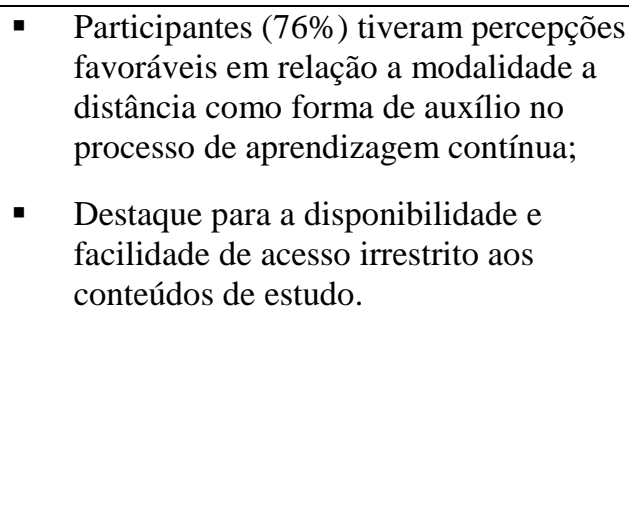 \\
\hline
\end{tabular}


Fonte: Martins (2015).

Pesquisa de Reações (Martins, 2015) (Continuação).

\begin{tabular}{lllll}
\hline Brown (2005) & $\begin{array}{l}\text { Testar um modelo } \\
\text { hierárquico de reação e } \\
\text { examinar hipóteses que } \\
\text { consideravam aspectos } \\
\text { motivacionais e } \\
\text { situacionais como } \\
\text { determinantes de }\end{array}$ & $\begin{array}{l}\text { um dos maiores } \\
\text { bancos da Índia }\end{array}$ & $\begin{array}{l}\text { Aplicação de } \\
\text { questionários enviados } \\
\text { por e-mail }\end{array}$ & $\begin{array}{l}\text { Análise fatorián } \\
\text { confirmatória }\end{array}$ \\
& satisfação & & \\
& $\begin{array}{l}\text { Avaliar as relações entre a } \\
\text { satisfação do aprendiz com } \\
\text { a autoeficácia e a utilidade } \\
\text { de um treinamento online }\end{array}$ & $\begin{array}{l}\text { uma agência } \\
\text { governamental } \\
\text { (Estados Unidos) }\end{array}$ & $\begin{array}{l}\text { Aplicação de } \\
\text { questionários }\end{array}$ & $\begin{array}{l}\text { Análises de } \\
\text { regressão } \\
\text { múltipla }\end{array}$ \\
\hline Womble (2008) & & &
\end{tabular}

- Apoiaram o modelo hierárquico e apontaram que a motivação é um correlato de satisfação, ou seja, motivação esteve positivamente relacionada à satisfação.

regressão

(Estados Unidos)

\section{Gunawardena,}

Linder-

VanBerschot,

LaPointe \& Rao

Carugati,

Sebastiano \&

Della Bella

(2010)
Investigar fatores

preditores de satisfação do

aprendiz e da transferência

de aprendizagem para $\mathrm{o}$

trabalho

\section{9 funcionários de}

uma empresa

multinacional;

instrutores e

desenhistas

instrucionais

13.753 treinandos agrupados em 1.230 cursos, envolvendo satisfação total de

treinandos (VD) com

treinamento - utilidade do

treinamento, desempenho
Aplicação de

questionários via e-

mail (treinandos) e

entrevistas (instrutores

e desenhistas

instrucionais)

\section{Análise de \\ regressão \\ múltipla}

Aplicação de

questionários online

Análise fatorial

exploratória
- Correlações positivas significativas entre as três variáveis, sendo a mais forte entre a satisfação do aluno e a utilidade do curso - este resultado sugere que os trabalhadores que acreditavam que participar do treinamento online iria melhorar seu desempenho, estavam também satisfeitos com o treinamento.

- Autoeficácia online foi o mais forte preditor de satisfação do aprendiz;

Apoio de pares foi o mais forte preditor de transferência de aprendizagem (impacto do treinamento em profundidade).

As três variáveis antecedentes tiveram papel na satisfação total dos treinandos com o treinamento;

Participação feminina tem um efeito positivo sobre a moderação da relação 
do instrutor e eficiência do

treinamento (VIs)
Análise de

regressão

múltipla entre a satisfação total e o desempenho

do instrutor.

Fonte: Martins (2015).

Pesquisa de Reações (Martins, 2015) (Continuação).

$\begin{array}{ll}\text { Zerbini \& Abbad } & \text { Identificar variáveis } \\ \text { explicativas da aplicação } \\ \text { de habilidades ensinadas } \\ \text { aos participantes de um } \\ \text { curso de qualificação } \\ \text { profissional a distância, via } \\ \text { internet }\end{array}$

$\begin{array}{lll}470 \text { participantes do } & \text { Aplicação de } & \text { Análise fatorial } \\ \text { curso a distância } & \text { questionários online } & \begin{array}{l}\text { exploratória }\end{array}\end{array}$

IPGN (SEBRAE)

exploratória

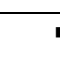

- Participantes com reações favoráveis

aos procedimentos instrucionais do

curso relataram maior ocorrência de

impacto do treinamento em

profundidade;

- A variável "reação ao desempenho do tutor" não consistiu em variável

explicativa de efetividade em cursos a distância e o tutor foi pouco acessado ao longo do curso.

\begin{tabular}{lll}
\hline Ramayah, Ahmad & Determinar os fatores & 163 funcionários \\
\& Hong (2012) & críticos que influenciam a & organizações \\
& efetividade de treinamento & multinacionais \\
& a distância & (Malásia)
\end{tabular}

\section{Aplicação de}

questionários

des

Anc

Análise fatorial

confirmatória

a distância

(Malásia)

- Motivação para aprender, suporte gerencial e suporte da organização foram preditores significativos da satisfação do usuário;

- Autoeficácia, facilidade de uso e conteúdo do treinamento não foram preditores significativos de satisfação;

- Satisfação do usuário não influenciou o benefício líquido, mas foi um forte preditor da intenção de continuar o uso do treinamento a distância

\begin{tabular}{|c|c|c|c|c|c|}
\hline $\begin{array}{l}\text { Teo \& Wong } \\
(2013)\end{array}$ & $\begin{array}{l}\text { Explorar preditores de } \\
\text { satisfação com o } e \text { - } \\
\text { learning: qualidade do } \\
\text { tutor, utilidade percebida, } \\
\text { facilidade de uso }\end{array}$ & $\begin{array}{l}387 \text { participantes } \\
\text { (professores) }\end{array}$ & $\begin{array}{l}\text { Aplicação de } \\
\text { questionários }\end{array}$ & $\begin{array}{l}\text { Modelagem por } \\
\text { Equações } \\
\text { Estruturais }\end{array}$ & $\begin{array}{l}\text { - Todos os constructos foram preditores } \\
\text { significativos da satisfação com o } e \text { - } \\
\text { learning, menos as condições } \\
\text { facilitadoras; }\end{array}$ \\
\hline
\end{tabular}


percebida, entrega do

curso, de condições

facilitadoras e satisfação

com o curso
- Contudo, as condições facilitadoras mediaram a percepção de facilidade de uso e a satisfação com o curso.

Fonte: Martins (2015). 


\section{ANEXO C - TERMO DE CONSENTIMENTO LIVRE E ESCLARECIDO}

Prezado participante,

Eu, Cláudio Gaspar de Mello, convido-o a participar voluntariamente da pesquisa intitulada "Estratégias de aprendizagem em ações educacionais a distância: Relação com características da clientela e reações ao curso.", que faz parte do meu projeto de mestrado no curso de Psicologia (FFCLRP-USP).

O objetivo deste estudo é propor e testar um modelo de avaliação de ações educacionais ofertadas a distância, visando identificar variáveis preditoras de estratégias de aprendizagem relacionadas às características da clientela, às reações aos procedimentos instrucionais e ao tutor. Para tal, preciso de sua colaboração para poder obter as informações necessárias. Sua forma de participação consiste em responder a um conjunto de questionários referente às estratégias de aprendizagem utilizadas no decorrer do curso, bem como suas reações quanto aos procedimentos instrucionais e ao seu tutor, para posterior análise dos dados. Tais informações nos auxiliarão a traçar estratégias de aprendizagem mais adequadas para alunos de graduação na modalidade a distância visando a qualidade da ação educacional ofertada.

A presente pesquisa possui baixo risco para os seus participantes por envolver no processo de coleta de dados questionário com questões fechadas, aplicado a distância, pela internet, sobre estratégias de aprendizagem, procedimentos instrucionais e desempenho do tutor, além de dados sociodemográficos. Contudo será tomado os cuidados éticos necessários para o desenvolvimento da pesquisa.Como forma de sigilo, seu nome não será utilizado em qualquer fase da pesquisa, garantindo seu anonimato acerca de sua identidade, o caráter de sua participação évoluntária e a qualquer momento desse estudo é possível sua desistência sem prejuízo algum.Será solicitada a autorização do uso de suas informações no estudo, conforme as diretrizes da Resolução 466 de 12/12/2012, do Conselho Nacional de Saúde (CNS).

Coloco-me à disposição para mais informações pelo $e$ mailclaudiomello@hotmail.com. Outros esclarecimentos sobre a pesquisa, favor entrar em contato com a Prof. ${ }^{a}$ Dr. ${ }^{a}$ Thaís Zerbini, responsável pela orientação deste projeto: (16) 33154687/ thaiszerbini@ffclrp.usp.br, ou ainda, caso tenha dúvidas éticas em relação ao projeto entrar em contado com Comitê de Ética em Pesquisa da Faculdade de Filosofia, Ciências e Letras de Ribeirão Preto - USP - Avenida Bandeirantes, 3900 - Bloco 23 - Casa 37 - 14040901 - Ribeirão Preto - SP - BrasilFone: (16) 3315-4811 / Fax: (16) 3633-2660E-mail: coetp@ffclrp.usp.br

Li e compreendi este Termo de Consentimento Livre e Esclarecido, portanto, concordo em dar meu consentimento para participar como voluntário desta pesquisa. 
Prezados Tutores,

A Universidade de São Paulo (USP - Ribeirão Preto) em parceria com o Pólo de Serrana das Universidades: Federal de São João Del Rei (UFSJ) e Universidade Federal de Juiz de Fora (UFJF), está desenvolvendo uma pesquisa sobre cursos de graduação oferecidos a distância via internet e os cursos de Licenciatura em Matemática e Pedagogia foram escolhidos.

A sua tarefa consiste em incentivar os seus alunos a responderem aos questionários no prazo estabelecido, para que possamos realizar a nossa avaliação e, assim, sugerir melhorias para as próximas turmas dos cursos de EAD. Você poderá fazer isso por meio de lembretes ou avisos hospedados no ambiente virtual de aprendizagem (AVA) ou enviados aos e-mails pessoais dos alunos durante todo o período da coleta de dados.

Os questionários abordam as estratégias de aprendizagem utilizadas pelos alunos ao longo do curso e tratam da satisfação deles com os procedimentos instrucionais do curso e com o desempenho dos tutores, bem como solicita alguns dados pessoais do alunado. A coordenação do curso irá encaminhar um e-mail a todos os alunos explicando o procedimento correto para efetuar a avaliação, e neste e-mail irá conter um link que remeterá os alunos aos quatro questionários - dados sociodemográficos, estratégias de aprendizagem, reação aos procedimentos instrucionais e ao desempenho do tutor, bastando clicar sobre cada um deles, informar o código do aluno de acesso ao AVA, preencher os questionários e enviar os dados.

Os questionários estarão disponíveis a partir do dia 01/03/2016. Os alunos terão o período que compreende as datas 01/03/2016 a 15/03/2016 para responder aos questionários.

O seu incentivo para que os alunos respondam aos questionários irá contribuir para a melhoria dos cursos nas próximas turmas, sendo a sua colaboração essencial para o sucesso da avaliação.

Desde já, nossos sinceros agradecimentos pela contribuição para o desenvolvimento deste estudo que certamente irá beneficiar todos os envolvidos nos cursos de EAD da Universidade Federal de São João Del Rei (UFSJ).

Favor acusar o recebimento desta.

Atenciosamente,

Coordenadoria de EAD do Pólo de Serrana e Pesquisadores da USP.

Em caso de dúvidas, entre em contato com:

Cláudio Gaspar de Mello: claudiomello@ hotmail.com 
Caros alunos,

A Universidade de São Paulo (USP - Ribeirão Preto) em parceria com o Pólo de Serrana está desenvolvendo pesquisa sobre cursos de graduação oferecidos a distância via internet.

Precisamos que você responda aos questionários que tratam das estratégias de aprendizagem usadas por você durante todo o curso e da sua satisfação com os procedimentos instrucionais e com o desempenho do tutor. Você deverá também informar alguns dados pessoais.

Para participar, basta clicar nos links respectivos a cada um dos questionários, disponíveis logo abaixo. Você deverá preencher os questionários, informar o seu código de acesso ao ambiente virtual de aprendizagem e enviar os dados.

A sua opinião como aluno será de extrema importância para o aperfeiçoamento deste e de outros cursos que venham a ser desenvolvidos pelas Universidades Federais

Os questionários estão disponíveis a partir de hoje 01/03/2016 e você terá até o dia 15/03/2016 para respondê-los e enviá-los.

Desde já nossos sinceros agradecimentos pela contribuição para o desenvolvimento desta pesquisa.

Atenciosamente,

Coordenação dos Cursos de Graduação EAD - Pólo de Serrana e Pesquisadores da USP.

Links questionários:

Dados sociodemográficos:

https://docs.google.com/forms/d/19ZC7jNWCh0LLmJrdbFgMCV44ogLzZ0Trtmqh71DkqpM/viewform?c=0\&

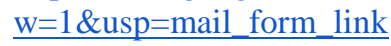

Estratégias de aprendizagem:

https://docs.google.com/forms/d/1jDVrvkn3MuiF3Rq7Q5qhguaNZODiiROihHRpqDi4lks/viewform?c=0\&w=1 $\underline{\text { \&usp }=\text { mail_form_link }}$

Procedimentos instrucionais:

https://docs.google.com/forms/d/1Ie9jL3_rN09VSpq_1dg3pQHuDG3RWOoTMJ3bwlY4elE/viewform?c=0\&w $=1$ \&usp=mail_form_link

Desempenho do tutor:

https://docs.google.com/forms/d/14ogxco-

stWyzglhy02KwIKGBiAIgREgSuJu633uaDbI/viewform?c=0\&w=1\&usp=mail_form_link

Em caso de dúvidas, entre em contato com:

Cláudio Gaspar de Mello: claudiomello@ hotmail.com

ANEXO F - ROTEIRO DE ANÁLISE DE CURSO- EAD 


\begin{tabular}{|l|l|}
\hline Nome do Curso: & $\begin{array}{l}\text { Carga Horária Mínima Sugerida pela DCN } \\
\text { (Diretriz Curricular Nacional): }\end{array}$ \\
\hline Origem do Curso: & Carga Horária Total do Curso: \\
\hline Público-Alvo: & Data da Análise: \\
\hline Nomes dos Responsáveis pela Análise: & $\begin{array}{l}\text { Disponibilização de Tutoria: } \\
\text { ( ) Sim ( ) Não }\end{array}$ \\
\hline & $\begin{array}{l}\text { Tipo de Tutoria: } \\
\text { ( ) Ativa ( ) Passiva }\end{array}$ \\
\hline
\end{tabular}

\section{ORIENTAÇÃO GERAL}

A análise documental aqui proposta será realizada por dois ou mais avaliadores, que deverão efetuar suas avaliações de forma independente.

\section{INSTRUÇÕES- PARTE 1}

Nesta primeira etapa, leia atentamente o material a ser analisado e julgue os aspectos abaixo relacionados, registrando suas observações nos parêntesis colocados à esquerda de cada afirmativa. Utilize para tanto a escala de 5 pontos apresentada abaixo. Utilize NA (não se aplica) caso o curso não aborde o conteúdo do item.

Caso considere necessário, utilize o espaço destinado a observações e sugestões ou o verso desta folha para justificar seu julgamento e detalhar suas considerações.

\begin{tabular}{ccccc}
1 & 2 & 3 & 4 & 5 \\
\hline Nenhum dos Casos & $\begin{array}{c}\text { Menos da Metade } \\
\text { dos Casos }\end{array}$ & Metade dos Casos & $\begin{array}{c}\text { Mais da Metade dos } \\
\text { Casos }\end{array}$ & $\begin{array}{c}\text { Todos os } \\
\text { Casos }\end{array}$
\end{tabular}

\section{OBJETIVOS INSTRUCIONAIS}

( ) 1. Descrição em termos de desempenhos observáveis.

( ) 2. Precisão na escolha do verbo de ação quanto à descrição do comportamento esperado.

( ) 3. Existência de critério.

( ) 4. Descrição clara do objeto de ação.

( ) 5. Definição clara das condições para a realização dos comportamentos esperados (quando essencial sua especificação)

\section{ADEQUAÇÃO DAS ESTRATÉGIAS INSTRUCIONAIS}

( ) 6. Adequação das estratégias instrucionais às características da clientela (escolaridade, cargo).

( ) 7. Adequação das estratégias utilizadas à natureza dos objetivos instrucionais (afetivo, cognitivo, psicomotor).

( ) 8. Adequação das estratégias utilizadas ao nível de complexidade dos objetivos instrucionais (com base nas taxonomias de Bloom e Simpson).

( ) 9. Diversificação das estratégias utilizadas ao longo do curso. (X ) Sim ( ) Não. Especifique no final.

( ) 10. Estratégias favorecem a interação entre os participantes (discussões presenciais e/ou virtuais, elaboração de trabalhos em grupos, etc).

Fornecimento de exemplos que ilustremna atuação profissionaldosparticipantes.o curso oferecido.

( ) 11. Utilização de recursos de apoio à aprendizagem (equipamento de vídeo-conferências, chats, fóruns, etc).

( ) 12. Fidelidade dos recursos de apoio à aprendizagem (simulações, vídeos, estudos de caso, vídeo-conferências, discussões em chats, fóruns, etc) às situações reais de trabalho.

( ) 13. Linguagem dos módulos do curso compatível com o nível de escolaridade dos participantes.

( ) 14. Fidelidade dos conteúdos à situação real de trabalho.

( ) 15. Pertinência dos tópicos de informações adicionais (links de outros endereços, glossário, bibliografia).

Leia atentamente o material a ser analisado e registre suas observações nos parênteses colocados à esquerda de cada afirmativa, utilizando a escala de 5 pontos apresentada abaixo. Utilize NA (não se aplica) caso o curso não aborde o conteúdo do item. Caso 
considere necessário, utiliza o espaço destinado a observações ou o verso desta folha para justificar seu julgamento e detalhar suas considerações.

\begin{tabular}{ccccc}
\hline 1 & 2 & 3 & 4 & 5 \\
\hline Nenhum dos Casos & $\begin{array}{c}\text { Menos da Metade } \\
\text { dos Casos }\end{array}$ & Metade dos Casos & $\begin{array}{c}\text { Mais da Metade dos } \\
\text { Casos }\end{array}$ & Todos os Casos
\end{tabular}

\section{INSTRUÇÕES - PARTE 2}

Nos itens a seguir, registre suas observações nos parêntesis colocados à esquerda de cada afirmativa, utilizando os códigos: "S" (sim), diante dos itens que descrevem os materiais em estudo, "N" (não), diante das características que não descrevem este material e "NA" (não se aplica), diante dos casos que não sejam pertinentes para o curso em estudo. Caso considere necessário, utilize o espaço destinado a observações ou o verso desta folha para justificar seu julgamento e detalhar suas considerações.

\section{PLANEJAMENTO DO CURSO}

( ) 16. Adequação da carga horária sugerida com relação ao volume das disciplinas apresentadas.

( ) 17. Informação ao aluno da estimativa de tempo a ser gasto em cada módulo/período por disciplina.

( ) 18. Informação ao aluno da estimativa de tempo a ser gasto com as atividades teóricas e praticas de cada disciplina.

( ) 19. Existência de um programa.

( ) 20. Disponibilização do programa no início do curso.

( ) 21. Existência de avaliações de aprendizagem.

( ) 22. Diversidade nas avaliações de aprendizagem.

\section{SEQÜENCIAÇÃO DO ENSINO}

( ) 23. Explicitação dos pré-requisitos necessários ao ingresso no curso.

( ) 24. Sequenciação adequada das disciplinas dentro de cada período/semestre.

( ) 25. Sequenciação das disciplinas atinge o nível de complexidade dos objetivos do curso.

\section{FONTES DE INFORMAÇÃO: BIBLIOGRAFIA E OUTROS MEIOS}

( ) 26. Apresentação das fontes bibliográficas utilizadas.

( ) 27. Utilização de bibliografia básica atualizada (ano 2010 em diante) .

( ) 28. Indicação de bibliografia complementar sobre os temas tratados no na disciplina (livros, periódicos, sites, etc.).

\section{INFORMAÇÕES GERAIS SOBRE O CURSO}

( ) 29. Orientação geral sobre o uso do material (sequiência de passos para utilizar o material).

( ) 30. Flexibilidade do ambiente eletrônico na seqüência de aprendizagem.

( ) 31. Acesso ao PPC (Projeto Político Pedagógico) do curso

\section{ANEXO G - QUESTIONÁRIO DE ESTRATÉGIAS DE APRENDIZAGEM}


Para responder às próximas questões, pense nos comportamentos utilizados por você durante o curso. A escala abaixo varia de 0 (nunca) a 10 (sempre). Leia atentamente os itens listados e escolha o ponto da escala $(0,1,2,3,4,5,6,7,8,9$ ou 10) que melhor representa a frequência com que você se comportou da maneira descrita em cada item. Registre sua resposta à direita de cada item com o número escolhido. Por favor, não deixe questões em branco.

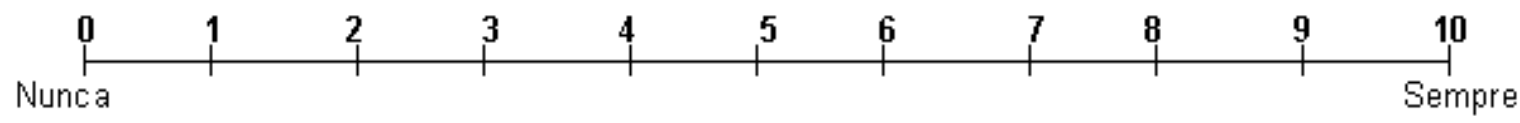

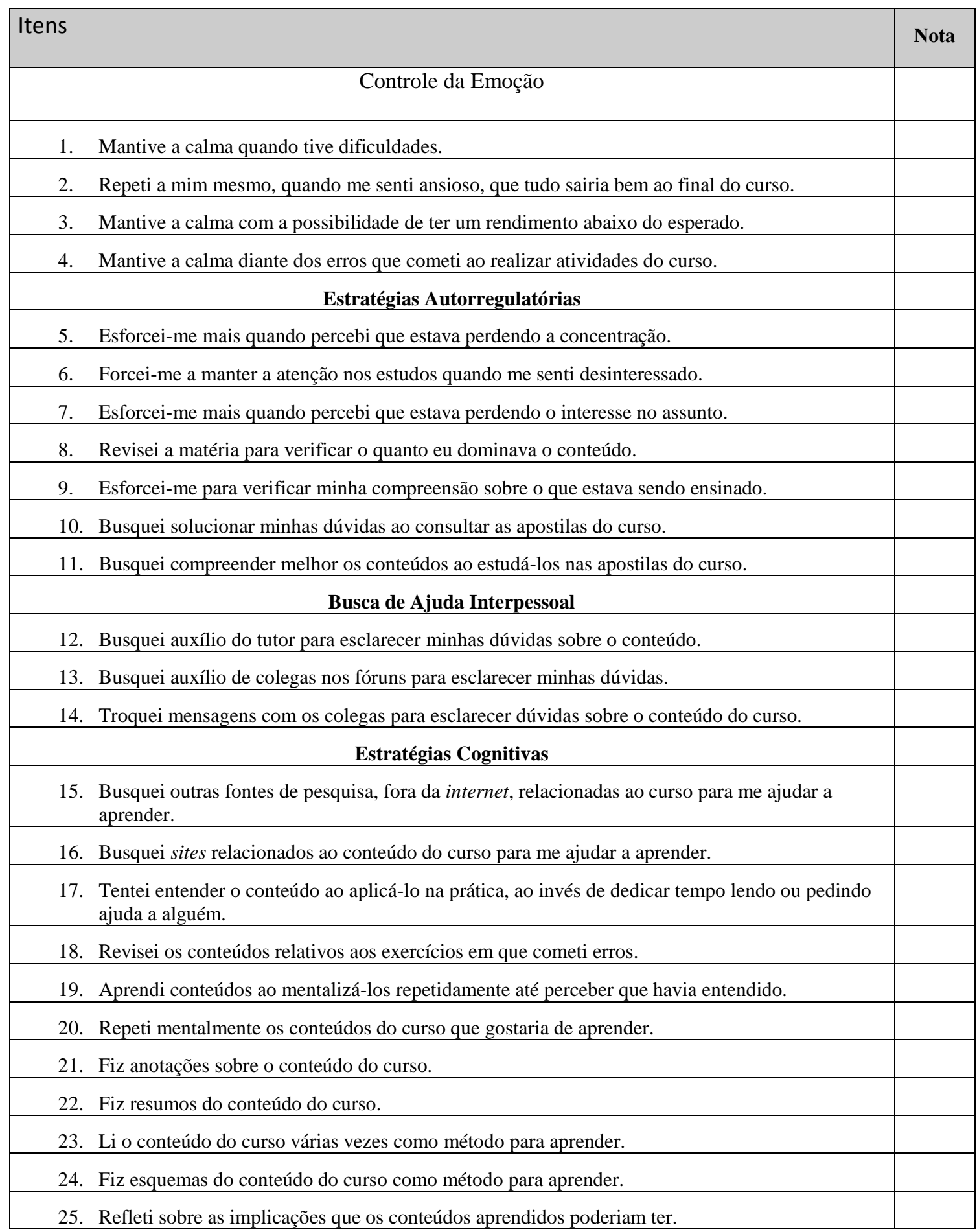


26. Busquei desenvolver uma ideia global sobre como os conteúdos do curso se relacionavam entre si.

27. Associei os conteúdos do curso aos meus conhecimentos anteriores.

28. Diferenciei, ao analisar os conteúdos do curso, os aspectos mais importantes dos menos importantes.

29. Identifiquei situações diárias em que eu pudesse aplicar os conteúdos do curso. 
Precisamos que você avalie os procedimentos do curso. Utilize a escala abaixo que varia de 0 (péssimo) a 10 (excelente). Leia atentamente os itens listados e escolha o ponto da escala $(0,1,2,3,4,5,6,7,8,9$ ou 10) que melhor representa a sua opinião sobre a qualidade do curso que você realizou. Registre sua resposta à direita de cada item com o número escolhido. Por favor, não deixe questões em branco.

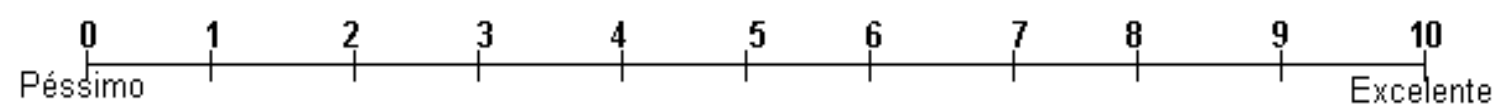

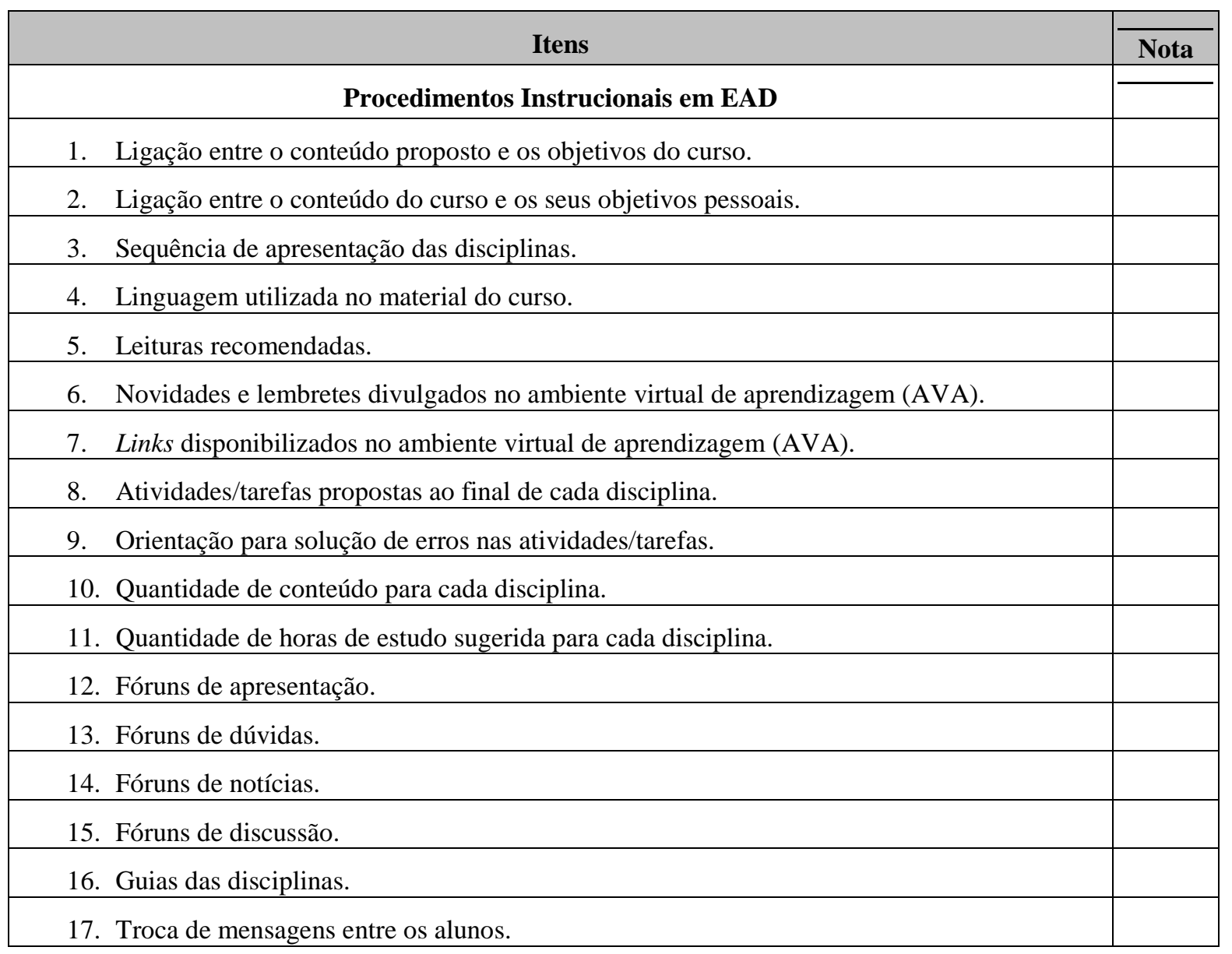

\section{ANEXO I - QUESTIONÁRIO DE REAÇÃO AO DESEMPENHO DO TUTOR}


Agora, você deve dar sua opinião sobre o tutor(es)que acompanhou(aram) seu desempenho no curso. Utilize a escala abaixo que varia de 0 (nunca) a 10 (sempre). Leia atentamente os itens listados e escolha o ponto da escala $(0,1,2,3,4,5,6,7,8,9$ ou 10) que melhor representa a frequência com que o(s) tutor(s) se comportou(aram) da maneira descrita em cada item. Por favor, não deixe questões em branco.

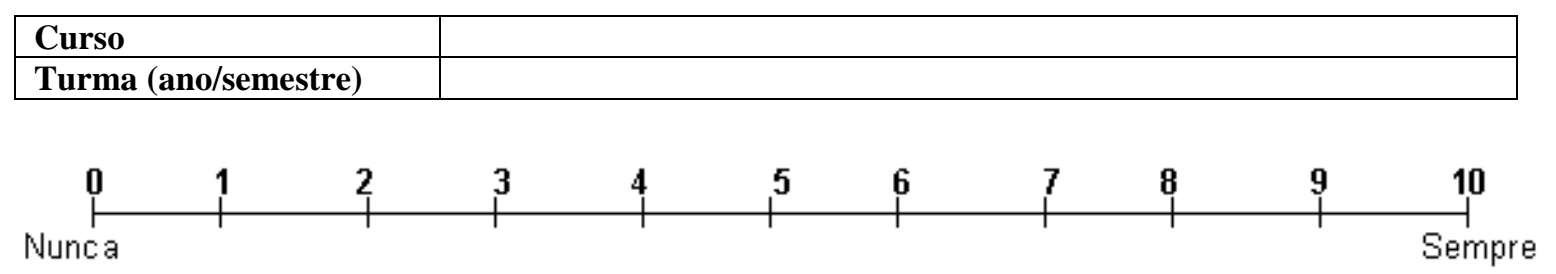

\begin{tabular}{|c|c|}
\hline Itens & Nota \\
\hline Desempenho do Tutor & \\
\hline 1. Utiliza os fóruns para estimular a interação entre os participantes. & \\
\hline 2. Encoraja os participantes a discutirem coletivamente suas dúvidas e questionamentos. & \\
\hline 3. Envia mensagens de incentivo aos participantes. & \\
\hline 4. Procura compreender os motivos que estão dificultando a participação no curso. & \\
\hline 5. Utiliza expressões afetuosas ao se dirigir aos participantes. & \\
\hline 6. Elogia a participação nos fóruns. & \\
\hline 7. Faz críticas construtivas. & \\
\hline 8. Está disponível nas horas marcadas. & \\
\hline 9. Respeita o ritmo de aprendizagem dos participantes. & \\
\hline 10. Leva em consideração as ideias dos participantes. & \\
\hline 11. Elogia os participantes pelo desempenho no decorrer do curso. & \\
\hline 12. Utiliza sua experiência profissional ao orientar os participantes. & \\
\hline 13. Fornece respostas que esclarecem completamente as dúvidas dos participantes. & \\
\hline 14. Utiliza linguagem de fácil compreensão. & \\
\hline 15. Participa, do início ao fim, das discussões nos fóruns. & \\
\hline 16. Cria situações de aprendizagem em que os participantes sintam-se capazes de resolver. & \\
\hline 17. Ressalta os benefícios práticos do curso nos contatos com os participantes. & \\
\hline 18. Indica caminhos ao invés de dar respostas prontas. & \\
\hline 19. Comunica-se sem erros de português. & \\
\hline 20. Utiliza todos os recursos de interação disponibilizados pelo curso. & \\
\hline 21. Apresenta exemplos que ilustram bem o tema discutido. & \\
\hline 22. Muda a forma de explicar até que os participantes compreendam os conteúdos. & \\
\hline $\begin{array}{l}\text { 23. Aproveita os acertos dos participantes para enfatizar os aspectos mais importantes do } \\
\text { tema discutido. }\end{array}$ & \\
\hline
\end{tabular}


24. Integra teoria e prática em suas explicações.

25. Direciona as discussões nos fóruns, evitando conversas que fujam do tema.

26. Cria oportunidades para os participantes manifestarem suas ideias.

27. Indica diversas fontes de pesquisa sobre os temas do curso.

ANEXO J - QUESTIONÁRIO SOCIODEMOGRÁFICO 


\begin{tabular}{|c|c|}
\hline \multicolumn{2}{|c|}{ QUESTIONÁRIO SOCIODEMOGRÁFICO } \\
\hline Sexo & $\begin{array}{l}\square \text { Feminino } \\
\square \text { Masculino } \\
\end{array}$ \\
\hline \multicolumn{2}{|l|}{ Idade } \\
\hline Estado civil & $\begin{array}{l}\square \text { solteiro } \\
\square \text { casado } \\
\square \text { divorciado } \\
\square \text { separado } \\
\square \text { outro }\end{array}$ \\
\hline Composição familiar & $\begin{array}{l}\square \text { filhos } \\
\square \text { não } \\
\end{array}$ \\
\hline Escolaridade & $\begin{array}{ll} & \text { Ensino Médio Completo } \\
\square & \text { Superior Incompleto } \\
\square & \text { Superior Completo } \\
\end{array}$ \\
\hline \multicolumn{2}{|l|}{ Profissão/Ocupação atual } \\
\hline Renda (salários mínimos) & $\begin{array}{l}\square \text { até } 1 \\
\square \text { 2-3 } \\
\square \text { 4-5 } \\
\square \text { 6-7 } \\
\square 7 \text { ou mais }\end{array}$ \\
\hline Região geográfica & $\begin{array}{ll}\square & \text { Norte } \\
\square & \text { Nordeste } \\
\square & \text { Centro-Oeste } \\
\square & \text { Sudeste } \\
\square & \text { Sul }\end{array}$ \\
\hline Experiência anterior no uso da internet & \begin{tabular}{|l} 
Sim \\
$\square$ Não
\end{tabular} \\
\hline
\end{tabular}

